Hans-Werner Seiler

\title{
Zur Durchsetzung der Einmalbesteuerung deutscher \\ Körperschaftsgewinne
}




\section{Zur Durchsetzung der Einmalbesteuerung deutscher Körperschaftsgewinne}

Die Anrechnung der Körperschaftsteuer auf die Einkommensteuer wird im deutschen Vollanrechnungssystem nur den unbeschränkt steuerpflichtigen Steuerinländern gewährt. Der Anrechnungsausschluß für die übrigen Steuerpflichtigen kann aber umgangen werden. Das sogenannte Dividendenstripping und die Gesellschafterfremdfinanzierung sind Wege, auf denen sich „Nichtanrechnungsberechtigte“ Gewinne deutscher Körperschaften aneignen, ohne daß es zu einer Belastung mit deutscher Körperschaftsteuer kommt. Eine Analyse zeigt, daß diesen Vermeidungsstrategien mit den bestehenden Steuergesetzen nicht ausreichend begegnet werden kann. Es werden verschiedene Lösungswege untersucht, wie diese Vermeidungsstrategien unterbunden werden könnten.

Hans-Werner Seiler wurde 1966 geboren. Nach einer Ausbildung zum Banckaufmann in Hannover und Hamburg studierte er Volkswirtschaft in Hamburg. Von 1994 bis 1998 war er wissenschaftlicher Angestellter am Institut für Ausländisches und Internationales Finanz- und Steuerwesen an der Universität Hamburg und hat dort 1999 seine Promotion abgeschlossen. Seit 1998 arbeitet der Autor in der Senatskanzlei der Freien und Hansestadt Hamburg. 
Zur Durchsetzung der Einmalbesteuerung deutscher Körperschaftsgewinne 


\section{FINANZWISSENSCHAFTLICHE SCHRIFTEN}

Herausgegeben von den Professoren

Albers, Krause-Junk, Littmann, Oberhauser, Pohmer, Schmidt

Band 96



Frankfurt am Main - Berlin - Bern - Bruxelles - New York · Wien 


\section{Hans-Werner Seiler}

\section{Zur Durchsetzung der Einmalbesteuerung deutscher Körperschaftsgewinne}

Strategien zur Vermeidung der im deutschen Körperschaftsteuersystem angelegten Benachteiligung ausländischer Anteilseigner

Eine finanzwissenschaftliche Analyse

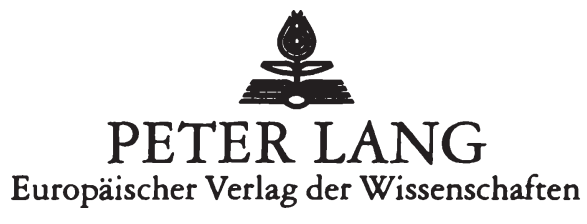


Die Deutsche Bibliothek - CIP-Einheitsaufnahme

Seiler, Hans-Werner:

Zur Durchsetzung der Einmalbesteuerung deutscher Körperschaftsgewinne : Strategien zur Vermeidung der im deutschen Körperschaftsteuersystem angelegten Benachteiligung ausländischer Anteilseigner ; eine finanzwissenschaftliche Analyse / Hans-Werner Seiler. Frankfurt am Main ; Berlin ; Bern ; Bruxelles ; New York ; Wien : Lang, 2000

(Finanzwissenschaftliche Schriften ; Bd. 96)

Zugl.: Hamburg, Univ., Diss., 1999

ISBN 3-631-35624-2

Open Access: The online version of this publication is published on www.peterlang.com and www.econstor.eu under the international Creative Commons License CC-BY 4.0. Learn more on how you can use and share this work: http://creativecommons. org/licenses/by/4.0.

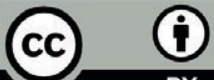

This book is available Open Access thanks to the kind support of ZBW - Leibniz-Informationszentrum Wirtschaft.

Gedruckt auf alterungsbeständigem, säurefreiem Papier.

D 18

ISSN 0170-8252

ISBN 3-631-35624-2

ISBN 978-3-631-75261-6 (eBook)

(C) Peter Lang GmbH

Europäischer Verlag der Wissenschaften

Frankfurt am Main 2000

Alle Rechte vorbehalten.

Das Werk einschließlich aller seiner Teile ist urheberrechtlich geschützt. Jede Verwertung außerhalb der engen Grenzen des

Urheberrechtsgesetzes ist ohne Zustimmung des Verlages unzulässig und strafbar. Das gilt insbesondere für

Vervielfältigungen, Übersetzungen, Mikroverfilmungen und die Einspeicherung und Verarbeitung in elektronischen Systemen.

Printed in Germany 124567

Hans-Werner Seiler - 978-3-631-75261-6 


\section{Mit Dank an alle,}

die beteiligt oder betroffen waren... 
Hans-Werner Seiler - 978-3-631-75261-6

Downloaded from PubFactory at 01/11/2019 06:36:03AM

via free access 


\section{Inhalt}

Tabellenverzeichnis

1. Einleitung

$\begin{array}{ll}\text { 1.1. Problemstellung } & 19\end{array}$

1.2. Gang der Untersuchung 25

2. Beurteilung der Körperschaftsteuer aus finanzwissenschaftlicher Sicht

2.1. Die Funktion der Körperschaftsteuer im Steuersystem

2.2. Allokative Anforderungen an die Körperschaftsteuer

2.2.1. Finanzierungsneutralität

2.2.2. Investitionsneutralität

2.2.3. Gewinnverwendungsneutralität

2.2.4. Rechtsformneutralität

2.2.5. Akquisitionsneutralität

2.2.6. Intersektorale Neutralität

2.3. Sonstige Anforderungen an die Körperschaftsteuer

2.3.1. Distributive Beurteilung

2.3.2. Administrierbarkeit

3. Die steuerliche Behandlung ausländischer Kapitalgeber

3.1. Grundlagen der internationalen Besteuerung von Kapitaleinkommen

3.1.1. Allokative Beurteilung der internationalen Besteuerung grenzüberschreitender Kapitaleinkommen

3.1.1.1. Kapitalimportneutralität

3.1.1.2. Kapitalexportneutralität 
3.1.1.3. Körperschaftsteuersystem und internationale Neutralitätspostulate

3.1.2. Distributive Beurteilung der internationalen Besteuerung grenzüberschreitender Kapitaleinkommen

3.1.3. Administrative Beurteilung der internationalen Besteuerung grenzüberschreitender Kapitaleinkommen

3.2. Die deutsche Besteuerung ausländischer Kapitalgeber

3.2.1. Die Beurteilung des Steuerstandortes Deutschland für ausländische Kapitalanleger

3.2.2. Die deutsche Körperschaftsteuer aus Sicht der ausländischen Anteilseigner

3.2.2.1. Technische Vorgehensweise des deutschen körperschaftsteuerlichen Vollanrechnungsverfahrens

3.2.2.2. Der Anrechnungsausschluß

3.2.2.3. Die Veränderung der steuerlichen Situation ausländischer Anteilseigner durch die Körperschaftsteuerreform von 1977

3.3. Die deutsche Besteuerung ins Ausland fließender Kapitalerträge

3.3.1. Die steuerliche Behandlung von Eigenkapitalvergütungen 67

3.3.2. Die steuerliche Behandlung von Fremdkapitalvergütungen $\quad 72$

3.3.3. Die steuerliche Behandlung von Veräußerungsgewinnen 74

3.3.4. Ökonomische Bewertung der unterschiedlichen deutschen Besteuerung ins Ausland fließender Kapitalerträge

4. Die Umgehung der Körperschaftsteuer durch Geschäfte mit dem Anrechnungsguthaben

4.1. Das Dividendenstripping - Begriffsklärung 80

4.2. Grundformen des Dividendenstripping 84

4.2.1. Dividendenstripping mittels separater Kassageschäften $\quad 85$

4.2.2. Dividendenstripping mit jungen Aktien $\quad 86$

4.2.3. Dividendenstripping in Verbindung mit Optionsgeschäften 86

4.2.4. Dividendenstripping in Verbindung mit Hedging 
4.2.5.1. Dividendenstripping mittels Wertpapierleihe 90

4.2.5.2. Dividendenstripping mittels Gewährung vergünstigter Kredite

4.2.5.3. Dividendenstripping mittels Swaps

4.3. Die späte Entdeckung des Dividendenstripping

4.3.1. Anonymer Börsenhandel

4.3.2. Finanzinnovationen

4.3.3. Verschärfte Börsenaufsicht

4.3.4. Kurzfristigkeit von Börsengeschäften

4.3.5. Besondere Motive für Börsengeschäfte um den Ausschüttungstermin

4.4. Gesetzgeberische Gegenmaßnahmen 100

4.4.1. Allgemeine Mißbrauchsvorschrift

4.4.2. Maßnahmen gegen die Weitergabe von Anrechnungsguthaben auf der Gesellschaftsebene

4.4.2.1. Die Ausgestaltung des Anrechnungsverbots

4.4.2.2. Ursachen für das Scheitern des Anrechnungsverbots

4.4.2.2.1. Unerwünschte Verletzung der Akquisitionsneutralität

4.4.2.2.2. Unerfüllbarkeit des Gesetzes

4.4.2.2.3. Umgehbarkeit des Anrechnungsverbots

4.4.3. Gesetzliche Maßnahmen gegen die Weitergabe von Anrechnungsguthaben auf der Gesellschafterebene im Zeitraum 1980-1993

4.4.3.1. Verweigerung der Berücksichtigung ausschüttungsbedingter Gewinnminderungen 
4.4.3.2. Methoden zur Rettung der Teilwertabschreibungen

4.4.4. Gesetzliche Maßnahmen gegen die Weitergabe von Anrechnungsguthaben auf der Gesellschaftsebene seit 1994

4.4.4.1. Unterbindung der Weitergabe von Anrechnungsguthaben seit 1994: Die neue Börsenklausel

4.4.4.1.1. Vor- und Nachteile der Fristenlösung

4.4.4.1.2. Probleme der Regelung für Kurssicherungsgeschäfte

4.4.4.1.3. Einschränkung der Geschäfte „,alt gegen jung"

4.4.4.1.4. Probleme der Entlastungsklausel

4.4.4.1.5. Überlappung der Abschreibungsmotive

4.4.4.1.6. Unwirksamkeit der Regelung gegen tarifbedingtes Dividendenstripping

4.4.4.2. Unterbindung der Weitergabe von Anrechnungsguthaben seit 1994: Das neue Anrechnungsverbot

4.4.4.2.1. Rechtsunsicherheiten des Anrechnungsverbots

4.4.4.2.2. Steuersystematische Probleme des Anrechnungsverbots

4.4.4.2.3. Zweifelhafte Anwendbarkeit des Anrechnungsverbots auf DTBGeschäfte

4.4.4.2.4. Umgehbarkeit des Anrechnungsverbots

4.4.5. Jüngste Gesetzesänderung: Wird die Börsenklausel null und nichtig?

4.5. Allokative Folgen des Dividendenstripping und der gesetzlichen Gegenmaßnahmen 
4.5.2. Steuerliche Beeinflussung der Gewinnverwendung

4.5.3. Auswirkungen auf den Börsenhandel

4.5.3.1. Attraktivität des Aktienmarktes

4.5.3.2. Spaltung des Aktienmarktes

4.6. Distributive Folgen des Strippings und der Gegenmaßnahmen

4.6.1. Interpersonelle Steuergerechtigkeit

4.6.2. Interstaatliche Steueraufkommensverteilung

4.7. Steuersystematische Aspekte

4.8. Reformvorschläge zur effizienteren Bekämpfung des Dividendenstripping

4.8.1. Vorschläge für eine effizientere Durchsetzung der bestehenden Gesetze gegen das Dividendenstripping

4.8.2. Alternative Lösungsansätze zur Unterbindung des Dividendenstripping

4.8.2.1. Limitierung verdächtiger Aktienbestände

4.8.2.2. Einführung einer Besteuerung von Veräußerungsgewinnen

4.8.2.3. Zurechnung der Dividende nach Haltedauer

4.9. Dividendenstripping, ein spezifisch deutsches Problem?

4.9.1. Italien

4.9.2. Großbritannien

4.9.3. Frankreich

156

4.9.4. Finnland und Norwegen

Fazit zum Problem des Dividendenstripping

5. Die Umgehung der Körperschaftsteuer durch Ausweichen auf Fremdfinanzierung

5.1. Gesellschafterfremdfinanzierung - Begriffsklärung 
5.1.1. Nichtsteuerliche Gründe für Gesellschafterfremdfinanzierungen

5.1.2. Steuerliche Gründe für Gesellschafterfremdfinanzierungen

5.1.2.1. Inländische steuerliche Motive

5.1.2.2. Internationale steuerliche Motive

5.1.3. Ist die Gesellschafterfremdfinanzierung tatsächlich ein Problem?

5.2. Die steuergesetzlichen Maßnahmen zur Einschränkung der Gesellschafterfremdfinanzierung

5.2.1. Allgemeine Mißbrauchsklausel als Mittel gegen die Gesellschafterfremdfinanzierung

5.2.2. Spezielle Vorschriften gegen die Gesellschafterfremdfinanzierung

5.2.2.1. Identifikation einer Gesellschafterfremdfinanzierung nach § 8a KStG - Die Quotenlösung

5.2.2.2. Identifikation einer Gesellschafterfremdfinanzierung: Ausnahmen von der Quotenlösung

5.2.2.3. Ungereimtheiten der gesetzlichen Regelungen

5.2.2.3.1. Unsicherheiten bei der Safe-HavenZuordnung

5.2.2.3.2. Bedeutung des Drittvergleichs

5.2.2.3.3. Behandlung zinslos zur Verfügung gestellter Gesellschafterdarlehen

5.2.2.3.4. Besondere Probleme im Verlustfall 179

5.2.2.3.5. Maßgeblichkeit der Vorjahresschlußbilanz

5.2.2.3.6. Darlehensgewährung durch Dritte

5.2.2.4.1. Negative Anreizwirkung der Beteiligungsgrenze

5.2.2.4.2. Umgehungsmöglichkeit durch Sachdarlehen 
5.2.2.4.3. Umgehungsmöglichkeit durch Personengesellschaften

5.2.2.4.4. Gründung von Holding-Gesellschaften

5.2.2.4.5. Ausnahme banküblicher Geschäfte

5.3. Allokative Beurteilung der Gesellschafterfremdfinanzierung und der gesetzlichen Gegenmaßnahmen

5.4. Distributive Beurteilung der Gesellschafterfremdfinanzierung und der gesetzlichen Gegenmaßnahmen

5.4.1. Interessenskonflikte zwischen Steuerinländern und Steuerausländern (Interpersonelle Verteilung)

5.4.2. Interstaatliche Steueraufkommensverteilung

5.5. Fiskalische Aspekte

5.6. Mögliche Alternativ-Lösungen zur Unterbindung der Gesellschafterfremdfinanzierung

5.6.1. Verschärfung des $\S 8 \mathrm{a} \mathrm{KStG}$

5.6.2. Durchsetzung der Quellenlandbesteuerung von Zinsen

5.7. Maßnahmen zur Einschränkung der Gesellschafterfremdfinanzierung im internationalen Bereich

5.7.1. Das Identifikationsproblem

5.7.1.1.1. Kanada, Spanien, Portugal: Quotenregelung für Nichtanrechnungsberechtigte

5.7.1.1.2. Belgien und Frankreich: FK-EKQuoten für In- und Ausländer

5.7.1.1.3. Japan: Die Overall-Quote

5.7.1.1.4. Andere Pauschalbegrenzungen

5.7.1.2. Länder mit Einzelfallprüfungen 
5.7.1.3. Bewertung der ausländischen Thin-Capitalization-Rules

5.7.2. Konsequenzen einer aufgedeckten Gesellschafterfremdfinanzierung

5.7.2.1. Zinsabzugsverbot

5.7.2.2. Umqualifizierung

Fazit zum Problem der Gesellschafterfremdfinanzierung

6. Alternative Lösungsansätze zur Besteuerung körperschaftsteuerpflichtiger Gewinne ausländischer Anteilseigner

6.1. Die Verbundaktie (Stapled Stock) - eine Marktlösung gegen die Diskriminierung ausländischer Anteilseigner

6.1.1. Die Verbundaktie - ein internationales Wertpapier für national beschränkte Anrechnungssysteme

6.1.1.1. Gestaltungsformen von Verbundaktien

6.1.1.2. Abgrenzung von Verbundaktien zu verwandten Kooperationsformen

6.1.2. Verbundaktien in Deutschland

6.1.2.1. Verbundaktien mit ausländischer Muttergesellschaft

6.2.2.2. Verbundaktien mit deutscher Muttergesellschaft

6.1.3. Ökonomische Beurteilung von Verbundaktien

6.2. Vorschläge zur Reform des Körperschaftsteuersystems

6.2.1. Ausweitung des Anrechnungssystems

6.2.1.1. Einseitige Körperschaftsteueranrechnung 
6.2.1.3. Grenzüberschreitende Anrechnung von Körperschaftsteuern in anderen Ländern

6.2.1.4. Finanzwissenschaftliche Bewertung der grenzüberschreitenden Anrechnung

6.2.2. Alternative Körperschaftsteuersysteme

6.2.2.1. Rückkehr zum klassischen System?

6.2.2.2. Körperschaftsteuersysteme mit Entlastungen auf Gesellschaftsebene

6.2.2.3. Dividendenfreistellung

Abkürzungsverzeichnis

Literaturverzeichnis 
Hans-Werner Seiler - 978-3-631-75261-6

Downloaded from PubFactory at 01/11/2019 06:36:03AM

via free access 


\section{Tabellenverzeichnis}

I Anteil der Körperschaftsteuer am Gesamtsteueraufkommen 22

II Anteil der Körperschaftsteuer am BIP 23

III Entwicklung der Körperschaftsteuersätze im internationalen 55

Vergleich

IV Dividendenbesteuerung der Nichtanrechnungsberechtigten

71

V Dividendenstripping in Verbindung mit Optionsgeschäften

VI Unschädliche Kombinationsmöglichkeiten von erfolgsabhängigem und erfolgsunabhängigem Fremdkapital

172

VII Ausländische Safe Haven-Regelungen 
Hans-Werner Seiler - 978-3-631-75261-6

Downloaded from PubFactory at 01/11/2019 06:36:03AM

via free access 


\section{Einleitung}

\subsection{Problemstellung}

Die vorliegende Arbeit hat zum Ziel, eine Achillesferse des deutschen Körperschaftsteuersystems zu analysieren: die Vermeidbarkeit der deutschen Körperschaftsteuer für ausländische Anteilseigner.

Nach deutschem Steuerrecht unterliegt das Einkommen inländischer natürlicher Personen der Einkommensteuer, dasjenige inländischer juristischer Personen, zu denen als bedeutsamste Gruppe Kapitalgesellschaften zählen, der Körperschaftsteuer ${ }^{1}$.

Um eine steuerliche Doppelbelastung eines Einkommens zu vermeiden, wird im deutschen Steuersystem die von Unternehmen abgeführte Körperschaftsteuer auf ausgeschüttete Gewinne beim inländischen, steuerpflichtigen Dividendenempfänger im vollen Umfang auf die Steuerschuld angerechnet ${ }^{2}$. Die Körperschaftsteuer hat für ihn nur den Charakter einer Steuervorauszahlung.

Der Gesetzgeber schränkt aber die Vollanrechnung auf inländische einkommenoder körperschaftsteuerpflichtige Personen ein, um eine einmalige deutsche Besteuerung zu gewährleisten. Diese Konstruktion führt zu einer unterschiedlichen Besteuerung von inländischen und ausländischen Steuerpflichtigen, wobei die Unterscheidung zwischen "inländisch" und "ausländisch" sich in der Regel auf den Sitz der natürlichen bzw. juristischen Person bezieht oder auf den Ort des gewöhnlichen Aufenthalts bzw. der Geschäftsleitung ${ }^{3}$. Ausländische Steuerpflichtige genießen keine Anrechnung ${ }^{4}$. Da der Fiskus für diese Steuerpflichtigen keine Erhebung einer persönlichen Einkommensteuer vornehmen kann, würde eine Anrechnung von deutscher Seite auf eine Erstattung der Körperschaftsteuer hinauslaufen. Abgesehen von der Kapitalertragsteuer blieben an Ausländer ausgeschüttete Gewinne im Inland unbesteuert.

Der Anrechnungsausschluß bewirkt, daß die deutsche Körperschaftsteuer für ausländische Anteilseigner definitiv wird. Ins Ausland fließende Dividenden sind

1 Vgl. $§ 1$ Abs. $1 \mathrm{EStG}, \S 1 \mathrm{Abs} .1 \mathrm{KStG}$.

2 Vgl. $§ 36$ Abs. 2 Nr. 3 EStG.

3 Vgl. $\S \S 8,9,10$ und 11 AO. Vgl. hierzu Baranowski, K.H. (1996): Besteuerung von Auslandsbeziehungen, 2. Aufl., Herne u. a. 1996, S. $24 \mathrm{ff}$. 
damit in Höhe des Ausschüttungssatzes von $30 \%$ endgültig belastet ${ }^{5}$. Zusätzlich fällt noch je nach Doppelbesteuerungsabkommen (DBA) die eben erwähnte Kapitalertragsteuer an, die Ausländer in ihren Wohnsitzländern anders, als die Körperschaftsteuer, auf ihre Einkommensteuer anrechnen lassen können ${ }^{6}$, wenn es die Gesetzgebung ihres Wohnsitzlandes zuläßt. Bei Ausschüttungen an Kapitalgesellschaften in der EU wird unter bestimmten Voraussetzungen keine Kapitalertragsteuer mehr erhoben.

Die mit inländischer Körperschaftsteuer belasteten Dividenden fließen in die Bemessungsgrundlage der ausländischen Einkommensteuer des ausländischen Anteilseigners ein, so daß de facto eine doppelte Steuerlast auf den ausgeschütteten Gewinnen liegt. Umgekehrt können auch deutsche Anteilseigner ausländischer Kapitalgesellschaften die ausländische Körperschaftsteuer generell nicht auf die deutsche Einkommensteuer anrechnen. Damit regt das deutsche Körperschaftsteuersystem Inländer zur Kapitalanlage im Inland an, bzw. diskriminiert Auslandsinvestitionen von Inländern, während sich für Ausländer die doppelte Steuerlast auf den Erwerb deutscher Beteiligungen eher abschreckend auswirkt. Dies gilt vor allem dann, wenn die doppelte Steuerlast im jeweiligen Wohnsitzland der Ausländer für dort inländische Dividenden gemildert oder beseitigt wird. Aus internationaler Sicht kann man von einer Diskriminierung nichtanrechnungsberechtigter Steuerausländer gegenüber anrechnungsberechtigten Steuerinländern sprechen? Von deutscher Seite wird diesem Vorwurf entgegengehalten, daß eine Anrechnung der Körperschaftsteuer Sache des Wohnsitzlandes des Anteilseigners sei ${ }^{8}$.

Allerdings enthält das deutsche Steuersystem Möglichkeiten zur Vermeidung der Körperschaftsteuer. Tatsächlich beweisen zahlreiche Steuergestaltungen, daß der Anrechnungsausschluß von den Nichtanrechnungsberechtigten nicht einfach hingenommen wird. Die Betroffenen - zu ihnen zählen neben Steuerausländern auch inländische, steuerbefreite Unternehmen - wissen sich mit variantenreichen Steuergestaltungen selbst zu helfen.

$5 \quad$ Vgl. $\S 50$ Abs. 1 KStG.

6 Vgl. Art. 10 OECD-MA.

7 Vgl. Böckli, P. (1979): Die Verweigenung der Steuergutschrift gegenüber Steuerausländern nach der deutschen Körperschaftsteuerreform 1977 aus Sicht eines Vertragsstaates, in: Steuer und Wirtschaft (StuW), 56. Jg./(1979), Nr. 1, S. 2ff.; vgl. Frotscher, G. (1994a): Gesellschafter-Fremdfinanzierung durch nicht anrechnungsberechtigte Anteilseigner, in: Internationales Steuerrecht (IStR), 3. Jg./(1994), Nr. 5, S. 201.

Vgl. BFH v. 04.02.1987, BStB1. II 1987, S. 68. 
Dabei geht es stets darum, zu vermeiden, daß körperschaftsteuerpflichtige Gewinne bei ausländischen Anteilseignern anfallen. Im Mittelpunkt dieser Arbeit stehen zwei wesentliche Gestaltungsmodelle, mit denen dieses Ziel erreicht wird.

Das erste Modell ist das sogenannte Dividendenstripping. Beim Dividendenstripping werden körperschaftsteuerpflichtige Gewinnausschüttungen an Steuerausländer in Veräußerungsgewinne umgewandelt, die in Deutschland in der Regel nicht steuerpflichtig sind. Das Dividendenstripping ist eine Steuervermeidungsstrategie, die vor allem deswegen möglich wird, weil die Besteuerung von ausgeschütteten Gewinnen zeitpunktbezogen ist. Das heißt, die Körperschaftsteuer fällt im vollen Umfang für denjenigen an, der zum Zeitpunkt der Ausschüttung der Körperschaftsgewinne im Besitz der dividendenberechtigten Wertpapiere ist. Durch Verkauf vor und Rückkauf nach dem Ausschüttungstermin können die beteiligten Geschäftspartner dafür sorgen, daß ein Anrechnungsberechtigter die Körperschaftsteueranrechnung geltend machen kann. Auf diese Weise wird der Anrechnungsausschluß umgangen und das Körperschaftsteuerguthaben kann zwischen den Geschäftspartnern aufgeteilt werden. Lohnend wird das Geschäft immer dann, wenn der Inländer Wertminderungen bzw. Veräußerungsverluste geltend machen kann, da die Anteile nach Gewinnausschüttung entsprechend weniger wert sind. In diesem Fall kommt es zu keiner inländischen Besteuerung.

Das zweite Modell führt nicht zur Umwandlung von Dividenden in Veräußerungsgewinne sondern in Zinsen. In Deutschland sind an Ausländer geleistete Zinszahlungen nicht steuerpflichtig. Deshalb lohnt es sich für einen ausländischen Anteilseigner, abgesehen von der gesetzlich vorgeschriebenen Mindesteinlage, seinem Unternehmen anstelle von Eigenkapital Fremdkapital zur Verfügung zu stellen. Die Zinsen mindern zum einen den Gewinn der Gesellschaft, zum anderen verlassen sie das Inland ohne deutsche Steuerbelastung. Das Ausweichen ausländischer Anteilseigner auf Fremdfinanzierung wird üblicherweise als Gesellschafterfremdfinanzierung bezeichnet. Die Gesellschafterfremdfinanzierung ist ein auch in anderen Ländern auftretendes Problem, für das sich das Schlagwort "ThinCapitalization" durchgesetzt hat. Eine Besteuerung der Zinsen aus Gesellschafterfremdfinanzierungen bzw. der Veräußerungsgewinne aus Dividendenstripping findet üblicherweise, wenn überhaupt, nur noch im Wohnsitzland des Gesellschafters statt. Dividendenstripping und Gesellschafterfremdfinanzierung führen im Ergebnis dazu, daß sich Nichtanrechnungsberechtigte ihre eigene Anrechnung genehmigen. Verlierer ist in beiden Fällen der inländische Fiskus, dessen Körperschaftsteueraufkommen sich verringert.

Es stellt sich dabei die Frage, inwieweit Auswirkungen dieser Steuervermeidungsstrategien überhaupt aufgedeckt werden können, da bislang keine Statistiken darüber existieren, welche Steuervermeidung welches Ausmaß angenommen hat, 
bzw. weil fraglich ist, welche Tatbestände überhaupt als Steuervermeidung eingeschätzt werden können. Es werden später noch Schätzungen angegeben, in welchem Umfang sich welche Steuergestaltung einnahmemindernd ausgewirkt hat.

Steuergestaltungen schlagen sich in Einnahmeausfällen des jeweiligen Steueraufkommens nieder. Die Bedeutung einer einzelnen Steuerart bzw. deren Ausfälle läßt sich im Gesamtsteuersystem erahnen, wenn man das Aufkommen dieser Steuer ins Verhältnis zum Gesamtsteueraufkommen eines Staates setzt.

\begin{tabular}{|c|c|c|c|c|c|c|c|c|c|}
\hline 1970 & 1971 & 1972 & 1973 & 1974 & 1975 & 1976 & 1977 & 1978 & 1979 \\
\hline 5,66 & 4,14 & 4,31 & 4,84 & 4,34 & 4,15 & 4,42 & 5,62 & 6,21 & 6,68 \\
\hline 1980 & 1981 & 1982 & 1983 & 1984 & 1985 & 1986 & 1987 & 1988 & 1989 \\
\hline 5,84 & 5,44 & 5,67 & 5,97 & 6,34 & 7,28 & 7,14 & 5,83 & 6,15 & 6,38 \\
\hline 1990 & 1991 & 1992 & 1993 & 1994 & 1995 & 1996 & 1997 & 1998 & \\
\hline 5,31 & 4,79 & 4,26 & 3,72 & 2,49 & 2,23 & 3,68 & 4,17 & 4,35 & \\
\hline
\end{tabular}

Bis einschl. 1990 altes Bundesgebiet; Quelle: eigene Berechnungen, Angaben des Bundesministeriums der Finanzen (BMF) 1999

Freilich sagen diese Zahlen noch nicht viel über mögliche Auswirkungen von Steuergestaltungen aus. Da die Körperschaftsteuer eine Gewinnsteuer ist, Unternehmensgewinne aber eine recht flexible Größe darstellen, kann ein Rückgang des Körperschaftsteueraufkommens am Gesamtsteueraufkommen auch mit einer Rezession zu erklären sein. Setzt man dagegen das Körperschaftsteueraufkommen in Relation zum Bruttoinlandsprodukt, so können konjunkturelle Schwankungen zumindest teilweise bereinigt werden.

Interessant ist, daß die abnehmende Bedeutung der Körperschaftsteuer in der Volkswirtschaft insgesamt noch deutlicher zu erkennen ist. Insbesondere die folgende Tabelle macht deutlich, daß der Rückgang der Körperschaftsteuereinnahmen seit Mitte der achtziger Jahre nicht mit der Konjunkturlage zu erklären ist. Während in den Jahren ab 1983 eine relativ lange konjunkturelle Aufschwungphase in Deutschland einsetzte, die mit der Vereinigung 1990 in einen Boom mündete, nahm der Anteil des Körperschaftsteueraufkommens am Sozialprodukt seit Mitte der achtziger Jahre ab. Diese Tendenz setzte sich in der nachfolgenden Abschwungs- und Rezessionsphase fort, wobei der Rückgang in dieser Zeit auffallend stärker ausfiel als beispielsweise in den Rezessionsjahren 1974 und 1975. 
Tabelle II: Anteil der Körperschaftsteuer am BIP (in \%)

\begin{tabular}{|l|l|l|l|l|l|l|l|l|l|}
\hline 1970 & 1971 & 1972 & 1973 & 1974 & 1975 & 1976 & 1977 & 1978 & 1979 \\
\hline 1,29 & 0,96 & 1,03 & 1,19 & 1,06 & 0,98 & 1,06 & 1,41 & 1,54 & 1,65 \\
\hline
\end{tabular}

\begin{tabular}{|l|l|l|l|l|l|l|l|l|l|}
\hline 1980 & 1981 & 1982 & 1983 & 1984 & 1985 & 1986 & 1987 & 1988 & 1989 \\
\hline 1,45 & 1,31 & 1,35 & 1,42 & 1,50 & 1,75 & 1,68 & 1,37 & 1,43 & 1,63 \\
\hline
\end{tabular}

\begin{tabular}{|l|l|l|l|l|l|l|l|l|}
\hline 1990 & 1991 & 1992 & 1993 & 1994 & 1995 & 1996 & 1997 & 1998 \\
\hline 1,24 & 1,11 & 1,01 & 0,88 & 0,59 & 0,52 & 0,83 & 0,92 & 0,98 \\
\hline
\end{tabular}

Bis einschl. 1990 altes Bundesgebiet; Quelle: eigene Berechnungen, Angaben des BMF 1999 und des Sachverständigenrates (SVR) 1997; für 1996-98 vorl. Zahlen der Bundesbank.

So wie es falsch wäre, das deutsche Körperschaftsteueraufkommen allein mit konjunkturellen Einflüssen zu erklären, so wäre es ebenfalls falsch, allein die Nutzung von Steuerschlupflöchern oder Steuergestaltungen in der Art des Dividendenstripping oder der Gesellschafterfremdfinanzierung als Erklärung heranzuziehen. In theoretischen und empirischen Untersuchungen werden als Determinanten der Investitionsentscheidungen vorrangig vor allem Absatzgesichtspunkte und relative Kostenunterschiede genannt ${ }^{9}$. Daraus resultierende Unternehmensverlagerungen dürften beim Rückgang der Körperschaftsteuereinnahmen keine geringe Rolle spielen. Die in dieser Arbeit behandelten Umgehungsmöglichkeiten werden freilich zur negativen Aufkommensentwicklung beigetragen haben. Auch die internationale Konzernbildung mit den Möglichkeiten der Produktions- und Kostenverlagerung und daraus folgende Gewinnverlagerungen zwischen In- und Ausland dürften bei der Suche nach den Ursachen der aufgezeigten Entwicklung von groBer Bedeutung sein.

In einem wichtigen Aspekt unterscheiden sich die in dieser Arbeit untersuchten Gestaltungsformen der Steuerausländer voneinander: Auch wenn eine Gesellschafterfremdfinanzierung im Ergebnis einer Erschleichung des Anrechnungsguthabens der Nichtanrechnungsberechtigten gleichkommt, so tritt diese Gestaltung im Gegensatz zum Dividendenstripping nicht nur in Staaten mit körperschaftsteuerlicher Anrechnung auf. Sie ist eher eine Methode zur Vermeidung jeglicher Körperschaftsteuerbelastung auf Ausländer entfallender Gewinne. Das heißt aber nicht, daß es nicht auch in Staaten ohne körperschaftsteuerlicher Anrechnung Dividendenstripping geben kann. Dividendenstripping kann sich $\mathrm{z}$. B. immer dann lohnen, wenn realisierte Veräußerungsgewinne steuerlich anders behandelt werden

9 Vgl. Deutsche Bundesbank (1997), Entwicklung und Bestimmungsgründe grenzüberschreitender Direktinvestitionen, in: Deutsche Bundesbank (Hrsg.): Monatsbericht August, 49.Jg./(1997), Nr. 8, S. 66ff. 
als Dividenden. Im weiteren geht es aber hauptsächlich um das Dividendenstripping, das der Umgehung nationaler Beschränkungen von Anrechnungssystemen dient.

Gesellschafterfremdfinanzierung kommt zwar in allen Ländern vor, ist aber in Anrechnungsländern insofern ein spezifisches Problem der Besteuerung von Ausländern, da die in der Regel auf Inländer beschränkte Anrechnung zu einer sehr unterschiedlichen Besteuerung von In- und Ausländern führt, so daß letztere geradezu zur Gesellschafterfremdfinanzierung getrieben werden. Die unterschiedliche Besteuerung grenzüberschreitender Kapitalerträge führt in Anrechnungssystemen zu einer Arbeitsteilung unter den Anteilseignern: die Inländer übernehmen die Eigenkapitalbereitstellung und ausländische Gesellschafter sorgen - abgesehen von den unvermeidbaren Eigenkapitalbeteiligungen - für die Bereitstellung von Fremdkapital.

Gemeinsam ist den Gestaltungsformen des Dividendenstripping und der Gesellschafterfremdfinanzierung, daß die Schaffung von Finanzinnovationen und die Zwischenschaltung weiterer Beteiligter dazu führen, daß den - in der Arbeit vorzustellenden - Steuergestaltungsstrategien nur sehr schwer mit Einzelgesetzen zu begegnen ist. Hieran scheitern auch die steuergesetzlichen Gegenmaßnahmen des deutschen Gesetzgebers. Besonders interessant ist dabei, daß frühere Maßnahmen gegen das Dividendenstripping Ähnlichkeiten mit aktuellen Gesetzen gegen Gestaltungen der Gesellschafterfremdfinanzierung aufweisen. Eine Analyse dieser Einzelmaßnahmen wird ebenfalls ein Schwerpunkt dieser Arbeit sein, denn nur so können Rückschlüsse auf ihre Wirksamkeit gezogen werden. Dabei werden "Risiken und Nebenwirkungen" der neuen Gesetze aus finanzwissenschaftlicher Sicht zu beurteilen sein. Besondere Beachtung soll weiter eine Finanzinnovation finden, die möglicherweise dazu führt, daß die national ausgerichteten Körperschaftsteuersysteme künftig über Marktprozesse internationalisiert werden. Die Analysen werden die Notwendigkeit von Alternativen zum national beschränkten Anrechnungsverfahren deutlich machen. Bei der Bewertung dieser Alternativen werden die Themenbereiche Dividendenstripping und Gesellschafterfremdfinanzierung parallel berücksichtigt, nur Lösungsvorschläge, die beide Probleme in den Griff bekommen, werden letztlich überzeugen können. Während der Entstehung dieser Arbeit ist hat die Themenstellung laufend an Aktualität gewonnen. So stehen inzwischen wichtige Gerichtsurteile des BFH im Bereich der Gesellschafterfremdfinanzierung wie vor allem beim Dividendenstripping aus ${ }^{10}$, zugleich hat sich die Diskussion um die Tauglichkeit des Anrechnungsverfahrens in einer zunehmend

10 Vor allem zum Dividendenstripping wird eine Grundsatzentscheidung im zweiten Halbjahr 1999 erwartet: BFH I R 29/97. 
globalisierten Welt - gerade aufgrund des Dividendenstrippings - verschärft ${ }^{11}$. In der nicht öffentlich arbeitenden Expertengruppe zur geplanten Unternehmensteuerreform, die zur Zeit für das Jahr 2001 erwartet wird, wurde unter anderem das ungelöste Problem des Dividendenstripping als Argument für die Abschaffung des derzeitigen Körperschaftsteuersystems angeführt.

\subsection{Gang der Untersuchung}

Im zweiten Kapitel werden alternative Begründungen einer Körperschaftsteuer und daraus resultierende unterschiedliche Stellungen der Körperschaftsteuer im Gesamtsteuersystem vorgestellt. Allokative und verteilungspolitische Beurteilungskriterien werden eingeführt und auf die zwei Grundtypen von Körperschaftsteuersystemen angewandt. Die Ausführungen zum Körperschaftsteuersystem beschränken sich in diesem Kapitel aus Gründen der Übersicht noch auf eine geschlossene Volkswirtschaft.

Im dritten Kapitel sollen die internationalen Aspekte der Körperschaftsteuer dargestellt werden. Im Mittelpunkt dieses Kapitels steht das deutsche Körperschaftsteuersystem und seine Wirkung auf ausländische Kapitalanleger sowie die deutsche Besteuerung ins Ausland fließender alternativer Kapitaleinkommen. Auch hier werden allokative und distributive Beurteilungen vorgenommen, auf die später zurückgegriffen werden.

Im vierten und fünften Kapitel werden die Steuergestaltungsformen Dividendenstripping und Gesellschafterfremdfinanzierung und die bisherigen Reaktionen des deutschen Gesetzgebers vorgestellt und analysiert. Sowohl die Problematik des Dividendenstripping als auch - und erst recht - die Gesellschafterfremdfinanzierung sind Gestaltungsformen, die auch ausländischen Körperschaftsteuersystemen das Wasser - oder besser gesagt: die Steuereinnahmen - abgraben. Es erscheint deswegen sinnvoll, jeweils zu prüfen, mit welchen Methoden und mit welchem Erfolg im Ausland gegen diese Steuergestaltungsformen vorgegangen wird.

Im sechsten Kapitel wird untersucht, inwieweit die Verbundaktie imstande ist, die Schlechterstellung von Steuerausländern in Anrechnungsländern zu überwinden. Insbesondere im angelsächsischen Raum hat diese Finanzinnovation Fuß gefaßt und zur Durchbrechung national beschränkter Anrechnungssysteme geführt. Die Verbundaktie ist ein multinationales Wertpapier, das in Anrechnungsländern als

11 Vgl. Herzig, N. / Dötsch, E. (1998): Körperschaftsteuer 2000, in: Der Betrieb (DB), 51. Jg./(1998), Nr. 1/2, S. 15. 
inländische Beteiligung an einem heimischen Unternehmen eingeordnet wird, so daß dem Anteilseigner der Verbundaktie die Körperschaftsteuergutschrift erhalten bleibt. Der Fall der Redland-Aktie zeigt, daß diese Wertpapierkreation auch hierzulande grundsätzlich eine Rolle spielen kann - ähnlich wie andere Finanzinnovationen aus dem angloamerikanischen Raum, die sich erst nach einiger Zeit in Deutschland durchgesetzt haben. Ein Durchbruch der Verbundaktie könnte einige Formen der Gesellschafterfremdfinanzierung und viele Fälle des Dividendenstripping überflüssig machen. Insofern muß sich die Arbeit auch mit dieser Wertpapiergattung auseinandersetzen.

Gleichfalls im sechsten Kapitel werden mögliche Auswege aus dem derzeitigen Dilemma hinsichtlich der Besteuerung ausländischer Anteilseigner aufgezeigt. Diese Auswege werden in der Reihenfolge des zunehmenden Reformaufwandes vorgestellt und diskutiert. Ein eigener Lösungsvorschlag schließt die Arbeit ab. 


\section{Beurteilung der Körperschaftsteuer aus finanzwissenschaftlicher Sicht}

Der Umfang des Angebots und der Nachfrage von Kapital in einem Land ist unter anderem abhängig von der Besteuerung dieses Faktors sowie der Besteuerung des Faktors Arbeit - und damit, wie aus der Optimal Taxation Theory bekannt, auch von der steuerlichen Behandlung anderer Komponenten, wie z.B. der Freizeit bzw. alternativer Formen der Faktorverwendung.

Die Struktur des Angebots und der Nachfrage von Kapital ist dagegen abhängig von der Besteuerung der einzelnen Arten der Kapitalbereitstellung. Kapital kann als Fremd- oder als Eigenkapital bereitgestellt werden. Entsprechend kann Kapitaleinkommen in Form von Zinseinkommen, Dividenden oder durch Wertzuwächse aufgrund von Gewinnthesaurierungen im Unternehmen entstehen. Diese Wertzuwächse kann ein Anteilseigner durch Veräußerung realisieren; Veräußerungsgewinne sind folglich eine weitere Form der Kapitaleinkommen. Besteuert man alle vier Kapitaleinkommensformen - inklusive möglicher Mischformen - einheitlich, so bleibt die Struktur des Kapitalangebots bzw. der Kapitalnachfrage unverändert, weil keine Substitutionseffekte zwischen den Kapitaleinkommensformen auftreten.

Für den Inhaber einer Personengesellschaft ist die Situation einer einheitlichen Besteuerung der Kapitaleinkommensarten gegeben, sieht man von der Veräußerungsgewinnbesteuerung in Deutschland ab. Gleichgültig, ob er eine Geldeinheit am Kapitalmarkt anlegt oder in seine Gesellschaft investiert: Sein Kapitalertrag unterliegt immer seinem persönlichen Einkommensteuersatz.

Nicht anders verhält es sich in Deutschland beim Anteilseigner einer Kapitalgesellschaft, die als juristische Person ein eigenständiges Steuersubjekt darstellt, soweit die Gewinne der Kapitalgesellschaft ausgeschüttet werden. Schüttet eine Kapitalgesellschaft ihre Gewinne an inländische Anteilseigner aus, so sind diese Gewinne in Deutschland zwar mit dem Ausschüttungssatz der Körperschaftsteuer belastet; da diese Körperschaftsteuer aber vollständig auf die inländische Einkommensteuer angerechnet werden kann, unterliegen die Bruttodividenden des inländischen Anteilseigners ebenfalls ausschließlich seiner persönlichen Einkommensteuer.

Verbleiben die Gewinne dagegen im Unternehmen, so erfolgt eine Besteuerung in Höhe des körperschaftsteuerlichen Thesaurierungssatzes auf einbehaltene Gewinne. Kapitaleinkommen entsteht hier durch Wertzuwächse, die in Deutschland nicht dem Anteilseigner zugerechnet werden, der letztlich als natürliche Person Eigentümer der Kapitalgesellschaft ist. Dieses Kapitaleinkommen wird folglich 
nicht oder höchstens zufällig gerade zu dem Steuersatz besteuert, der dem persönlichen Einkommensteuersatz des Anteilseigners entspricht.

Werden die Wertzuwächse durch Veräußerung von Anteilen realisiert, so findet unter Umständen eine Veräußerungsgewinnbesteuerung beim Anteilseigner statt ${ }^{12}$.

Anders als in Deutschland existieren in vielen Staaten einheitliche Körperschaftsteuersätze für einbehaltene und ausgeschüttete Gewinne. Die Höhe der Körperschaftsteuer ist damit unabhängig von der Gewinnverwendung. Grundsätzlich gilt, daß ausgeschüttete Gewinne beim Anteilseigner wiederum der persönlichen Einkommensteuer unterliegen. Dabei erfolgt oft keine oder nur eine unvollständige Berücksichtigung der schon erhobenen Körperschaftsteuer. In vielen Ländern werden auch realisierte Kursgewinne zum persönlichen Einkommensteuersatz des (ehemaligen) Anteilseigners besteuert. Sehr verbreitet ist aber auch eine differenzierte Besteuerung diese Gewinne.

Das Zusammenspiel der Einkommensteuer und der Körperschaftsteuer wird als Körperschaftsteuersystem bezeichnet. Es hängt nun einerseits vom Zusammenspiel der Besteuerung auf der Gesellschafts- und auf der Gesellschafterebene ab, welche allokativen, distributiven und stabilitätspolitischen Wirkungen eine Körperschaftsteuer erzeugt. Andererseits ist auch die Besteuerung der alternativen Kapitaleinkommensarten relevant.

In der Wahl des Körperschaftsteuersystems spiegeln sich die Vorstellungen über die Funktion wider, die eine Körperschaftsteuer im Steuersystem ausüben soll. Über die Funktion der Körperschaft gibt es allerdings einen Streit, der so alt ist wie die Körperschaftsteuer selbst.

\subsection{Die Funktion der Körperschaftsteuer im Steuersystem}

Die Körperschaftsteuer wird in allen OECD-Staaten als eine unverzichtbare Steuer angesehen, die einer Durchsetzung des Konzeptes einer umfassenden persönlichen Einkommensteuer nach Schanz, Haig und Simons dient. Ein Verzicht auf die Körperschaftsteuer würde dazu führen, daß Gewinne einer Kapitalgesellschaft steuerfrei bleiben, solange keine Gewinnausschüttung an Anteilseigner erfolgt ${ }^{13}$.

12 Vgl. $\S 17,23,34$ EStG. Auf Einzelheiten wird weiter unten eingegangen.

13 Vgl. Boadway, R. / Bruce, N. (1992): Problems with integrating Corporate Income Taxes in an open Economy, in: Journal of Public Economics, Vol. 48/(1992), S. 39. 
Eine unbefristete Steuerfreistellung dieser Gewinne erscheint aus mehreren Gründen aber nicht akzeptabel. Erstens würde die Steuerfreistellung einen Verstoß gegen die Wettbewerbsneutralität darstellen, da Personengesellschaften eine steuerfreie Thesaurierung nicht möglich ist. Zweitens müssen thesaurierte Gewinne nach dem Konzept der von Schanz entwickelten Reinvermögenszugangstheorie berücksichtigt werden. Nach dieser Theorie ist das umfassende Einkommen eines Individuums die Veränderung seines Reinvermögens innerhalb einer Periode zuzüglich seines Konsums ${ }^{14}$. Thesaurierte Gewinne einer Kapitalgesellschaft stellen in diesem Konzept einen Vermögenszugang dar, weil sie sich wertsteigernd auf die Beteiligungen der Anteilseigner auswirken. Die Körperschaftsteuer erfüllt deswegen eine Ergänzungsfunktion als Einkommensteuer auf der Unternehmensebene ${ }^{15}$. Zur Frage, ob die Körperschaftsteuer über die Rolle einer ergänzenden Einkommensteuer für thesaurierte Gewinne hinaus eine eigenständige Steuer für Unternehmen sein sollte oder nicht, werden jedoch gegensätzliche Standpunkte vertreten.

Anhänger der Integrationstheorie betrachten eine Besteuerung auf der Körperschaftsebene nur als Methode zur Sicherung der Besteuerung von Körperschaftsgewinnen. Die Körperschaftsteuer stellt damit nur eine Steuervorauszahlung dar. Tatsächlich soll das Einkommen aus Körperschaften in die einkommensteuerliche Bemessungsgrundlage des Anteilseigners integriert werden. Befürworter dieser Sichtweise verlangen daher eine Berücksichtigung der vom Unternehmen gezahlten Körperschaftsteuer bei der Einkommensteuererhebung. Unterbliebe eine Berücksichtigung, so würde wirtschaftlich eine doppelte steuerliche Belastung auf den Ausschüttungen an Anteilseigner lasten: zum einen die Körperschaftsteuer der Kapitalgesellschaft, zum anderen die Einkommensteuer der Anteilseigner. Anhänger einer Integration lehnen diese doppelte Belastung ab. Diese Sicht hat sich zumindest bezüglich ausgeschütteter Gewinne im Verlauf der letzten dreißig Jahre in vielen Volkswirtschaften durchgesetzt. Deutlich wird dies an den Körperschaftsteuerreformen der Nachkriegsjahrzehnte, die verstärkt integrierende Körperschaftsteuersysteme hervorbrachten ${ }^{16}$.

14 Vgl. Schanz, G. (1896): Der Einkommensbegriff und die Einkommensteuergesetze, in: Finanzarchiv, 13.Jg./(1896), S. 7ff.; vgl. Brümmerhoff, D. (1990): Finanzwissenschaft, 5. Aufl., München 1990, S. 290 f.

15 Vgl. Haller, H. (1971): Die Steuern. Grundlinien eines rationalen Systems öffentlicher Abgaben, 2. Aufl., Tübingen 1971, S. 326.

16 So führten z.B. folgende Länder Voll- oder Teilanrechnungssysteme ein: Frankreich (1966), Großbritannien (1973), Deutschland (1977), Italien (1977), Spanien (1978), Australien (1986), Neuseeland (1988), Finnland (1993), Norwegen (1993). 
Die Separationstheorie rechtfertigt die Körperschaftsteuer dagegen als eine "eigenständige" Steuer für Körperschaften, die separat von der Einkommensteuer zu betrachten sei. In der Praxis erfordert diese Ansicht eine Besteuerung der Körperschaftsgewinne auf der Gesellschaftsebene durch die Körperschaftsteuer und im Fall der Ausschüttung eine erneute steuerliche Erfassung auf der Anteilseignerebene durch die Einkommensteuer. Es besteht dann wirtschaftlich eine zweifache Steuerbelastung desselben Einkommens, die im folgenden als Doppelbelastung bezeichnet werden soll ${ }^{17}$.

Die häufigsten Begründungen für eine Doppelbelastung sind eine angebliche besondere Leistungsfähigkeit von Kapitalgesellschaften und äquivalenztheoretische Argumente. Kapitalgesellschaften sind nach Ansicht vieler Separationstheoretiker besonders leistungsfähig, da sie im Vergleich zu Personengesellschaften über günstigere Möglichkeiten der Eigen- und Fremdkapitalbeschaffung verfügen, umfangreichere Haftungsbeschränkungen sowie wirtschaftliche und juristische Unabhängigkeit genießen. Äquivalenztheoretisch kann man argumentieren, daß der Staat den Kapitalgesellschaften durch besondere Leistungen, wie z.B. die Einrichtung von Börsenstandorten, spezielle infrastrukturelle Vorteile bietet, für die er im Gegenzug einen Preis in Form der eigenständigen Körperschaftsbesteuerung erhebt ${ }^{18}$.

Mitunter wird auch verteilungspolitisch für die Doppelbelastung angeführt, daß die meisten Anteilseigner eher höhere Einkommen bezögen und daß deswegen eine separate Körperschaftsteuer für eine zusätzliche Progressivität der Einkommensteuer sorge ${ }^{19}$.

Im Streit um die Notwendigkeit einer eigenständigen Körperschaftsteuer werden nicht selten Aspekte der Steuerüberwälzung außer acht gelassen. In dem Umfang, in dem die Körperschaftsteuer vor- oder rücküberwälzt werden kann, belastet diese Steuer de facto nicht mehr die einbehaltenen und ausgeschütteten Gewinne, sondern trifft via Preis- und Lohnfindung die privaten Haushalte, die als Konsumenten und Arbeitsanbieter auftreten. Eine mögliche Überwälzbarkeit spricht allerdings gegen die Forderung einer eigenen Einkommensteuer für juristische Per-

17 Vgl. zur Stellung der Körperschaftsteuer im Steuersystem: Musgrave, R.A. / Musgrave, P.B. / Kullmer, L. (1993): Die offentlichen Finanzen in Theorie und Praxis, 5. Aufl., Tübingen 1993 , Bd. 2, S. $243 \mathrm{ff}$.

Vgl. Herber, B.P (1983): Modern Public Finance, 5. Aufl., Illinois 1983, S. 189.

Vgl. van den Tempel, A.J. (1970): Corporation Tax and Individual Income Tax in the European Communities, Brüssel 1970, S. 20. 
sonen, wie sie von der Separationstheorie erhoben wird ${ }^{20}$. Soweit Kapitalgesellschaften aber in Konkurrenz mit Personengesellschaften stehen, ist eine Überwälzbarkeit im bedeutenderen Umfang nur schwer vorstellbar.

Die unterschiedliche Einordnung der Körperschaftsteuer hat in Theorie und Praxis zu verschiedenen Steuersystemen geführt, die sich auf drei Grundtypen reduzieren lassen:

1. Das klassische System

2. Die Teilhabersteuer

3. Systeme, die anteilige oder vollständige Integration der ausgeschütteten Gewinne gewähren

Im klassischen System werden alle Körperschaftsgewinne unabhängig von ihrer Verwendung mit einem einheitlichen Körperschaftsteuersatz ( $\mathrm{t}(\mathrm{KSt})$ ) belegt. Die ausgeschütteten Gewinne unterliegen anschließend der Einkommensteuer des Anteilseigners ( $t$ (p.ESt) ). Damit gilt für ausgeschüttete Gewinne eine effektive steuerliche Gesamtbelastung ( $t$ (eff.ausg.Gewinne)) von

$$
t \text { (eff.ausg.Gewinne) }=t(K S t)+(1-t(K S t)) t(p . E S t)
$$

Der Steuersatz für einbehaltene ( $(\mathrm{KSt}, \mathrm{e}))$ entspricht dem Steuersatz für ausgeschüttete Gewinne ( $(\mathrm{KSt}, \mathrm{a}))$.

$$
\mathrm{t}(\mathrm{KSt}, \mathrm{e})=\mathrm{t}(\mathrm{KSt}, \mathrm{a})
$$

Da Zinseinkommen üblicherweise nur einmal zum persönlichen Einkommensteuersatz besteuert werden, ist offensichtlich, daß im klassischen Körperschaftsteuersystem Dividenden höher besteuert werden als Zinsen. Die Körperschaftsteuer ist in diesem System eine "eigenständige" Steuer; das klassische System somit die Verwirklichung der Separationstheorie. In vielen Staaten mit klassischem System wird zugleich eine Veräußerungsgewinnbesteuerung praktiziert ${ }^{21}$. Damit wird die Doppelbelastung ausgeschütteter Gewinne um eine Doppelbelastung einbehaltener Gewinne ergänzt.

20 Vgl. Kampmann, R. (1983): Theoretische und ökonometrische Untersuchungen zur Körperschaftsteueruberwälzung, Frankfurt am Main 1983.

21 Dies gilt z.B. für die USA und die Schweiz. 
Zur Zeit wird das klassische System in den USA, den Niederlanden ${ }^{22}$, der Schweiz und in einer Reihe osteuropäischer Staaten angewendet ${ }^{23}$.

Das Gegenteil des klassischen Systems ist die vollständige Integration ausgeschütteter und einbehaltener Gewinne in die einkommensteuerliche Bemessungsgrundlage des Anteilseigners. Dieses Konzept wird als Teilhabersteuer bezeichnet $^{24}$. Unabhängig von der Ausgestaltung einer möglichen Quellenbesteuerung im Unternehmen, werden letztlich alle einbehaltenen und ausgeschütteten Gewinne nur dem persönlichen Einkommensteuersatz des Anteilseigners unterworfen. Werden Zinsen ebenfalls von der persönlichen Einkommensteuer erfaßt und wird konsequenterweise auf eine Veräußerungsgewinnbesteuerung verzichtet - die Wertsteigerungen werden dem Anteilseigner hier ja steuerwirksam zugerechnet so unterliegen alle Kapitaleinkommensformen ausschließlich dem persönlichen Einkommensteuersatz des Anteilseigners.

Dieses Konzept scheitert bisher vor allem an erheblichen administrativen Schwierigkeiten bei der Erfassung der Teilhabererträge und der Zuordnung der Teilhabersteuer, da viele Dividendenpapiere aufgrund ihrer Fungibilität häufig den Eigentümer wechseln ${ }^{25}$. Ebenfalls problematisch wären Steuerkorrekturen aufgrund

22 Die Niederlande gehören traditionell zu den Ländern mit klassischem System. Seit Jahresanfang 1997 gilt allerdings für Dividenden ein ermäßigter Einkommensteuersatz von 25\%, sofern der Anteilseigner zusammen mit seinem Ehepartner direkt oder indirekt über mindestens $5 \%$ des ausgegebenen Kapitals verfügt und das Einkommen des Anteilseigners die erste Einkommensklasse übersteigt. Vgl. Blokland, T. / Burgers, I.J.J. (1997): New Dutch Rules on the Taxation of Gains derived from "Substancial Participations", in: Bulletin for International Fiscal Documentation, Vol. 51/(1997), Nr. 7, S. 321.

23 Für Angaben zur Anwendung von Körperschaftsteuersystemen in einzelnen Länder, vgl. International Bureau of Fiscal Documentation (Hrsg.)(1999): European Tax Handbook, Amsterdam 1999.

24 Vgl. zur Teilhabersteuer: Engels, W. / Stützel, W. (1968): Teilhabersteuer, 2. Aufl., Frankfurt am Main 1968; Croneberg, M. (1973): Die Teilhabersteuer. Ein Betrag zur Körperschaftssteuerreform unter besonderer Berücksichtigung der Unternehmensfinanzierung, Braunschweig 1973.

25 Vgl. Boadway, R ./ Wildasin, D. (1984): Public Sector Economics, 2. Aufl., Toronto 1984, S. 434. Brown, C. V. / Jackson, P. M. (1990): Public Sector Economics, 4. Aufl., Oxford u.a. 1990, S. $525 \mathrm{ff}$. Allerdings enthält das US-amerikanische Steuerrecht Elemente einer Teilhabersteuer: Kleine Firmen haben die Wahlmöglichkeit, als "Subchapter" oder als SCorporation behandelt zu werden. Für die Subchapter-Form gilt, daß diese steuerlich einer Art von Ausschüttungsfiktion unterliegen: “...are assumed to pass their profits straight through to their shareholders so that all the tax is borne by the shareholders", Brown, C.V.I Jackson, P. M. (1990), a.a.O., S. 526. 
nachträglicher Korrekturen der Geschäftsergebnisse ${ }^{26}$. Dies gilt insbesondere bei Beteiligungsketten oder gegenseitigen Beteiligungen ${ }^{27}$. Zudem ist eine Besteuerung von Einkommen, das nicht unmittelbar zufließt, schwierig, weil der Steuerpflichtige keine Liquidität erhält, mit der er die Steuerschuld begleichen kann ${ }^{28}$. Neben diesen ökonomischen Aspekten wird von juristischer Seite mitunter argumentiert, daß eine Teilhabersteuer die rechtliche Selbständigkeit der juristischen Person im Bereich des Steuerrechtes mißachte und folglich einen juristischen Systembruch bewirke ${ }^{29}$. Vor allem wegen der ökonomischen Schwierigkeiten konnte die Teilhabersteuer nirgendwo erfolgreich verwirklicht werden.

Die Körperschaftsteuersysteme der meisten Staaten liegen etwa in der Mitte zwischen den Extremfällen des klassischen Systems einerseits bzw. der vollständigen Integration durch die Teilhabersteuer andererseits. Das Anrechnungssystem gewährt die Integration allein der ausgeschütteten Gewinne in die einkommensteuerliche Bemessungsgrundlage, indem die gezahlte Körperschaftsteuer auf die Einkommensteuer angerechnet und gegebenenfalls erstattet wird. Damit wird eine doppelte Belastung ausgeschütteter Gewinne auf der Gesellschafterebene beseitigt. Dies geschieht vollständig im Vollanrechnungssystem und anteilig im Teilanrechnungssystem. Im Vollanrechnungssystem unterliegen die Dividenden effektiv allein dem persönlichen Einkommensteuersatz des Anteilseigners. Damit ist das Vollanrechnungssystem die Umsetzung der Integrationstheorie für ausgeschüttete Gewinne.

$$
t(\text { eff.ausg.Gewinne })=t(p . E S t)
$$

Freilich ist diese Umsetzung nicht vollständig, weil eine Kapitalgesellschaft normalerweise nicht alle Gewinne ausschüttet. Werden Zinsen mit der persönlichen Einkommensteuer besteuert, so besteht für Anrechnungsberechtigte kein steuerlicher Unterschied zwischen der Bereitstellung von Eigen- und Fremdkapital ${ }^{30}$.

26 Vgl. Willemsen, A. (1986): Hat sich das Körperschaftsteuergesetz 1977 bewährt ?, in: Institut für Ausländisches und Internationales Finanz- und Steuerwesen (Hrsg.): Hefte zur Internationalen Besteuerung, Nr. 20, Hamburg 1986, S. 7 f.

27 Vgl. Schwarzkopf, O. (1993): Die Problematik unterschiedlicher Körperschaftsteuersysteme innerhalb der EG, Frankfurt am Main 1993, S. 39.

28 Vgl. Wisser, L. (1992): Überlegungen zu einem gemeinsamen Körperschaftsteuersystem für die Mitgliedstaaten der Europäischen Gemeinschaft, Frankfurt am Main u.a. 1992, S. 136ff.

29 Tatsächlich führt die Teilhabersteuer zu einer Durchbrechung der Abschirmwirkung der Kapitalgesellschaft. Dies gilt allerdings für Dividenden auch im herkömmlichen Anrechnungssystem, weshalb das Argument kaum zu überzeugen vermag

30 Diese Aussage gilt nur, sofern andere Steuem wie Gesellschaftsteuern oder Gewerbeertragsteuern vernachlässigt werden. 
Unterstellt man, daß Wertzuwächse von Unternehmensbeteiligungen ausschließlich durch Thesaurierung von Gewinnen erfolgen, so wäre eine Veräußerungsgewinnbesteuerung im Vollanrechnungssystem nicht systemkonform, solange eine Körperschaftsteuer die einbehaltenen Gewinne erfaßt. Allerdings erfordert eine gleichmäßige Besteuerung, daß der Thesaurierungssatz in der Nähe des Einkommensteuersatzes des (durchschnittlichen) Anteilseigners liegt. Vollanrechnungssysteme finden sich in Deutschland, Norwegen, Finnland, Italien, Frankreich, Australien und Neuseeland. Teilanrechnungssysteme existieren z.B. in Großbritannien, Irland und Spanien.

Alternativ kann die Doppelbelastung auch auf der Gesellschaftsebene durch ermäßigte Körperschaftsteuer bzw. durch ermäßigte Dividendenbesteuerung auf der Gesellschafterebene gemildert oder beseitigt werden. Ermäßigte Einkommensteuersätze auf Dividenden werden z.B. in Österreich und Belgien angewendet. In Deutschland ist die Einbeziehung der hälftigen Dividendeneinkommen in die Einkommensteuer geplant (sog. Halb-Einkünfte-Verfahren). In Kroatien und Griechenland werden Dividenden gar nicht von der Einkommensteuer erfaßt.

Im weiteren soll die vorgestellte Problematik der Doppelbelastung abgegrenzt werden vom Begriff der Doppelbesteuerung. Kennzeichnend für eine Doppelbelastung ist, daß ein Steuergegenstand mehrfach steuerlich von einer Steuerhoheit belastet wird. Üblicherweise beschreibt die Doppelbelastung damit ein innerstaatliches Problem ${ }^{31}$. Dabei muß das Steuersubjekt nicht identisch $\operatorname{sein}^{32}$. Als Doppelbelastung soll im weiteren die mehrfache Besteuerung ausgeschütteter Gewinne bezeichnet werden, wie sie in Körperschaftsteuersystemen mit keiner oder unvollständiger Integration auftritt. Steuersubjekt ist hier zum einen die körperschaftsteuerpflichtige Kapitalgesellschaft, zum anderen der einkommensteuerpflichtige Anteilseigner.

Doppelbesteuerung liegt vor, wenn ein Steuergegenstand eines Steuersubjektes von verschiedenen Steuerhoheiten mehrfach belastet wird. Im juristischen Sinne spricht man heute von internationaler Doppelbesteuerung, wenn dieselben Einkünfte, innerhalb eines Besteuerungszeitraumes bei ein und demselben Steuersubjekt, in zwei oder mehreren Staaten einer identischen Steuer unterzogen wer$\mathrm{den}^{33}$. Die Doppelbesteuerung ist damit ein Problem auf zwischenstaatlicher Ebe-

31 Vgl. Thümler, A. (1994): Körperschaftsteuerliches Anrechnungsverfahren und internationales Steuerrecht, Frankfurt am Main u.a. 1994, S. 66.

Vgl. Tipke, K. / Lang, J. (1996): Steuerrecht, 15. Aufl., Köln 1996, § 7, S. 182.

Vgl. Pumbo, M. (1995): Ausländische Einkünfte im körperschaftsteuerlichen Anrechnungsverfahren, Hamburg 1995, S.10f. 
ne. Der juristische Begriff der Doppelbesteuerung ist allerdings ökonomisch zu eng gefaßt. Eine wirtschaftliche Doppelbesteuerung kann auch im Fall einer fehlenden Steuersubjektidentität vorliegen.

Die im Mittelpunkt dieser Arbeit stehende Besteuerung ausländischer Dividendenempfänger ist also streng genommen sowohl eine Doppelbelastung als auch eine Doppelbesteuerung im wirtschaftlichen Sinn. Zwecks einer genauen Differenzierung soll der Fall einer Doppelbelastung aus Körperschaft- und Einkommensteuer bei grenzüberschreitenden Vorgänge im weiteren als internationale Doppelbelastung bezeichnet werden ${ }^{34}$. Internationale Doppelbelastung liegt also vor, wenn eine inländische (bzw. ausländische) Körperschaft körperschaftsteuerlich belastete Dividenden an einen ausländischen (bzw. inländischen) Anteilseigner ausschüttet, der diese Dividende seiner Einkommensteuer unterwerfen muß.

Weder der Begriff der Doppelbelastung noch der Begriff der Doppelbesteuerung sind wörtlich zu verstehen. Es handelt sich nicht um eine verdoppelte Belastung oder Besteuerung, sondern um einen mehrfachen steuerlichen Zugriff.

\subsection{Allokative Anforderungen an die Körperschaftsteuer}

Allokativ wird eine Besteuerung günstig beurteilt, wenn sie sich auf das Verhalten der Akteure in einer Wirtschaft entweder positiv oder neutral auswirkt. Sofern das Verhalten überhaupt positiv zu beeinflussen ist, muß ohne Besteuerung ein Fehlverhalten vorgelegen haben, z.B. ein sogenanntes Marktversagen. Die Korrektur eines Marktversagens durch einen Staatseingriff in Form einer Besteuerung kann jedoch auch noch schädlichere Folgen haben als das Marktversagen selbst. Eine neutrale Besteuerung ist aus allokativer Sicht dann zu fordern, wenn angenommen werden kann, daß eine steuerliche Beeinflussung der Akteure zu Wohlfahrtsverlusten führen würde. Es ist also keine notwendige Bedingung einer neutralen $\mathrm{Be}-$ steuerung, daß sich die von der Steuer Betroffenen vor Steuereinführung optimal verhalten haben und folglich ein Allokationsoptimum vor Steuereinführung erreicht gewesen sein muß. Entscheidend ist, daß eine Besteuerung in einer Volkswirtschaft keine zusätzlichen Wohlfahrtsverluste erzeugt. Unter einer neutralen Besteuerung ist im weiteren also eine Besteuerung zu verstehen, die keine Verhaltensänderungen der Besteuerten, also keine Substitutionseffekte auslöst ${ }^{35}$.

34 Diese Differenzierung nimmt z.B. auch Scheffler vor. Vgl. Scheffler, W. (1996): Steuerfreistellung für Auslandsinvestitionen, in: Jacobs, O.H. / Spengel, C. (Hrsg.): Aspekte der Unternehmensbesteuerung, Baden-Baden 1996, S. 155. 
In der Finanzwissenschaft ist die Forderung nach einer neutralen Besteuerung mit der Forderung spezieller Neutralitäten spezifiziert worden. Die Neutralitätspostulate, die im weiteren von besonderer Bedeutung sein werden, sollen hier kurz vorgestellt werden. Die Auswirkung eines Integrationsverzichts der Körperschaftsteuer auf die Erfüllung allokativer Anforderungen an die Besteuerung werden untersucht. Auch das Vollanrechnungssystem soll an diesen Anforderungen gemessen werden. Eine Analyse der anderen Körperschaftsteuersysteme soll aufgrund der Themenstellung nur bei Bedarf an späterer Stelle erfolgen.

\subsubsection{Finanzierungsneutralität}

Einem Unternehmen stehen in der Regel verschiedene Finanzierungsmöglichkeiten offen. Grundsätzlich kann es sich für Eigen- und Fremdfinanzierung entscheiden. Die Eigenfinanzierung kann weiter unterteilt werden in die Beteiligungsfinanzierung und die Selbstfinanzierung. Unter Beteiligungsfinanzierung wird die Aufnahme von Eigenkapital über Aktien, unter Selbstfinanzierung die Verwendung thesaurierter Gewinne verstanden. In allen OECD-Staaten sind Steuersysteme nach dem Schanz-Haig-Simons-Typ üblich, das heißt, Schuldzinsen können nach der Reinvermögenszugangstheorie vom zu versteuernden Einkommen abgezogen werden und Zinseinkünfte werden besteuert. Damit werden Zinsen, die ein Unternehmen für entliehenes Fremdkapital zahlt, nur auf der Empfängerseite - also auf der Haushaltsebene - von der Einkommensteuer erfaßt. Die Körperschaftsteuer erfaßt dagegen auf der Unternehmensebene die Gewinne ${ }^{36}$, die ein Unternehmen erwirtschaftet.

Ein Steuersystem ist finanzierungsneutral, wenn es den Finanzierungsumfang eines Unternehmens nicht beeinflußt. Ob Finanzierungsneutralität auch erfordert, daß die Wahl der Finanzierungsform durch die Besteuerung unverändert bleiben muß, hängt ab von Annahmen über die Substituierbarkeit der einzelnen Finanzierungsformen. Verneint man jede Substituierbarkeit, so muß die Finanzierungsneutralität sehr streng formuliert werden: Ein Steuersystem gilt unter diesen Umständen dann als finanzierungsneutral, wenn die Wahl der Finanzierung einer Investition immer so ausfällt, wie in einer Referenzsituation ohne Steuern.

Diese relativ enge Auslegung der Finanzierungsneutralität erfordert eine gleiche Besteuerung von Zinsen, einbehaltenen und ausgeschütteten Gewinnen (Old

36 Diese können natürlich auch aus Zinseinnahmen resultieren, wenn Unternehmen selbst Fremdkapital verleihen. 
View) ${ }^{37}$. Nachfolgend soll diese Finanzierungsneutralität als totale Finanzierungsneutralität bezeichnet werden.

Verhalten sich dagegen die einzelnen Finanzierungsformen substitutional zueinander, dann läßt eine höhere Besteuerung einer einzelnen Finanzierungsart den Gesamtumfang der Finanzierungen unberührt. Sind z.B. Selbst- und Beteiligungsfinanzierung völlig austauschbar, so könnte eine höhere Besteuerung ausgeschütteter Gewinne unproblematisch sein, weil Unternehmen sich auch über die Selbstfinanzierung finanzieren könnten (New View) ${ }^{38}$. In diesem Fall erzeugt das klassische System nicht automatisch allokative Verzerrungen. Es genügt dann eine partielle Finanzierungsneutralität, die erreicht ist, wenn nur eine Form der Eigenfinanzierung (also entweder die Selbst- oder die Beteiligungsfinanzierung) steuerlich wie die Fremdfinanzierung behandelt wird ${ }^{39}$.

Da es auf den Finanzierungsumfang ankommt, kann man auch formulieren, daß eine hinreichende Bedingung für Finanzierungsneutralität erfüllt ist, wenn der effektive Grenzsteuersatz eines Anlegers sowohl beim Erwerb von Eigenkapitalanteilen als auch beim Erwerb von Fremdkapitaltiteln gleich hoch ist ${ }^{40}$.

Schätzt man sogar die Eigen- und die Fremdfinanzierung vollständig substitutional ein, so verursacht selbst ein Körperschaftsteuersystem, das thesaurierte Gewinne höher besteuert als zum Höchstsatz der Einkommensteuer und auch die Doppelbelastung ausgeschütteter Gewinne zuläßt, keine Verzerrungen, weil ein Unternehmen seine Grenzinvestition immer mit der günstigsten Finanzierungs-

37 Vgl. Sinn, H.-W. (1991): Taxation and the Cost of Capital: The "old" View, The "new" View and another View, in: Bradford, D. (Hrsg.): Tax Policy and the Economy 5, Cambridge Massachusetts.

38 Vgl. Head, J. (1997): Company Tax Systems - From Theory to Policy, in: Head, J. G. I Krever, R. (Hrsg.): Company Tax Systems, Victoria 1997, S. 9ff. Vgl. Sinn, H.-W. (1991), a.a.O., S. $29 \mathrm{ff}$.

39 Kaiser spricht im Fall, daß nur die Beteiligungsfinanzierung gegenüber der Selbst- und der Fremdfinanzierung diskriminiert wird von einer partiellen Finanzierungsneutralităt. Vgl. Kaiser, M. (1992): Konsumorientierte Reform der Unternehmensbesteuerung, Heidelberg 1992, S. 123.

40 Der effektive Grenzsteuersatz umfaßt sowohl die Belastung der Kapitalbildung durch Besteuerung der Unternehmen als auch die persönlichen Steuern des Kapitalanlegers. Der effektive Grenzsteuersatz ergibt sich aus dem Verhältnis der Bruttorendite einer Investition abzüglich der Nettorendite des Sparers in Beziehung gesetzt zur Bruttorendite der Investition. Vgl. Kaiser, M. (1992), a.a.O., S. 24. 
form, der Fremdfinanzierung, vornehmen $\operatorname{kann}^{41}$. Sinn sieht deswegen in der Doppelbelastung des klassischen Systems sogar eine weitgehend allokationsneutrale Einnahmequelle des Staates und bedauert die Reduzierung oder Abschaffung dieser Doppelbelastung in Staaten mit integrierten Körperschaftsteuersystemen ${ }^{42}$.

Die völlige Substituierbarkeit von Eigen- und Fremdfinanzierung ist allerdings eine sehr gewagte Annahme, gegen die schon die Tatsache spricht, daß Fremdkapital - anders als Eigenkapital - Gläubigerschutz genießt, der allerdings in den Staaten unterschiedlich weitgehend ist. Zum Ausgleich der fehlenden Absicherung muß Eigenkapital daher eine höhere Risikoprämie erwirtschaften, als es für die Bedienung des Fremdkapitals erforderlich ist. Gegen eine totale Substituierbarkeit spricht weiterhin, daß die Eigenfinanzierung größere Sicherheit gegen Liquiditätsengpässe als Fremdfinanzierung gewährt, da die Zinsansprüche aus der Aufnahme von Fremdkapital unabhängig von der Geschäftslage zu bedienen sind.

In den meisten westlichen Ländern ist allein aus Sicht einer Kapitalgesellschaft die Fremdfinanzierung der Eigenfinanzierung vorzuziehen, weil die Kosten der Fremdfinanzierung (Zinszahlungen) steuerlich abzugsfähig sind, die Kosten des Eigenkapitals (Dividendenzahlungen) dagegen nicht ${ }^{43}$. In Vollanrechnungsländern wie Deutschland besteht deswegen aber keine Diskriminierung der Eigenfinanzierung gegenüber der Fremdfinanzierung, weil die Zinsen beim inländischen Empfänger voll der inländischen persönlichen Einkommensteuer des Sparers unterliegen, während die Körperschaftsteuer, die auf den Dividenden liegt, beim anrechnungsberechtigten Anteilseigner auf dessen Einkommensteuer angerechnet und gegebenenfalls erstattet wird. Damit richtet sich die Beteiligungsfinanzierung wie die Fremdfinanzierung letztlich allein nach der persönlichen Einkommensteuer

41 Unterstellt man eine Wertzuwachsbesteuerung auf der Haushaltsebene im Rahmen der Einkommensteuer, so ist Fremdfinanzierung immer die steuerlich am geringsten belastetete Alternative, solange die Körperschaftsteuersätze auf einbehaltene Gewinne $>0$ sind. Fehlt eine solche Wertzuwachssteuer, dann ist die Fremdfinanzierung noch solange günstiger, wie die Körperschaftsteuersätze auf einbehaltene Gewinne höher sind als die Einkommensteuer.

42 Vgl. Sinn, H.-W. (1984): Systeme der Kapitaleinkommensbesteuerung. Ein allokationstheoretischer Vergleich, Sonderdruck aus: Bös, D. / Rosen, M. / Seidl, C. (Hrsg.): Beiträge zur neuen Steuertheorie, Berlin u.a. 1984, S. 231. Ders. (1985), a.a.O., S. 178ff.

43 Eine Ausnahme bildet hier Kroatien, wo seit 1994 eine sogenannte Normalverzinszung des Eigenkapitals von der kroatischen Gewinnsteuer unberthrt bleibt. Es ist aber fraglich, ob im kroatischen Steuersystem, das keine Zinsbesteuerung kennt, Finanzierungsneutralität erreicht wird, da Eigenkapitalvergütungen nur zum Teil, die Zinsen auf Fremdkapital aber in voller Hohe unversteuert bleiben. 
des Anlegers ${ }^{44}$. Das Vollanrechnungssystem ist folglich zumindest hinsichtlich der Beteiligungsfinanzierung - also partiell - finanzierungsneutral.

In Staaten, die eine Doppelbelastung ausgeschütteter Gewinne nicht vollständig beseitigen, wird die partielle Finanzierungsneutralität zwischen Beteiligungs- und Fremdfinanzierung sowie - einheitliche Körperschaftsteuersätze vorausgesetzt zwischen Beteiligungs- und Selbstfinanzierung immer verletzt. Die Doppelbelastung führt stets zu einer steuerlichen Diskriminierung der Beteiligungsfinanzierung. Die partielle Finanzierungsneutralität zwischen Selbst- und Fremdfinanzierung kann, wie im Vollanrechnungssystem, mehr zufällig erreicht sein, wenn der effektive Grenzsteuersatz eines Investors für beide Finanzierungsformen gerade gleich ist.

Daraus wird ersichtlich, daß eine totale Finanzierungsneutralität nur erreicht werden kann mit einer Teilhabersteuer in Verbindung mit einer Zinsbesteuerung in Höhe der Einkommensteuer oder einer Flat-Rate-Besteuerung aller Kapitaleinkommen, wie sie nach dem sogenannten nordischen Steuermodell in Finnland, Norwegen und Schweden praktiziert wird.

\subsubsection{Investitionsneutralität}

Investitionsneutralität besteht, wenn ein Steuersystem gegenüber einer Situation ohne Steuern keine Veränderung der Investitionsplanung bewirkt. Weder die Rangfolge noch der Umfang der Investitionsprojekte verändern sich aufgrund der Besteuerung. Damit dies erfüllt ist, muß eine Investition, die in einer Situation ohne Steuern gerade eine Rendite in Höhe des Marktzinssatzes erwirtschaftet, in einer Situation mit Besteuerung immer noch eine Nettorendite in Höhe des Marktzinssatzes erwirtschaften. Eine investitionsneutrale Kapitaleinkommensbesteuerung erfordert also, daß aus Sicht des Investors die Grenzinvestition einer gleichen Besteuerung unterliegt wie eine alternative Finanzanlage ${ }^{45}$.

Sind Investitionen nicht ohne Beteiligungsfinanzierung durchführbar, so verletzen klassische Körperschaftsteuersysteme die Investitionsneutralität. Eine Investition muß gegenüber einer entsprechenden Anlage auf dem Geldmarkt eine um die Körperschaftsteuer erhöhte Bruttorendite erwirtschaften.

44 Eine Zinsbesteuerung, die günstiger ist als die Einkommensteuer auf Dividenden unterläuft die Finanzierungsneutralităt, vgl. hierzu Cnossen, S. (1993): What Kind of Corporation Tax, in: Bulletin for International Fiscal Documentation, Vol. 47/(1993), Nr. 1, S. 14. 
Folglich werden im klassischen System weniger Investitionsprojekte realisiert als in einem Vollanrechnungssystem. Unter der Annahme einer tatsächlich durchführbaren Zinsbesteuerung aller Zinseinkünfte zum Einkommensteuersatz, kann ein Vollanrechnungssystem dem Sparer bzw. Investor Investitionsneutralität gewähren, da die Vollanrechnung dazu führt, daß Beteiligungseinkommen und Zinseinkommen dem gleichen Steuersatz unterliegen. Steht jedoch auch die Möglichkeit der Selbstfinanzierung uneingeschränkt offen, so ist die Investitionsbereitschaft nicht allein abhängig vom Körperschaftsteuersystem, sondern auch vom Verhältnis des Thesaurierungssatzes der Körperschaftsteuer zum persönlichen Einkommensteuersatz des Investors.

Analog zur Finanzierungsneutralität stellt sich die Frage, ob eine Investition tatsächlich ohne Eigenkapital bzw. ohne Beteiligungskapital erfolgen kann und somit eine Eigenkapitalertragsbesteuerung für die Investitionswahl unerheblich ist. Trifft dies nicht zu, kommt auf jeden Fall die Körperschaftsteuer ins Spiel. Ein klassisches Körperschaftsteuersystem treibt im Fall einer unvermeidlichen Beteiligungsfinanzierung durch die Körperschaftsteuer einen Keil zwischen die Investition und die alternativen Geldmarktanlage. Ein Vollanrechnungssystem läßt diesen Keil bezogen auf die ausgeschütteten Gewinne nicht entstehen.

Allerdings bevorzugen viele Kapitalanbieter die Bereitstellung von Fremdkapital noch aus einem anderen Grund und sind deswegen auch im Vollanrechnungssystem noch nicht bereit, beteiligungsfinanzierte Investitionen einzugehen: Zinsen lassen sich oft leichter hinterziehen, weil diese Einkommensart zumindest bei grenzüberschreitenden Finanzierungsströmen nicht durch eine angemessen hoch angesetzte Kapitalertragsteuer erfaßt wird ${ }^{46}$.

\subsubsection{Gewinnverwendungsneutralität}

Gewinnverwendungsneutralität besteht, wenn ein Unternehmen in seiner Entscheidung, ob es Gewinne ausschüttet oder thesauriert, nicht von steuerlichen Faktoren beeinflußt wird. Die Bedeutung der Gewinnverwendungsneutralität ist umstritten.

Als "betriebswirtschaftliche" Sicht wird der Standpunkt bezeichnet, daß die Thesaurierung der Gewinne zu fördern sei, um Unternehmen mit einer stärkeren Eigenkapitalbasis auszustatten. Ein erweitertes Risikokapital fördere eine wachsende

46 Dies führt dazu, daß auch Steuerinländer in einem Vollanrechnungsland angeregt sein können, Fremdkapital über das Ausland zur Verfugung zu stellen. Damit verliert die gleiche Besteuerung von Zinsen und Dividenden im Vollanrechnungsland aufgrund der Hinterziehbarkeit aber ihre praktische Bedeutung. 
Investitionstätigkeit. Diese Ansicht ist zweifelhaft. Unternehmen sind nämlich aufgrund ihrer Entscheidungsfreiheit keineswegs gezwungen, zusätzliche Investitionen zu tätigen. Ebenfalls zweifelhaft ist der als "volkswirtschaftlich" bezeichnete Standpunkt, daß eine Begünstigung der Gewinnthesaurierung abzulehnen sei, weil das firmeninterne Kapital der Marktlenkung entzogen $\operatorname{se}^{47}$. Diese Sichtweise unterstellt, daß das Kapital in einem Unternehmen zur Erwirtschaftung geringerer Renditen eingesetzt wird.

Mindert ein Körperschaftsteuersystem die Doppelbelastung nicht, so verstößt es gegen die Gewinnverwendungsneutralität: Anteilseigner werden darauf drängen, daß die Gewinne in der Kapitalgesellschaft verbleiben und nicht eine zusätzliche einkommensteuerliche Belastung erfahren. Dies gilt natürlich weniger für Kleinaktionäre mit relativ geringer persönlicher Einkommensteuer, als vielmehr für Großaktionäre mit höherem Einkommensteuersatz. Da diese in der Regel stärkeren Einfluß auf die Gewinnverwendungspolitik des Unternehmens ausüben können, wird die Gewinnverwendung zugunsten der Thesaurierung beeinflußt. Vollanrechnungssysteme bewirken dagegen, daß die Anteilseigner keine Präferenz für Ausschüttung oder Thesaurierung haben, solange der Steuersatz auf einbehaltene Gewinne in der Nähe ihres persönlichen Einkommensteuersatzes liegt. Unterstellt, daß die meisten Anteilseigner hoch besteuerte Großaktionäre sind, so ist zur Erfüllung der Gewinnverwendungsneutralität ein Körperschaftsteuersatz in der Nähe des Einkommensteuerspitzensatzes erforderlich.

\subsubsection{Rechtsformneutralität}

Natürliche Personen, die sich gemeinsam unternehmerisch betätigen wollen, haben grundsätzlich die Wahl, ob sie als Personen- oder Kapitalgesellschaft firmieren. Rechtsformneutralität ist erfüllt, wenn diese Wahl nicht von steuerlichen Gegebenheiten bestimmt wird. Die Entscheidung über die Rechtsform soll idealerweise aus betriebswirtschaftlichen Aspekten getroffen werden ${ }^{48}$.

Rechtsformneutralität liegt vor, wenn die unternehmerische Entscheidung für eine bestimmte Rechtsform keine steuerlichen Konsequenzen auslöst. Die Besteuerung von Kapital- und Personengesellschaften muß folglich aus Sicht des Gesellschafters im Ergebnis identisch sein. Rechtsformneutralität ist im Voll-

47 Vgl. Wenger, E. (1989): Wirtschaftswachstum, Unternehmensfinanzierung und internationaler Kapitalverkehr unter dem Einfluß der Besteuerung von Vermögenseinkunften, in: Finanzarchiv, NF, Bd. 47, S. 226.

Natürlich stellt sich die Frage der Rechtsformwahl für sehr große oder sehr kleine Unternehmen nur sehr eingeschränkt. 
anrechnungssystem erfüllt, da das Zusammenspiel zwischen Einkommen- und Körperschaftsteuer zu einer gleichen Gesamtbelastung führt wie eine alleinige Einkommensteueranwendung. Auch ein Thesaurierungssatz, der über dem persönlichen Einkommensteuersatz des Anteilseigners liegt, würde an dieser Aussage nichts ändern, könnte man die Kosten des Schütt-Aus-Hol-Zurück-Verfahrens und einige weitere Schwierigkeiten bezüglich der Rückholung des Kapitals bei diesem Verfahren außer acht lassen ${ }^{49}$. Dagegen führt ein im Verhältnis zur Einkommensteuer niedrigerer Thesaurierungssatz bei Substituierbarkeit von Beteiligungs- und Selbstfinanzierung zur steuerlichen Bevorzugung der Kapitalgesellschaften. Letzteres gilt natürlich systemunabhängig, das heißt, auch für das klassische System. Das klassische System diskriminiert allerdings die Rechtsform der Kapitalgesellschaft, wenn für diese die Beteiligungsfinanzierung unvermeidbar ist. Daraus folgt, daß mehr Kapital in Personengesellschaften fließt als gesamtwirtschaftlich eigentlich sinnvoll wäre.

Sieht man die Beteiligungs- und die Selbstfinanzierung nicht als vollkommen substituierbar an, so erfordert die Erfüllung der Rechtsformneutralität auch bei Vollanrechnungssystemen noch eine weitere Bedingung. Wie im Fall der Gewinnverwendungsneutralität muß eine Besteuerung einbehaltener Gewinne in der Nähe des Höchstsatzes der Einkommensteuer liegen, wenn anzunehmen ist, daß die Mehrheit der Gesellschafter von Personengesellschaften mit ihrem persönlichen Einkommensteuersatz in diesem Bereich liegen.

\subsubsection{Akquisitionsneutralität}

Eine Besteuerung ist akquisitionsneutral, wenn sie die Entscheidung über Art und Umfang eines Erwerbs von Unternehmensbeteiligungen bzw. Unternehmen nicht beeinflußt. Ein Erwerb von Beteiligungen muß steuerlich gleichbehandelt werden mit einem Erwerb der entsprechenden Bestandteile des Unternehmens, z.B. der Produktionsanlagen. Für den Beteiligungserwerb durch Kapitalgesellschaften ist die Akquisitionsneutralität in vielen Ländern verletzt. Ursache hierfür ist das $\mathrm{Zu}-$ sammentreffen von Körperschaftsteuersystemen ohne Vollanrechnung und das in

49 Dies ist allerdings bei großen Publikumsgesellschaften nur eingeschränkt mőglich, da viele Anleger insbesondere Streubesitzanleger, an einer Wiederanlage kleinerer Beträge kaum interessiert sind. Außerdem werden Körperschaftsteuer- und Kapitalertragsteuergutschriften - sofern sie den Sparerfreibetrag überschreiten - erst ein Jahr nach der Dividendenzahlung bei den Anteilseignern liquiditätswirksam, da sie gemäß $\S 36 \mathrm{KStG}$ erst im Jahr nach der Ausschüttung durch die Finanzverwaltung ausgezahlt werden. Anteilseigner sind aber nicht unbedingt bereit, in eine Gesellschaft Beträge einzulegen, die sie erst ein Jahr später erhalten, vgl. Perridon, L. / Steiner, M. (1995): Finanzwirtschaft der Unternehmung, 8. Aufl., München 1995, S. 481f. 
den meisten Ländern übliche Schachtelprivileg für Gewinnausschüttungen von Tochter- an Muttergesellschaften. Durch kreditfinanzierte Unternehmensaufkäufe vermeiden Kapitalgesellschaften Gewinnausschüttungen und damit in klassischen Systemen die steuerliche Doppelbelastung dieser Gewinne.

Das in den meisten Ländern übliche Schachtelprivileg führt dazu, daß sich ein kreditfinanzierter Kauf einer Kapitalgesellschaft durch eine andere Kapitalgesellschaft in einem Land ohne Vollanrechnung mehr lohnt als ein Erwerb entsprechender Produktionsanlagen. Sinn zeigt, daß die Nutzung des Schachtelprivilegs zwischen den Unternehmen zu einem Nettokursgewinn der Anteile des übernehmenden Unternehmens führt ${ }^{50}$, da durch Unternehmenszusammenschlüsse die Steuerkosten der Ausschüttungen an Anteilseigner verringert werden. Auch hinsichtlich der Akquisitionsneutralität schneidet damit das Vollanrechnungssystem gegenüber dem klassischen System vorteilhaft ab.

\subsubsection{Intersektorale Neutralität}

Eine Besteuerung soll hier als intersektoral neutral bezeichnet werden, wenn sie nicht gegen einzelne Wirtschaftszweige oder Branchen diskriminiert. Sind einzelne Wirtschaftszweige oder Branchen auf die Inanspruchnahme körperschaftsteuerpflichtiger Rechtsformen stärker angewiesen als andere, so diskriminiert das klassische System auch in intersektoraler Hinsicht. Das Vollanrechnungssystem wirkt dagegen neutral.

\subsection{Sonstige Anforderungen an die Körperschaftsteuer}

\subsubsection{Distributive Beurteilung}

Verteilungspolitische Beurteilungen einer Besteuerung knüpfen einerseits an Normen der Gerechtigkeit an, dabei spielen Aspekte der Äquivalenz bzw. der Leistungsfähigkeit eine Rolle. Andererseits können verteilungspolitische Ziele auch weitergehende Inhalte haben. Starke Umverteilungen bis hin zu angestrebten Gleichverteilungen können politische Ziele sein, die sich mit Gerechtigkeitsüberlegungen kaum begründen lassen. Dieser Politikbereich ist sehr wertebehaftet. Im folgenden sollen deswegen bei der distributiven Beurteilung Gerechtigkeitsaspekte im Vordergrund stehen.

Steuergerechtigkeit wird üblicherweise unterschieden in horizontale und vertikale Gerechtigkeit. Horizontale Gerechtigkeit erfordert den Grundsatz, gleiche Tatbe- 
stände gleich zu besteuern, vertikale Gerechtigkeit verlangt eine ungleiche $\mathrm{Be}$ steuerung ungleicher Sachverhalte. Eine gleiche Besteuerung von Kapital- und Personengesellschaften wird von der Integrationstheorie zwecks Erfüllung horizontaler Gerechtigkeit gefordert, da die Anhänger dieser Sicht die Kapitalgesellschaft nicht anders bewerten als die Personengesellschaft. Mit der Forderung nach vertikaler Gerechtigkeit argumentieren Verfechter des klassischen Systems für eine ungleiche Behandlung dieser Rechtsform, wenn sie eine besondere Leistungsfähigkeit der Kapitalgesellschaft behaupten.

Als zusätzliches distributives Ziel kann eine möglichst breite Vermögensstreuung innerhalb einer Volkswirtschaft formuliert werden. Auch in dieser Hinsicht schneidet das klassische System schlechter ab als das Anrechnungsverfahren. Im klassischen System verhalten sich die Interessen von Anteilseignern mit relativ hohem Einkommensteuersatz konträr zu denen der Kleinaktionäre. Erstere sind eher an der Gewinnthesaurierung interessiert, letztere eher an Ausschüttungen, da für geringerverdienende Kleinaktionäre einerseits die Doppelbelastung - aufgrund der niedrigen persönlichen Einkommensteuer - weniger ins Gewicht fällt, andererseits gerade diese Gruppe eher an Liquiditätszuflüssen interessiert ist.

Dieser Interessenskonflikt zwischen Groß- und Kleinaktionären ist im Anrechnungssystem aufgrund der Beseitigung der Doppelbelastung gemindert. Ein Thesaurierungssatz in der Nähe des Höchstsatzes der Einkommensteuer bei gleichzeitiger Vollanrechnung hebt den Interessenskonflikt möglicherweise sogar ganz auf. Hiervon kann man sich eine höhere Transparenz für den Steuerzahler versprechen, weil die Umverteilungswirkungen eines Steuersystems allein durch den Einkommensteuertarif erreicht wird. Nicht zuletzt verspricht man sich von der Interessensharmonisierung der Anteilseigner eine höhere Beteiligung breiter Bevölkerungsschichten am Produktivvermögen der Volkswirtschaft ${ }^{51}$, die zu einer Verringerung von Verteilungskonflikten beiträgt und deswegen auch zu einem höheren Gesamtoutput einer Volkswirtschaft führen $\mathrm{kann}^{52}$.

\subsubsection{Administrierbarkeit}

Hinsichtlich der Körperschaftsteuersysteme kann gesagt werden, daß eine Körperschaftsteuer grundsätzlich ein entwickeltes System der Gewinnermittlung erfordert.

51 Das deutsche Vollanrechnungssystems wurde u.a. ausdrücklich auch aus diesem Grund eingeführt, vgl. BT-Drs. 7/1470, S. 327.

Aus eben diesen Gründen wird die Einführung von Investivlöhnen diskutiert. 
Weiterhin muß die Konstruktion der juristischen Person im Rechtssystem verankert sein. Sind diese Grundvoraussetzungen - in vielen weniger entwickelten Staaten durchaus noch keine Selbstverständlichkeit - erfüllt, so gilt, daß ein klassisches Körperschaftsteuersystem weniger verwaltungsaufwendig ist als ein Volloder Teilanrechnungssystem. Daher erfreut sich das klassische System auch in den Transformationsstaaten Mittel- und Osteuropas einer höheren Beliebtheit.

\section{Zwischenfazit}

Zusammenfassend kann festgehalten werden, daß die Doppelbelastung ausgeschütteter Gewinne gegen die Finanzierungs-, die Investitions-, die Gewinnverwendungs-, die Rechtsform- und die Akquisitionsneutralität verstößt, unter Umständen wird auch die intersektorale Neutralität verletzt . Allokativ schneidet das klassische Körperschaftsteuersystem grundsätzlich schlechter ab als ein System mit voller Integration, weil es Substitutionseffekte auslöst, die der Vermeidung der Doppelbelastung der Beteiligungsfinanzierung dienen. Die nationalen Neutralitätspostulate sind im Anrechnungssystem zumindest grundsätzlich erreichbar. Distributiv kann man eine Beseitigung der Doppelbelastung mit einer ausgeglicheneren Verteilung von Vermögenswerten auf breitere Bevölkerungsschichten begründen. Die resultierende Interessensbündelung bewirkt positive allokative und verteilungspolitische Effekte. Die Vollanrechnung führt auch zu einer Erhöhung der Transparenz hinsichtlich der Verteilungswirkung eines Steuersystems. Allein aus administrativer Sicht erscheint das klassische System vorteilhafter. 
Hans-Werner Seiler - 978-3-631-75261-6

Downloaded from PubFactory at 01/11/2019 06:36:03AM

via free access 


\section{Die steuerliche Behandlung ausländischer Kapitalgeber}

Im vorangegangen Kapitel wurde deutlich, daß das körperschaftsteuerliche Vollanrechnungssystem vielfältige allokative und distributive Vorzüge aufweist. Es kann nun gezeigt werden, daß viele dieser Vorzüge nur innerhalb einer geschlossenen Volkswirtschaft im vollen Umfang erhalten bleiben. Tatsächlich wirkt ein Vollanrechnungssystem international keineswegs allokativ neutral. Auch treten bei einer Betrachtung des Vollanrechnungssystems für eine offene Volkswirtschaft andere distributive und administrative Aspekte hinzu, die bei einer geschlossenen Volkswirtschaft außer acht gelassen werden konnten. Diese Aspekte sollen zuerst vorgestellt werden, bevor die deutsche Besteuerung ausländischer Kapitalgeber untersucht werden wird. Dabei wird zum einen auf die körperschaftsteuerliche Behandlung eingegangen, zum anderen werden alternative Finanzierungswege untersucht.

\subsection{Grundlagen der internationalen Besteuerung von Kapitaleinkommen}

Man unterscheidet bei der Besteuerung internationaler Einkommensströme zwei Ansätze: das Quellenlandprinzip und das Wohnsitzlandprinzip. Bezüglich der Kapitaleinkommen ist das Quellenlandprinzip verwirklicht, wenn Kapitaleinkommen ausschließlich im Land der Einkommensentstehung besteuert wird. Der Wohnsitz des Einkommensbeziehers ist für die Besteuerung unerheblich. Eine Besteuerung nach dem Quellenlandprinzip wird häufig äquivalenztheoretisch begründet, z.B. damit, daß das Quellenland seine Infrastruktur für die Einkommenserzielung zur Verfügung stellt und über das Besteuerungsrecht eine entsprechende Kompensation für den Ressourcenverbrauch erfährt.

Dagegen wird nach dem Wohnsitzlandprinzip das Welteinkommen des Steuerpflichtigen ausschließlich im Wohnsitzland besteuert. Der Ort der Einkommensentstehung ist dabei unerheblich. Das Wohnsitzlandprinzip wird vor allem damit begründet, daß eine Besteuerung des gesamten Einkommens im Wohnsitzland leichter eine Berücksichtigung der wirtschaftlichen Leistungsfähigkeit des Steuerpflichtigen ermöglicht.

Hinsichtlich der Dividendenbesteuerung kann man differenzieren zwischen dem juristischen und dem ökonomischen Wohnsitzlandprinzip. Berücksichtigt man die Existenz juristischer Personen, so kann als Wohnsitzland der Sitz einer Kapitalgesellschaft gesehen werden. Das juristische Wohnsitzlandprinzip ist danach erfüllt, wenn die Besteuerung der Einkommen einer Kapitalgesellschaft im Staat der Ansässigkeit der Gesellschaft erfolgt. Das juristische Wohnsitzlandprinzip entspricht damit dem Grundgedanken der Separationstheorie, die keine Verbindung zwi- 
schen Kapitalgesellschaften und natürlichen Personen sieht, sondern beide als unabhängige Steuersubjekte auffaßt. Das ökonomische Wohnsitzlandprinzip berücksichtigt, daß hinter jeder juristischen Person letztlich natürliche Personen stehen, die durch Ausschüttung, Anteilsveräußerung oder Liquidation irgendwann in den Genuß sämtlicher Kapitaleinkommen einer Kapitalgesellschaft gelangen. Hinter dieser Sichtweise steckt die Begründung der erörterten Integrationstheorie. Das ökonomische Wohnsitzlandprinzip betrachtet als Wohnsitzland damit das Wohnsitzland des Anteilseigners. Als Quellenland wird hier das Land bezeichnet, in dem der Sitz der ausschüttenden Kapitalgesellschaft liegt bzw. in dem Kapitalgeber Zinsen, Dividenden oder Veräußerungsgewinne erzielen. Soweit nicht anders erwähnt, soll unter Wohnsitzland im weiteren immer das Land verstanden werden, in dem der Anteilseigner (natürliche Person) seinen Wohnsitz hat.

Eine einheitliche Anwendung entweder des Wohnsitzlandprinzips oder des Quellenlandprinzips könnte zuverlässig zu einer Vermeidung der Doppelbesteuerung grenzüberschreitender Kapitaleinkommen führen ${ }^{53}$. Voraussetzung hierfür ist, daß alle Staaten den Begriff der Einkommensquelle bzw. den Begriff des Wohnsitzes übereinstimmend definieren ${ }^{54}$.

Im weiteren sollen allokative, distributive und administrative Aspekte hinsichtlich der beiden Grundformen der Besteuerung internationaler Kapitaleinkommen gegenübergestellt werden. Im Mittelpunkt steht dabei wiederum die Körperschaftsteuer.

\subsubsection{Allokative Beurteilung der internationalen Besteuerung grenzüber- schreitender Kapitaleinkommen}

Wie innerhalb einer Volkswirtschaft so kann aus oben genannten Gründen auch für die internationale Kapitalallokation eine neutrale Besteuerung gefordert werden. Üblicherweise werden hier zwei Neutralitätspostulate unterschieden: die Kapitalimportneutralität und die Kapitalexportneutralität.

53 Vgl. Frenkel, J. A. / Razin, A. / Sadka, E. (1991): International Taxation in an Integrated World, Massachusetts 1991, S. 22f.

54 Vgl. Peffekoven, R. (1983): Probleme der internationalen Finanzordnung, in: Handbuch der Finanzwissenschaft, 3. Aufl., Tübingen 1983, Bd. 4, S. 241 f. 


\subsubsection{Kapitalimportneutralität}

Kapitalimportneutralität ist erfüllt, wenn die Kapitalertragsbesteuerung in einem Land unabhängig davon ist, aus welchem Land die Investitionen erfolgen. Mit einer ausschließlichen Anwendung des Quellenlandprinzips in allen Ländern kommt es zur Kapitalimportneutralität, weil Investitionen in einem Land allein der Besteuerung dieses Landes unterliegen. Existiert auch eine Wohnsitzlandbesteuerung, so kann Kapitalimportneutralität nur bei konsequenter Anwendung des Freistellungsverfahrens in den (Wohn-)Sitzländern der Investoren erreicht werden. Freistellung bedeutet, daß das Wohnsitzland Einkommen, das bereits im Quellenland besteuert wurde, nicht in die Bemessungsgrundlage des ansässigen Steuerpflichtigen einbezieht.

Stellt das (Wohn-)Sitzland nicht frei, so könnte Kapitalimportneutralität nur erreicht werden, wenn das Kapitalimportland die steuerlichen Unterschiede der Kapitalexportländer ausgleicht ${ }^{55}$. Ein solches Vorgehen ist aber aus Gründen der Gleichbehandlung völlig unüblich und wäre auch administrativ kaum zu bewältigen. Kapitalimportneutralität würde - unabhängig von der Art der Herstellung dazu führen, daß Kapitalgeber aus Hochsteuerländern einen starken Anreiz hätten, in Niedrigsteuerländern zu investieren. Kritiker sehen deswegen in der Verwirklichung der Kapitalimportneutralität die Gefahr, daß zuviel Kapital aus steuerlichen Gründen in Niedrigsteuerländer fließt, so daß die Grenzproduktivität des Kapitals in diesen Ländern vor Steuern niedriger ist als bei Kapital, das in höher besteuernden Ländern bleibt ${ }^{56}$. So kann man zwar aus Gründen der Chancengleichheit im Wettbewerb innerhalb eines Landes die Kapitalimportneutralität begrüßen, denn es wird eine effiziente Allokation im Inland erreicht (National Efficiency) $)^{57}$, dies gilt aber nur, sofern man unterschiedliche Kapital(bereitstellungs)kosten in den Kapitalexportländern vernachlässigen könnte.

\subsubsection{Kapitalexportneutralität}

Kapitalexportneutralität besteht, wenn die Kapitalertragsbesteuerung in einem Land davon unabhängig ist, ob die Investoren ihr Kapital im In- oder Ausland an-

Vgl. Peffekoven, R. (1983), a.a.O., S. 244.

56 Vgl. Commission of the European Communities (1992) (Europäische Kommission): Report of the Committee of independent Experts on Company Taxation, Brussel, Luxemburg 1992, S. $35 \mathrm{f}$.

57 Vgl. Sato, M. / Bird, R.M. (1975): International Aspects of the Taxation of Corporations and Shareholders, in: IMF-Staff Papers, Vol. 22/(1975), S. 409. 
legen ${ }^{58}$. Mit einer ausschließlichen Anwendung des Wohnsitzlandprinzips in allen Ländern kommt es zur Kapitalexportneutralität, da die Investitionserträge dann stets allein der Besteuerung des Wohnsitzlandes unterliegen. Existiert auch eine Quellenlandbesteuerung, so kann Kapitalexportneutralität nur bei konsequenter, d.h. unbegrenzter Anrechnung der ausländischen Besteuerung im Inland erreicht werden. Anrechnung bedeutet, daß das Wohnsitzland Steuern nur im Umfang der Differenz erhebt, um die eine inländische Steuerschuld auf dasselbe im Inland erzielte Einkommen die effektiv gezahlte ausländische Steuer übersteigt. Streng gesehen wird Kapitalexportneutralität in der Praxis nie erreicht, weil die im Wohnsitzland besteuerten Investoren von der Doppelbesteuerung durch eine Steuergutschrift für alle im Ausland entrichteten Steuern ohne zeitliche Verzögerung entlastet werden müßten ${ }^{59}$. Der Time-lag zwischen Steuerzahlung und wirksam werdender Anrechnung verhindert tatsächliche Neutralität ebenso wie nicht erstattete Anrechnungsüberhänge, die aufgrund einer höheren ausländischen Besteuerung entstehen.

Kapitalexportneutralität wird gefordert, um die Investitions- bzw. Anlageentscheidung der Investoren von der Steuerpolitik des Investitionslandes unabhängig zu machen. Bei Verwirklichung der Kapitalexportneutralität und vollständiger Kapitalmobilität dürfte Kapital nur in das Land mit den günstigsten nichtsteuerlichen Standortfaktoren fließen, was zu einer weltweiten Angleichung der Kapitalrenditen vor Steuern führen würde (World Efficiency). Kritiker sehen in der Verfolgung der Kapitalexportneutralität die Gefahr, das Investoren ihren Wohnsitzstaat nach steuerlichen Gesichtspunkten auswählen.

\subsubsection{Körperschaftsteuersystem und internationale Neutralitätspostula- te}

Bei einer gleichen effektiven Steuerbelastung in allen Ländern sind beide Neutralitäten gleichzeitig erfüllbar - sofern Doppel- oder Minderbesteuerung vermieden wird. Bei Steuerbelastungsunterschieden kann nur eines der beiden Neutralitätspostulate erfüllt sein. Eine Verwirklichung beider Allokationsziele erfordert letztlich eine internationale Harmonisierung der Steuersätze und Steuersysteme. Schon aufgrund der verschiedenen nationalen Besteuerungspräferenzen gilt eine solche Harmonisierung in näherer Zukunft als utopisch.

Vgl. Peffekoven, R. (1983), a.a.O., S. 244.

59 Vgl. Commission of the European Communities (Europäische Kommission) (1992), a.a.O., S. 37. 
Umstritten ist, welche Neutralität vorrangig zu erfüllen ist. Fehlende Kapitalimportneutralität, z.B im Fall einer Nicht-Freistellung im Kapitalexportland - führt dazu, daß Investoren aus Hochsteuerländern Wettbewerbsnachteile in Ländern mit niedrigeren Besteuerungsniveaus gegenüber Steuerinländern erleiden. Fehlende Kapitalexportneutralität, z.B. im Fall der Freistellung im Kapitalexportland und bei unterschiedlichem Besteuerungsniveau im Kapitalexport- und im Kapitalimportland, führt dazu, daß Kapital weltweit auch nach steuerlichen Gesichtspunkten angelegt wird. Horst weist nach, daß bei mittelmäßig elastischem Kapitalangebot und mittelmäßig elastischer Kapitalnachfrage zumindest aus Sicht der internationalen Kapitalallokation ein Mittelweg zwischen kapitalimportneutraler und kapitalexportneutraler Besteuerung optimal ist ${ }^{60}$.

Hinsichtlich der Körperschaftsteuersysteme können folgende Aussagen zur Neutralität der Besteuerung getroffen werden: Grundsätzlich gewährt ein klassisches Körperschaftsteuersystem Kapitalexportneutralität, da sowohl die inländische als auch die ausländische Körperschaftsteuer im Wohnsitzland des Anteilseigners einkommensteuerlich nicht angerechnet werden. Die Doppelbelastung besteht sowohl in nationaler wie in internationaler Hinsicht. Da unterschiedliche Körperschaftsteuersätze die Anlageentscheidung in diesem System beeinflussen, ist tatsächliche Kapitalexportneutralität allerdings erst bei gleichen Körperschaft- und Einkommensteuersätzen ${ }^{61}$ oder - im Fall mittelbarer Beteiligungen - bei Anrechnung der ausländischen Körperschaftsteuer auf die inländische Körperschaftsteuer erreicht.

Das klassische Körperschaftsteuersystem kann auch Kapitalimportneutralität gewähren, sofern ausländische und inländische Einkommensteuer identisch sind, da ausländisches und inländisches Kapital derselben Körperschaftsteuer unterliegt. Damit wirkt dieses Körperschaftsteuersystem grundsätzlich international neutral. Unterschiedliche Steuersätze und Bemessungsgrundlagen führen allerdings dazu, daß auch in einer Welt der klassischen Systeme die Wahl des Investitionsortes steuerlich beeinflußt wird.

Ein körperschaftsteuerliches Anrechnungssystem, das nur auf inländische Körperschaftsteuer eine Anrechnung gewährt, verletzt die Kapitalexportneutralität zugunsten inländischer Investitionen. Üblicherweise ist die Anrechnung auf im Inland steuerpflichtige Anteilseigner beschränkt. Kapitalimportneutralität ist ebenfalls verletzt, da die Körperschaftsteuer für Ausländer eine Definitivbelastung dar-

60 Vgl. Horst, T. (1980): A Note on the optimal Taxation of international Investment Income, in: Quarterly Journal of Economics, Vol. 94/(1980), Nr. 4, 793-798.

61 Vgl. Musgrave, P. B. (o.J.): Interjurisdictional Coordination of Taxes on Capital Income, in: Cnossen, S.(Hrsg.): Tax Coordination in the European Community, Series on International Taxation, Nr. 7, o. O., S. $218 \mathrm{ff}$. 
stellt, die sich um die zusätzliche Besteuerung im Wohnsitzland erhöht, während Inländer mit der Einkommensteuer eine Besteuerungskorrektur erfahren.

Ein Verstoß gegen die Kapitalexportneutralität könnte vermieden werden, wenn ausländische Körperschaftsteuer im gleichen Umfang angerechnet wird wie inländische Körperschaftsteuer im Wohnsitzland des Anteilseigners. Im Fall eines Vollanrechnungslandes wären für den Investor dann sogar Körperschaftsteuersatzdifferenzen zwischen dem anrechnenden Wohnsitzland und dem Ausland irrelevant ${ }^{62}$, solange keine Anrechnungsüberhänge entstehen. Kapitalimportneutralität läßt sich dagegen nur im Zusammenwirken mit dem Ausland erreichen. Die im Investitionsland als Quellensteuer wirkende Körperschaftsteuer könnte dem Dividendenempfänger im Wohnsitzland erstattet werden und zwar in dem Umfang, in dem das Anrechnungsland den Inländern eine Anrechnung gewährt. Dabei müßte eine ausländische Einkommensbesteuerung sichergestellt sein, die der inländischen Einkommensteuer entspricht, andernfalls käme es zu einer Besserstellung ausländischer Anleger gegenüber inländischen Anlegern.

Vor allem aus fiskalischen Gründen sind üblicherweise Körperschaftsteueranrechnungen auf die inländische Einkommensteuer auf im Inland erhobene Körperschaftsteuern beschränkt. Auch das deutsche Anrechnungssystem sieht weder eine Anrechnung ausländischer Körperschaftsteuer auf die Einkommensteuer inländischer Anteilseigner noch eine Erstattung inländischer Körperschaftsteuer für im Ausland einkommensteuerpflichtige Anteilseigner vor. Das deutsche Körperschaftsteuersystem ist folglich weder kapitalexport- noch kapitalimportneutral.

\subsubsection{Distributive Beurteilung der internationalen Besteuerung grenz- überschreitender Kapitaleinkommen}

Die im Mittelpunkt stehende grenzüberschreitende Besteuerung von Körperschaftsgewinnen wirft Fragen zur Gerechtigkeit zwischen Steuerzahlergruppen (interpersonelle Gerechtigkeit) auf. Fragen ergeben sich auch bezüglich der Aufteilung der Steuereinnahmen aus internationalem Kapitaleinkommen (interstaatliche Gerechtigkeit). Beide Bereiche sind, wie alle Maßstäbe der Verteilungspolitik, sehr wertbehaftet.

Die Forderung einer gerechten Besteuerung auf der Ebene des Steuerzahlers verlangt aus Sicht des Leistungsfähigkeitsprinzips, daß internationale Kapitalein-

62 Vgl. Musgrave, P.B. (o.J.), a.a.O., S. 218. Diese Aussage gilt natülich nicht für die beteiligten Länder, deren Steueraufkommen sich nach der Höhe der Körperschaftsteuer im Quellenland richtet. 
künfte steuerlich ebenso zu erfassen sind wie Einkünfte aus anderen Quellen. Diese Forderung kann allein durch ausschließliche Anwendung des Wohnsitzlandprinzips erfüllt werden, weil nur das Wohnsitzland tatsächlich die Leistungsfähigkeit des Einkommensbeziehers berücksichtigen kann, z.B. durch Beachtung individueller Lebensumstände. Allerdings kollidiert das Wohnsitzlandprinzip und die damit verbundene Berücksichtigung der Leistungsfähigkeit immer mehr mit der Schwierigkeit, das internationale Kapitaleinkommen überhaupt steuerlich zu erfassen. Marktderegulierungen und die Globalisierung der Unternehmenstätigkeiten haben im Verlauf der letzten Jahrzehnte die Mobilität des Faktors Kapital bedeutend erhöht. Der distributive Grundsatz einer gleichen Behandlung verschiedener Einkunftsarten (synthetische Einkommensbesteuerung) scheitert zunehmend an der allokativen Grundregel, daß elastische Größen schlechte Bemessungsgrundlagen für eine Besteuerung abgeben.

Das klassische System führt unter der Annahme gleicher Körperschaftsteuersätze im In- und Ausland zu einer gleichen Besteuerung nationaler und internationaler Kapitaleinkommen, während das national beschränkte inländische Anrechnungssystem inländische Anteilseigner bevorteilt, die im Inland investieren. Diese Aussage gilt natürlich nur für die Beteiligungsfinanzierung. Interpersonell gerecht wäre eine Ausdehnung der Anrechnung auch auf ausländische Körperschaftsteuern, die auf den Bruttodividenden lastet. Nur so wäre eine gleiche Besteuerung gleicher Steuerobjekte - nämlich ausländischer und inländischer Bruttodividenden nach dem Leistungsfähigkeitsprinzip zu gewährleisten und die Grundidee der Integrationstheorie befolgt.

Aus äquivalenztheoretischer Sicht ist allerdings zu fragen, ob und inwieweit eine Auslandsinvestition eine gleiche Besteuerung wie eine Inlandsinvestition erfahren soll. Möglicherweise resultieren die höhere Erträge einer Auslandsinvestition aus einem höheren Ressourcenverbrauch im Quellenland, die dort eine höhere Besteuerung rechtfertigen können. Warum sollte hierfür der Fiskus des Wohnsitzlandes aufkommen?

Hier gerät die interpersonelle Steuergerechtigkeit bereits in einen Konflikt mit der interstaatlichen Steuergerechtigkeit, bei der es um die Frage der Aufteilung von Besteuerungsrechten geht. Umstritten ist die Frage, ob die Bereitstellung des Kapitals aus dem Exportland oder die Ertragsmöglichkeiten die dieses Kapital im Importland nutzt, höher zu bewerten ist. Entsprechend schwer gestaltet sich die Suche nach einer gerechten Aufteilung des Steueraufkommens zwischen Kapitalexport- und Kapitalimportland bzw. zwischen Wohnsitzland und Quellenland. Gerechtigkeit wird hier oft durch Maßnahmen angestrebt, die Nichtdiskriminierung, Gegenseitigkeit und Äquivalenz beinhalten. 
Eine alleinige Anwendung des Wohnsitz- bzw. des Quellenlandprinzips bei der Besteuerung der Bruttodividende würde zu relativ ungerechten Steueraufkommensverteilungen führen, sofern eine Umverteilung über ein Clearingverfahren ausgeschlossen wird. Die ausschließliche Quellenlandbesteuerung von Bruttodividenden benachteiligt Kapitalexportländer, die ausschließliche Wohnsitzlandbesteuerung benachteiligt Kapitalimportländer. Die generelle Beschränkung auf ein Besteuerungsprinzip erscheint nur sinnvoll zwischen Staaten mit ausgeglichenen Kapitalströmen. Es überrascht folglich wenig, daß eine Beschränkung auf ein Besteuerungsprinzip im internationalen Steuerrecht nie durchgesetzt werden konn$t^{63}$.

Allerdings ist die eben getroffene Aussage zu relativieren: Eine dauerhafte Selbstfinanzierung führt zur ausschließlichen Besteuerung durch die Körperschaftsteuer des Quellenlandes, sofern man eher unübliche Wertzuwachssteuern auf nichtrealisierte Wertzuwächse im Wohnsitzland außer acht läßt.

\subsubsection{Administrative Beurteilung der internationalen Besteuerung grenzüberschreitender Kapitaleinkommen}

Sowohl im klassischen System als auch im Anrechnungssystem ohne grenzüberschreitende Anrechnungsgewährung wirkt die Körperschaftsteuer auf ausgeschüttete Gewinne wie eine Quellensteuer im Land der Körperschaft. Abgesehen von den Schwierigkeiten der Ermittlung des körperschaftsteuerpflichtigen Gewinns, der insbesondere bei multinationalen Konzernen nicht leicht abzugrenzen ist, entsteht bei der Steuererhebung ein relativ geringer administrativer Aufwand, weil der Fiskus keine Rücksicht auf die persönlichen Verhältnisse der ausländischen Dividendenbezieher nehmen muß.

\subsection{Die deutsche Besteuerung ausländischer Kapitalgeber}

\subsubsection{Die Beurteilung des Steuerstandortes Deutschland für ausländische Kapitalanleger}

Für die in der Einleitung aufgezeigte Negativentwicklung des Körperschaftsteueraufkommens gibt es die unterschiedlichsten Gründe. Die zunehmende Kapitalmobilität hat ohne Zweifel seit den siebziger Jahren zu einem wachsenden Steuer- 
wettbewerb auf internationaler Ebene um diesen Produktionsfaktor geführt ${ }^{64}$. Dieser Wettbewerb hat sich sichtbar im Bereich der Körperschaftsteuersätze ausgewirkt. Ausgelöst von der Körperschaftsteuerreform der USA von 1986 wurden in den meisten entwickelten Industriestaaten die Körperschaftsteuersätze gesenkt und zugleich die Bemessungsgrundlage der Körperschaftsteuer verbreitert. Die folgende Tabelle gibt die Körperschaftsteuersätze auf einbehaltene Gewinne an. Gegenwärtig liegt Deutschland trotz mehrfacher Senkung des Steuersatzes sogar noch mit Berücksichtigung der jüngsten Absenkung auf $40 \%$ an der Spitze der OECDStaaten $^{65}$.

Tabelle III: Entwicklung der Körperschaftsteuersätze im internationalen Vergleich

\begin{tabular}{|l|l|l|lr|}
\hline & $\begin{array}{l}1977 \\
\text { nominal }\end{array}$ & $\begin{array}{l}1999 \\
\text { nominal }\end{array}$ & $\begin{array}{l}\text { 1998 } \\
\text { effektiv (beispiel- } \\
\text { haft) }\end{array}$ \\
\hline Belgien & 48.0 & 39.0 & 40.17 & $5)$ \\
Dänemark & 37.0 & 32.0 & & $6)$ \\
Deutschland & 56.0 & 40.0 & 42.2 & $7)$ \\
Frankreich 2)3) & 50.0 & 33.33 & $36.67 / 41.67$ & 75.0 \\
Griechenland & 39.0 & $35.0 / 40.0$ & $35 / 40.0$ & $8)$ \\
Großbrit. 1)3) & 52.0 & 30.0 & & \\
Irland 2)3) & 45.0 & 32.0 & & $9)$ \\
Italien 2) & 49.7 & 37.0 & $28.36 \%$ & \\
Luxemburg & 40.0 & 30.0 & & \\
Niederlande & 48.0 & 35.0 & & \\
Norwegen 2) & 50.8 & 28.0 & 34.0 & $6)$ \\
Österreich 2) & 55.0 & 34.0 & & \\
Portugal 2) & 36.0 & 34.0 & & \\
Schweden & 57.8 & 28.0 & 35.0 & $10)$ \\
Spanien & 36.0 & 35.0 & & $11)$ \\
Australien 1) & 50.0 & 36.0 & & \\
Japan & 55.0 & 37.5 & 45.3 & \\
Kanada 1)2) & 46.0 & $38.0 / 28.0$ & & \\
USA 3) & 48.0 & 35.0 & & \\
\hline
\end{tabular}

1. Ermäßigte Körperschaftsteuersätze für kleine Kapitalgesellschaften.

64 Dieser Steuerwettbewerb dürfte dabei zu Lasten des vergleichsweise weniger mobilen Faktors Arbeit gegangen sein. So hat die EU-Kommission ermittelt, daß zwischen 1980 und 1994 die durchschnittliche Steuerbelastung auf unselbständige Arbeit von 34,7\% auf 40,5\% stieg, wăhrend im selben Zeitraum die durchschnittliche Belastung anderer Produktionsfaktoren von 44,1\% auf 35,2\% absank. Vgl. Monti, M. (1997): The Single Market and beyond: Challenges for Tax Policy in the European Union, in: EC-Tax-Review, Vol. 6/(1997), S. 3.

65 Vgl. BR-Drs. 129/99. Zum 01.04.1999 trat rückwirkend fur 1999 ein korperschaftsteuerlicher Thesaurierungssatz von 40 v.H. in Kraft. 
2. Ermäßigte Körperschaftsteuersätze für Kapitalgesellschaften in bestimmten Regionen des Landes.

3. Niedrigere Besteuerung für einen Mindestgewinn, bzw. für Gewinne unterhalb festgelegter Grenzen.

4. Steuersätze mit Berucksichtigung von Steuersatzaufschlägen und erhebungstechnischen Besonderheiten. Der Vermerk "effektiv" steht hier nicht für die Berücksichtigung der Bemessungsgrundlagen, wie sie zu Ermittlung tatsächlicher Effektivsteuersätze nötig ist.

5. Dänemark erhebt die Körperschaftsteuer in einem Vorabverfahren, das den Steuersatz effektiv um rund vier Prozentpunkte erhöht.

6. In Deutschland existiert ein abweichender Körperschaftsteuersatz für ausgeschüttete Gewinne. Dieser betrug bis 1990 36\%, bis 1993 34\%, seit 1994 30\%. Unter Berücksichtigung des Solidaritătszuschlags von 5,5\% beträgt dieser Satz 31,65\%, für einbehaltene Gewinne bei 42,2\%; in Österreich existierte 1977 ein hălftiger Ausschüttungssatz.

7. In Frankreich existieren unterschiedliche Steuersatzaufschläge, die sich nach Umsatzgrößen der Kapitalgesellschaft richten.

8. Griechenland erhebt den niedrigeren Körperschaftsteuersatz von $35 \%$ für Kapitalgesellschaften, die an der inländischen Aktienbörse notiert sind, und für einige Rechtsformen.

9. Anteilig ermäßigter Körpersteuersatz (19\%) für Dividenden aus Eigenkapital, das nach dem 30.9.96 aufgenommen wurde.

10. Unter Berücksichtigung KSt.-ähnlicher Steuern von nachgelagerter Gebietskörperschaften.

11. $28 \%$-Satz gilt für Einkommen innerhalb einer Provinz/eines Territoriums.

Quelle: International Bureau of Fiscal Documentation (1998): European Tax Handbook, Amsterdam 1998; International Bureau of Fiscal Documentation (1999): European Tax Handbook, Amsterdam 1999; Fecht, R. (1977): Einkommensbesteuerung, II: Körperschaftsteuer, in: Handwörterbuch der Wirtschaftswissenschaften, Bd. 2, Stuttgart u.a. 1980, S. $228 \mathrm{f}$.

Betrachtet man allein die Thesaurierungssätze der Körperschaftsteuer, so wirkt die Belastung der Selbstfinanzierung in Deutschland extrem hoch. Im internationalen Vergleich könnte man fast von einer Prohibitivsteuer für Investoren sprechen.

Als einziger der aufgeführten Staaten kennt Deutschland noch einen eigenen Körperschaftsteuersatz von $30 \%$ für ausgeschüttete Gewinne. Damit ergibt sich ein differenzierteres Bild des deutschen Steuerstandortes. Unterstellt man, daß ausländische Investoren sich ihre Gewinne regelmäßig ausschütten lassen, so rangiert der deutsche Körperschaftsteuersatz nur noch im unteren Mittelfeld der OECDStaaten. Auf den ersten Blick scheint die Beteiligungsfinanzierung damit für ausländische Investoren eine günstigere Alternative zur Selbstfinanzierung zu sein.

Ein Vergleich allein der Steuersätze ist allerdings wenig aussagefähig, wie schon die zahlreichen Anmerkungen zu Tabelle III deutlich machen. Erst die Berücksichtigung der steuerlichen Bemessungsgrundlagen und des Körperschaftsteuersy- 
stems sowie der steuerlichen Behandlung alternativer Finanzierungswege ermöglichen eine treffendere Bewertung eines Steuerstandortes.

Die Literatur weist zahlreiche Aufsätze auf, in denen - basierend auf dem Ansatz von King und Fullerton ${ }^{66}$ - der Versuch unternommen wird, die Kapitalkosten für hypothetische nationale und grenzüberschreitende Investitionsprojekte zu ermitteln ${ }^{67}$. Das Konzept ist allerdings problematisch, weil es den einen effektiven Satz für ein Land nicht gibt. Abhängig von den getroffenen Annahmen über das Investitionsobjekt und seine Finanzierung, ändert sich das Ergebnis. Darüber hinaus zeigt die Praxis, daß die Einschätzung der Steuerbelastung von Unternehmern und Anlegern vom Steuersatzniveau dominiert wird. Differenzierte Betrachtungen von Bemessungsgrundlagen und Tarifregelungen sind eher die Ausnahme.

Die Berechnung effektiver Grenzsteuersätze ist auch im Zusammenhang mit der Themenstellung dieser Arbeit besonders interessant, weil mögliche Steuergestaltungen ausländischer Anteilseigner bei der Berechnung berücksichtigt werden können. So hat die OECD in einer umfassenden Studie 1991 effektive Steuersätze ihrer Mitgliedsstaaten errechnet, die sich durch Einsatz der Gesellschafterfremdfinanzierung ergeben. Eine fremdfinanzierte ausländische Direktinvestition von Anteilseignern aus verschiedenen Wohnsitzländern schnitt regelmäßig günstiger $a b$ als eine Beteiligungs- oder Selbstfinanzierung der Investition. In einer ländervergleichenden Querschnittsanalyse ergab sich weiter, daß in Deutschland fremdfinanzierte ausländische Direktinvestition steuerlich für den Investor günstiger behandelt werden als in den meisten anderen OECD-Staaten ${ }^{68}$.

Die OECD-Studie stammt allerdings aus einer Zeit vor Einführung der gesetzlichen Einschränkungen dieser Finanzierungsform und den letzten beiden Verringerungen der Körperschaftsteuersätze in Deutschland. Insofern müßte eine aktualisierte Studie zwar noch die gleiche Rangfolge hinsichtlich der Vorteilhaftigkeit der Finanzierungsformen aufweisen. Allerdings wäre heute eine etwas geringere Spreizung der Effektivsteuersätze zu erwarten.

66 Vgl. King, M. A. / Fullerton, D. (1983): The Taxation of Income from Capital: A Comparative Study of the U.S., U.K., Sweden and West Germany - The Theoretical Framework, NBER Working Paper 1058, Cambridge 1983.

67 Vgl. z.B. Alworth, J. (1988): The finance, taxation and investment decision of multinationals, Oxford 1988.

OECD (1991): Taxing Profits in a Global Economy - Domestic and International Issues, Paris 1991 , S. $128 \mathrm{ff}$. 
Deutlich wird damit, daß ein Körperschaftsteuersystem und seine Wirkung auf steuerpflichtige Investoren nicht zuletzt von der Vermeidbarkeit der Körperschaftsteuer abhängt.

\subsubsection{Die deutsche Körperschaftsteuer aus Sicht der ausländischen An- teilseigner}

Schon vor Einführung einer einheitlichen deutschen Körperschaftsteuer im Jahr $1920^{69}$ wurde das Einkommen juristischer Personen in Deutschland selbständig besteuert. Die Besteuerung war in den Einkommensteuergesetzen der einzelnen deutschen Staaten geregelt. Die Besteuerung der juristischen Personen erfolgte unabhängig von der Besteuerung der natürlichen Personen, die entstehende Doppelbelastung wurde nicht eingeschränkt. Allerdings kam der Doppelbelastung auf ausgeschüttete Gewinne auch keine hohe Bedeutung zu, da die Steuertarife aus heutiger Sicht unfaßbar niedrig waren. So lag z.B. der Spitzensteuersatz des PreuBischen Einkommensteuerrechts von 1891 bei $4 \%$ ab einem Einkommen von 100.000 Reichsmark. An der klassischen Besteuerung wurde auch festgehalten, als 1920 im Rahmen der Erzbergerschen Steuerreform eine reichseinheitliche Einkommensteuer und, davon losgelöst, eine reichseinheitliche Körperschaftsteuer eingeführt wurde.

In der Begründung dieser Steuereinführung wurde festgestellt, daß juristische Personen - damals noch als nichtphysische Personen bezeichnet - ein eigenes Einkommen erzielen und daher als eigenständige Steuersubjekte zu behandeln sei$\mathrm{en}^{70}$. Die proportionale Körperschaftsteuer betrug bei Einführung $10 \%$ für einbehaltene Gewinne und erhöhte sich um einen zwei bis zehnprozentigen Zuschlag im Ausschüttungsfall. Eine Berücksichtigung der Körperschaftsteuer bei der Einkommensteuererhebung auf Anteilseignerebene fand in den ersten beiden Jahren nicht statt. Die Doppelbelastung bestand im vollen Umfang. Die klassische Besteuerung erforderte keine unterschiedliche Behandlung von Steuerinländern und Steuerausländern. Dies galt für den Zeitraum von 1920 bis 1922.

Interessant ist, daß ab 1922 in Deutschland für sehr kurze Zeit die Doppelbelastung ausgeschütteter Gewinne durch Einführung einer teilweisen Anrechnung der Körperschaftsteuer beim Anteilseigner verringert wurde ${ }^{71}$. Diese Teilanrech-

69 Körperschaftsteuergesetz v. 30.03.1920, vgl. RGBl. S. 393.

70 Vgl. Evers (1923): Kommentar zum Körperschaftsteuergesetz 1920/22, Berlin 1923, S. 49f.

$71 \S 12 \mathrm{KStG}$ i.d.F. vom 8.4.1922 ließ eine anteilige Milderung der Körperschaftsteuer beim Einkommensempfänger eintreten, und zwar degressiv mit steigendem Gesamteinkommen. 
nungsmöglichkeit für Inländer konnte allerdings kaum besondere Bedeutung erlangen, weil die kurze Anwendungsdauer in den Zeitraum der Hochinflation fiel ${ }^{72}$. Zudem wirkte der erwähnte Dividendenaufschlag entgegengerichtet.

So verschwand im Jahr 1925 die Teilanrechnung ebenso wie die höhere Belastung der ausgeschütteten Gewinne ${ }^{73}$. Der Körperschaftsteuersatz stieg in den folgenden Jahren nach und nach an, die Doppelbelastung blieb im vollen Umfang bestehen. Der alliierte Kontrollrat führte 1946 einen nach der Höhe gestaffelten Körperschaftsteuersatz zwischen $35 \%$ und $65 \%$ ein. Da zu dieser Zeit der Spitzensteuersatz der Einkommensteuer bei 95\% lag, ergab sich zumindest rechnerisch eine historische maximale Doppelbelastung ausgeschütteter Gewinne von $98,25 \%$.

Mit der Währungsreform von 1948 trat wieder ein einheitlicher Körperschaftsteuersatz in Kraft, nun in Höhe von 50\%, ab 1951 in Höhe von 60\%. Mit Einführung eines Körperschaftsteuersystems mit gespaltenen Satz im Jahr 1953 wurde zum ersten Mal seit 1924 wieder eine Milderung der Doppelbelastung vorgenommen. Der Steuersatz für ausgeschüttete Gewinne fiel mit dieser Reform auf $30 \%$, der Satz für einbehaltene Gewinne blieb zunächst bei $60 \%$, wurde aber im darauffolgenden Jahr auf $45 \%$ verringert. Da die Milderung der klassischen Doppelbelastung ausgeschütteter Gewinne auf der Ebene der Gesellschaft erfolgte, gelangten Inländer wie Ausländer in den Genuß der verringerten Doppelbelastung.

Diese Milderung vergrößerte der Gesetzgeber 1958 mit einer Absenkung des Ausschüttungssatzes auf $15 \%$ bei einem Thesaurierungssatz von $51 \%$. Die echte Ausschüttungsbelastung der Kapitalgesellschaft lag aber bei über 15\%; weil die Ausschüttungskörperschaftsteuer als nichtabzugsfähige Betriebsausgabe galt, wurde sie einbezogen in die Bemessungsgrundlage des nichtausgeschütteten Körperschaftseinkommens. Somit ergab sich eine faktische Körperschaftsteuerbelastung für ausgeschüttete Gewinne in Höhe von $23,4 \%{ }^{74}$, bzw. $24,55 \%$ inklusive Ergänzungsabgabe ${ }^{75}$.

72 Vgl. Koblenzer, T. (1997): Die Besteuerung Nichtansässiger - ein historischer Rückblick, in: Internationales Steuerrecht (IStR), 6. Jg./(1997), Nr. 4, S. 100.

73 Vgl. Bay, W. (1990): Dividenden, Steuern und Steuerreformen. Ein internationaler Vergleich, Wiesbaden 1990, S.45.

74 Zur sog. "Schattenwirkung" der Ausschüttungssteuer: Bundesministerium der Finanzen (1971): Gutachten der Steuerreformkommission, in: Schriftenreihe des Bundesministeriums der Finanzen, Nr. 17, Bonn 1971. 
Die Doppelbelastung ausgeschütteter Gewinne existierte also trotz diverser Abschwächungen bis 1976. Für ausländische Anteilseigner bedeutete die Einführung eines gespaltenen Satzes eine Milderung der internationalen Doppelbelastung, so wie sie für deutsche Anteilseigner eine Milderung der nationalen Doppelbelastung bewirkte.

Für Inländer und Ausländer konträr wirkte dagegen die Abschaffung der Doppelbelastung durch die Körperschaftsteuerreform von 1977. Die Einführung eines Anrechnungssystems beseitigte die Doppelbelastung für anrechnungsberechtigte Inländer. Sie erhöhte dagegen die Doppelbelastung für die von der Anrechnung ausgeschlossenen Steuerausländer, weil mit der Steuerreform auch eine Erhöhung des Ausschüttungssatzes von $15 \%$ auf $36 \%$ erfolgte. Ursprünglich sahen zwei Referentenentwürfe zur Körperschaftsteuerreform eine begrenzte Erstattung von Körperschaftsteuer für ausländische natürliche Personen und für ausländische Kapitalgesellschaften ohne wesentliche Beteiligungen vor. Damit sollte allerdings ein anfangs vorgesehener, genereller Körperschaftsteuersatz von $56 \%$ abgemildert werden, der sonst für Ausländer definitiv geworden wäre ${ }^{76}$.

Der Gesetzgeber begründete die Steuerreform mit den schon aufgezeigten allokativen Vorteilen des Anrechnungssystems. Explizit werden in der Gesetzesbegründung folgende Argumente für das Vollanrechnungssystem aufgeführt ${ }^{77}$ :

1. Verbesserung der Eigenfinanzierung der Unternehmen

2. Verringerung des Interessengegensatzes zwischen Groß- und Kleinaktionär

3. Stärkere Unabhängigkeit der Besteuerung von der Wahl der Rechtsform

4. Verbesserung der Vermögensbildung

Auch wenn weitere Motive der Steuerreform nicht in der Gesetzesbegründung genannt werden, ist $\mathrm{zu}$ vermuten, daß es noch andere, auf die steuerliche Behandlung von ausländischen Anteilseignern zielende Gründe gab; an anderer Stelle wurde dies seinerzeit auch offen zugegeben ${ }^{78}$. Hierauf wird im folgenden genauer eingegangen $^{79}$.

76 Vgl. Vogel, K. (1973): Der ausländische Aktionär, München 1973, S. 15ff., ebd. im Anhang: Referentenenwurf I und II eines Körperschaftsteuergesetzes 1974

77 Vgl. BT-Drs. 7/1470, S. $326 \mathrm{ff}$.

78 Vgl. Manke, K. (1977): Auswirkungen der Körperschaftsteuerreform auf das Außensteuerrecht, in: Steuerberater-Jahrbuch (StbJb) 1977/78, Bd. 29, S. 278.

Vgl. Unterabschnitt 3.2.2.3. 
Der Gesetzgeber betonte 1976 ausdrücklich, daß die Doppelbelastung nicht deswegen abgeschafft werde, weil eine mehrmalige Belastung ausgeschütteter $\mathrm{Ge}$ winne nicht zu rechtfertigen se $^{80}$. Damit stellte er indirekt klar: Weder ein Anrechnungsausschluß von Steuerausländern noch ein Anrechnungsausschluß ausländischer Körperschaftsteuern stand nach seiner Ansicht im Widerspruch zur Reformbegründung. Von 1977 bis 1990 existierten im Rahmen des Vollanrechnungssystems Körperschaftsteuersätze von $36 \%$ auf ausgeschüttete und von $56 \%$ auf einbehaltene Gewinne. 1990 wurden diese Steuersätze in einem ersten Schritt auf 34\% bzw. auf 50\%, 1993 im Rahmen des Standortsicherungsgesetzes weiter auf $30 \%$ bzw. $45 \%$ gesenkt. Inzwischen erfolgte eine Absenkung des Thesaurierungssatzes auf $40 \%^{81}$.

\subsubsection{Technische Vorgehensweise des deutschen körperschaftsteuerli- chen Vollanrechnungsverfahrens}

Die Besteuerung der Körperschaft und der Anteilseigner ist spiegelbildlich miteinander verbunden. Grundsätzlich gilt das Anrechnungsverfahren für alle ausgeschütteten Gewinne, unabhängig davon, ob die Gesellschaft aus laufenden Gewinnen oder aus zunächst in Rücklagen eingestellten Gewinnen ausschüttet. Im Fall der Ausschüttung hat das Unternehmen grundsätzlich die Ausschüttungsbelastung in Höhe von $30 \%$ herzustellen. Die Herstellung der Ausschüttungsbelastung von $30 \%$ wird in der Literatur häufig als erster Schritt der Beiseitigung der Doppelbelastung gewertet, in dessen Genuß auch ausländische Dividendenempfänger kommen ${ }^{82}$. Dieser "Genuß" entspricht allerdings angesichts der inzwischen international üblichen Körperschaftsteuersätzen und zahlreicher regionaler Sonderkörperschaftsteuersätzen eher einer Anpassung an ein internationales Durchschnittsniveau.

Das deutsche Körperschaftsteuerrecht gliedert das für die Ausschüttung verwendbare Eigenkapital nach der Höhe seiner Körperschaftsteuerbelastung und stellt bei der Herstellung der Ausschüttungsbelastung Fiktionen auf, in welcher Reihenfolge die unterschiedlich belasteten Eigenkapitalanteile als für die Ausschüttung verwendet gelten. Dabei wird fingiert, daß zunächst das vollbelastete Eigenkapital (EK 45, bzw. künftig EK 40), danach ermäßigt belastetes Eigenkapital (EK 30) und zuletzt nicht belastetes Eigenkapital (EK 0) verwendet wird. Die Ausschüttungsbelastung wird nicht hergestellt für EK 01 (aus steuerfreien ausländischen

80 Vgl. BT-Drs. 7/1470, S. 326.

81 Vgl. BR-Drs. 129/99; speziell zu den Steuersätzen: S. 102.

Vgl. Manke, K. (1977), a.a.O., Bd. 29, S. 274. 
Einkünften und nach $\S 8 \mathrm{~b} \mathrm{KStG}$ außer Ansatz bleibende Beträge) und für EK 04 (aus Gesellschaftereinlagen). Das heißt, daß aus dem Ausland ins Inland geschüttete Gewinne nur mit ausländischer Körperschaftsteuer belastet bleiben. Für die Gewinne, die in Deutschland von einer Kapitalgesellschaft erzielt und an Steuerinländer ausgeschüttet werden, beseitigt das deutsche Körperschaftsteuersystem die Doppelbelastung in einem geschlossenen System, da es für die Herstellung der Ausschüttungsbelastung nicht darauf ankommt, ob die Gesellschaft laufenden oder zunächst in Rücklagen eingestellten Gewinn ausschüttet oder ob der Anteilseigner den Gewinn erst bei Liquidation erhält ${ }^{83}$.

Die Ausschüttungsbelastung wird den anrechnungsberechtigten Anteilseignern als Steuergutschrift gewährt. Die Anteilseigner haben die Ausschüttung zuzüglich der Steuergutschrift zu versteuern. Die Steuergutschrift wird auf die Einkommenbzw. Körperschaftsteuer der Anteilseigner angerechnet und gegebenenfalls erstattet. Ökonomisch liegt damit allein die Einkommensteuer bzw. die Körperschaftsteuer des Anteilseigners auf den Ausschüttungen einer Kapitalgesellschaft. Ausschüttungen aus dem EK 01 erfahren dagegen keine Anrechnung. Auf ihnen lastet auch keine deutsche, sondern gegebenenfalls ausländische Körperschaftsteuer. Der deutsche Anteilseigner wird also nur mit in Deutschland erwirtschafteten Dividenden von der Doppelbelastung befreit. Auf ausländische Dividenden bzw. Dividendenanteile kann eine natürliche Person im Inland keine Anrechnung geltend machen. Der Steuerinländer wird hier "klassisch" besteuert, das heißt, sein Dividendeneinkommen unterliegt einer Mehrfachbesteuerung.

Die Doppelbelastung wird im deutschen Steuersystem also in einem zweistufigen Verfahren beseitigt, bei dem Steuerausländer und inländische Nichtanrechnungsberechtigte nur von der ersten Stufe (Herabschleusung auf die Ausschüttungsbelastung), nicht aber von der zweiten Stufe (Anrechnung auf die Einkommensteuer) berührt werden.

\subsubsection{Der Anrechnungsauschluß}

Länder, die ein Körperschaftsteuersystem mit Anrechnung der ausgeschütteten Gewinne praktizieren, gewähren diese Integration oft nur den Steuerinländern. Damit soll gewährleistet bleiben, daß ausgeschüttete Unternehmensgewinne zumindest einmal einer Besteuerung im Land der ausschüttenden Kapitalgesellschaft unterliegen. Diese Einmalbesteuerung erfolgt bei anrechnungsberechtigten Steuerinländern endgültig durch die persönliche Einkommensteuer. Im Fall des Steuerausländers erfolgt sie mit der definitiv erhobenen Körperschaftsteuer und der Ka- 
pitalertragsteuer. Der Grund dafür liegt auf der Hand: Beseitigt ein Quellenland, also das Land, in dem die ausschüttende Kapitalgesellschaft ihren Sitz hat, die internationalen Doppelbelastung, so müßte es den ausländischen Anteilseignern vollständig die Körperschaftsteuer erstatten und - sollte keine Berücksichtigung im Wohnsitzland erfolgen - auf Kapitalertragsteuer verzichten. Folglich blieben im Inland erwirtschaftete Gewinne frei von inländischer Besteuerung. Die Anrechnungsberechtigung ist deswegen in Deutschland an die unbeschränkte inländische Steuerpflicht geknüpft ${ }^{84}$.

Ob jemand im Inland unbeschränkt steuerpflichtig ist, richtet sich bei natürlichen Personen, wie erwähnt, nach dem Wohnsitz oder dem gewöhnlichen Aufenthalt ${ }^{85}$. Ist zumindest einer dieser Anknüpfungspunkte im Inland gegeben, so gilt die natürliche Person als in Deutschland ansässig ${ }^{86}$. Die Steuerpflicht erstreckt sich für ansässige Personen auf sämtliche Einkünfte und Vermögenswerte des Steuerpflichtigen. Es erfolgt eine Besteuerung des Welteinkommens ${ }^{87}$. Die Steuerpflicht ist sozusagen unbeschränkt ${ }^{88}$. Die unbeschränkte Steuerpflicht ist damit der juri-

84 Der Anrechnungsausschluß ist in $\S 51 \mathrm{KStG}$ kodifiziert.

85 Anzumerken ist, daß das Kriterium des Wohnsitzes bei der Steuerpflicht natürlicher Personen innerhalb der EU nicht mehr uneingeschränkt gilt. Der EuGH hat in seinem Urteil zur Grenzpendlerbesteuerung betont, daß das Recht der Freizigigkeit der Arbeitnehmer (vgl. Art. 48 EGV) nicht durch steuerlich ungleiche Behandlung eingeschränkt werden darf, die allein mit einem ausländischen Wohnsitz begründet wird. Eine steuerliche Gleichbehandlung mit Steuerinländern ist für Personen zu fordern, die ihren Wohnsitz oder gewöhnlichen Aufenthalt in einem EU-Staat haben, ihr Einkommen ganz oder fast ganz in einem anderen EU-Staat erzielen. Vgl. EuGH-Urteil vom 14.02.1995, Rs. C-279/93, abgedruckt in: Der Betrieb (DB), 48. Jg.(1995), Nr. 8, S. 407. Der deutsche Gesetzgeber hat hierauf reagiert und im Jahressteuergesetz 1996 das deutsche Einkommensteuerrecht so angepaßt, daß der betroffene Personenkreis weitgehend eine materielle Gleichstellung mit Steuerinländern erfährt. Vgl. BStBI. I 1995, S. 438.

86 Weder aus $\S 8 \mathrm{AO}$ noch aus $\S 9 \mathrm{AO}$ läßt sich folgern, welcher der Anknüpfungspunkte vorrangig ist. In der Praxis wird aber primär auf den Wohnsitz abgestellt, vgl. Schaumburg, $\mathrm{H}$. (1993): Internationales Steuerrecht, Köln 1993, S. 51.

87 Menck, T. (1985): Welteinkommen und Territorialität der Besteuerung nach deutschem Recht und in deutscher Sicht, in: Engelschalk, M. u.a. (Hrsg.): Steuern auf ausländische Einkünfte, München 1985, S. 33 ff.

88 Im Rahmen der am Wohnsitz bzw. gewöhnlichen Aufenthaltsort anknüpfenden unbeschränkten Steuerpflicht wird zwar prinzipiell eine Besteuerung des Welteinkommens angestrebt, allerdings existieren diverse Durchbrechungen dieses Grundsatzes: Zu diesen zählen Personen, die Fiskalimmunität genießen (Diplomaten und deren Familienangehörige), Beschränkungen des Verlustausgleichs, Steuerfreistellungen aufgrund von DBA oder innerstaatlichem Recht, vgl. Schaumburg, H. (1993): a.a.O., S. $63 \mathrm{ff}$. 
stische Ausdruck des bereits vorgestellten Wohnsitzlandprinzips. Wenn keiner der oben genannten Anknüpfungspunkte erfüllt ist, so gilt der Steuerpflichtige als gebietsfremd. Es handelt sich dann um einen Steuerausländer. Der deutsche Fiskus hat nur einen beschränkten Steueranspruch auf die in Deutschland bestehenden Steuersachverhalte, die sich aus inländischen Einkünften und im Inland vorhandenem Vermögen ergeben. Es besteht die sogenannte beschränkte Steuerpflicht; sie ist die gesetzliche Verwirklichung des Quellenlandprinzips ${ }^{89}$. Die Körperschaftsteuer erfüllt in beiden Fällen die Funktion einer Quellensteuer, im Fall der beschränkt steuerpflichtigen Ausländer erfüllt sie zusätzlich die Funktion einer Quellenlandsteuer. Wie bei der Einkommensteuer, so unterscheidet man in Deutschland auch bei der Körperschaftsteuer zwischen unbeschränkter und beschränkter Steuerpflicht. Anknüpfungspunkt ist auch hier die Ansässigkeit im Inland.

Neben der Gruppe der beschränkt steuerpflichtigen Ausländer existieren auch noch beschränkt steuerpflichtige Inländer, die von der Körperschaftsteueranrechnung ausgeschlossen sind: Hierunter fallen juristische Personen des öffentlichen Rechts wie Bund, Länder, Kommunen, Religionsgemeinschaften, Kammern und Innungen. Auch steuerbefreite Körperschaften, wie gemeinnützige Vereinigungen, bestimmte öffentlich-rechtliche Banken und öffentlich-rechtliche Versorgungseinrichtungen, Berufsverbänden und Gewerkschaften, sind von der Körperschaftsteueranrechnung ausgenommen ${ }^{90}$.

Zusammenfassend kann festgehalten werden, daß sich die Nichtanrechnungsberechtigten in drei Gruppen unterteilen lassen:

1. Beschränkt steuerpflichtige Steuerausländer

2. Beschränkt steuerpflichtige Steuerinländer

3. Steuerbefreite Körperschaften

Der Anrechnungsausschluß ist keine Randerscheinung im deutschen Anrechnungssystem. Zwar existieren keine genauen Zahlen, wie viele Anteilseigner keine Körperschaftsteueranrechnung geltend machen können. Amtliche Schätzungen belaufen sich aber darauf, daß ca. 23\% aller Anteilseigner Steuerausländer sind, während ca. $26 \%$ aller Anteilseigner nichtanrechnungsberechtigte Steuerinländer

89 Vgl. hierzu ausführlich Koblenzer, T. (1997), a.a.O., S. $97 \mathrm{ff}$.

90 Vgl. § 5 Abs. $1 \mathrm{KStG}$. Die Aufzählung in diesem Gesetz hat keinen abschließenden Charakter. 
sind. Damit gilt für knapp die Hälfte aller Anteilseigner der Anrechnungsausschluß $\beta^{91}$.

Die internationale Doppelbelastung stellt auch keinen Verstoß gegen geltende Doppelbesteuerungsabkommen dar. Grundsätzlich steht es nämlich jedem Staat frei, ob und inwieweit er im Rahmen seiner Einkommensbesteuerung bereits erhobene Körperschaftsteuer berücksichtigt.

DBA-Regelungen beziehen sich grundsätzlich nur auf Fälle, in denen mehrere Staaten auf das gleiche Einkommen eine gleichartige Steuer erheben. Schon aufgrund fehlender Subjektidentität zwischen dem körperschaftsteuerpflichtigen Unternehmen und dem einkommensteuerpflichtigen Anteilseigner erfahren ausländische Anteilseigner keine Berücksichtigung der in Deutschland definitiv gewordenen Körperschaftsteuer. Regelungen des OECD-MA und der bilateralen deutschen DBA zur Vermeidung einer doppelten Besteuerung von Dividenden beziehen sich ausschließlich auf die Dividende abzüglich der erhobenen Körperschaftsteuer, also auf die sogenannte Bardividende.

Der Anrechnungsauschluß führt dazu, daß das deutsche Körperschaftsteuersystem bei grenzüberschreitenden Sachverhalten wie ein klassisches System wirkt.

\subsubsection{Die Veränderung der steuerlichen Situation ausländischer An- teilseigner durch die Körperschaftsteuerreform von 1977}

Mit der Körperschaftsteuerreform stieg von einem Veranlagungszeitraum zum nächsten der körperschaftsteuerliche Ausschüttungssatz um einundwanzig Prozentpunkte von $15 \%$ auf $36 \%$. Für unbeschränkt steuerpflichtige Inländer ergab sich trotz der Steuersatzerhöhung eine Verbesserung, weil die frühere Ausschüttungssteuer von $15 \%$ eine Definitivbelastung darstellte, während der Ausschüttungssatz seit 1977 Vorauszahlungscharakter hat. Die Situation der Steuerausländer verschlechterte sich dagegen, weil für sie der neue Ausschüttungssatz - ebenso wie der alte Steuersatz - Definitivcharakter besa $\beta^{92}$.

91 Vgl. Dötsch, E. / Cattelaens, H. / Gottstein, S. / Stegmüller, H. / Zenthöfer, W. (1995): Körperschaftsteuer, 11. Aufl., Stuttgart 1995, S. 321.

92 Die Höhe des Ausschüttungssatzes von gerade $36 \%$ erklärt sich mit einer Spezialregelung vieler DBA, nach der Gewinnausschüttungen inländischer Tochtergesellschaften an auslăndische Muttergesellschaften nur dann mit einer Kapitalertragsteuer von mehr als $15 \%$ belegt werden durften, wenn die Differenz zwischen Thesaurierungs- und Ausschüttungssatz mindestens 20 Prozentpunkte betrug. Vgl. Dötsch, E. / Cattelaens, H. / Gottstein, S. / Stegmüller, H. / Zenthöfer, W. (1995), a.a.O., S. 318. 
Obwohl dieses Resultat nicht als ausdrückliches Ziel in der Gesetzesbegründung genannt wird, ist zu vermuten, daß eine gewisse Schlechterstellung der Ausländer - zumindest ausländischer Muttergesellschaften - durchaus beabsichtigt $\operatorname{war}^{93}$. Zuviele Klagen wurden in den Jahren vor der Steuerreform über den sogenannten positiven Ausländereffekt im alten Recht geführt.

Bis 1976 unterlag eine inländische Körperschaft einem Körperschaftsteuersatz von $51 \%$, wobei sich durch berücksichtigungsfähige Ausschüttungen dieser Satz je nach Ausschüttungsumfang ermäßigte. Ein vielfach kritisierter positiver Ausländereffekt ergab sich, wenn eine inländische Tochtergesellschaft an eine ausländische Muttergesellschaft ausschütten konnte. Diese Ausschüttung unterlag der Ausschüttungssteuer von $15 \%$. Aufgrund der Schattenwirkung ergab sich eine Belastung von 23,4\%. Zuzüglich deutscher Kapitalertragsteuer von $25 \%$ im NichtDBA-Fall, bedeutete dies eine Gesamtsteuerbelastung der Ausschüttungen an Ausländer von $42,55 \%$ (bzw. weniger bei ermäßigter Kapitalertragsteuer durch entsprechende DBA-Regelungen). Bei Anwendung des internationalen Schachtelprivilegs, wie es für wesentliche Beteiligungen schon damals teilweise praktiziert wurde, blieb es im Fall der Reinvestition der ausländischen Muttergesellschaft bei dieser Steuerbelastung. Die Ausschüttung an eine inländische Muttergesellschaft wurde vergleichweise höher besteuert. Grund dafür war eine Nachversteuerung in Höhe von 36\%, die bei der Empfängerin der Ausschüttung erfolgte, so daß die Gewinne insgesamt wieder der Thesaurierungsbelastung von $51 \%$ unterlagen $(15 \%+36 \%)$. Der sogenannte positive Ausländereffekt betrug also immerhin 8,45 Prozentpunkte ${ }^{94}$.

Ist schon die Existenz eines positiven Ausländereffekts von der Gewährung des internationalen Schachtelprivilegs abhängig, so läßt sich die Schlechterstellung des ausländischen Streubesitzes kaum mit einleuchtenden Argumenten begründen, da hier kein positiver Ausländereffekt bemängelt werden konnte. Einleuchtende wettbewerbliche Begründungen für deren Schlechterstellung sind nur schwer zu finden ${ }^{95}$.

93 Vgl. Raupach, A. (1997): Das körperschaftsteuerliche Anrechnungsverfahren - Bestandsaufnahme und Kritik, in: Widmann, S. (Hrsg.): Besteuerung der GmbH und ihrer Gesellschafter, Deutsche Steuerjuristische Gesellschaft, Bd. 20, Köln 1997, S. $25 \mathrm{ff}$.

94 Vogel wendet kritisch ein, daß das Schachtelprivileg (damals) nur in verhältnismäßig wenigen Staaten Anwendung fand und daß bei Anrechnung durchaus ein "benachteilgender" Ausländereffekt eintreten konnte. Vgl. Vogel, K. (1973), a.a.O., S. 8f.; vgl. Streck, M. (1991), a.a.O., S. 575ff., der ausgehend von einer körperschaftsteuerlichen Schattenwirkung von 24,55\% einen positiven Ausländereffekt von 9,12 Prozentpunkten errechnet.

95 Sieht man von überholten, merkantilistischen Ängsten vor einer Überfremdung der einheimischen Volkswirtschaft ab. 
Neben diesen Wettbewerbsaspekten ist die Erhöhung der Besteuerung von Ausländern auch unter Aspekten des internationalen Kapitalverkehrs eher kritisch zu sehen. Die Erhöhung der deutschen Besteuerung ausländischer Eigenkapitalgeber dürfte in ihrer Auswirkung eindeutig sein: Die Investitionsbereitschaft ausländischer Kapitalgeber mußte zwangsläufig sinken ${ }^{96}$. Die Tatsache, daß das ausländische Wirtschaftsengagement in Deutschland in den Jahren seit Einführung des Anrechnungssystems stagniert, obwohl weltweit eine Tendenz zu Marktöffnungen und Auslandsinvestitionen zu beobachten ist, spricht für die investitionshemmende Wirkung des deutschen Körperschaftsteuersystems.

Eine abrupte Steuererhöhung von 21 Prozentpunkten - bzw. von immer noch 12,6 Prozentpunkten bei Berücksichtigung der Schattenwirkung - löste sozusagen zwangsläufig eine Suche nach alternativen Formen der Kapitalbereitstellung durch Steuerausländer bzw. des Kapitaleinkommensbezugs dieser Gruppe aus. In den Steuergestaltungsmodellen geht es bis heute regelmäßig darum, Dividendenausschüttungen an Ausländer nicht als in Deutschland steuerpflichtiges Einkommen anfallen zu lassen.

Entsprechend wurde die Umwandlung in Veräußerungsgewinne (Dividendenstripping) bzw. in Zinsen (Gesellschafterfremdfinanzierung) zum zentralen Folgeproblem der Körperschaftsteuerreform von $1977^{97}$.

Bevor eine Analyse dieser Gestaltungsformen vorgenommen werden kann, ist es notwendig, die Besteuerung der verschiedenen Alternativen einer Kapitalbereitstellung durch Steuerausländer vollständig zu erörtern.

\subsection{Die deutsche Besteuerung ins Ausland fließender Kapitalerträge}

\subsubsection{Die steuerliche Behandlung von Eigenkapitalvergütungen}

Die deutsche Besteuerung ausgeschütteter Gewinne setzt sich zusammen aus der vorgestellten deutschen Körperschaftsteuer und der deutschen Kapitalertragsteuer bzw. Dividendenabzugssteuer. Die Besteuerung sei im folgenden kurz skizziert:

Auf eine Bruttodividende entfällt zuerst die Körperschaftsteuer auf ausgeschüttete Gewinne in Höhe von 30\%. Die verbleibenden 70\% (Bardividende) sind die Bemessungsgrundlage der Kapitalertragsteuer. Diese beträgt $25 \%$ im Nicht-DBA-

96 Vgl. Böckli, P. (1979), a.a.O., S. 4.

97 Vgl. Bippus, B.E. (1994): Dividenden-Stripping, in: Recht der Internationen Wirtschaft (RIW), 40. Jg./(1994), Nr. 11, S. 946. 
Fall. Nach Abzug beider Steuern verbleiben netto somit 52,5\% der Bruttodividen$\mathrm{de}^{98}$. Während unbeschränkt steuerpflichtige Personen beide Steuern auf ihre persönliche Einkommensteuer bzw. Körperschaftsteuer anrechnen können, ist diese Möglichkeit beschränkt Steuerpflichtigen grundsätzlich nicht gegeben. Zwar können ausländische juristische Personen die deutsche Körperschaftsteuer auf ihre Körperschaftsteuer im Sitzland anrechnen lassen oder erfahren dort gegebenenfalls eine Freistellung, jedoch liegt bei Weiterausschüttung an natürliche Personen wieder die internationale Doppelbelastung auf den Dividenden. Allerdings können natürliche Personen die Kapitalertragsteuer in ihrem Wohnsitzland auf ihre Einkommensteuer anrechnen lassen. Die Kapitalertragsteuer verringert sich zudem bei Vorliegen eines DBA in unterschiedlichem Ausmaß.

Das OECD-MA, dem die deutschen Abkommenspolitik im wesentlichen folgt, teilt die Besteuerung der Dividenden ${ }^{99}$ zwischen dem Quellen- und dem Wohnsitzland des Anteilseigners auf. Dabei bezieht sich der Begriff "Dividende" nicht auf die Bruttodividende, die die Körperschaftsteuer auf ausgeschüttete Gewinne umschließt, sondern auf die sogenannte Bardividende, d.h. die Ausschüttung abzüglich der Körperschaftsteuer auf ausgeschüttete Gewinne.

Das OECD-MA beinhaltet damit einen Kompromiß zwischen Quellen- und Wohnsitzland hinsichtlich der Dividendenbesteuerung. Es weist dem Wohnsitzstaat ein Besteuerungrecht zu:

"Dividenden, die eine in einem Vertragsstaat ansässige Gesellschaft an eine im anderen Vertragsstaat ansässige Person zahlt, können im anderen Staat besteuert werden."

Zugleich räumt das OECD-MA dem Quellenland ein begrenztes Steuerrecht ein. Danach darf das Land, in dem die Dividenden entstehen, 5\% des "Bruttobetrages der Dividende" dann als Quellensteuer einbehalten, wenn der Anteilseigner eine Kapitalgesellschaft ist und unmittelbar über eine wesentliche Beteiligung verfügt. Als wesentliche Beteiligung qualifiziert Art. 10 Abs. 2 OECD-MA eine Beteili-

98 Unter Vernachlässigung des Solidaritătszuschlags von 5,5\% auf Körperschaft- und Kapitalertragsteuer.

99 Der Dividendenbegriff variiert international. So beinhaltet das OECD-MA keine Definition, was unter der Sammelbezeichnung zu verstehen ist. Beispielhaft werden Einkunfte aus Aktien, Genußscheine, Kuxen oder Gründeranteilen zu den Einkünften aus Dividenden gezählt. In den abgeschlossenen deutschen DBA finden sich häufig weitergehende Aufzăhlungen von Einkunftsarten, die unter den Dividendenbegriff fallen. So sind in diesen Abkommen auch meistens die Einnahmen stiller Gesellschafter, Einnahmen aus Gewinnobligationen, Einnahmen aus partiarischen Darlehen sowie Ausschuttungen auf Investmentanteile unter dem Dividendenbegriff erfaßt. Vgl. Baranowksi, K. H. (1996), a.a.O., S. 166. 
gung zu mindestens $25 \%$. Ist die Beteiligung geringer, handelt es sich also um Streubesitz von Kapitalgesellschaften oder natürlichen Personen, so gilt ein Höchstsatz von $15 \%$. Bemessungsgrundlage ist der Bruttodividendenertrag, das heißt, es können keine Aufwendungen für die Dividendenerzielung im Quellenland geltend gemacht werden ${ }^{100}$.

Aus dem Vorstehenden wird deutlich, daß bei der Besteuerung von ausländischen Anteilseignern zu unterscheiden ist,

- ob der ausländische Anteilseigner eine natürliche Person ist, d.h. ein Aktionär, der deutsche Anteilspapiere in seiner Hand hält (unmittelbarer Anteilseigner) oder ob es sich um eine Kapitalgesellschaft im Sinne einer juristischen Person handelt, hinter der letztlich wiederum eine natürliche Person steht (mittelbarer Anteilseigner),

- ob der ausländische Anteilseigner eine wesentliche oder eine nicht wesentliche Beteiligung besitzt und

- ob die Bundesrepublik Deutschland und das Land des ausländischen Anteilseigners ein DBA abgeschlossen haben oder nicht.

Artikel 10 OECD-MA und hierauf basierende DBA werden zum Teil überlagert von der Mutter-Tochter-Richtlinie der EU. Diese Richtlinie verpflichtet die EUStaaten, auf Ausschüttungen einer Tochtergesellschaft keinen Quellensteuerabzug vorzunehmen, wenn diese Ausschüttungen an eine in einem anderen EU-Staat bestehende Muttergesellschaft fließen ${ }^{101}$.

Voraussetzung ist, daß die Muttergesellschaft wesentlich an der Tochtergesellschaft beteiligt ist, d.h. ihr Anteil muß mehr als $25 \%$ betragen. Allerdings wendet Deutschland die Mutter-Tochter-Richtlinie schon ab einer Beteiligungshöhe von $10 \%$ an, sofern der Sitzstaat der Muttergesellschaft umgekehrt Tochtergesellschaften deutscher Muttergesellschaften die Quellensteuervergünstigung $a b$ einer Beteiligung von $10 \%$ einräumt ${ }^{102}$.

100 Vgl. Debatin, H. (1983): Probleme der internationalen Doppelbesteuerung, in: Handbuch der Finanzwissenschaft, 3. Aufl., Tübingen 1983, S. 299.

101 Der Sitzstaat der Muttergesellschaft ist zugleich verpflichtet, die Ausschüttung der Tochtergesellschaft freizustellen oder die auf ihr lastende Körperschaftsteuer anzurechnen. Eine Anrechnung dieser Art wird als indirekte Anrechnung bezeichnet.

102 Vgl. § 44 d Abs. 3 EStG. Dieser Absatz nennt als zusătzliche Bedingung auch die Gewăhrung einer Anrechnung deutscher Körperschaftsteuer auf - bzw. eine Freistellung von - ausländischer Körperschaftsteuer der Muttergesellschaft durch den ausländischen Fiskus, wie sie bei grenzuber-schreitenden Tochter-Mutter-Ausschüttungen üblich sind. 
Das OECD-MA empfiehlt also einen geringeren Quellensteuersatz bei Vorliegen einer wesentlichen Beteiligung einer Kapitalgesellschaft gegenüber allen anderen Anteilseignern. In den meisten deutschen DBA ist eine entsprechende Differenzierung vorgenommen worden. Hintergedanke der Besserstellung wesentlich beteiligter Kapitalgesellschaften, wie sie das OECD-MA und die Mutter-TochterRichtlinie der EU vorsieht, ist

1. die Berücksichtigung des Unternehmerrisikos ${ }^{103}$ und

2. die Beschränkung ökonomischer Mehrfachbesteuerung von Konzerndividenden.

Für wesentlich beteiligte, beschränkt steuerpflichtige Kapitalgesellschaften, die ihren Sitz außerhalb der EU haben, sind die Regelungen der DBA relevant. Die meisten deutschen DBA enthalten einen höheren als den von der OECD empfohlenen Steuersatz für Schachteldividenden in Höhe von 5\%. So ist oft auch für wesentlich beteiligte Kapitalgesellschaften eine Dividendenquellenbesteuerung von 10\% oder $15 \%$ vorgesehen. Erst in jüngerer Zeit scheint die deutsche Abkommenspolitik der $5 \%$-Empfehlung verstärkt nachzukommen ${ }^{104}$. Aus einigen älteren Abkommen ist zudem ein früher vereinbarter 5\%-Satz durch die Absenkung der deutschen Körperschaftsteuersätze 1990 bzw. 1994 wieder in Kraft getreten, da mit der Senkung vielfach eine allgemein angewendete Suspensionsklausel außer Kraft trat, die zuvor in der Bundesrepublik Deutschland die Ansetzung eines vereinbarten 5\%Schachteldividendensatzes generell verhinderte ${ }^{105}$. Im Nicht-DBA-Fall wird die deutsche Kapitalertragsteuer regelmäßig in voller Höhe erhoben, das heißt die Quellenbesteuerung der Dividenden erfolgt in Höhe von $25 \%{ }^{106}$.

Für wesentlich beteiligte natürliche Personen gilt nach OECD-MA der gleiche (höhere) Quellensteuersatz auf Dividenden wie für nicht wesentlich beteiligte ausländische Kapitalgesellschaften. Die deutsche Abkommenspolitik wendet hier fast durchgehend den von der OECD empfohlenen Steuersatz von $15 \%$ an.

103 Diese Begründung vermag solange nicht zu uberzeugen, wie wesentlich beteiligte Anteilseigner, die keinen Status einer Kapitalgesellschaft innehaben, von dieser Begünstigung ausgeschlossen sind. Das unternehmerische Risiko dieser Gruppe von Anteilseignern kann m. E. kaum anders eingeschätzt werden.

104 DBA mit 5\%iger Schachteldividendenbesteuerung finden sich u.a. in den Abkommen mit den USA (1989) und der Schweiz (1989/92).

105 Siehe zur Problematik der Suspensionsklausel z.B.: Vogel, K. (1996): Doppelbesteuerungsabkommen der Bundesrepublik Deutschland auf dem Gebiet der Steuern vom Einkommen und Vermögen, Kommentar, 3. Aufl., München 1996, S. 816f., bzw. Rz 90.

106 Unter bestimmten Umständen ist auch eine höhere Kapitalertragsteuer möglich, vgl. § 43a EStG. 
Tabelle IV: Dividendenbesteuerung der Nichtanrechnungsberechtigten (in\%)

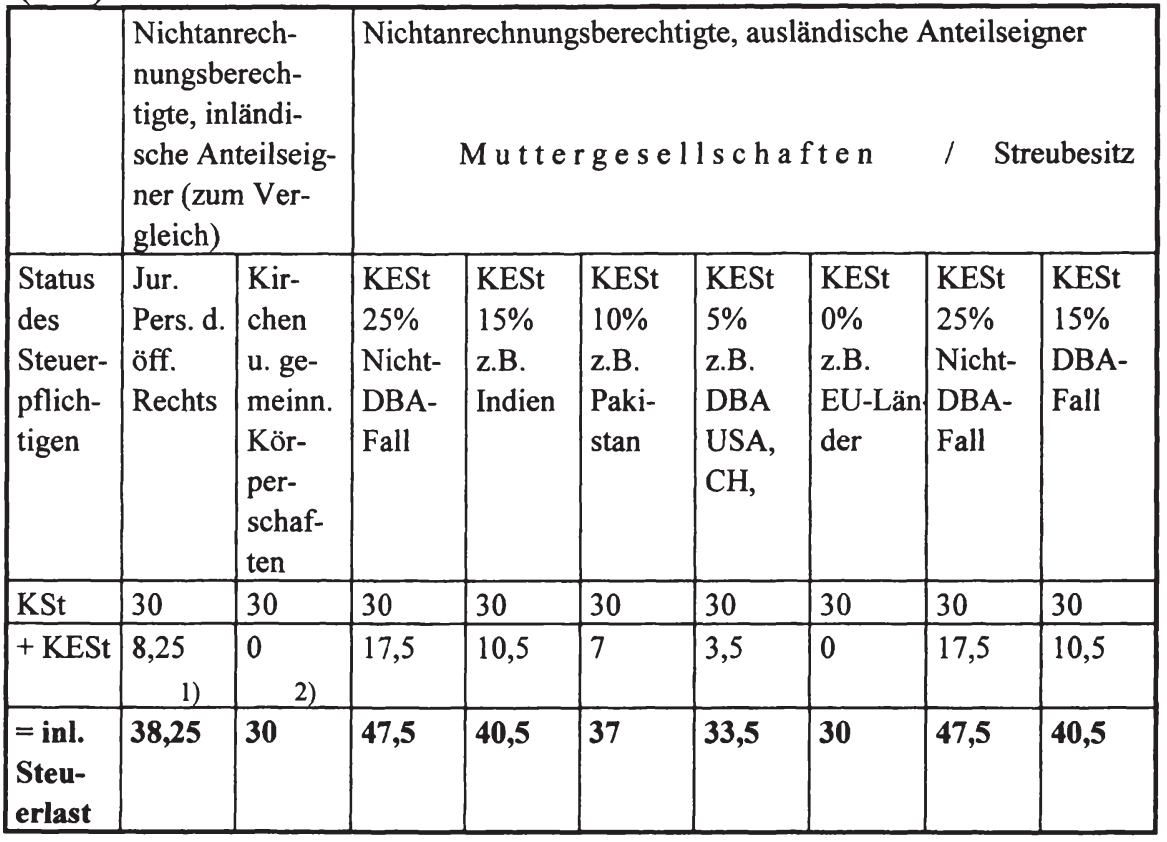

Quelle: Eigene Zusammenstellung, ohne Berücksichtigung des Solidaritätszuschlags.

1) wg. $\S 43$ a Abs 1 EStG in Verbindung mit $\S 44 c$ Abs. 2 Satz 2 EStG.

2) wg. $\S 43$ a Abs 1 EStG in Verbindung mit $\S 44 \mathrm{c}$ Abs. 1 Satz 1 EStG.

Zusätzlich unterliegen ausländische, unmittelbare Anteilseigner der Dividendenbesteuerung ihres Wohnsitzlandes, die in der Regel im Rahmen der persönlichen Einkommensteuer erfolgt. Auf diese Einkommensteuer können ausländische Anteilseiger üblicherweise ihre in Deutschland verbliebene Kapitalertragsteuer anrechnen lassen.

Die Bundesrepublik Deutschland versuchte nach Einführung des Anrechnungssystems die Gesamtsteuerbelastung der Steuerausländer mit einer Senkung der Kapitalertragsteuer zu mindern ${ }^{107}$. Die Anrechenbarkeit der deutschen Kapitalertragsteuer und die Nichtanrechenbarkeit der deutschen Körperschaftsteuer führt aber dazu, daß eine Erhöhung der Körperschaftsteuer für Ausländer nicht durch eine gleichzeitige Senkung der Kapitalertragsteuer zu mindern ist. Von einer solchen Senkung profitiert nur der Fiskus des Wohnsitzlandes - außer im Fall der Nichtde-

107 Vgl. Kaiser, H. (1980): Körperschaftsteuerliches Anrechnungsverfahren und Ausländerproblematik, in: Steuerberaterkongreß-Report 1980, S. 193f. 
klarierung der Dividenden bei der Einkommensteuererhebung. Der Blick auf die deutsche Gesamtsteuerbelastung ${ }^{108}$ ist deswegen nicht weitgehend genug.

\subsubsection{Die steuerliche Behandlung von Fremdkapitalvergütungen}

Im Gegensatz zu Eigenkapitalentlohnungen sind Fremdkapitalentlohnungen in Steuersystemen vom Schanz-Haig-Simons-Typ beim Schuldner abziehbar und werden allein beim Bezieher von Zinseinkommen besteuert. Zinszahlungen unterliegen folglich keiner Gewinnsteuer beim Zahler, sondern stellen einkommensteuerpflichtige Kapitalerträge für den Empfänger dar. Steuerausländer haben Zinsen normalerweise im Rahmen ihrer Einkommensteuer im Wohnsitzland zu versteuern. Im Fall grenzüberschreitender Zinszahlungen gesteht das OECD-MA wie bei der Dividendenbesteuerung aber sowohl dem Quellenland als auch dem Wohnsitzland Besteuerungsrechte auf Zinseinkommen zu. Zum einen bestimmt Art. 11 Abs. 1 OECD-MA ein ausdrückliches Recht des Wohnsitzstaates:

"Zinsen, die aus einem Vertragsstaat stammen und an eine im anderen Vertragsstaat ansässige Person gezahlt werden, können im anderen Staat besteuert werden."

Zum anderen räumt Art 11. Abs. 2 OECD-MA auch dem Quellenland ein Besteuerungsrecht ein, das jedoch durch Festsetzung eines Höchstsatzes von 10\% begrenzt ist ${ }^{109}$. Bemessungsgrundlage ist dabei wie im Fall der Quellenbesteuerung auf Dividenden der Bruttoertrag, es kann also kein Abzug von mit den Zinseinnahmen zusammenhängenden Aufwendungen vorgenommen werden ${ }^{110}$. Das OECD-MA enthält somit im Bereich der Zinsbesteuerung eine Steueraufteilung, die als Kompromißlösung zwischen Quellen- und Wohnsitzlandbesteuerung gesehen werden kann ${ }^{111}$.

108 Vgl. z.B. Argumentation von Kaiser, H. (1980), a.a.O. S. 194.

109 Das UN-MA spricht ebenfalls grundsätzlich dem Wohnsitzstaat die Zinsbesteuerung zu, räumt aber dem Quellenland gleichfalls ein Besteuerungsrecht ein, fur das es aber keine Höchstgrenze vorgibt. Dies entspricht der stärkeren Orientierung des UN-MA zugunsten der Steuerrechte der Entwicklungs- und Schwellenländer, die typischerweise eher Kapitalimportländer sind. Dagegen gewăhrt das US-MA - entsprechend dem fiskalischen Interesse von kapitalexportierender entwickelter Staaten - eine ausschließliche Wohnsitzlandbesteuerung von Zinseinkünften. Vgl. Art. 11 UN-MA bzw. Art 11. US-MA.

110 Vgl. Debatin, H. (1983), a.a.O., S. 299.

111 Vgl. Vogel, K. (1996), a.a.O., S. 744. 
In ihrer Abkommenspolitik hat die Bundesrepublik Deutschland dagegen sehr oft das ausschließliche Recht des Wohnsitzlandes bei der Zinsbesteuerung durchgesetzt $^{112}$. Die Durchsetzung des Wohnsitzlandprinzips bei der Zinsbesteuerung könnte als Interessenwahrung eines Kapitalexportlandes interpretiert werden, wie es die Bundesrepublik Deutschland in ihrer Vergangenheit überwiegend war.

Heute ist vor allem mit jenen Staaten ein Verzicht auf Quellenbesteuerung vereinbart, aus denen die relevanten Kapitalströme von und nach Deutschland fließen ${ }^{113}$. Die Frage ist allerdings, ob die relativ einfache Hinterziehbarkeit von im Ausland verdienten Zinsen im Wohnsitzland nicht über kurz oder lang zu einem international koordinierten Quellenabzug zwingt. Hierauf wird später noch zurückzukommen sein.

Höhere Quellensteuern auf Zinseinkünfte sind in der Regel eher in deutschen DBA mit Entwicklungsländern zugelassen ${ }^{114}$. In der Regel sind die Steuersätze auf Gegenseitigkeit vereinbart. In der Praxis stellen allerdings die Kapitalströme insbesondere aus den meisten Entwicklungsländern zu vernachlässigende Größen dar, so daß die Einräumung der Quellenbesteuerung unter dem Aspekt des Steueraufkommens als grundsätzlich vorteilhaft für diese Länder angesehen werden kann, weil Kapital eher in diese Länder exportiert wird ${ }^{115}$.

112 So enthalten z.B. die deutschen DBA mit folgenden, aus Sicht des deutschen Außenhandels überwiegend sehr wichtigen Vertragspartnern ein ausschließliches Besteuerungsrecht des Wohnsitzlandes: Bulgarien, Dänemark, Finnland, Frankreich, Großbritannien, Irland, Island, Luxemburg, Kuwait, jugoslawische Nachfolgestaaten, Namibia, Niederlande, Norwegen, Österreich, Polen, Rußland, Schweden, Schweiz, Slowakei, Tschechische Republik, Ungarn, USA und Vereinigte Arabische Emirate.

113 Eine Ausnahme bildet hier Japan. Mit diesem Land besteht noch eine grundsätzliche Quellenbesteuerung von Zinseinkunften in Höhe von 10\%; vgl. DBA-Deutschland-Japan, Art. 11 Abs. 2 und 3.

114 Quellensteuersätze von $10 \%$ sind mit vielen afrikanischen und asiatischen Staaten vereinbart, dies trifft z.B. zu auf China, Indien, Mongolei, Bangladesh, Simbabwe, Sambia und Südafrika. Mit einem Satz von $15 \%$ übersteigen die deutschen DBA mit der Türkei, Ägypten, der Elfenbeinküste, Kenia, Iran, Israel, Südkorea, Malaysia, Kanada und fast allen lateinamerikanischen Staaten die Begrenzung der Quellenbesteuerung des OECD-MA. Gleiches gilt für Liberia und Pakistan (20\%), Thailand (25\%) und Mauritius (keine Begrenzung).

115 Debatin, H. (1983), a.a.O., S. 308. 
Bedenkt man, daß die meisten grenzüberschreitenden Kapitalbewegungen zwischen den weiter entwickelten oder voll entwickelten Volkswirtschaften stattfindet, so kann festgehalten werden, daß

1. die Besteuerung von Zinseinkünften de facto fast ausschließlich im Wohnsitzland stattfindet, und

2. ausländisches Fremdkapital in Deutschland regelmäßig steuerfreie Einkünfte erwirtschaftet.

Solange Deutschland als Hochsteuerland gilt, resultieren hieraus Anreize, Kapitaleinkommen von Ausländern im Inland als Zinseinkommen anfallen zu lassen, damit es nicht der deutschen Besteuerung unterliegt. Für ausländische Anteilseigner, die Fremdkapital statt Eigenkapitaleinlagen leisten, ergibt sich ein zusätzlicher Effekt: Die Kapitalgesellschaft kann die ins Ausland gezahlte Fremdkapitalentlohnung als Betriebsausgabe geltend machen, wodurch sich die inländische Bemessungsgrundlage für die Gewinnsteuern verringert. Es kommt zu einer inländischen "Keinmal-Besteuerung".

\subsubsection{Die steuerliche Behandlung von Veräußerungsgewinnen}

Wie schon kurz erwähnt, werden Gewinne aus der Veräußerung von Wertpapieren in Deutschland nur ausnahmsweise besteuert. $\mathrm{Zu}$ unterscheiden ist zwischen Beteiligungsveräußerungen aus Privatvermögen und aus Betriebsvermögen. Verkauft jemand Anteile aus einem Privatvermögen, so erfolgt nur dann eine Besteuerung, wenn die Beteiligung nicht mehr als ein Jahr gehalten wurde ${ }^{116}$ oder wenn der veräußernde Anteilseigner innerhalb der letzten fünf Jahre mittelbar oder unmittelbar wesentlich an der Kapitalgesellschaft beteiligt war $^{117}$. Im ersten Fall erfolgt eine Besteuerung zum persönlichen Einkommensteuersatz des Veräußerers, im zweiten Fall existiert noch eine ermäßigte Besteuerung ${ }^{118}$.

116 Diese Frist gilt ab dem 01.04.1999 rückwirkend seit dem 01.01.1999, vgl. Steuerentlastungsgesetz 1999/2000/2002, BR-Drs. 129/99, S. 19.

117 Vgl. § 17 Abs. 1 EStG. Eine wesentliche Beteiligung liegt im Fall der Anteilsverăußerung seit der jüngsten Steuerreform bei einer Beteiligung (mittelbar und/oder unmittelbar) von mindestens $10 \%$ vor. Bisher lag eine wesentliche Beteiligung vor, sofern der Veräußerer zu mehr als zu $25 \%$ beteiligt war.

118 Vgl. § 34 EStG. Die ermäßigte Besteuerung für außerordentliche Einküfte § 34 EStG wurde allerdings in letzter Zeit mehrfach erheblich eingeschränkt. Vgl. § 34 Abs. 1 EStG a.F., § 34 Abs. 1 EStG für VZ 1998 und § 34 EStG n.F. 
Die Konsequenzen der vergleichsweise geringen bzw. fehlenden Veräußerungsgewinnbesteuerung sind schon früh erkannt worden, allerdings eher im Bereich der personenbezogenen Kapitalgesellschaften. So wird seit Beginn der achtziger Jahre das Steuergestaltungsmodell der Anteilsrotation diskutiert, bei dem nicht wesentlich beteiligte Gesellschafter nach einer Phase der Gewinnthesaurierung ihre Anteile zeitweise an einen wesentlich Beteiligten veräußern. Anschließend erfolgt eine Gewinnausschüttung, die der wesentlich Beteiligte durch eine ausschüttungsbedingte Teilwertabschreibung steuerlich neutralisiert, bevor eine Rückveräußerung an nicht wesentlich Beteiligte stattfindet. Im Extremfall kann so eine vollständige Freistellung der Gewinne einer Kapitalgesellschaft von der Einkommen- und Körperschaftsteuer erreicht werden ${ }^{119}$. Dieser zwischen Steuerinländern mögliche Vorgang ist allerdings vom Finanzgericht Münster 1992 als Gestaltungsmißbrauch nach $\S 42 \mathrm{AO}$ eingestuft ${ }^{120}$ und durch Gesetzesreformen seit 1997 stark beschränkt worden ${ }^{121}$.

Die prinzipielle deutsche Steuerfreiheit für Veräußerungsgewinne nicht wesentlich beteiligter Anteilseigner gilt auch für Steuerausländer ${ }^{122}$. Wesentlich Beteiligte unterliegen aber einer Veräußerungsgewinnbesteuerung, sofern ihre Veräußerungsgewinne als Spekulationsgewinne eingestuft werden ${ }^{123}$ bzw. einer ermäßigten Veräußerungsgewinnbesteuerung ${ }^{124}$. Wesentlich beteiligte Steuerausländer werden in Deutschland allerdings nicht besteuert, sofern ein DBA nach dem OECD-MA besteht. Die meisten deutschen DBA folgen hier dem OECD-MA, so daß überwiegend das Wohnsitzlandprinzip für Veräußerungsgewinne gilt. Allein im Nicht-DBA-Fall bzw. aufgrund bestimmter DBA ${ }^{125}$ werden wesentlich beteiligte Steuerausländer auch in Deutschland besteuert. Steuerausländer können natürlich unabhängig von der Beteiligungshöhe mit ihren Veräußerungsgewinnen noch in ihrem Wohnsitzland steuerpflichtig sein.

119 Vgl. Herzig, N. (1981): Anteilsrotation bei laufender Geschäftstätigkeit, in: BetriebsBerater (BB), 36. Jg./(1981), Nr. 2, S. 109-113.

120 Vgl. Weindl, J. (1992), Die Kombination von Verăußerungs- und Ausschüttungsvorgängen als Gestaltungsmißbrauch?, in: Betriebs-Berater (BB), 47. Jg./(1992), Nr. 21, S. $1467 \mathrm{ff}$.

121 Vgl. § 50c Abs. 11 EStG; vor 1997.

122 Vgl. § $49 \mathrm{EStG}$ in Verbindung mit $\S 2$ Abs. $1 \mathrm{EStG}$.

123 Vgl. § 49 Abs. 1, Nr. 8 EStG.

124 Vgl. $\S \S 34,49$ Abs. 1, Nr. 2 Buchst. e EStG.

125 Vgl. Vogel, K. (1996), a.a.O., S. 1092, Rz. 98a. 
Die Ausnutzung der deutschen Steuerfreiheit für Veräußerungsgewinne der nicht wesentlich beteiligten Nichtanrechnungsberechtigten auf dem Weg der Anteilsrotation ist allerdings durch ein Verbot der Teilwertabschreibung des inländischen Erwerbers unterbunden. Auf diese Regelung - $\S 50 \mathrm{c} \mathrm{EStG} \mathrm{-} \mathrm{wird} \mathrm{noch} \mathrm{ausführlich}$ eingegangen.

Das OECD-MA spricht das Besteuerungsrecht auf Veräußerungsgewinne aus Beteiligungsveräußerungen dem Wohnsitzland des Veräußereres $\mathrm{zu}^{126}$. Eine Ausnahme gilt für Veräußerungen beweglicher Vermögen, soweit es zu einer inländischen Betriebsstätte gehört ${ }^{127}$. Diese Veräußerungen werden im Staat der Betriebstätte besteuert.

Im wesentlichen gilt für Veräußerungsgewinne aus Beteiligungen damit das Wohnsitzlandprinzip ${ }^{128}$. Eine Veräußerungsgewinnbesteuerung, die überwiegend im Wohnsitzland erfolgt, führt im Normalfall dann zu einer ökonomischen Doppelbesteuerung, wenn ein ausländischer Anteilseigner die Gewinne seiner Kapitalgesellschaft im Inland dem körperschaftsteuerlichen Thesaurierungssatz und im Veräußerungsfall im Ausland nochmals der Veräußerungsgewinnbesteuerung unterwerfen muß. Mit einer verlängerten Haltedauer kann natürlich die Doppelbelastung dadurch verringert werden, daß der Steuerausländer die Veräußerungsgewinnbesteuerung in seinem Wohnsitzland verringert bzw. bei unendlicher Haltedauer ganz vermeidet. Allerdings scheint fraglich, ob sich eine ewige Thesaurierung bei dem bisher relativ hohen deutschen Thesaurierungsatz wirklich lohnt. Umgekehrt kann Steuerarbitrage zu Lasten des Inlandes erreicht werden, wenn der Ausländer Gewinnausschüttungen in Veräußerungsgewinne umwandelt, indem er vor Ausschüttungstermin Beteiligungen an Inländer veräußert, die nach Gewinnausschüttung das Körperschaftsteuerguthaben realisieren können und versuchen werden, Teilwertabschreibungen geltend zu machen.

Damit erreicht der ausländische Veräußerer eine Umwandlung der internationalen Doppelbelastung in eine (höchstens) einmalige Besteuerung im Wohnsitzland. Besser noch: In vielen Ländern unterliegen sogenannte "Capital gains" einer pauschalen, häufig geringeren Steuer als die Einkommensteuer, die auf den Dividendenbezug angefallen wäre. Die Besteuerung im Wohnsitzland kann dem Steuerausländer also zusätzliche Gründe liefern, Dividenden als Veräußerungsgewinne anfallen zu lassen.

126 Vgl. Art. 13 Abs. 4 OECD-MA.

127 Vgl. Art. 13 Abs. 2 OECD-MA.

128 Vgl. Rose, G. (1995): Grundzilge des Internationalen Steuerrechts, 3. Aufl., Wiesbaden 1995, S. $72 f$. 


\subsection{4. Ökonomische Bewertung der unterschiedlichen deutschen Be- steuerung ins Ausland fließender Kapitalerträge}

Bei einer Betrachtung der Besteuerung einzelner Kapitaleinkommensarten fällt auf, daß internationale Kapitaleinkommen sowohl nach dem Wohnsitzlandprinzip als auch nach dem Quellenlandprinzip steuerlich erfaßt werden. Hinsichtlich der Eigenkapitalbereitstellung sichert die Körperschaftsteuer dem Quellenland ein Besteuerungsrecht auf die Bruttodividenden wie auf die thesaurierten Gewinne. Im Fall der Ausschüttung tritt beim ausländischen Anteilseigner eine Doppelbelastung der Dividenden sowohl bei unmittelbaren wie bei mittelbaren Beteiligungsbesitz auf. Dies gilt auch, wenn keine Ausschüttungen erfolgen, aber der Steuerausländer auf Liquiditätszuflüsse angewiesen ist und in seinem Wohnsitzland Veräußerungsgewinne steuerpflichtig sind. Die Doppelbelastung kann jedoch zumindest anteilig - vermieden werden, wenn der Ausländer statt Ausschüttungen zu erhalten seine Beteiligungen zwischenzeitlich verkauft und sich über Inländer einen Teil der Körperschaftsteuergutschrift sichern kann. Gleichfalls kann die Doppelbelastung durch Einbringung von Fremdkapital vermieden werden. In beiden Fällen bleibt für den ausländischen Anteilseigner dann nur noch die Wohnsitzlandbesteuerung relevant - sieht man von gesetzlichen Mindesteinlagen im Fall der Gesellschafterfremdfinanzierung und von dem an den Inländer fließenden Anteil der Körperschaftsteuergutschrift beim Dividendenstripping ab. Damit muß das in Deutschland eingesetzte Kapital geringere Bruttoerträge erwirtschaften als im Fall des Dividendenbezugs.

Dieses Ergebnis relativiert die in Abschnitt 3.2. festgestellten allokativen Vorteile des klassischen Körperschaftsteuersystems auf internationaler Ebene. Sofern für Veräußerungsgewinne und Zinsen ausschließlich das Wohnsitzlandprinzip gilt, verlieren die Neutralitätseigenschaften des klassischen Systems an praktischer Bedeutung, weil Dividendenstripping und Gesellschafterfremdfinanzierung unter der Annahme einer synthetischen (Kapital-)Einkommensbesteuerung im Wohnsitzland für Steuerausländer immer günstiger sind. Dieses Ergebnis gilt generell für Körperschaftsteuersysteme, die ausländischen Anteilseignern keine Anrechnung gewähren. Es gilt allerdings verstärkt für Länder mit Anrechnungssystemen, weil hier das Dividendenstripping zusätzlich motiviert wird durch die Erlangung eines weiteren Vorteils: des Anrechnungsguthabens. Da das Anrechnungssystem eine unterschiedliche Bewertung von Anteilen durch in- und ausländische Anteilseigner bewirkt, müssen Ausländer theoretisch eine höhere Bruttorendite auf ihre $\mathrm{Be}$ teiligungen erzielen als Inländer. Da dies nicht möglich ist, besteht aus steuerlichen Gründen praktisch ein Zwang, auf die genannten Gestaltungen zurückzugreifen. Natürlich können nichtsteuerliche Gründe dafür sprechen, die steuerliche Diskriminierung hinzunehmen. Diese Überlegungen verdeutlichen zum einen die Konsequenzen einer Umgehung bzw. einer Unterbindung von Umgehungen des 
Anrechnungsausschlusses. Zum anderen erklären sie, warum trotz zunehmender Liberalisierungsprozesse der internationalen Märkte die Beteiligung ausländischer Anteilseigner an deutschen Kapitalgesellschaften seit Einführung des Anrechnungsverfahrens stagniert, bzw. sogar leicht rückläufig ist. 


\section{Die Umgehung der Körperschaftsteuer durch Geschäfte mit dem Anrechnungsguthaben}

Im deutschen Körperschaftsteuersystem wird die Einmalbesteuerung der Kapitalerträge von Nichtanrechnungsberechtigten auf der Ebene der Kapitalgesellschaft sichergestellt. Dies trifft allerdings nur im Fall der Ausschüttung an nichtanrechnungsberechtigte Anteilseigner zu. Ein Nichtanrechnungsberechtigter könnte sich die Anrechnung aber auch auf Umwegen verschaffen, indem er seine Anteile an anrechnungsberechtigte Erwerber veräußert und sich im Verkaufspreis den Wert der stillen Reserven, der Gewinnvorträge und des vollständigen oder anteiligen Körperschaftsteueranrechnungsguthabens bezahlen läßt. Dem Veräußerer entsteht dadurch ein Veräußerungsgewinn, der sehr oft im Inland nicht steuerpflichtig ist. Aufgrund eines erhöhten Veräußerungsgewinns, der bei Mitvergütung des Anrechnungsguthabens entsteht, erlangen Nichtanrechnungsberechtigte somit eine "Quasi-Anrechnung"129.

Ein bilanzierender Anrechnungsberechtigter könnte den erhöhten Erwerbspreis für die Anteile, der die Rücklagen und das Körperschaftsteuerguthaben umfaßt, deswegen bezahlen, weil die spätere Ausschüttung für ihn keine Betriebsvermögensmehrung sondern eine Betriebsvermögensumschichtung darstellt. Zum einen erhöht sich zwar sein Geldbestand durch die Ausschüttung, zum anderen könnte er aber eine Teilwertabschreibung aufgrund der ausschüttungsbedingten Wertminderung oder alternativ Veräußerungsverluste geltend machen. Das Anrechnungsguthaben in Höhe von 3/7 der Ausschüttung könnte der Erwerber mit seiner persönlichen Einkommensteuerschuld verrechnen.

Insoweit weist das vorgestellte geschlossene System der deutschen Vollanrechnung hier eine Lücke auf. Erforderlich wäre es, nicht nur die Besteuerung jeder Ausschüttung eines Gewinns zu gewährleisten, sondern auch jede Gewinnrealisierung durch eine Veräußerung zu besteuern.

Wie gezeigt, läßt sich ohne gesetzliche Gegenmaßnahmen der Anrechnungsausschluß relativ leicht umgehen, solange auf eine generelle deutsche Veräußerungsgewinnbesteuerung verzichtet wird. Diese Lücke im Anrechnungsverfahren, die von einigen als Crux des Anrechnungsverfahrens bezeichnet wird ${ }^{130}$, hat der Gesetzgeber in mehreren Anläufen zu unterbinden versucht.

129 Vgl. Rabald, B. (1986): Zur Berücksichtigung von Steuerguthaben beim Erwerb nichtnotierter Anteile, in: Die Wirtschaftsprüfung (Wpg), 13. Jg./(1986), Nr. 1, S. 13.

130 Vgl. Thiel, J. (1997): Die Besteuerung der Gesellschafter - eine Crux des Körperschaftsteuer-Anrechnungsverfahrens, in: Steuerberater Jahrbuch (StbJb) 1996/97, Köln 1997, S. 81. 
So galt in den ersten Jahren unter bestimmten Voraussetzungen ein Anrechnungsverbot für Steuerinländer, wenn Beteiligungen von Nichtanrehnungsberechtigten erworben wurden. Ab 1980 bestand anstelle des schwer praktikablen Anrechnungsverbots ein Teilwertabschreibungsverbot innerhalb eines Zeitraumes von 10 Jahren in allen Fällen des Anteilserwerbs, in denen der Veräußerungsgewinn nicht von einer deutschen Einkommen- oder Gewinnsteuer erfaßt wurde. Von dieser Regel blieb der Aktienerwerb aber ausgenommen.

Diese Ausnahme verführte zum sogenannten Dividendenstripping. Ein Nichtanrechnungsberechtigter realisierte dabei das Körperschaftsteuerguthaben über die Börse, während ein erwerbender Steuerinländer, z.B. eine inländische Bank, aufgrund der Teilwertabschreibung keine Nachteile erfuhr.

Seit 1994 greift zwar unter bestimmten Vorausetzungen auch für börsennotierte Beteiligungen ein Teilwertabschreibungsverbot, das auf Dividendenstrippinggeschäfte zielt. Wie weit dieses Verbot tatsächlich geht, ist allerdings umstritten. Zusätzliche Unklarheiten bestehen seit einer weiteren Gesetzesreform aus dem Jahr 1997. Keinesfalls ist das aktuelle Recht in der Lage, jede Form des Dividendenstripping zu unterbinden.

\subsection{Das Dividendenstripping - Begriffsklärung}

In den letzten Jahren hat sich der Begriff des Dividendenstripping etabliert, ohne daß damit ein eindeutiger Sachverhalt gemeint ist. Das englische Wort "Stripping" bezeichnet in diesem Zusammenhang das "Abstreifen" des Dividendenrechtes von einem Beteiligungswertpapier. Der Vorgang des Dividendenstripping beinhaltet zwar dieses Abstreifen, geht aber darüber hinaus. Im weiteren Sinne sind Abläufe gemeint, bei denen ein Anteilseigner fällige Gewinnrechte von seinen Stammrechten abtrennt und durch andere Personen einlösen läßt ${ }^{131}$. Nicht gemeint ist also das bloße Kuponschneiden und Einlösen eines Dividendenscheins. Das Dividendenstripping im weiteren Sinn schließt also nicht zwingend einen Rückerwerb der Anteile nach der Dividendenausschüttung ein. $\mathrm{Zu}$ unterscheiden vom Dividendenstripping ist auch das seit kurzem mögliche Zinsstripping ${ }^{132}$.

131 Vgl. Krawitz, N.(1994): Aktuelle Änderung der einkommensteuerlichen Behandlung des sog. Dividenden-Stripping, in: Deutsche Steuerrecht (DStR), 32. Jg./(1994), Nr. 25, S. 882.

132 Das sogenannte "Anleihe-Stripping" oder Zinsstripping ist seit Juli 1997 zum Teil zulässig; vgl. o.Verf. (1996): "Anleihe-Stripping" ab Mitte nächsten Jahres erlaubt, in: Handelsblatt vom 21./22.12.1996, S. 26. 
Durchgesetzt hat sich unter dem Begriff des Dividendenstripping der beschriebene Vorgang mit Rückerwerb oder Rückübertragung gleicher oder gleichartiger Anteile ${ }^{133}$.

Dividendenstripping bezeichnet weiterhin ausschließlich Geschäfte, die aus steuerlichen Motiven abgeschlossen werden. Kennzeichnend ist, daß die beteiligten Geschäftspartner beim Dividendenstripping einer unterschiedlichen Besteuerung unterliegen. Durch Übertragung der Dividendenpapiere vor einem Ausschüttungstermin wird diese unterschiedliche Besteuerung so ausgenutzt, daß insgesamt eine Steuerminimierung erlangt wird. Dividendenstripping reicht dabei von legaler Steuervermeidung bis zur Steuerhinterziehung. In Deutschland hat sich seit Anfang der neunziger Jahre der Begriff des Dividendenstripping auf bestimmte Erscheinungsformen konkretisiert: Diesen Ausprägungen des Stripping-Geschäfts ist gemeinsam, daß ein Nichtanrechnungsberechtigter seine Anteile vor dem Dividendentermin an einen Anrechnungsberechtigten weitergibt. Dem Anrechnungsberechtigten sind die dann fälligen Ausschüttungen steuerlich zuzurechnen. Statt der Dividende erhält der Nichtanrechnungsberechtigte eine Zahlung, z.B. in Form eines erhöhten Verkaufspreises oder einer erhöhten Leihgebühr, die nicht der deutschen Besteuerung unterliegt ${ }^{134}$. Im Kaufpreis läßt sich der Nichtanrechnungsberechtigte den auf den Rücklagen ruhenden Körperschaftsteueranrechnungsanspruch vergüten. Der Anrechnungsberechtigte bezieht die steuerpflichtige Dividende und rechnet die Körperschaftsteuer an. Er erwirbt beim Kauf anteiliges Körperschaftsteuerguthaben, zudem erfährt er durch die Dividendenausschüttung einen Wertverlust, den er in Form einer ausschüttungsbeingten Teilwertabschreibung ${ }^{135}$ oder als Veräußerungs- oder Entnahmeverlust steuerlich neutralisieren $\operatorname{kann}^{136}$.

133 Vgl. Bippus, B.E. (1994), a.a.O., S. 949; vgl. Sorgenfrei, U. (1997a): Dividendenstripping, in: Steuerpraxis der Kreditinstitute, 42. Lfg., April 1997, Nr. 4413, S. 1.

134 Vgl. Sorgenfrei, U. (1997a), a.a.O., S. 1f.

135 Im Gegensatz zur verlustbedingten Teilwertabschreibung handelt es sich bei der ausschulttungsbedingten Teilwertabschreibung um eine ertragsteuerliche Neutralisierung gekaufter Rücklagen. Zwar geht es um Gewinnausschüttungen, allerdings um Gewinne, die vom Vorbesitzer erwirtschaftet wurden, und die vom Erwerber bereits bezahlt wurden. Beim Erwerber hat dieser Vorgang nur einen Aktivtausch ausgelöst (per Gewinnanspruch an Kasse), vgl. Weber-Grellet, H. (1999): § 50c Abs. 11 EStG - Zur Belastbarkeit des Einkommensteuerrechts, in: Betriebs-Berater (BB), 54. Jg./(1999), Nr. 6, vom 11.02.1999, S. 289.

136 Vgl. Klein, M. (1997): § 50c Abs. 10 EStG und der "Anteilserwerb über die Börse" als Mittel des Dividenden-Strippings, in: Finanz Rundschau, 79. Jg./(1997), Nr. 13, $473 \mathrm{f}$. 
Über die Preissetzung des Handels zwischen Anrechnungs- und Nichtanrechnungsberechtigten kann eine Teilung des Körperschaftsteuerguthabens erfolgen, das juristisch nur dem Anrechnungsberechtigten zusteht.

Dividendenstripping ist folglich ein steuerinduziertes Arbitragegeschäft. Arbitragegeschäfte entstehen immer dann, wenn eine austauschbare gleichwertige Ware zu unterschiedlichen Preisen gehandelt wird. Im Fall von Aktien liegt dabei eine äußerst hohe Austauschbarkeit (Fungibilität) vor. Anrechungssysteme, die eine fungible Ware wie Aktien mit unterschiedlichen Preisen belegen, indem sie einer Gruppe von Anteilseignern die Anrechnung gewähren, einer anderen Gruppe dagegen die Anrechnung verweigern, provozieren geradezu Geschäfte, die sich mit der steuerlichen Diskriminierung von Nichtanrechnungsberechtigten machen lassen.

In dieser Arbeit geht es ausschließlich um das Dividendenstripping zwischen Anteilseignern, die zur Körperschaftsteueranrechnung berechtigt sind und solchen, die dies nicht sind ${ }^{137}$. Der Vollständigkeit halber sollen aber die beiden anderen Formen des Dividendenstripping zumindest kurz erläutert werden.

Einerseits existiert das tarifbedingte Dividendenstripping. Tarifbedingtes Dividendenstripping findet hauptsächlich zwischen Anrechnungsberechtigten statt. Es ist aber auch zwischen Nichtanrechnungsberechtigten oder zwischen Anrechnungs- und Nichtanrechnungsberechtigten denkbar. Der Grund für diese Stripping-Geschäfte ist die Ausnutzung unterschiedlicher persönlicher Einkommensteuersätze ${ }^{138}$. Ein Anteilseigner mit einem höheren Einkommensteuersatz veräußert seine Anteile über den Dividendentermin an eine Person mit einem niedrigeren persönlichen Einkommensteuersatz. Der Veräußerer muß einen Veräußerungsgewinn dann nicht versteuern, wenn er die Aktien im Privatvermögen hält und weder eine einjährige Spekulationsfrist unterschreitet- noch eine Beteiligungshöhe von $10 \%$ erreicht ${ }^{139}$. Der Erwerber kann von der Steuererstattung bzw. der Anrechnung stärker profitieren als der Veräußerer. Bei der Rückveräußerung kann er unter Umständen noch ausschüttungsbedingte Kursverluste geltend machen. Tarifbedingtes Dividendenstripping kann auch in Staaten mit klassischem

137 Diese Form des Dividendenstrippings wird auch als bilaterales Dividendenstripping bezeichnet, vgl. Sorgenfrei, U. (1997), a.a.O., S. 1.

138 Vgl. Eckert, R. (1995): § 50c Abs. 10 EStG zur Vermeidung des Dividendenstripping verfassungsgemäß?, in: Der Betrieb (DB), 48, Jg./(1995), Nr. 2, S. 62.

139 Nach $\S 23$ EStG bzw. $§ 17$ Abs. 1 EStG in der Fassung, die am 01.04.1999 rückwirkend in Kraft treten wird. 
System erfolgen, sofern Dividenden und Veräußerungsgewinne nicht gleich besteuert werden ${ }^{140}$.

Andererseits ist auch das Dividendenstripping mit Auslandsaktien bekannt. Hier geht es für den Anteilseigner um die Erlangung einer günstigeren Kapitalertragsteuer nicht aber um Körperschaftsteuerguthaben. Ausländer aus Staaten, die kein DBA mit dem Land ihrer Beteiligung abgeschlossen haben und deren Steuerrecht keine unilaterale Anrechnung enthält, die dem deutschen $\S 34 \mathrm{c}$ EStG entspricht, erfahren durch den Quellensteuerabzug (Kapitalertragsteuer) eine definitve Belastung von $25 \%$. Durch sogenanntes Treaty Shopping können Steuerausländer diese Definitivbelastung vermeiden. Dabei findet wiederum ein Dividendenstripping statt $^{141}$.

Beispiel: Ein Anteilseigner aus dem Ausland A besitzt Beteiligungen aus dem Ausland B. Zwischen A und B besteht kein DBA und Land A wendet keine unilaterale Maßnahme wie Anrechnung oder Freistellung an, die eine Doppelbesteuerung beseititigt. Der ausländische Anteilseigner leitet nun ein Dividendenstripping mit einem in Deutschland unbeschränkt Steuerpflichtigen ein. Der Steuerinländer profitiert von einem bestehenden DBA zwischen Deutschland und dem Land B oder nutzt $\S 34 \mathrm{c}$ EStG, das heißt entweder erhebt das Land B die Quellensteuer gegenüber Deutschland gar nicht bzw. es erstattet sie oder die Steuer ist anrechenbar auf die Steuerschuld des zwischenzeitlichen Anteilseigners in Deutschland. Die gerettete Quellensteueranrechnung läßt sich über Verkaufspreis oder Leihgebühr aufteilen ${ }^{142}$.

Verlierer ist der ausländische Fiskus (Land B). Er nimmt statt der vollen nur die ermäßigte Quellensteuer ein. Verlierer ist weiterhin der deutsche Fiskus. Er erstattet die ausländische Quellensteuer, obwohl er selbst kaum Steuereinnahmen

140 Vgl. z.B. für die USA Willens, R. (1993): Dividend-Stripping Proposed Regulations Broaden the Scope of Risk Diminution, in: The Journal of Taxation, Vol. 79/(1993), S. 138ff.

141 Vgl. Landeszentralbank Hessen (1998): Dem Dividendenstripping auf der Spur, Frankfurter Finanzmarkt-Bericht, Nr. 29, Februar 1998, S. 7 f.

142 Vgl. BFH-Urteil vom 24.10.1981, BStBl. II 1982, S. 150. Der BFH lehnte hier einen allgemeinen Gestaltungsmißbrauch nach $\S 42$ AO ab. Der Gesetzgeber reagierte 1993 mit $\S$ 50d Abs. 1a EStG, nach dem eine ausländische Gesellschaft keinen Anspruch auf Steuerentlastung aus uni- oder bilateralen Maßnahmen (DBA) genießt, soweit an ihr Personen beteiligt sind, denen die Steuerentlastung bei unmittelbar erzielten Einkünften nicht zustände, sofern für die Zwischenschaltung keine wirtschaftlichen "oder sonst beachtliche" Gründe erkennbar sind. Vgl. Ward, D.A. (1995): Abuse of Tax Treaties, in: International Tax Review (Intertax), Vol. 23/(1995), Nr. 4, S. 183. 
sieht, weil der Steuerinländer zwar steuerbare Dividenden aber in der Regel auch einen entsprechenden Kursverlust geltend machen kann.

Gegen diese Gestaltung greifen höchstens allgemeine Mißbrauchsklauseln wie $\S$ $42 \mathrm{AO}$, und dies offenbar auch erst im Zusammenspiel mit allgemeinen Mißbrauchsklauseln, die in deutschen DBA erst seit kürzerem vereinbart werden, so z.B.im deutschen DBA mit den USA ${ }^{143}$. Gesetzliche Maßnahmen, mit denen in Deutschland das Dividendenstripping bekämpft wird, laufen hier ins Leere, weil diese Maßnahmen nur auf die Anrechnung der Körperschaftsteuer zielen.

\subsection{Grundformen des Dividendenstripping}

Beschränkt steuerpflichtige Anteilseigner können ihre Anteile an einer inländischen Kapitalgesellschaft

1. als Bestandteil eines ausländischen Privatvermögen,

2. als Bestandteil eines ausländischen Betriebsvermögens oder

3. als Bestandteil eines inländischen Betriebsvermögens halten.

Der Fall, daß sich die Anteile des beschränkt Steuerpflichtigen in einem inländischen Betriebsvermögen befinden, ist für die weiteren Betrachtungen zum Dividendenstripping nicht von Bedeutung. Anteile, die sich im inländischen Betriebsvermögen befinden, sind gewerbliche Einkünfte ${ }^{144}$. Gewinne, die einer inländischen Betriebstätte zuzurechnen sind, werden nach Art. 7 des OECD-MA im Quellenstaat besteuert. Dieses sogenannte Betriebsstättenprinzip findet sich auch in den meisten DBA der Bundesrepublik Deutschland ${ }^{145}$. Betriebsstätteneinkünfte unterliegen nicht dem abgeltenden Steuerabzug bezüglich der Körperschaftsteuer und der Kapitalertragsteuer. Entsprechend sind diese Einkünfte auch nicht von der Körperschaftsteueranrechnung ausgeschlossen. Veräußerungsgewinne, die sich aus dem Verkauf von Gesellschaftsanteilen aus inländischem Betriebsvermögen ergeben, sind - wie schon erörtert - ebenfalls als Betriebsstättengewinne im Inland zu versteuern.

143 Vgl. Art. 28 des deutschen DBA mit den USA. Siehe hierzu: Arthur Anderson \& Co GmbH (Hrsg.): Doppelbesteuerungsabkommen Deutschland-USA, Kommentar, Köln 1990, S. $372 \mathrm{ff}$.

Vgl. § 49 Abs. 1 Nr. 2a EStG.

Vgl. Baranowski, K.-H. (1996), a.a.O., S. 109ff. 
Die nachfolgenden Varianten des Dividendenstripping sind relevant für die Fälle, in denen der beschränkt Steuerpflichtige die Anteile an einer inländischen Kapitalgesellschaft im ausländischen Betriebs- oder Privatvermögen hält. Die ausgeschüttete Körperschaftsteuer in Höhe von 30\% ist dann nicht anrechenbar und somit endgültig. Die Einkünfte unterliegen weiterhin dem abgeltenden Steuerabzug durch die Kapitalertragsteuer.

Im folgenden soll ein Überblick über die vielfältigen Ausprägungen des Dividendenstripping gegeben werden. Auch wenn die folgenden Ausführungen eher etwas technisch anmuten, wird deutlich werden, wie schwierig ein Dividendenstripping auszumachen und somit zu verfolgen ist. Dabei kann nur ein grober Überblick über bekanntgewordene Gestaltungsmodelle gegeben werden. Ein Anspruch auf Vollständigkeit ist schon deswegen nicht haltbar, weil davon auszugehen ist, da $\beta$ noch viele Ausprägungen existieren, die auch die Finanzverwaltung noch nicht kennt.

\subsubsection{Dividendenstripping mittels separater Kassageschäften ${ }^{146}$}

Hier handelt es sich um die einfachste Ausprägung eines Dividendenstripping: Ein nichtanrechnungsberechtigter Anteilseigner verkauft seine Anteile kurz vor dem Fälligkeitstermin der Dividendenzahlung an ein inländisches Kreditinstitut. Die inländische Bank veräußert das Aktienpaket (cum Dividende) an einen (anrechnungsberechtigten) Börsenmakler mit Wertstellung des Hauptversammlungstermins weiter und bezieht vom selben Börsenmakler gleichzeitig oder fast gleichzeitig ein entsprechendes Aktienpaket (ex Dividende). Dieses Aktienpaket veräußert das Kreditinstitut an den Nichtanrechnungsberechtigten weiter. Der anrechnungsberechtigte Börsenmakler realisiert aufgrund des Kursabschlages einen Veräußerungsverlust, der allerdings überkompensiert wird, da er neben dem Dividendenertrag das Körperschaftsteueranrechnungsguthaben geltend machen kann. Makler und Kreditinstitut berechnen Provisionen. Der Nichtanrechnungsberechtigte erzielt einen steuerfreien Veräußerungsgewinn anstelle mit inländischer Körperschaftsteuer belasteter Kapitalerträge. Es hängt dabei vom ausgehandelten Verkaufspreis ab, in welchem Umfang der Nichtanrechnungsberechtigte am Körperschaftsteuerguthaben des Maklers partizipieren kann. Diese Form des Dividendenstripping beinhaltet allerdings beim Rückkauf der Aktien ein Kursrisiko, das sich erhöht, je größer der zeitliche Abstand zwischen beiden Kassageschäften ausfällt. Starke Kursschwankungen können den ausschüttungsbedingten Kursabschlag überlagern. Aus Sicht des Nichtanrechnungsberechtigten besteht die Gefahr, durch

146 Unter einem Kassageschäfte versteht man ein Wertpapiergeschäft, das innerhalb von zwei Tagen geldmäßig (kassenmäßig) erfulltt werden muß. 
den Ver- und Rückkauf der Beteiligungen schlechter gestellt zu sein, als wenn er selbst die körperschaftsteuerbelastete Dividende am Ausschüttungstag realisiert hätte ${ }^{147}$.

Bei dieser Grundform des Dividendenstripping ist es nicht erforderlich, daß der Veräußerer den Käufer seiner Anteile kennt. Insofern wirkt auch Börsenanonymität nicht hinderlich auf diese Geschäfte. Dies sieht bei den nachfolgenden Varianten häufig anders aus, weil ein Geschäftskontrahent gefunden werden muß, der bereit ist, mit dem Ankauf der Anteile spezielle Gegenleistungen einzuräumen.

\subsubsection{Dividendenstripping mit jungen Aktien}

Das Geschäft findet wie im Fall der separaten Kassageschäfte statt, allerdings liefert der anrechnungsberechtigte Geschäftspartner im Gegengeschäft junge Aktien, die normalerweise zum Dividendenausschüttungstermin noch keinen Gewinnausschüttungsanspruch verbriefen und entsprechend billiger sind als Altaktien ${ }^{148}$. In der Regel entspricht der Kurs der jungen Aktie dem Kurs der Altaktie abzüglich der Dividendenausschüttung. Dies gilt um so eher, je näher der Dividendenstichtag liegt. Ursache ist die Verpflichtung des Vorstands einer Aktiengesellschaft, einen Monat vor der Hauptversammlung diese einzuberufen und einen Vorschlag zur Gewinnverwendung zu machen ${ }^{149}$. Von diesem Vorschlag wird regelmäßig insbesondere bei bedeutenden Aktiengesellschaften nicht mehr abgewichen. Nach dem Ausschüttungstermin entsprechen sich junge und alte Aktien hinsichtlich des zukünftigen Dividendenanspruchs.

\subsubsection{Dividendenstripping in Verbindung mit Optionsgeschäften}

Ein Kassaverkauf durch den Nichtanrechnungsberechtigten kann auch begleitet werden von einem Gegengeschäft mit Optionsscheinen. Eine Option gewährt dem Inhaber das Recht, zu einem bestimmten Preis (Basispreis) innerhalb einer bestimmten Frist (Optionsfrist) einen Optionsgegenstand zu kaufen (Call-Option) oder zu verkaufen (Put-Option) ${ }^{150}$.

147 Vgl. Bippus, B. E. (1994), a.a.O., S. 949.

148 Vgl. Krawitz, N. (1994), a.a.O., S. 883.

149 Vgl. §§ 123 Abs. 1 und 175 Abs. 2 AktG.

150 Vgl. Gondert, H.-G. / Rützel, G. / Dreyer, G. (1995): Arbitragegeschäfte an der DTB, in: Die Bank, o. Jg./(1995), Nr. 9, S. 562. 
Beim Dividendenstripping kann das Kursrisiko durch ein Optionsgeschäft ausgeschaltet werden. Erwirbt z.B. der Steuerinländer mit den Aktien auch eine Verkaufsoption von dem Steuerausländer, so erhält letzterer bei Ausübung der PutOption seinen ursprünglichen Aktienbestand zurück. Ausgeübt wird die Option vom Put-Inhaber (Anrechnungsberechtigter) nur dann, wenn der Basispreis deutlich über dem Kassakurs liegt. Damit sich das Dividendenstripping für beide Kontrahenten lohnt, müssen für den Käufer des Put der Kursgewinn und die vereinnahmte Dividende höher sein als die zu zahlende Prämie. Für den nichtanrechnungsberechtigten Anteilseigner gilt, daß die Optionsprämie, die er als Stillhalter erhält, höher sein muß als die Dividende nach Steuern zuzüglich der Differenz zwischen Kassaverkaufspreis und Basispreis.

Beispiel: Eine Aktie zum Kurswert von 100 DM wird von einem Nichtanrechnungsberechtigten an einen Anrechnungsberechtigten verkauft. Zugleich geht der Nichtanrechnungsberechtigte eine Stillhalteposition für eine Put-Option ein, die er dem Anrechnungsberechtigten verkauft.

Voraussetzung dafür, daß der Nichtanrechnungsberechtigte die Aktie wieder angedient bekommt, ist - wie erwähnt - ein Basispreis, der deutlich über dem Verkaufspreis liegt, zu dem er die Aktie an den Anrechnungsberechtigten verkauft, z.B. 112 DM.

Die potentielle Optionsprämie errechnet sich für den Nichtanrechnungsberechtigten aus der erwarteten Dividende, z.B. 5 DM und der Differenz zwischen Kassaverkaufspreis uns Basispreis (sogenannter innerer Wert der Option), im Beispiel $12 \mathrm{DM}$, insgesamt also $17 \mathrm{DM}$. Für den Anrechnungsberechtigten ist die potentielle Optionsprämie höher, denn er kalkuliert die Dividende (5 DM), das KSt-Guthaben von 3/7 der Dividende (2,14 DM) und den inneren Wert der Option (12 DM), insgesamt also 19,14 DM.

Tabelle V: Dividendenstripping in Verbindung mit Optionsgeschäften

\begin{tabular}{|l|l|l|}
\hline & Ausländer & Inländer \\
\hline Verkauf einer Aktie & $+100,--$ & $-100,--$ \\
\hline Put-Verkauf (Basispreis 112,--) & $+18,10$ & $-18,10$ \\
\hline (erwartete) Dividendenzahlung & & $+5,--$ \\
\hline Steuerguthaben & & $+2,14$ \\
\hline Put-Ausübung & $-112,--$ & $+112,--$ \\
\hline Saldo & $+6,10$ & $+1,04$ \\
\hline
\end{tabular}

Quelle: Beispiel angelehnt an Krawitz, N. (1994), a.a.O., S. 883; der in seinem Beispiel auch noch die KESt mit einbezieht. 
Einigen sich die beiden auf eine Optionprämie "in der Mitte" also z.B. auf 18,10 DM, dann erhält der Nichtanrechnungsberechtigte statt einer Dividende von 5 DM einen Erlös von 6,10 DM, steht also um 1,10 DM besser dar als ohne Dividendenstripping; der Anrechnungsberechtigte verdient bei dem Geschäft 1,04 DM. Er übt die Put-Option am Tag nach der Ausschüttung aus und erhält Dividende und Körperschaftsteuerguthaben.

Das Aktiengeschäft kann auch auf umgekehrtem Wege mit einer Call-Option verknüpft werden. In diesem Fall löst der Nichtanrechnungsberechtigte das Gegengeschäft aus.In beiden Fällen kann der Optionspreis so ausgehandelt werden, daß das Körperschaftsteuerguthaben unter den Vertragspartnern aufgeteilt wird. Unter Umständen können das Aktiengeschäft und Optionsgeschäft nicht zeitgleich abgeschlossen werden. In derartigen Fällen kann das Kursrisiko auch über sogenannte Over-the-Counter-Optionen (OTC-Optionen) begrenzt bzw. ausgeschaltet wer$\operatorname{den}^{151}$. Zum Teil wird die Auffassung vertreten, daß für Optionsgeschäfte zwecks Dividendenstripping gleichfalls nur ein bestimmter zeitlicher Rahmen in Frage kommt. Werden Optionen zeitlich erst viel später fällig, so kann der Optionspreis zu stark durch andere Markteinflüsse bestimmt werden ${ }^{152}$.

Noch komplizierter stellt sich der Fall dar, wenn zwischen ausländischem Anteilseigner und inländischem Geschäftspartner eine ausländische Muttergesellschaft zwischengeschaltet wird. Bekannt geworden sind Fälle, in denen eine anrechnungsberechtigte, inländische Kapitalgesellschaft Aktien von einem Steuerausländer kurz vor dem Ausschüttungstermin erwirbt. Zugleich verkauft die inländische Kapitalgesellschaft OTC-Call-Optionen an eine ausländische Muttergesellschaft, die nach dem Dividendentermin die Optionen ausübt und an den ursprünglichen ausländischen Anteilseigner weiterleitet. Der zusätzlichen Verschleierung dient ein Weiterverkauf der Aktien durch die inländische Tochtergesellschaft an der Börse, die entsprechende Aktien aber gleichzeitig erwirbt, um den eingegangenen Optionsverpflichtungen nachkommen zu können ${ }^{153}$.

Indem der Call-Preis im Innenverhältnis des Konzerns festgelegt werden kann, erlangt die inländische Kapitalgesellschaft die Vorteile des Anrechnungsguthabens, das de facto im Ausland zwischen ausländischer Muttergesellschaft und ausländischem Partner des Dividendenstripping aufgeteilt wird. Ein Nachweis in-

151 Vgl. Bippus, B.E. (1994), a.a.O., S. 951.

152 Vgl. Dötsch, E. (1996), Kommentar zu § 50c EStG, in: Dötsch, E. / Eversberg, H. / Jost, W.F. / Witt, G. (Hrsg.) Die Körperschaftsteuer, Loseblattsammlung, Bd. 3, 27. Erg.Lfg., S. $1132 / 41$.

Vgl. Landeszentralbank Hessen (1998), a.a.O., S. 5. 
dividueller Vereinbarungen, die teilweise im Ausland ohne deutsche Beteiligung getroffen werden, dürfte den inländischen Steuerbehörden kaum gelingen und selbst wenn er gelänge, wäre der Call-Preis - entsprechend dem Vorgehen bei Verrechnungspreisen - möglicherweise über einen Drittvergleich durch den Konzern zu rechtfertigen.

Ein anrechnungsberechtigter Erwerber kann die gezahlten Optionsprämien als Anschaffungskosten der Optionsrechte geltend machen, das heißt, die Optionsprämien haben den Charakter von Betriebsausgaben. Diese Art des Dividendenstripping ist für private Erwerber nicht praktikabel, da eine Geltendmachung der gezahlten Optionsprämie als Werbungskosten nicht möglich ist.

\subsubsection{Dividendenstripping in Verbindung mit Hedging}

Zumindest eine Begrenzung des Kursrisikos kann auch durch ein begleitendes Hedge-Geschäft erreicht werden. Das zweite Geschäft des Stripping-Vorganges, also der Rückerwerb gleicher oder gleichartiger Aktien, wird durch ein gegenläufiges Termingeschäft in Aktien oder Aktienderivaten abgesichert. Verluste aus dem einen Geschäft werden dabei durch Gewinne des gegenläufigen Geschäftes ausgeglichen. Solche Absicherungen können erreicht werden durch Verkauf von DTB-Kaufoptionen oder von DTB-DAX-Futures, Kauf von DTBVerkaufoptionen, Absicherungen über DTB-Optionen oder durch Leerverkäufe branchengleicher oder anderer Aktien. Auch Gewinne des Steuerausländers aus Hedgegeschäften unterliegen nicht der inländischen Besteuerung, Veräußerungsgewinne aus Optionsgeschäften fallen nicht unter die Spekulationsgeschäfte, die der Gesetzgeber der beschränkten Steuerpflicht unterwirf ${ }^{154}$. Dies gilt allerdings nicht für wesentliche Beteiligungen. Stripping-Geschäfte mit wesentlichen Beteiligungen stellen aber in jedem Fall eine extreme Ausnahme dar.

\subsubsection{Dividendenstripping ohne Veräußerungsvorgänge}

Dividendenstripping ist auch ohne Verkaufsvorgänge denkbar. Nichtanrechnungsberechtigte Anteilseigner können über Leih- und Tauschgeschäfte mit Wertpapieren indirekt in den Genuß des Körperschaftsteuerguthabens gelangen ohne der deutschen Besteuerung zu unterliegen:

154 Vgl. § 49 Abs. 8 EStG. Selbst wenn es sich doch um Veräußerungsgewinne nach $\S 23$ EStG handeln wïde, wăren die Gewinne nach OECD-MA nur im Wohnsitzland zu besteuern. 


\subsubsection{Dividenstripping mittels Wertpapierleihe}

Ein nichtanrechnungsberechtigter Anteilseigner kann seine Aktien auch einem Anrechnungsberechtigten leihen. Anstelle der steuerpflichtigen Dividende bzw. anstelle eines erhöhten Verkaufspreises im einfachen Stripping-Geschäft erhält der Nichtanrechnungsberechtigte eine erhöhte (i.d.R. steuerfreie) Leihgebühr, die zumindest im Fall ohne dingliche Absicherung nicht der beschränkten Steuerpflicht unterliegt und somit nicht im Inland steuerpflichtig ist ${ }^{155}$. Der anrechnungsberechtigte Geschäftspartner setzt die Leihgebühr als Betriebsausgabe ab oder als Werbungskosten bei den Einkünften aus Kapitalvermögen an. Er erhält die Dividende einschließlich der Körperschaftsteuergutschrift.

Das Dividendenstripping mittels Wertpapierleihe dürfte zur Zeit hauptsächlich durch bilaterale Vereinbarungen möglich sein. Eine Wertpapierleihe über den Deutschen Kassenverein ist grundsätzlich nicht über den Dividendenausschüttungstermin möglich. Die Wertpapiere müssen spätestens einen Tag vor Ausschüttung an die Eigentümer zurückgegeben werden. Geschieht dies nicht, so nimmt der Kassenverein eine Ausgleichsverrechnung der Bruttodividende einschließlich einbehaltener Steuern vor ${ }^{156}$. Auch die inländischen Kreditinstitute sind seit einigen Jahren im Bereich ihrer Leihsysteme zu dieser Behandlung übergegangen.

Während durch dieses Verhalten der Kreditinstitute und des Kassenvereins sowie durch noch vorzustellende gesetzliche Maßnahmen viele einfache Leihgeschäfte zwischen In- und Ausländern unattraktiv geworden sind, ist das Problem der bilateralen Kettenleihgeschäfte bisher ungelöst.

Ein Kettenleihgeschäft liegt vor, wenn ein Steuerausländer an einen unbeschränkt steuerpflichtigen Steuerinländer Aktien verleiht, der wiederum an einen unbeschränkt steuerpflichtigen Steuerinländer weiterverleiht. Zweck dieser Geschäfte ist zum einen die Verschleierung des Dividendenstripping, zum anderen dient diese Konstruktion der Umgehung einschränkender gesetzlicher Maßnahmen, auf die im weiteren noch einzugehen sein werden.

$155 \S 49$ Abs. 1, Nr. 9 EStG greift nicht, da es sich nicht um die Nutzung beweglicher Sachen handelt. Vgl. Krawitz, N. (1994), a.a.O., S. 889. 


\subsubsection{Dividendenstripping mittels Gewährung vergünstigter Kredite}

Als Gegengeschäft für eine Überlassung von Wertpapieren können auch vergünstigte Kredite vom Steuerinländer eingeräumt werden. Das Steuerguthaben wird so über die Kreditkonditionen geteilt. Solche unechten Wertpapierpensionsgeschäfte sind in der Vergangenheit vor allem im Rahmen des Dividendenstripping zwischen nichtanrechnungsberechtigten Kommunen und Kreditinstituten beobachtet worden. Die Kommunen haben dabei Beteiligungen von Kapitalgesellschaften, die in ihrem Hoheitsbereich liegen, anrechnungsberechtigten Kreditinstituten überlassen ${ }^{157}$. Grundsätzlich sind solche Geschäftskonstruktionen auch mit Steuerausländern möglich. Der Nachweis, ob tatsächlich eine vergünstigte Kreditgewährung erfolgt, kann nur über einen erfolgreichen Drittvergleich geführt werden. Zur Verschleierung könnten auch hier wieder Kettengeschäfte eingerichtet werden.

\subsubsection{Dividendenstripping mittels Swaps}

Swapgeschäfte sind Vorgänge, bei denen Wertpapiere und Ansprüche auf Erträge aus diesen Wertpapieren zwischen Vertragspartnern getauscht werden. Dividendenstripping mittels Swaps läßt sich bewerkstelligen, indem der nichtanrechnungsberechtigte Anteilseigner seine Aktien cum Dividende über den Zeitpunkt der Ausschüttung gegen andere Wertpapiere tauscht, die Fremdkapitalcharakter haben. Dafür erhält der Steuerausländer neben den für ihn im Inland steuerfreien Zinserträgen eine Ausgleichszahlung, die ebenfalls nicht der inländischen $\mathrm{Be}-$ steuerung unterliegt ${ }^{158}$ so daß er insgesamt um die entgangene Dividende voll kompensiert wird und darüber hinaus am Körperschaftsteuerguthaben partizipiert. Wie noch gezeigt wird, sind Swap-Geschschäfte auch gegenwärtig noch so konstruierbar, daß keine gesetzlichen Spezialvorschriften zur Einschränkung des Dividendenstripping greifen.

\subsubsection{Sonstige Stripping-Geschäfte}

Eine endgültige Aufzählung aller Ausprägungen des Dividendenstripping ist nicht zu bewerkstelligen, weil insbesondere das Gegengeschäft - wie bei Betrachtung der vorgestellten Varianten deutlich wird - leicht durch jede nur denkbare Gegenleistung erfüllt werden kann.

157 Vgl. Dötsch, E.(1996), a.a.O., S. 1016/25. 
Während das Grundgeschäft, in der Regel der Verkauf der Aktien von einem Nichtanrechnungsberechtigten an einen Anrechnungsberechtigten, offen an der Börse erfolgen kann, kann man das Gegengeschäft auch außerhalb der Börse stattfinden lassen. Denkbar sind Variationen mit verschiedenen Kreditinstituten. So könnten Swap-Geschäfte, die über verschiedene Kreditinstitute abgewickelt werden, nur schwer von inländischen Steuerbehörden aufgedeckt werden. Die Vielfalt der möglichen Gegengeschäfte macht es fast aussichtlos für die Steuerverwaltung, dem Handel mit Anrechnungsguthaben auf die Spur zu kommen. Vor allem der Verschleierung dienen die heute sehr "verfeinerten" Methoden, die beim Dividendenstripping registriert werden ${ }^{159}$.

\subsection{Die späte Entdeckung des Dividendenstripping}

Während die vorgestellten komplizierteren Varianten des Dividendenstripping für Steuerbehörden nur schwer erkennbar sind, gilt dies weniger für die einfacheren Grundvarianten. Es überrascht daher, daß erst fünfzehn Jahre nach Einführung des Vollanrechnungssystems, das Dividendenstripping überhaupt als Problem in die öffentliche Wahrnehmung geriet, obwohl diese Steuergestaltung mit hoher Wahrscheinlichkeit seit Einführung des Anrechnungsverfahrens praktiziert wurde.

Als Auslöser fungierte dabei ein Bericht des Wirtschaftsministeriums von Hessen aus dem Jahr $1991^{160}$, der - allerdings mit einer gewissen Zeitverzögerung - eine Lawine von Pressepublikationen lostrat ${ }^{161}$. Bis in die jüngste Zeit hält zudem eine Diskussion an, in welchem Umfang unnötige Zeit zwischen Aufdeckung und Verfolgung der ersten Stripping-Geschäfte verstrichen ist ${ }^{162}$.

Die Schäden in Form von Fiskalausfällen durch Dividendenstripping sind dabei nur schwer zu schätzen. So summieren sich die Umsätze aus bekanntgewordenen

159 Vgl. Keidel, S. (1996a): Steuerforderungen in Millionenhöhe, Handelsblatt, 19.2.1996; mündliche Auskunft von Dötsch am 28.11.1997.

Vgl. Bippus, B. E. (1994), a.a.O., S.945f.

161 Vgl. o. Verf. (1993): Börsenreform: Enormes Ausmaß, WirtschaftsWoche 1993, Nr. 41, S. 131f., o. Verf.(1994): Strip in der Zockerstube, in: Der Spiegel 1994, Nr. 34, S. $64 f f$.

162 Vgl. Keidel, S. (1997): "Dividendenstripping” und kein Ende. Hessischer Sumpf., in: Handelsblatt 10./11.01.1997, S. 21; o. Verf. (1997): Dividendenstripping früh bekannt, ebd., S. 33. 
Stripping-Geschäften in dreistelliger Millionenhöhe ${ }^{163}$. Es muß davon ausgegangen werden, daß dies nur die "Spitze des Eisbergs" ist.

$\mathrm{Zu}$ fragen ist, warum vor Beginn der neunziger Jahre die Gefahr des Dividendenstripping nicht angemessen eingeschätzt wurde. Die Gefahr einer Umgehung des Anrechnungsausschlusses durch Dividendenstripping wurde nämlich durchaus schon lange vor Einführung des Anrechnungssystems gesehen. Im Rahmen der Diskussion über die Einführung eines Anrechnungssystems erkannten Anfang der siebziger Jahre Thiel und Schad die Möglichkeit, daß ein anrechnungsberechtigter Erwerber bereit wäre, einen höheren Erwerbspreis für Anteile von Nichtanrechnungsberechtigten zu zahlen, wenn er durch eine ausschüttungsbedingte Teilwertabschreibung und Erlangung des Anrechnungsguthabens steuerlich kompensiert werden könnte ${ }^{164}$. Schon im Vorfeld der Einführung eines Anrechungssystems wurde darüber nachgedacht, wie diese Umgehung von Anrechnungsausschlüssen zu gewährleisten sei. Entsprechend enthielt schon der erste Referentenentwurf eines Körperschaftsteuergesetzes vom August 1971 ein Anrechnungsverbot für Erwerber von Anteilen Nichtanrechnungsberechtigter. Dieses Verbot wurde zwar vom neuen Körperschaftsteuerrecht übernommen ${ }^{165}$, jedoch schon wenig später abgelöst durch ein Verbot ausschüttungsbedingter Teilwertabschreibung.

Die gesetzlichen Maßnahmen zur Einschränkung der Weitergabe von Anrechnungsguthaben bzw. der Körperschaftsteuererstattungen beschränkten sich allerdings bis 1993 entweder auf Geschäfte mit wesentlichen Beteiligungen oder auf den außerbörslichen Bereich. Das typische Dividendenstippinggeschäft scheint sich aber eher auf das Strippen mit Streubesitzbeteiligungen zu konzentrieren und kann ganz offensichtlich auch über die Börse stattfinden.

Um so überraschender erscheint es, daß auch die Börse seit Bestehen des Anrechnungssystems als möglicher Ort für den Handel mit Anrechnungsguthaben erkannt wurde. Dies belegt ein Erlaß des Finanzministeriums Nordrhein-Westfalen an den

163 Vgl. Keidel, S. (1997), a.a.O. S.21. Das hessische Finanzministerium schătzt die Steuerausfälle der Geschäfte mit Maklerbeteiligung auf ca. 176 Millionen DM. Als möglicherweise noch größer werden die Steuerausfälle aus Stripping-Geschăften mit Banken geschätzt. Vgl. Keidel, S. (1996b): Finanzbehörden wollen Banken zur Kasse bitten, Handelsblatt vom 25.9.1996. Die Zahlen für den jährlichen Steuerausfall belaufen sich nach Schătzungen des Bundesministeriums der Finanzen - zumindest fur Anfang der neunziger Jahre auf etwa 450 Millionen DM. In der Presse kursieren allerdings auch doppelt so hohe Schätzungen des Steuerausfalls; vgl. Bippus, B. E. (1994), S. 946.

164 Vgl. Thiel, R. / Schad, J.(1972): Die Veräußerung von Anteilen an einer Kapitalgesellschaft, in: Der Betrieb (DB), 25. Jg/(1972), Nr. 11, S. 497ff. 
Bundesverband deutscher Banken aus dem Jahr 1978: Darin betonte das Ministerium, daß ein Gestaltungsmißbrauch nach $\S 42 \mathrm{AO}$ bei Geschäften zu vermuten sei, wenn der Steuerpflichtige bei der Gestaltung seiner Verhältnisse Formen wähle, die ausschließlich der Steuerumgehung dienten, ansonsten aber keine erkennbare wirtschaftliche Bedeutung hätten. Der Erlaß enthält eine Beschreibung eines bilateralen Dividendenstripping, bei dem aber offenbar keine Börsenanonymität besteht:

"Ein unbeschränkt Steuerpflichtiger kauft kurz vor dem Zeitpunkt der Dividendenausschüttung deutsche Aktien von einem beschränkt Steuerpflichtigen. Gleichzeitig gibt er dem beschränkt Steuerpflichtigen die Zusage, ihm diese Aktien kurze Zeit nach dem Zeitpunkt der Dividendenausschüttung zurückzuübereignen." 166

Dieser Erlaß, der im Einvernehmen mit dem Bundesfinanzministerium und den Finanzbehörden anderer Länder erfolgte, hatte unmittelbare Folgen: Der Bundesverband deutscher Banken informierte im gleichen Jahr in einer Mitteilung die Kreditwirtschaft und nannte Kriterien, die zur steuerlichen Nichtanerkennung führen können. Er empfahl den Verbandsmitgliedern, Geschäfte zu unterlassen, bei denen folgende Umstände kumulativ auftreten:

1. Verkauf von Dividendenpapieren vor deren Ausschüttungstermin mit gleichzeitiger Vereinbarung einer Rückübertragung,

2. Verkauf und Rückkauf zwischen denselben Geschäftspartnern,

3. Geschäfte, bei denen außer Steuervermeidung kein wirtschaftlicher Zweck zu erkennen ist $^{167}$.

Ursache für die Zurückhaltung des Gesetzgebers bezüglich der Unterbindung dieser offensichtlich bekannten Geschäfte ist die erst spät gereifte Erkenntnis, daß das Dividendenstripping eine durchaus leichter zu praktizierende Steuerumgehungsstrategie ist als zuvor angenommen wurde.

In den ersten fünfzehn Jahren seit Einführung des Anrechnungssystems sah man vor allem in der Anonymität des Börsenhandels eine Garantie dafür, daß Stripping-Geschäfte mit börsennotierten Wertpapieren kaum möglich seien. Anonymität galt als Garant dafür, daß der Veräußerer keine Abstimmung mit dem Erwerber über die Aufteilung des Anrechnungsguthabens oder den späteren Rückerwerb des

166 Finanzministerium Nordrhein-Westfalen (1978): Erlaß des Finanzministeriums NordrheinWestfalen vom 28.08.1978, abgedruckt in: Die Wirtschaftsprufung (Wpg), 31. Jg./(1978), S. 609.

167 Vgl.Landeszentralbank Hessen (1992): "Dividendenstripping" im Zwielicht, in: Frankfurter Finanzmarktbericht Nr. 11/92, S. 2. 
gleichen Aktienpaketes vornehmen kann. Die Anonymität der Börsengeschäfte erwies sich aber später als fraglich. Weitere Faktoren haben sich erst seit Einführung des Anrechnungssystems begünstigend für Stripping-Geschäfte entwickelt: Dies gilt insbesondere für die Entwicklung und Ausbreitung von Finanzinnovationen, die der Kurssicherung dienen. Kurssicherungsgeschäfte spielen bei vielen Stripping-Geschäften eine entscheidende Rolle. Zudem erschwert der Einsatz von Finanzinnovationen auch heute die Aufdeckung des Dividendenstripping.

Schwierigkeiten bereiten auch Abgrenzungsprobleme zwischen nicht mehr legalem Dividendenstripping und "normalen" Börsengeschäften. Innerhalb welchen zeitlichen Rahmens lassen sich Geschäfte als Stripping-Geschäfte qualifizieren? Wie sind Stripping-Geschäfte von anderen Geschäften ohne steuerliche Motivation zu unterscheiden? Beim ersten Punkt spielt die Kurzfristigkeit eine entscheidende Rolle. Die für Stripping-Geschäfte typische Kurzfristigkeit ist jedoch auch für viele andere Aktiengeschäfte üblich. Der zweite Punkt zielt auf die Existenz nichtsteuerlicher Motive für Aktiengeschäfte speziell in der Zeitspanne um den Ausschüttungstermin. Beide Probleme haben im Zusammenhang mit der Einführung gesetzlicher Maßnahmen gegen das Stripping zu heftigen Diskussionen geführt, die bis heute anhalten.

\subsubsection{Anonymer Börsenhandel}

Gesetzgeber und Steuerverwaltung überschätzten offensichtlich lange Zeit die Anonymität von Börsengeschäften. Grundsätzlich ist unbestritten, daß Geschäftspartner auf dem Aktienmarkt nicht wissen, ob sie einem anrechnungsberechtigten oder einem nichtanrechnungsberechtigten Kontraktpartner gegenüberstehen ${ }^{168}$. Selbst die geschäftsausführenden Börsenmakler und Bankenhändler kennen häufig die hinter den Aufträgen stehenden Geschäftskunden nicht.

Bankenhändler sind schon aufgrund des Bankgeheimnisses an die Schweigepflicht gebunden. Das Bankgeheimnis läuft allerdings dann ins Leere, wenn die Banken selbst die Initiative beim Dividendenstripping übernehmen.

Weiterhin existiert in Deutschland eine sogenannte Börsenanonymität, die seit 1977 auch von einer Empfehlung der Europäischen Kommission eingefordert

168 Vgl. Dotsch, E. (1980): Das Gesetz zur Änderung des Einkommensteuergesetzes, des Körperschaftsteuergesetzes und anderer Gesetze, in: Der Betrieb (DB), 33. Jg./(1980) 1980, Nr. 33, S. 1563. 
wird, um einen funktionierenden Kapitalmarkt und einen angemessenen Publikumsschutz zu gewährleisten ${ }^{169}$.

Die angenommene Anonymität des Börsenhandels ist zumindest im Zeitraum von 1980 bis 1993 ausdrücklicher Grund für die Ausklammerung von Börsengeschäften aus gesetzlichen Vorschriften zur Unterbindung des Handels mit Anrechnungsguthaben gewesen ${ }^{170}$. Hierauf deutet auch der oben zitierte Wortlaut des Erlasses aus Nordrhein-Westfalen hin, in dem offenbar direkte Absprachen als Voraussetzung für ein Dividendenstripping gesehen werden. Auch die Gefahr des sogenannten Paketverkaufs über die Börse zur Umgehung des Anrechnungsausschlusses wurde als gering erachtet, da die Wahrscheinlichkeit einer Zersplitterung von Aktienpaketen aufgrund des anonymen Handels als recht hoch erachtet wur$\mathrm{de}^{171}$.

An der Börse werden sowohl Geschäfte auf Zuruf im Parketthandel als auch Abschlüsse von Individualvereinbarungen abgewickelt. Die Individualität dieser Individualvereinbarungen beschränkt sich allerdings häufig auf Valutierungen des Kaufpreises. Keineswegs erfordern diese Geschäfte zwangsläufig die Aufdeckung der hinter den Börsenkontrahenten stehenden Auftraggeber. Umgekehrt ist es freilich schwer, absolute Anonymität zu gewährleisten.

Im Regelfall wird es aber weder einem inländischen Auftraggeber, der über eine inländische Bank Aktien erwirbt, noch den Steuerbehörden möglich sein, festzustellen, ob die erworbenen Aktien von einem Nichtanrechnungsberechtigten stammen. Selbst der Nachweis, daß ein Aktienpaket von einem ausländischen Kreditinstitut erworben wurde, läßt noch nicht den Rückschluß zu, daß die Wertpapiere von einem Nichtanrechnungsberechtigten erworben wurden.

Ausnahmen bestehen natürlich beim Handel mit Namensaktien und vinkulierten Namensaktien ${ }^{172}$ sowie bei Aktien bestimmter Unternehmen, von denen bekannt

169 Vgl. EG (1977): Europäische Wohlverhaltensregeln für Wertpapiertransaktionen vom 25.7.1977, Amtsblatt der EG Nr. L 212/37 v. 20.8.1977.

170 Vgl. § 50c Abs. 8 Satz 2 EStG a.F. i.V.m. der Gesetzesbegründung zum § 50c EStG: BRDrs. 511/79, S. 22.

171 Vgl. BR-Drs. 511/79, S. 24.

172 Namensaktien werden in der Praxis übertragen, indem der Depotkunde neben einem Antrag auf Umschreibung der Namensaktien im Aktionärsbuch eine Blankoabtretungserklărung unterschreibt, die den späteren Weiterverkauf ermöglicht. Der Eigentümer einer Namensaktie steht somit mit Namen und Anschrift im Aktienbuch einer AG. Gleiches gilt furr vinkulierte Namensaktien, die nur mit Zustimmung der Aktiengesellschaft ubertragbar sind. 
ist, daß sie sich vollständig oder im wesentlichen in der Hand eines Anteilseigners befinden. Häufig ist dies der Fall bei kleineren Familienunternehmen, die an die Börse gehen.

Eine vollständige Anonymität verhindert, daß es vertragliche Aufteilungen eines Anrechnungsguthabens bei Aktiengeschäften geben kann. Es erwies sich aber, daß eine vollständige Anonymität aller Börsengeschäfte nicht existiert. Vor allem Börseninsidern ist es im großen Maße gelungen, außerbörsliche Absprachen über die Börse umzusetzen. Zudem haben sich durchaus Anrechnungsberechtigte und Nichtanrechnungsberechtigte gezielt für Stripping-Geschäfte an der Börse gefunden. Auch in dem bisher spektakulärsten Urteil zum Dividendenstripping wurde vom Hessischen Finanzgericht eine mangelnde Anonymität festgestellt ${ }^{173}$, die es ermöglicht, daß Anrechnungsberechtigte und Nichtanrechnungsberechtigte gezielt im Börsenhandel zusammenkommen können.

Es verwundert allerdings, daß im Rahmen der Diskussion über mögliche Maßnahmen zur Einschränkung des Dividendenstripping kaum erörtert wird, ob für die Abwicklung eines Dividendenstripping die Börsenanonymität überhaupt durchbrochen werden muß. Diese Frage ist von grundsätzlicher Natur. Ihre Verneinung müßte dazu führen, daß jeder Erwerb einer Aktie von einem Nichtanrechnungsberechtigten den Verdacht eines Dividendenstripping auslöst. Im vorausgehenden Abschnitt wurde bereits deutlich, daß nicht alle Stripping-Geschäfte eine Durchbrechung der Börsenanonymität erforderlich machen.

Tatsache ist, daß sich ein Arbitragehandel zwischen Anrechnungs- und Nichtanrechnungsberechtigten automatisch ergeben kann. Man stelle sich vor: Ein ausländischer Anteilseigner verkauft seine Anteile an der Börse an irgend jemanden und eine inländische Gesellschaft kauft zum gleichen Zeitpunkt von irgendeinem anonymen Verkäufer zufällig die gleichen Mengen von Beteiligungen. Wenn der ausländische Anteilseigner durch Limitierung des Auftrags seine Preisvorstellung durchsetzen kann, z.B. weil der inländische Erwerber unlimitiert einkauft, könnte schon ein Dividendenstripping erfolgt sein. Dies träfe besonders dann zu, wenn sich der ausländische Veräußerer zugleich eine Kaufoption für einen Rückerwerb sichert, die der üblichen Preisgestaltung eines Dividendenstripping entspricht.

Für derartige Geschäfte ist Börsenanonymität kein Hindernis. Sollen sie jedoch als Dividendenstripping steuerlich erfaßt werden, so müßten alle Börsengeschäfte von Nichtanrechnungsberechtigten registriert werden, und die entsprechenden Transaktionen müßten gegebenenfalls durch eine Strafsteuer beim Erwerber oder beim

173 Vgl. Hessisches Finanzgericht (1996): Urteil vom 02.12.1996, Geschăftsnummer $4 \mathrm{~K}$ 3180/94, Kassel 1996, S. 36ff, das Verfahren ist allerdings vor dem BFH anhängig. 
Veräußerer so korrigiert werden, daß der Nichtanrechnungsberechtigte auf jeden Fall letztlich nur die ihm zustehende Nettodividende bezieht ${ }^{174}$.

Resultat dieser Überlegungen: Eine Erörterung allein der Erfüllung oder Nichterfüllung der Börsenanonymität greift zu kurz. Es ist auch zu überlegen, ob bzw. unter welchen Umständen Geschäfte als Dividendenstripping anzusehen sind, bei denen der nichtanrechnungsberechtigte Veräußerer durch anonyme Börsentransaktionen gegenüber einem Dividendenstripping mit Absprachen zwischen den Vertragspartnern eine Besserstellung erreicht.

Nach wie vor gilt jedoch, daß die Börsenanonymität - soweit tatsächlich vorhanden - ein Dividendenstripping erschwert, während die Möglichkeit außerbörslicher Absprachen oder eine Durchbrechung der Anonymität durch eine aktive Geschäftsbeteiligung von Börseninsidern das Dividendenstripping erleichtern, da Kursrisiken leichter minimiert oder gar ausgeschaltet werden können.

\subsubsection{Finanzinnovationen}

Als zweite Ursache der späten Aufdeckung des Dividendenstripping ist die Entwicklung und Ausbreitung von Finanzinnovationen in den achtziger und neunziger Jahren zu nennen. Die vorgestellten Stripping-Techniken bedienen sich zahlreicher Kurssicherungsmethoden in Verbindung mit Rückkaufvereinbarungen. Damit ergeben sich insbesondere für das Gegengeschäft zahlreiche Ausprägungen. Zwar existierten einige diese Geschäftsformen auch schon bei Einführung des Anrechnungssystems, allerdings wurden die möglichen Gestaltungen von StrippingGeschäften z.B. durch die Installierung der Deutschen Terminbörse (DTB) im Jahr 1990 erheblich erweitert.

\subsubsection{Verschärfte Börsenaufsicht}

Ein weiterer wichtiger Grund sind zweifellos Veränderungen der Kontrollmöglichkeiten der Börsenaufsicht. Mit dem Gesetz zur Änderung des Börsengesetzes vom 11.07.1989 ${ }^{175}$ wurden neue Prüfungen zur Wirtschaftlichkeit der Börsenmar-

174 Tatsächlich sind die Meinungen wohl geteilt, ob ein Dividendenstripping auch bei voller Anonymităt der Börse also ohne Absprachen möglich ist. Verneinend hierzu: Kindermann, E. (1994): Börsengechăfte im zeitlichem Zusammenhang mit Dividendenterminen = Dividenden-Stripping"? Eine Bewertung nach neuem und altem Recht, in: Wertpapier Mitteilungen (WM), 48. Jg./(1994), Nr. 20, 21.05.1994, S. 877.

Vgl. BGBl. I 1989, 1412. 
kler ermöglicht. Erst diese erweiterten Prüfungsmöglichkeiten führten Anfang der neunziger Jahre zur Aufdeckung vieler Stripping-Geschäfte ${ }^{176}$.

\subsubsection{Kurzfristigkeit von Börsengeschäften}

Das Börsengeschäft ist zunehmend gekennzeichnet durch rasch handelnde Marktteilnehmer, die auf immer schneller und zahlreicher fließende Informationen entsprechend schnell reagieren. Dies gilt schon für Kleinanleger, um so mehr aber für institutionelle Anleger, die gerade in Deutschland eine bedeutende Rolle spielen, da hier die Bedeutung der langfristigen Kapitalanlage in Aktien durch Kleinaktionäre relativ schwach ausgeprägt ist. Die neuen Börsentechniken, insbesondere der Ausbau des elektronischen Handels, verstärken die Tendenz zur schnelleren Bestandsumschichtung bzw. zum Schließen offener Positionen ${ }^{177}$. Es ist insofern problematisch, Stripping-Geschäfte, die häufig durch den kurzfristigen Verkauf und Rückkauf gekennzeichnet sind, als "schlechte" Geschäfte von den börsenüblichen "guten" Geschäften zu trennen. Eine schlichte Einstufung aller kurzfristigen Geschäfte als Dividendenstripping, die um den Dividendenstichtag herum stattfinden, dürfte einer Pauschalverurteilung gleichkommen.

\subsubsection{Besondere Motive für Börsengeschäfte um den Ausschüttungstermin}

Börsengeschäfte um den Dividendentermin finden aus sehr verschiedenen Gründen statt. Steuerliche Motive können das tarifbedingte Dividendenstripping sein oder -im Fall der Steuerausländer - die Erlangung eines Teils der Körperschaftsteuergutschrift bzw. die Vermeidung inländischer Körperschaftsteuer. Neben diesen steuerlichen Motiven existieren aber auch zahlreiche andere Gründe: z.B. negative Erwartungen über die Beschlüsse der Hauptversammlung auf der Verkäuferseite oder mangelndes Interesse an der Ausübung der Stimmrechte beim Anbieter und starkes Interesse an Stimmrechten bei Nachfragern der Aktien.

Gerade im zeitlichen Umfeld der Hauptversammlung eines Unternehmens erhalten die Marktteilnehmer üblicherweise vermehrt Informationen über die $\mathrm{Ge}$ schäftslage und -ziele der Aktiengesellschaft. Es gibt also viele nichtsteuerliche Motive für Verkaufs- und Rückkaufsgeschäfte um den Dividendentermin. Eine Regelung, die Stripping-Geschäfte treffen will, trifft damit zwangsläufig auch nicht steuerlich motivierte Börsengeschäfte ${ }^{178}$.

\footnotetext{
176 Vgl. Landeszentralbank Hessen (1992), a.a.O., S. 1

177 Vgl. Sorgenfrei, U. (1997a), a.a.O., S. 20.

178 Vgl. Kindermann, E. (1994), a.a.O., S. 821.
} 
Die Gefahr einer Steuerumgehung via Dividendenstripping wurde in der Vergangenheit aus verschiedenen Gründen verkannt. Dieselben Gründe, die zur späten Aufdeckung der Vorgänge des Dividendenstripping führten, sind auch Ursache dafür, daß gesetzliche Gegenmaßnahmen zur Verhinderung dieser Steuergestaltungsmodelle nur schwer zu entwickeln sind. Insbesondere die unterschiedliche Beurteilung der Börsenanonymität bereitet große Probleme, zumal hier ein beachtliches Abgrenzungsproblem zu nicht steuermotivierten Geschäften besteht.

\subsection{Gesetzgeberische Gegenmaßnahmen (Überblick)}

Um die Weitergabe von Anrechnungsguthaben an Nichtanrechnungsberechtigte zu verhindern, wurde schon vor Einführung des Anrechnungssystems über ein Anrechnungsverbot nachgedacht, das einen anrechnungsberechtigten Erwerber treffen sollte, der Anteile von einer nichtanrechnungsberechtigten Person erwirbt. Der erste Referentenentwurf zur Körperschaftsteuerreform von 1971 enthielt ein solches Verbot für Fälle, in denen beschränkt steuerpflichtige Veräußerer innerhalb der letzten fünf Jahre vor Veräußerung zu mindestens $10 \%$ am Nennkapital einer inländischen Kapitalgesellschaft beteiligt gewesen waren und der Erwerber Anteile im Wert von mehr als 50.000 DM erwirbt. Aus Kontrollzwecken sah der Entwurf eine Meldepflicht des Erwerbers gegenüber der Kapitalgesellschaft vor, deren Anteile erworben wurden. Für Kapitalgesellschaften war eine entsprechende Verpflichtung zur Weiterleitung dieser Meldungen an die Finanzbehörden geplant $^{179}$.

Da sich die Regelung auch auf den Erwerb von börsennotierten Wertpapieren erstreckt hätte, wäre die Einführung einer umfassenden Meldepflicht für den erwerbenden Anteilseigner erforderlich gewesen. Eine derartige Anzeigepflicht im Börsenhandel wurde jedoch als unzumutbar angesehen. Kritik entzündete sich ebenfalls daran, daß das Anrechnungsverbot auch galt, wenn eine ausschüttungsbedingte Teilwertabschreibung gar nicht möglich war $^{180}$, nämlich beim Erwerb durch Privatpersonen.

Die damalige Bundesregierung entschloß sich letztlich für ein Anrechnungsverbot bei bestimmten Fällen des Anteilserwerbs von Nichtanrechnungsberechtigten.

179 Vgl. Thiel, R. / Schad, H.J.(1972), a.a.O., S. 499.

180 Vgl. Thiel,R. / Schad, H.J. (1972), a.a.O., S. 500. 
Allerdings wurden die Voraussetzungen für das Anrechnungsverbot sehr viel großzügiger formuliert, so daß weniger Geschäfte betroffen waren. Außerdem entschied man sich für eine andere Durchsetzung des Anrechnungsverbots: $\S 39$ $\mathrm{KStG}$ zwang die Gesellschaft, deren Beteiligungen von Nichtanrechnungsberechtigten an Anrechungsberechtigte veräußert wurden, durch eine Eigenkapitalumgliederung eine Nichtanrechnung zu veranlassen. Eine Analyse dieser Regelung ist sehr aufschlußreich, weil Konstruktionsmängel dieses Gesetzes zu Fehlallokationen führten, die zum Teil identisch sind mit den Auswirkungen der aktuell gültigen Maßnahmen gegen die Gesellschafterfremdfinanzierung durch Nichtanrechnungsberechtigte. Diese dienen dem gleichen Ziel, nämlich der Unterbindung des Handels mit Anrechnungsguthaben, also der Sicherstellung einer einmaligen inländischen Besteuerung von Unternehmensgewinnen durch die inländische Körperschaftsteuer. Die Kritik, die sich damals am $\S 39 \mathrm{KStG}$ entzündete und zu dessen schneller Abschaffung führte, könnte auch noch im Fall des $\S 8 \mathrm{a} \mathrm{KStG}$ zu einem ähnlichen Ergebnis führen.

Seit 1980 wendet der Gesetzgeber nicht mehr das Anrechnungsverbot nach $\S 39$ $\mathrm{KStG}$ an, sondern versagt dem Käufer, daß er Gewinnminderungen nach einer Gewinnausschüttung durch den Ansatz mit dem niedrigeren Teilwert oder durch Verluste aus ihrer Veräußerung geltend macht - im Fall der Weiterveräußerung gilt dies auch für den jeweiligen Rechtsnachfolger. Diese Regelung hat als $\S 50 \mathrm{c}$ EStG Eingang in das Einkommensteuergesetz gefunden. Eine inzwischen geänderte Börsenklausel sorgte dafür, daß diese Bestimmung nicht im Fall des Aktienerwerbs galt. Wie sich erst in jüngster Zeit herausstellte, legitimierte die alte Börsenklausel aber keineswegs alle Formen des Dividendenstripping.

Im Standortsicherungsgesetz vom 13.09.1993 ${ }^{181}$ und im Mißbrauchsbekämpfungsund Steuerbereinigungsgesetz vom 21.12.1993 ${ }^{182}$ hat der Gesetzgeber mit einer Neufassung der Börsenklausel für Rechtsklarheit sorgen wollen ${ }^{183}$. Ergänzend wurde gleichzeitig ein Anrechnungsverbot eingeführt, das auf Dividendenstripping ohne An- und Verkaufsvorgänge zielt ${ }^{184}$. Allerdings werfen diese Regelungen zahlreiche Fragen hinsichtlich ihrer Durchsetzbarkeit bzw. ihrer Regelungsweite auf, so daß - um das Ergebnis vorwegzunehmen - die Rechtssicherheit kaum erhöht wurde.

181 Vgl. BGBl. 1993 I, S. $1569 f f$.

182 Vgl. BGBI. 1993 I, S. $2310 \mathrm{ff}$.

183 Vgl. § 50c Abs. 10 EStG.

Vgl. § 36 Abs. 2 Nr. 3 Satz 4 Buchst. g EStG. 
Dies gilt erst recht für eine Steuergesetzänderung von 1997, nach der ausschüttungsbedingte Teilwertabschreibungen bzw. die Geltendmachung von Verlusten dem Erwerber auch dann versagt werden, wenn ein anrechnungsberechtigter Veräußerer, der mit seinem Veräußerungsgewinn nicht im Inland steuerpflichtig ist, an einen anderen Anrechnungsberechtigten Beteiligungen verkauft ${ }^{185}$. Diese Gesetzesänderung trifft nicht nur das bis dahin vom Gesetzgeber nicht mit speziellen Gesetzen verfolgte Dividendenstripping zwischen Anrechnungsberechtigten, das als tarifbedingtes Dividendenstripping vorgestellt wurde, sondern hat möglicherweise auch Rückwirkungen auf das Dividendenstripping mit Steuerausländern.

Unvollständig bliebe eine Analyse der gesetzlichen Regelungen ohne die Betrachtung der allgemeinen Antimißbrauchsregelung des $\S 42 \mathrm{AO}$ und ihr Zusammenspiel mit den Spezialregelungen.

\subsubsection{Allgemeine Mißbrauchsvorschrift}

Zur Bekämpfung von illegalen Steuergestaltungen steht der Steuerverwaltung in Deutschland grundsätzlich eine allgemeine Mißbrauchsvorschrift zur Verfügung: $\S 42 \mathrm{AO}$.

$\S 42 \mathrm{AO}$ galt nach Einführung des Anrechnungssystems als wirksames Gesetz gegen das Dividendenstripping durch Ver- und Rückkauf von Anteilen um den Ausschüttungstermin ${ }^{186}$. Der schon vorgestellte Erlaß des Finanzministeriums Nordrhein-Westfalen ordnete das aus zwei separaten Kassageschäften bestehende Dividendenstripping ausdrücklich als einen Fall des $\S 42 \mathrm{AO}$ ein. Verwiesen wird im Erlaß auf ein früheres Urteil des RFH, bei dem es allerdings nicht um Dividendenstripping zwecks Aufteilung von Körperschaftsteuerguthaben, sondern zwecks Erlangung einer anderen Art von Kapitaleinkommen (Veräußerungsgewinne) geht $^{187}$.

$\S 42 \mathrm{AO}$ ist jedoch eine sehr allgemein gehaltene Vorschrift, die einfordert, daß der in Mißbrauchsverdacht geratene Vorgang allein einer Steuervermeidung dient. Dies ist für die meisten Stripping-Geschäfte kaum nachweisbar. Dividendenstripping im weitesten Sinn, also der ausschließliche Verkauf eines Dividendenpapiers, wird von der Vorschrift überhaupt nicht tangiert: Natürlich steht es jedem nichtan-

185 Vgl. § 50c Abs. 11 EStG.

186 Vgl. Streck, M. (1991), a.a.O., S. 579.

187 Vgl. Finanzministerium Nordrhein-Westfalen (1978), a.a.O., S. 609, siehe auch RFH-Urteil vom 11.7.1934, RStBl. 1934, S. 979. 
rechnungsberechtigten Anteilseigner genauso wie jedem Anrechnungsberechtigten frei, jederzeit seine Anteile zu verkaufen. Ein Verkaufstermin vor einem Dividendenstichtag kann isoliert betrachtet kein Mißbrauchstatbestand sein, da börsengängige Wertpapiere sich ja gerade durch ihre fortwährende schnelle Erwerbbzw. Veräußerbarkeit auszeichnen. Die Tatsache, daß ein ausländischer Aktionär mit der Erzielung eines Veräußerungsgewinnes statt einer Dividendenrealisierung unterschiedlichen Steuerhoheiten und damit auch einer unterschiedlichen Besteuerung unterliegt, reicht auf keinen Fall für einen Mißbrauchsverdacht nach § $42 \mathrm{AO}$ aus.

Aber selbst ein Dividendenstripping im engeren Sinn kann in vielen Fällen wirtschaftlich begründet werden. Dividendenstripping mit Rückkaufvereinbarungen oder auf Basis eines Leiheschäfts kann fast immer mit Liquiditätsbedarf des Verleihers erklärt werden oder damit, daß der Veräußerer weniger am Stimmrecht interessiert ist als der zwischenzeitliche Erwerber. Ein Nachweis, daß hier ausschließlich steuerliche Motivationen vorliegen, wird einer nachweispflichtigen Finanzverwaltung kaum möglich $\operatorname{sein}^{188}$. Selbst bei Vorliegen von steuerlichen Gründen können weitere wirtschaftliche Überlegungen nicht ausgeschlossen wer$\operatorname{den}^{189}$. Geäußerte Befürchtungen z.B. eines erwarteten Kursrückganges in den Tagen nach der Hauptversammlung reichen bereits aus, den $\S 42 \mathrm{AO}$ zu entkräften. Damit kann aber jedes Dividendenstripping in Zusammenhang mit einem Kurssicherungsgeschäft als wirtschaftlich begründbarer Vorgang dargestellt wer$\operatorname{den}^{190}$.

Die Schwäche einer allgemeinen Mißbrauchsvorschrift, wie sie der $\S 42 \mathrm{AO}$ darstellt, ist, daß es zur Ausräumung des Vorwurfes eines Steuermißbrauchs genügt, daß der Steuerpflichtige irgendeine plausible Erklärung für seine Geschäftsgestaltung vorbringt. Der Einwand des Gestaltungsmißbrauchs ist somit leicht zu entkräften.

Sofern eine Spezialvorschrift eine bestimmte Steuergestaltung verfolgt, hängt die Wirksamkeit einer allgemeinen Antimißbrauchsklausel nach herrschender Meinung immer von der Zielsetzung dieser Spezialvorschriften ab. § 42 AO kann nach dieser Ansicht nur angewendet werden, wenn die Steuergestaltung einer Spezialvorschrift - in diesem Fall den Vorschriften des $\S 50 \mathrm{c} \mathrm{EStG}$ und $\S 36 \mathrm{EStG}$ - inhaltlich zuwiderläuft.

188 Vgl. Kaiser, H. (1980), a.a.O., S. 208.

189 Vgl. Krawitz, N. (1994), a.a.O., S. 886.

190 Vgl. Kindermann, E. (1994), a.a.O., S. 873. 
$\mathrm{Da} \S 50 \mathrm{c}$ EStG als Spezialvorschrift gegen die Weitergabe von Anrechnungsguthaben Börsengeschäfte bis 1993 ausdrücklich ausnahm, konnte nach dieser Sicht ein Stripping-Geschäft an der Börse bzw. unter börsenüblichen Usancen ${ }^{191}$ kein Fall der allgemeinen Mißbrauchsnorm sein ${ }^{192}$. Die Vorrangigkeit von Spezialvorschriften führte auch dazu, daß im einzigen Urteil zum Dividendenstripping zwecks Weitergabe von Körperschaftsteuerguthaben $\S 42 \mathrm{AO}$ nicht einschlägig $\operatorname{war}^{193}$.

\subsubsection{Maßnahmen gegen die Weitergabe von Anrechnungsguthaben auf der Gesellschaftsebene}

Zusammen mit der Einführung des deutschen Vollanrechnungssystems wurde eine Regelung in das Körperschaftsteuergesetz eingefügt, die eine Weitergabe von Anrechnungsguthaben an Nichtanrechnungsberechtigte verhindern sollte: $\S 39 \mathrm{KStG}$. Diese Regelung galt auch für Börsengeschäfte. Offensichtlich sah der Gesetzgeber bei Einführung des Anrechnungssystems die Börsenanonymität keineswegs als ausreichenden Garant dafür an, daß Dividendenstripping an der Börse generell unmöglich ist.

\subsubsection{Die Ausgestaltung des Anrechnungsverbots}

Das Anrechnungsverbot zielte auf Geschäfte, bei denen ein nichtanrechnungsberechtigter Anteilseigner Anteile an einen Anrechnungsberechtigten veräußert.

191 Kindermann kommt zum gleichen Ergebnis, argumentiert aber radikaler: Er erkennt in der Einhaltung börsenmäßiger Usancen quasi eine Garantie, daß kein Gstaltungsmißbrauch nach § 42 AO betrieben werden könne, vgl. Kindermann, E. (1994), a.a.O. S. 871.

192 Vgl. Sorgenfrei, U. (1997b), "Bilaterales Dividenden-Stripping” und Kapitalverkehrsfreiheit, in: Internationales Steuerrecht (IStR), 6 .Jg./(1997), Nr. 23 und 24, S. 738.

193 Vgl. Hessisches Finanzgericht (1996), a.a.O., S. 46ff. Vgl. hierzu auch Wied. E. (1997): Dividendenstripping, Kommentierte Finanzrechtsprechung (KFR), Oktober 1997, S. 309. Der BFH hat in einem Gerichtsbescheid vom 17.11.1998 festgestellt, daß allein An- und Verkäufe um den Dividendenstichtag nicht rechtsmißbräuchlich auszulegen sei, vgl. o Verf. (1998): Kapitalmarkt / Grundsatzentscheidung des Bundesfinanzhofs "Dividendenstripping kein Rechtsmißbrauch, in: Handelsblatt vom 23.11.1998, S. 25. Nach telefonischer Auskunft beim BFH vom 24.03.1999 ist dieser Gerichtsbescheid z.Z.allerdings ohne rechtliche Wirkung, da ein endgültiges BFH-Urteil in Sachen Dividendenstripping noch aussteht. Da der BFH z.Z. noch auf eine Stellungnahme des Bundesministeriums der Finanzen wartet, ist mit einem Urteil über die Recht- oder Unrechtmäßigkeit von Dividendenstripping fruhestens im zweiten Halbjahr 1999 zu rechnen. 
Allerdings kam $\S 39 \mathrm{KStG}$ nur zur Anwendung, wenn der Nichtanrechnungsberechtigte einen wirtschaftlichen Einfluß in seiner Gesellschaft ausüben konnte, das heißt, wenn er wesentlich an einer inländischen Kapitalgesellschaft beteiligt war oder wenn er zu einem Zeitpunkt innerhalb der letzten fünf Jahre vor Veräußerung Anteile zum Nennwert von mehr als einer Million DM besessen hatte ${ }^{194}$. Eine weitere Vorausetzung war, daß die Veräußerungsgewinne des Nichtanrechnungsberechtigten im Inland - z.B. aufgrund eines DBA - nicht steuerpflichtig waren ${ }^{195}$.

Das Anrechnungsverbot griff allerdings nicht direkt bei der Besteuerung des Anteilkäufers, indem dessen Anrechnungsanspruch beseitigt wurde, sondern indirekt bei der Gesellschaft, deren Anteile veräußert wurden. Lagen die genannten Voraussetzungen vor, so sorgte die Vorschrift dafür, daß die Körperschaftsteuer auf den im Kaufpreis für offene und stille Reserven vergüteten Betrag definitiv wurde. Praktisch erfolgte eine Besteuerung der im Kaufpreis bezahlten Rücklagen, soweit sie anteilig auf den anrechnungsberechtigten Erwerber entfielen ${ }^{196}$.

Technisch wurde dies mit einer Kapitalumgliederung in der Buchführung der Kapitalgesellschaft erreicht: Die Kapitalgesellschaft hatte das für Ausschüttungen verwendbare Eigenkapital so zu gliedern, als ob der Erwerber in dieser Höhe eine Einlage geleistet hätte ${ }^{197}$ (sog. Einlagenfiktion). Mit anderen Worten: Das für Ausschüttungen verwendbare Eigenkapital wurde, soweit es der vom Erwerber übernommenen Beteiligung anteilig entsprach, steuerlich als Nennkapital behandelt. Die Kapitalgesellschaft hatte eine Umgliederung ins EK 04 vorzunehmen ${ }^{198}$. Folglich wurden Gewinnausschüttungen an den Erwerber steuerlich wie Rückzahlung von Nennkapital behandelt ${ }^{199}$. Für die Kapitalgesellschaft entfiel damit die Herstellung der Ausschüttungsbelastung nach $\S 27 \mathrm{Abs} .1 \mathrm{KStG}$, die betroffenen Anteile der erzielten Gewinne konnten bei Ausschüttung nicht von einer Körperschaftsteuerbelastung von damals $56 \%$ auf den damaligen Ausschüttungssatz

194 Vgl. § 39 Abs. 2 KStG (aufgehoben durch ÄndG. vom 20.8.1980).

195 Vgl. § 39 Abs. 1 KStG (aufgehoben durch ÄndG. vom 20.8.1980).

196 Vgl. Frotscher, G. (1994b): Kommentar zum EStG, zu § 50c EStG, in: Frotscher, G. (Hrsg.): EStG Praxis Kommentar, Freiburg, S. 5f., Rz. 4.

197 Vgl. § 39 Abs. $3 \mathrm{KStG}$ (aufgehoben durch ÄndG. vom 20.8.1980).

198 Nach $\S 30$ Abs. 2 Nr. 4 KStG.

199 Vgl. Krebs, H.-J.(1980): Änderungen des Körperschaftsteuerrechts, in: Betriebs-Berater (BB), 35. Jg./(1980), Nr. 24, S. 1258. 
von $36 \%$ herabgeschleust werden ${ }^{200}$. In der Folge entfielen dann bei allen Anteilseignern die Anrechnung dieses Körperschaftsteuerbetrages, da die Einlagenfiktion dazu führte, daß im betroffenem Umfang keine anrechenbaren Dividenden anfie$\mathrm{len}^{201}$. Die Regelung traf also das gesamte sogenannte Ausschüttungspotential der Kapitalgesellschaft. Immer dann, wenn "zuviel" EK 56 vorhanden war, nämlich mehr als 79,2\% des Bestandes an EK 01 bis EK 03, wurden automatisch alle Anteilseigner getroffen ${ }^{202}$.

Ökonomisch betrachtet wurde damit zwar den Nichtanrechnungsberechtigten die Körperschaftsteueranrechnung verwehrt, denn diese konnten keinen Verkauf von Anrechnungsguthaben erzielen; die Steuerlast trugen aber alle Anteilseigner, sofern kein Ausgleich zwischen den am Veräußerungsgeschäft unbeteiligten Gesellschaftern und dem Anteilserwerber erfolgte.

Umgekehrt konnte die Wirkung des $\S 39 \mathrm{KStG}$ natürlich auch vorteilhaft sein: Wurden nämlich nicht mit Körperschaftsteuer belastete Eigenkapitalanteile, z.B. EK 01, in das EK 04 umgegliedert, und galt der umgegliederte Teilbetrag für die Ausschüttung verwendet, so trat bei der Gesellschaft keine Körperschaftsteuererhöhung ein ${ }^{203}$. Beim Erwerber fiel keine weitere Besteuerung an, damit wurde de facto eine Steuerbefreiung von der Gesellschaftsebene an die Anteilseignerebene durchgeleitet ${ }^{204}$.

Der Gesetzgeber wollte mit der Einführung von $\S 39 \mathrm{KStG}$ verhindern, daß der nichtanrechnungsberechtigte Veräußerer die tatsächliche oder potentielle Körperschaftsteuerbelastung auf Rücklagen als Wertfaktor in den Verkaufspreis einkalkuliert, da für den Erwerber die Körperschaftsteuerbelastung quasi einen Vermögensgegenstand darstellt ${ }^{205}$.

200 Vgl. Koch, K. (1980): Verbot ausschüttungsbedingter Teilwertabschreibungen und ausschüttungsbedingter Veräußerungsverluste - 50c EStG -, Deutsche Steuer-Zeitung (DStZ), 68. Jg./ (1980), Nr. 18, S. 339.

$201 \S 20$ Abs. 1 Nr. 1 EStG qualifiziert Zahlungen aus dem Nennkapital (EK 04) nicht als Einkommen aus Kapitalvermögen.

202 Borggräfe, J. (1979), Steuerrecht zwischen verfassungswidriger Konzeption und gesetzeswidriger Anwendung - Eine Stellungnahme zur Änderung des $\S 39 \mathrm{KStG}$-, in: Der Betrieb (DB), 32. Jg./(1979), Nr. 19, S. 910.

203 Für EK 01 muß erst seit 1994 keine Ausschüttungsbelastung mehr hergestellt werden.

204 Vgl. Krebs, H.-J. (1980), a.a.O., S. 1259.

Vgl. Streck, M. (1997), Körperschaftsteuergesetz, 5. Aufl., § 39 Anm. 1, S. 513. 
Ohne diese Regelung hätte sich der Nichtanrechnungsberechtigte im Fall des Verkaufs vor Gewinnausschüttung die Körperschaftsteuer durch einen entsprechenden Aufschlag auf den Verkaufpreis zurückholen können ${ }^{206}$, also auch Dividendenstripping betreiben können. Tatsächlich hätte die Regelung Strippinggeschäfte aber nur dann verhindern können, wenn durch Ausgleichsverträge zwischen den Gesellschaftern immer sichergestellt wird, daß allein der Erwerber die Last aus der Einlagenfiktion trägt.

Aufgrund der Tatsache, daß die Regelung auf der Gesellschaftsebene griff, und folglich nicht allein den Erwerber sondern alle Anteilseigner betraf, ergaben sich also vielfältige Mängel, die dazu führten, daß das Gesetz nur sehr kurzlebig war:

\subsubsection{Ursachen für das Scheitern des Anrechnungsverbots}

\subsection{Unerwünschte Verletzung der Akquisitionsneutralität}

Auch wenn die Regelung des $\S 39 \mathrm{KStG}$ einem Anrechnungsverbot entsprach, so wirkte sich die Vorschrift für die Gesellschaft insgesamt gewinnmindernd aus. Zwar richtete sich der Übertrag ins EK 04 im Umfang danach, welche Beteiligungen ein Anrechnungsberechtigter von einem Nichtanrechnungsberechtigten erworben hatte, die verbotene Herstellung der Ausschüttungsbelastung traf aber, wie eben dargestellt, natürlich die Kapitalgesellschaft insgesamt. Man kann deswegen von einer falschen Wirkungsebene der Regelung sprechen. Korrekt wäre ein Anrechnungsausschluß auf der Gesellschafterebene gewesen. So aber waren alle Gesellschafter entsprechend ihrer Beteiligungsquote von den Gesetzesauswirkungen betroffen, unabhängig von ihrer Berechtigung zur Anrechnung, unabhängig von ihrem Einfluß in der Gesellschaft und unabhängig davon, ob sie selbst Anteile von Nichtanrechnungsberechtigten erworben hatten oder nicht.

Aus steuerlichen Gründen wurde so die rechtliche Trennung zwischen der juristischen Person der Kapitalgesellschaft und der natürlichen bzw. juristischen Person des Anteilseigners aufgehoben: Die Besteuerung der Kapitalgesellschaft war abhängig vom Steuerstatus der Anteilseigner. Dies muß man aus ökonomischer Sicht nicht zwangsläufig negativ beurteilen, schließlich entspricht die Aufhebung des Trennungsprinzips auch der Idee der vollständigen Integration. Problematisch ist eher die unterschiedliche steuerliche Behandlung des Erwerbs von Beteiligungen von Anrechnungs- und von Nichtanrechnungsberechtigten: Zusammensetzung

206 Vgl. Littmann, E. (1981): Besteuerung von Gewinnausschuttungen an Anteilseigner nach Erwerb von einem nicht anrechnungsberechtigten Anteilseigner - $\S 50 \mathrm{c} \mathrm{EStG}$, in: Deutsche Steuer-Zeitung (DStZ), 69. Jg./(1981), Nr. 17, S. 355. 
und Veränderungen der Zusammensetzung der Anteilseigner an einer Kapitalgesellschaft wirkten sich nach $\S 39 \mathrm{KStG}$ unmittelbar auf das Ergebnis dieser Gesellschaft nach Steuern aus. Entsprechend entstanden zivilrechtliche Ausgleichsansprüche der Altgesellschafter gegenüber den Anteilserwerbern von Nichtanrechnungsberechtigten ${ }^{207}$. Solche zivilrechtlichen Ausgleichsansprüche könnte man zwar als Internalisierung der Steuerkosten auf den Verursacher (anrechnungsberechtigter Käufer) positiv bewerten, aber die Durchsetzung solcher Ausgleichsansprüche dürfte wohl schwierig gewesen sein oder muß zumindest abschreckend für inländische Erwerber gewirkt haben, denn $\S 39 \mathrm{KStG}$ führte in manchen Fällen dazu, daß sich Steuerinländer nicht mehr an deutschen Kapitalgesellschaften beteiligten ${ }^{208}$, bzw. das Anteile von Nichtanrechnungsberechtigten möglichst nur an Nichtanrechnungsberechtigte weiterveräußert wurden. Damit verstieß die Regelung aber gegen die Akquisitionsneutralität: Das Beteiligungskapital von Nichtanrechnungsberechtigten befand sich sozusagen in einer Steuerfalle. Die Anteilseigner hatten ein steuerinduziertes Interesse daran, daß sich möglichst alle Beteiligungen ihrer Gesellschaft von vornherein in anrechnungsberechtigten Händen befanden bzw. daß keine (Rück-)Erwerbungen aus dem Ausland erfolgten $^{209}$. Insoweit wirkte $\S 39 \mathrm{KStG}$ prohibitiv auf grenzüberschreitende Beteiligungsübertragungen, die Regel trug folglich zu einer ineffzienten internationalen Kapitalallokation bei. Steuersystematisch korrekt wäre allein eine Gewährleistung des Anrechnungsausschlusses auf der Ebene der Gesellschafter.

Dieselben Wirkungen stellten sich im Veräußerungsfall von nichtanrechnungsberechtigten Steuerinländern ein. Folglich war schon die inländische Kapitalallokation gestört.

\subsection{Unerfüllbarkeit des Gesetzes}

$\S 39 \mathrm{KStG}$ galt - wie dargestellt - ausnahmslos, also auch für Börsengeschäfte. Obwohl schon die damalige Gesetzesbegründung einen Hinweis auf die fehlende Nachprüfbarkeit bei Börsengeschäften enthielt ${ }^{210}$, wollte der Gesetzgeber (noch) nicht grundsätzlich Börsengeschäfte ausschließen. Die Regelung galt aber nur,

207 Vgl. Jebens, (o.Vorn.) (1980): Kommentar zum 50c EStG, Nachtrag Nr. 50, November 1980, in: Lademann, Soffing, Brockhoff: Kommentar zum Einkommensteuergesetz, S. 6, Rz. 3.

Vgl. Sorgenfrei, U. (1997a), a.a.O., S. 3.

Vgl. Krebs, H.-J. (1980), a.a.O., S. 1259.

Vgl. BT-Drs. 7/1470, S. 375. 
wenn der nichtanrechnungsberechtigte Veräußerer zu einem Zeitpunkt innerhalb der letzten fün Jahre vor Anteilsveräußerung eine wesentliche Beteiligung gehalten hatte oder mit einem Nennbetrag an der Kapitalgesellschaft beteiligt war, der eine Million DM überstieg. Probleme bereitete dies schon deswegen, weil die betroffene Kapitalgesellschaft nicht immer Kenntnis von einer Veräußerung erhielt, die sie zu einer EK-Umgliederung verpflichtete. Da bis heute nur eine gesetzliche Meldepflicht ${ }^{211}$ für den Erwerb wesentlicher Beteiligungen besteht $t^{212}$, nicht aber für Fälle, in denen ein Anteilseigner Beteiligungen in Höhe von mehr als einer Million DM hält, die noch keine wesentliche Beteiligung ausmachen, konnte eine Kapitalgesellschaft der Verpflichtung zur Kapitalumgliederung nicht in allen Veräußerungsfällen folgen ${ }^{213}$. Schon damals erkannte man zudem als weiteres Problem des $\S 39 \mathrm{KStG}$, daß bei einem Erwerb über die Börse in vielen Fällen nicht feststellbar ist, ob der Veräußerer ein Nichtanrechnungsberechtigter ist ${ }^{214}$.

Die Begrenzung auf wirtschaftlich einflußreiche nichtanrechnungsberechtigte Veräußerer erfolgte deswegen, weil der Gesetzgeber sicherstellen wollte, daß nur Veräußerer getroffen werden, die Einfluß auf den Verkaufspreis ihrer Beteiligungen und damit auf die Aufteilung des Anrechnungsguthabens ausüben konnten. Mit einer solchen Begrenzung bleiben aber die erst viel später aufgedeckten Fälle des Dividendenstripping fast durchgehend unverfolgt, da sich diese Steuerumgehung gerade für nicht wesentlich Beteiligte aufgrund des Fehlens einer inländischen Veräußerungsgewinnbesteuerung lohnt.

\subsection{Umgehbarkeit des Anrechnungsverbots}

Zusätzlich problematisch erwies sich die relativ leichte Umgehbarkeit des Anrechnungsverbots. Zum einen sah $\S 39 \mathrm{KStG}$ eine Bagatellgrenze in Höhe von 100.000 DM vor. Eine Veräußerung an mehrere Anrechnungsberechtigte, die pro Veranlagungsjahr diesen Betrag nicht überschritt, löste keine § $39 \mathrm{KStG}$ Wirkungen aus.

211 Vgl. § 20 AktG.

212 Beteiligungen in Höhe von mehr als $25 \%$ des Gesamtkapitals (Rechtslage vor dem 01.04.1999).

213 In der Praxis erfolgten Umgliederungen bei Aktiengesellschaften daher nur in bedeutsamen Fallen, wenn wesentlich beteiligte Nichtanrechnungsberechtigte an Anrechnungsberechtigte veräußerten. Vgl. Sø̈ffing, G. / Wrede, F. (1980): Das Gesetz zur Änderung des EStG, des KStG und anderer Gesetze (Teil II), in: Finanz-Rundschau, 35. (62.) Jg./(1980), Nr. 17 , S. 399.

214 Vgl. Borggräfe, J. (1979), a.a.O., S. 912. 
Diese Tatsache regte Vereinbarungen an, die eine allmähliche Übernahme von Gesellschaftsanteilen in jährlichen Staffelungen über mehrere Personen vorsahen $^{215}$. Bezüglich des Dividendenstripping kann festgehalten werden, daß eine geschickte vielfache Nutzung der Bagatellgrenze Stripping-Geschäfte auch für wesentlich Beteiligte im großen Umfang steuerunschädlich ermöglicht hätte. Zum anderen ließ sich die Regelung, die wesentlich Beteiligte traf, durch Aufteilung der Beteiligungen umgehen. Bei Veräußerung eines Unternehmens verkaufte der Nichtanrechnungsberechtigte zuerst an vier oder fün Nichtanrechnungsberechtigte. Dieses Quartett oder Quintett löste bei Weiterveräußerung kein Anrechnungsverbot mehr aus.

Noch bedeutsamer war allerdings die Zwischenschaltung eines Erwerbers in einem Nicht-DBA-Land: Wie erwähnt, setzte die Anwendung des $\S 39 \mathrm{KStG}$ voraus, daß der Gewinn aus der Veräußerung der Anteile im Inland nicht steuerpflichtig war. Folglich war es sinnvoll, die Anteilsverkäufe an Anrechnungsberechtigte über einen Zwischenerwerber in einem Land, mit dem die Bundesrepublik Deutschland kein DBA abgeschlossen hatte, laufen zu lassen ${ }^{216}$. Der in einem DBA-Land ansässige nichtanrechnungsberechtigte Veräußerer übertrug seine Anteile z.B. an eine in Liechtenstein ansässige Gesellschaft. Diese Gesellschaft veräußerte zum gleichen Preis weiter an den anrechnungsberechtigten Erwerber ${ }^{217}$. Der Gewinn des ersten Veräußerers konnte so in Deutschland mangels Steuerzugriff nicht besteuert werden, der zweite Veräußerer erzielte keinen Veräußerungsgewinn mehr, der in Deutschland hätte besteuert werden können, da dieser im ersten Veräußerungsgeschäft bereits abgeschöpft wurde.

Aufgrund der zahlreichen Mängel des $\S 39 \mathrm{KStG}$ ist diese Regelung, die mit der Körperschaftsteuerreform von 1977 in Kraft trat, schon 1980 aufgehoben wor$\operatorname{den}^{218}$. Der Gesetzgeber reagierte mit einer Neuregelung, die zeitgleich mit der Abschaffung des $\S 39 \mathrm{KStG}$ gültig wurde. Somit gab es durchgängig Spezialvorschriften zur Bekämpfung der Weitergabe von Anrechnungsguthaben an Nichtanrechnungsberechtigte ${ }^{219}$.

215 Vgl. Borggrăfe, J. (1979), a.a.O., S. 913.

216 Vgl. Littmann, E. (1981), a.a.O., S. 356, Dötsch, E. (1980), a.a.O., S. 1562.

217 Vgl. BT-Drs. 8/3648, S. 23.

218 Vgl. BGBl. I 1980, S.1545, BStBl. I 1980, S.589.

219 Vgl. Koch, K. (1980), a.a.O., S. 341. 
Das Anrechnungsverbot des $\S 39 \mathrm{KStG}$ führte allokativ zu unerwünschten Verzerrungen und erwies sich insbesondere für Aktiengesellschaften als unpraktikabel und leicht vermeidbar. Ein Dividendenstripping von nicht wesentlich Beteiligten wäre von dieser Regelung überhaupt nicht erfaßt worden. Ein Dividendenstripping eines wesentlich beteiligten Anteilseigners wäre zu Lasten aller übrigen Anteilseigner der Gesellschafter steuerlich bestaft worden, da sich der ausgeschüttete Gewinn einer Kapitalgesellschaft insgesamt gemindert hätte. Allerdings hätten auch wesentlich Beteiligte durch geschickte Ausnutzung der Bagatellgrenze oder Zwischenschaltung eines Strohmannes in einem Nicht-DBA-Land das Anrechnungsverbot relativ einfach umgehen können.

\subsubsection{Gesetzliche Maßnahmen gegen die Weitergabe von Anrechnungs- guthaben auf der Gesellschafterebene im Zeitraum 1980 - 1993}

\subsubsection{Verweigerung der Berücksichtigung ausschüttungsbedingter Ge- winnminderungen}

Seit 1980 erfolgt die gesetzliche Bekämpfung der Anrechnungsumgehung nicht mehr bei der Kapitalgesellschaft sondern beim erwerbenden Anteilseigner. Wirtschaftlich soll dagegen der Veräußerer getroffen werden.

Der andere Ansatzpunkt der Nachfolgeregelung des $\S 39 \mathrm{KStG}$ deutet sich auch dadurch an, daß sie nicht mehr im Körperschaftsteuergesetz erscheint, sondern im Einkommensteuergesetz steht: Es handelt sich um den § 50c EStG. Die Verhältnisse der Kapitalgesellschaft, deren Anteil ein Nichtanrechnungsberechtigter veräußert, werden durch den $\S 50 \mathrm{c}$ EStG nicht mehr direkt tangiert. Damit werden steuerliche Auswirkungen bei Gesellschaftern vermieden, die gar nicht am Veräußerungsgeschäft beteiligt sind.

Ebenfalls unberücksichtigt bleibt die Besteuerung des veräußernden Nichtanrechnungsberechtigten. So ist es für die Anwendung des § 50c EStG auch nicht erforderlich, daß der Gewinn des Nichtanrechnungsberechtigten im Inland steuerfrei bleibt. Eine solche Vorbedingung war im $\S 39 \mathrm{KStG}$ noch enthalten gewesen. Aus ihrer Abschaffung kann sich eine Doppelbelastung folglich immer dann ergeben, wenn der Veräußerungsgewinn im Inland (doch) besteuert wird ${ }^{220}$. Allerdings sind

220 Im Nicht-DBA-Fall bzw. in wenigen DBA, die vom OECD-MA abweichen. 
die Finanzämter gehalten, derartige ökonomische Doppelbesteuerungen durch sogenannte Billigkeitsmaßnahmen zu berücksichtigen ${ }^{221}$.

Dem erwerbenden Anteilseigner wird die Vereinnahmung des Steuerguthabens mit einer steuerlichen Nichtanerkennung ausschüttungsbedingter Teilwertabschreibungen oder von Verlusten aus einer Weiterveräußerung bzw. eine Entnahme von Anteilen aus einem Betriebsvermögen des anrechnungsberechtigten Erwerbers verwehrt, sofern diese Anteile zuvor von Nichtanrechnungsberechtigten erworben worden sind ${ }^{222}$. Diese Nichtanerkennung gilt für das Jahr des Erwerbs sowie in den nachfolgenden neun Jahren. Technisch gesehen wird die Nichtanerkennung durch einen Sperrbetrag gewährleistet ${ }^{223}$, der verhindert, daß die ausschüttungsbedingten Wertminderungen der Anteilspapiere ertragsteuerlich berücksichtigt werden.

Bis 1997 zielte der $\S 50$ c EStG allein darauf, eine Vereinnahmung des Steuerguthabens und stiller Reserven durch den nichtanrechnungsberechtigten Anteilseigner über die Preissetzung bei der Anteilsveräußerung zu verhindern ${ }^{24}$.

Der Sperrbetrag, der diesem Zweck dient, ist der Unterschiedsbetrag zwischen Nennbetrag der erworbenen Anteile und den Anschaffungskosten ${ }^{225}$. Er entspricht

221 Diese inländische Doppelbelastung ist vom Gesetzgeber nicht unbedingt gewollt, daher kommt in diesen Fällen eine sogenannte Billigkeitsmaßnahme nach $\S 163 \mathrm{AO}$ in Betracht, wonach z.B. eine Sperrbetragsminderung um den Betrag erfolgt, den der Nichtanrechnungsberechtigte im Inland versteuert hat. Vgl. Ülner, A. (1994): Wertminderung von Anteilen durch Gewinnausschüttung, Kommentar zum § 50c EStG, Erg.-Lfg. Nr. 48, Oktober 1994, in: Blumich (Hrsg.): Einkommensteuergesetz, Körperschaftsteuergesetz, Gewerbesteuergesetz Kommentar, München 1997, S. 7, Rz. 11. Es sind auch Billigkeitsmaßnahmen vorgesehen für den Fall, daß der nichtanrechnungsberechtigte Veraußerer seine Anteile zuvor von einem Anrechnungsberechtigten erworben hat und die stillen Reserven beim Erwerb der inländischen Besteuerung von Verăußerungsgewinnen unterlegen haben, vgl. BRDrs. 11/79 S. 23.

222 Eine Unterbindung des Anrechnungshandels uber die Verwehrung einer Teilwertabschreibung wurde schon 1972 von Thiel und Schad vorgeschlagen. Vgl. Thiel, R. / Schad. H.J.(1972), a.a.O., S. 501 f.

223 Vgl. § 50c Abs. 4 EStG.

224 Vgl. Rabald, B. (1986): Zur Berulcksichtigung von Steuerguthaben beim Erwerb nichtnotierter Anteile, in: Die Wirtschaftsprufung (Wpg), 39.Jg./(1986), Nr. 1, S.14.

225 Liegen keine Anschaffungskosten vor, so behilft man sich mit den Anschaffungskosten des Rechtsvorgăngers in den Fällen einer Einlage in ein Betriebsvermögen des Erwerbers oder einer nicht betrieblich veranlaßten unentgeltlichen Übertragung in das Privatvermögen des Erwerbers; vgl. § 50c Abs. 4 Satz 2 i. V. m. § 6 Abs. 1 Nr. 5 EStG, § 17 EStG, §§ 7 Abs. 2, $11 \mathrm{~d}$ EStDV. 
den im Kaufpreis mitbezahlten offenen und stillen Reserven der Kapitalgesellschaft $^{226}$.

Aufgrund des Sperrbetrags kann der Erwerber die ihm zufließenden Gewinne der Kapitalgesellschaft nicht mehr steuerlich neutralisieren. Für das Wirksamwerden des Sperrbetrags war in der ersten Fassung des $\S 50 \mathrm{c}$ EStG einzig entscheidend, daß ein Übergang von einer Nichtanrechnungsberechtigung zu einer Anrechnungsberechtigung stattfindet. Dieser Übergang kann durch eine Veräußerung erfolgen ${ }^{227}$ oder - nachträglich - durch eine Einlage der Anteile des beschränkt Steuerpflichtigen in ein inländisches Betriebsvermögen ${ }^{228}$. Nur im Vererbungsfall fällt kein Sperrbetrag $a^{229}$, hier wird der Verdacht auf Gestaltungsmißbrauch grundsätzlich ausgeschlossen ${ }^{230}$. Bedeutend ist, daß der Sperrbetrag des $\S 50 \mathrm{c} \mathrm{EStG} \mathrm{un-}$ abhängig davon ist, ob ein bewußter Mißbrauch des Veräußerers vorliegt.

Auch eine Kapitalherabsetzung nach vorheriger Erhöhung aus Gesellschaftsmitteln ist ein Fall des $\S 50 \mathrm{c} \mathrm{EStG}{ }^{231}$, da sich andernfalls durch eine Einstellung der Nennbetrag (vorübergehend) erhöhen und zu einem niedrigeren Sperrbetrag führen würde.

Die Liquidation der Kapitalgesellschaft könnte nach einem Übergang der Anteile vom Nichtanrechnungsberechtigten zum anrechnungsberechtigten Erwerber zur Wertrealisierung genutzt werden. Auch hier hat der Gesetzgeber einen Riegel vorgeschoben $^{232}$. Der Sperrbetrag (soweit nicht schon vorher aufgebraucht) ist während der neunjährigen Sperrfrist nach Anteilserwerb durch den Anrechnungsberechtigten gewinnerhöhend zu berücksichtigen.

226 Die Einbeziehung der stillen Reserven war schon aus praktischen Gründen nötig: Sie befreit das Finanzamt von dem Problem der Ermittlung dieser Reserven zwecks einer potentiellen Abzugs vom Sperrbetrag. Der Sperrbetrag kann so in der Regel vom Finanzamt ohne Analyse der Unterlagen einer Kapitalgesellschaft ermittelt werden.

227 Vgl. § 50c Abs. 1 EstG.

$228 \mathrm{Vgl}$ § 50c Abs. 6 EStG.

229 Vgl. § 50c Abs. 1, Satz 2 EStG; fur Schenkungen gilt diese Ausnahme nicht.

230 Vgl. Krebs, H.-J.(1980), a.a.O., S. 1260.

231 Vgl. $\S 50$ c Abs. 2 EStG.

232 Vgl. § 50c Abs. 3 EStG. 
Ferner sind auch Rechtsnachfolger des ersten anrechnungsberechtigten Erwerbers von der Regelung betroffen, andernfalls könnte ein Kettengeschäft mit einem zwischengeschalteten Steuerinländer die Regelung aushebeln ${ }^{233}$.

$\S 50 \mathrm{c} \mathrm{EStG}$ führt beim Erwerber zur Besteuerung der stillen Reserven und des im Erwerbspreis vergüteten Anrechnungsguthabens in Höhe seines individuellen Steuersatzes. Wenn der Erwerber aber die Ausschüttung und das hierauf entfallende Anrechnungsguthaben versteuern muß, wird er grundsätzlich nicht mehr bereit sein, dem Veräußerer im Kaufpreis das Steuerguthaben mitzuvergüten. Damit schießt der $\S 50 \mathrm{c}$ EStG über das Ziel einer Weitergabe allein des Anrechnungsguthabens hinaus, weil beim Erwerber der Sperrbetrag eine Steuerpflicht in Höhe seines persönlichen Einkommensteuersatzes auslöst. Im Fall eines ausländischen Anteilseigners, der der 30\%igen Definitivbelstung durch die Körperschaftsteuer per Dividendenstripping ausweichen will, wird der inländische Geschäftspartner häufig stärker besteuert, als es die Sicherstellung der sogenannten Einmalbesteuerung ins Ausland ausgeschütteter Gewinne rechtfertigen könnte.

\subsubsection{Methoden zur Rettung der Teilwertabschreibungen}

Die erste Fassung des $\S 50 \mathrm{c}$ EStG enthielt zwei Ausnahmen. Bis heute gültig ist die sogenannte Bagatellgrenze, nach der Geschäfte unter einem Volumen von 100.000 DM von der Regelung unberührt bleiben.

Die Bagatellgrenze des $\S 50 \mathrm{c} \mathrm{EStG}$ bereitet damit ähnliche Probleme wie im Fall des Anrechnungsverbots nach $\S 39 \mathrm{KStG}$. So sind bei der Übernahme von Gesellschaftsanteilen zeitliche Staffelungen denkbar ${ }^{234}$, die keinen Sperrbetrag auslösen. Gestaltungsmöglichkeiten, die diese Grenze ausnutzen, werden allenfalls durch die allgemeine Gestaltungsmißbrauchsvorschrift des $\S 42 \mathrm{AO}$ beschränkt ${ }^{235}$. Eine wirtschaftliche Begründung für eine allmähliche Beteiligungsübernahme dürfte den Betroffenen aber nicht allzu schwer fallen.

Auch eine personelle Gestaltung zur Ausnutzung der Bagatellgrenze ist nach herrschender Meinung möglich. Da ein mittelbarer Erwerb hier einem unmittelbaren Erwerb nicht gleichgestellt ist, bietet sich auch bei Ausnutzung der Bagatellgrenze eine sogenannte "Quartettlösung" ("Quintettlösung") an, indem der Erwerber bei

233 Vgl. § 50c Abs. 7 EStG a.F. und § 50c Abs. 8 EStG n.F.

234 Vgl. Frotscher, G. (1994b), a.a.O., S. 41, Rz. 56.; anders Söffing, G. / Wrede, F. (1980), a.a.O., S. 399. 
einem Anteilserwerb von 400.000 DM (500.000 DM) in Gestalt von vier (fün) Tochtergesellschaften auftritt ${ }^{236}$. Es ist aber fraglich, ob sich dieser Aufwand überhaupt lohnt ${ }^{237}$.

Für das Dividendenstripping bedeutender ist die zweite Ausnahme, die nur bis 1993 gültig war. Danach waren typische Börsengeschäfte von der Regelung ausgenommen. Wörtlich hieß es in § 50c Abs. 8 Satz 2 EStG:

"Hat der Erwerber die Anteile über ein Kreditinstitut erworben, das den Kaufauftrag über die Börse ausgeführt hat, sind die Absätze 1 bis 7 nicht anzuwenden."

Diese sogenannte Börsenklausel war offenbar das Ergebnis der festgestellten mangelnden Durchsetzbarkeit des $\S 39 \mathrm{KStG}$ aufgrund der Börsenanonymität ${ }^{238}$. Die Legislative ging davon aus, daß sich bei Börsengeschäften regelmäßig nicht ermitteln läßt, ob ein Anteil von einem anrechnungsberechtigten oder einem nichtanrechnungsberechtigten Anteilseigner erworben wurde, und daß folglich eine Regelung wie der $\S 50 \mathrm{c}$ EStG bei Börsengeschäften nicht durchführbar sei ${ }^{239}$. Ganz offensichtlich habe sich der Gesetzgeber an dieser Stelle "gründlich verschätzt", wie Dötsch betont ${ }^{240}$.

Gerade im Rahmen der Diskussion um die Verschärfung der Börsenklausel in den Jahren 1993 und 1994 wurde deutlich, daß die alte Börsenklausel oft zu weit ausgelegt wurde. Offenbar war es herrschende Meinung, daß die alte Börsenklausel alle Börsengeschäfte aus dem Anwendungsbereich des $\S 50 \mathrm{c} \mathrm{EStG}$ ausnahm. ${ }^{241}$ Der Gesetzgeber wollte aber schon mit der alten Börsenklausel nur eine Nichtanwendung des $\S 50 \mathrm{c} \mathrm{EStG}$ für typische Börsengeschäfte sicherstellen ${ }^{242}$.

236 Weber-Grellet hălt diese Gesatltung zwar fur bedenklich, aber für praktikabel. Vgl. WeberGrellet, H(1998): Wertminderungen von Anteilen durch Gewinnausschüttungen, in: Schmidt, L. (Hrsg.): Einkommensteuergesetz Kommentar, 17. Aufl., zu 50c EStG, S. 2242, Rz. 66.

237 Vgl. Dotsch, E (1996), a.a.O., S. 1132/35 Rz. 143.

238 Vgl. BT-Drs. 7/1470, S.375; Borggrăfe, J.(1979), a.a.O., S. 912.

239 Vgl. BT-Drs. 8/3648, S. 24; Littmann, E. (1981), a.a.O., S. 360.

240 Vgl. Dötsch, E. (1996), a.a.O., S. 1132/35.

241 Vgl. Bippus, B.E. (1994), a.a.O., S. 954; Krawitz, N. (1994), a.a.O., S. 887; Dotsch, E. (1980), a.a.O., S. 1563f.

Vgl. BT-Drs. 12/5016, S. 90. 
Aus dem Wortlaut der alten Börsenklausel geht deutlich hervor, daß der Gesetzgeber die Börsenanonymität erst dann als ausreichend gewährleistet ansah, wenn sie auch das Bankgeheimnis begleitete, dem Kreditinstitute verpflichtet sind. Damit ist klar, daß die alte Börsenklausel zwar für die üblichen Kommissionsgeschäfte galt, die Banken für ihre Kunden ausüben, nicht jedoch für Geschäfte in eigener Rechnung. Eher indirekt kann man aus der Formulierung der alten Börsenklausel schließen, daß es gleichfalls bedeutend ist, von wem die Initiative eines Geschäftes ausgeht.

Auch das Hessische Finanzgericht machte in seinem Urteil zum Dividendenstripping vom 2.12.1996 eine entsprechende Gesetzesauslegung geltend und betonte, daß für Erwerber, die selbst im Aktienhandel tätig sind, keine typische Börsenanonymität bestehe ${ }^{243}$. Dies gelte erst recht, wenn die Initiative zum Geschäft von beteiligten Kreditinstituten ausgehe, die auf der Veräußerungsseite ständen ${ }^{244}$.

Tatsächlich scheint in vielen Fällen von Dividendenstripping die Initiative von Kreditinstituten ausgegangen zu sein, hinter denen nichtanrechnungsberechtigte Anteilseigner standen. Auf diese aktive Rolle der Kreditinstitute lassen auch Nachforschungen des Finanzministeriums Hessen schließen.

Die früher vorherrschende Ansicht, daß Börsengeschäfte generell vom § 50c EStG ausgenommen seien, scheint nicht selten die Rechtsformwahl der Investoren beeinflußt zu haben: Besaß ein Nichtanrechnungsberechtigter eine $\mathrm{GmbH}$, so lohnte sich vor einer Anteilsveräußerung eine Umwandlung in eine Aktiengesellschaft. Zur Vermeidung des ebenfalls noch zu beachtenden $\S 42 \mathrm{AO}$ reichte die Erklärung eines wirtschaftlichen Zwecks, z.B. daß der nichtanrechnungsberechtigte Veräußerer davon ausgegangen sei, nur an der Börse Kaufinteressenten zu finden ${ }^{245} . J e-$ bens betont, daß auch ein erfolgreicher Nachweis, daß Kaufinteressenten ausdrücklich eine Freistellung von Wirkungen des $\S 50 \mathrm{c}$ EStG eingefordert hatten und nichtanrechnungsberechtigte Aktionäre deswegen ihre Anteile über die Börse veräußerten, noch keinen Gestaltungsmißbrauch beweise, weil immer noch die theoretische Gefahr einer Aktienpaketzersplitterung bestände ${ }^{246}$. Es wird deutlich, daß eine Durchsetzung des mit der alten Börsenklausel verfolgten Ziels eine klarstellende Neuformulierung erforderte. Die Aufdeckung vieler Stripping-Geschäfte Anfang der neunziger Jahre sorgte dabei für den nötigen Handlungsdruck. Damals

\footnotetext{
243 Vgl. Hessisches Finanzgericht (1996), a.a.O., S. $43 \mathrm{ff}$.

244 Vgl. Hessisches Finanzgericht (1996), a.a.O., S. 44.

245 Vgl. Jebens, (o.Vorn.) (1980), a.a.O., S. 10f., Rz. 13.

246 Vgl. Jebens, (o.Vorn.) (1980), a.a.O., S.11f., Rz. 14.
} 
wurde außerdem erkannt, daß die Weitergabe von Anrechnungsguthaben auch ohne Veräußerungsvorgänge - und ohne Teilwertabschreibungen möglich ist.

\subsubsection{Gesetzliche Maßnahmen gegen die Weitergabe von Anrechnungs- guthaben auf der Gesellschafterebene seit 1994}

1994 trat eine neue Börsenklausel in Kraft, die darauf abzielte, auch das Dividendenstripping über die Börse durch ein Verbot der ausschüttungsbedingten Teilwertabschreibung für den anrechnungsberechtigten Erwerber unattraktiv zu machen. Gleichzeitig führte der Gesetzgeber ein Anrechnungsverbot für Dividendenstripping ein, das ohne Veräußerungsvorgänge stattfindet. Beide Maßnahmen sollen in den nächsten beiden Abschnitt vorgestellt werden. Dabei soll vor allem die Wirksamkeit dieser Maßnahmen untersucht werden.

\subsubsection{Unterbindung der Weitergabe von Anrechnungsguthaben seit 1994: Die neue Börsenklausel}

Als der Umfang der Stripping-Geschäfte bekannt wurde, begann man nach einer neuen Börsenklausel zu suchen. Die aus der Erkenntnis der mangelnden Börsenanonymität resultierende Forderung nach vollständiger Streichung der Börsenklausel wurde schnell verworfen, weil man einen gespaltenen Aktienmarkt befürchtete ${ }^{247}$. Ähnlich wie bei $\mathrm{GmbH}$-Anteilen müßte es dann niedrigere Preise für $\S-50$ c-behaftete Beteiligungen geben als für Anteile von Anrechnungsberechtigten.

Ein Gesetzentwurf der Bundesregierung sah dagegen vor, die Börsenklausel so zu formulieren, daß $\S 50 \mathrm{c} \mathrm{EStG}$ nicht auf Erwerber angewendet wird, wenn Anteile über ein Kreditinstitut an der Börse erworben werden und dem Erwerber nicht erkennbar ist, ob der Veräußerer anrechnungsberechtigt ist oder nicht ${ }^{248}$. Eine solche Regelung hätte Anwendungen des $\S 50 \mathrm{c} \mathrm{EStG}$ für anonyme oder scheinbar anonyme Börsengeschäfte ausgeschlossen ${ }^{249}$. Dieser Entwurf wurde zum Teil als Aufforderung zum Dividendenstripping eingeschätzt ${ }^{250}$. Der Haken des Entwurfs

247 Vgl. Dostsch, E. (1996), a.a.O., S. 1132/37.

248 Vgl. BR.-Drs. 368/93 vom 28.05.1993, S. 15.

249 Vgl. Klein, M. (1997), a.a.O., S. 475.

250 Vgl. o.Verf. (1993): Das Dividenden-Stripping wird künftig erleichtert, in: Handelsblatt vom 31.05.1993. 
lag freilich an anderer Stelle: Die Finanzverwaltung wäre verpflichtet gewesen, in jedem fraglichen Fall nachzuweisen, daß dem Erwerber bekannt war, daß er von einem Nichtanrechnungsberechtigten erworben hat. Hauptsächlich aus diesem Grund wurde der Entwurf vom Bundesrat verworfen.

Der Bundesrat forderte statt dessen eine Umkehr der Beweislast. Nicht die Finanzverwaltung sondern der Erwerber sollte glaubhaft machen, daß er die Aktien von einem Anrechnungsberechtigten erworben habe.

Mit dieser Forderung hat sich der Bundesrat im Vermittlungsausschuß durchgesetzt. Das Ergebnis war $\S 50 \mathrm{c}$ Abs. $10 \mathrm{EStG}$. Danach werden bestimmte - näher spezifizierte - Börsengeschäfte von der Ausnahmeregel für Börsengeschäfte ausgenommen, sofern dem Erwerber der Gegenbeweis nicht gelingt, daß er nur von Anrechnungsberechtigten erworben hat.

Der Erwerb über ein Kreditinstitut wird dabei in der konsensfähig gewordenen und in Kraft getretenen neuen Börsenklausel nicht mehr eingefordert. Wörtlich heißt es seit 1994 in $\S 50$ c Abs. 10 EStG:

"Werden Anteile über die Börse erworben, sind die Absätze 1 bis 9 nur anzuwenden...."

Die neue Formulierung spiegelt die Erkenntnis wider, daß der Erwerb über ein Kreditinstitut keineswegs eine Garantie für eine tatsächlich Anonymität des Börsengeschäftes ist.

Die neue Börsenklausel stellt zwar wie die alte Börsenklausel eine Ausnahmeregelung dar und nimmt Börsengeschäfte von den Regelungen des § 50c EStG aus, sie enthält aber einen Katalog von Börsengeschäften, für die diese Ausnahme nicht mehr gilt. Die Festlegung, welche Börsengeschäfte aufgrund eines StrippingVerdachts steuerlich sanktioniert werden, erfolgte nach dem Wissensstand von 1993 über die praktizierten Varianten des Dividendenstripping. Ein Dividendenstripping wird danach vom Gesetzgeber grundsätzlich unterstellt, wenn entweder

“a) zwischen dem Erwerb der Anteile und der Veräußerung dieser oder gleichartiger Anteile nicht mindestens 10 Tage liegen und der Gewinnverwendungsbeschluß der ausschüttenden Kapitalgesellschaft in diesen Zeitraum fällt oder b) die oder gleichartige Anteile unmittelbar oder mittelbar zu Bedingungen rückveräußert werden, die allein oder im Zusammenhang mit anderen Vereinbarungen dazu führen, daß das Kursrisiko begrenzt ist oder 
c) die Gegenleistung für den Erwerb der Anteile ganz oder teilweise in der Verpflichtung zur Übertragung nicht oder nicht voll dividendenberechtigter Aktien besteht..."251

Der Erwerber kann jedoch die Anwendung des $\S 50 \mathrm{c}$ EStG ausschließen, indem er glaubhaft macht, daß der Veräußerer zur Anrechnung berechtigt ist. Läßt man die Möglichkeit dieses Entlastungsbeweises vorerst außer Betracht, so erscheint eine genaue Spezifizierung der Börsengeschäfte, die unter $\S 50 \mathrm{c}$ EStG fallen, zweischneidig.

Mit der Spezifizierung entsteht zwar einerseits Rechtssicherheit für alle Betroffenen, andererseits führt jede Spezifizierung erneut zu Abgrenzungsproblemen, da es nachweislich eine Grauzone von Geschäften gibt, bei denen unklar ist, ob sie unter die Buchstabenfälle der neuen Börsenklausel fallen. Weiterhin werden Geschäfte, die nicht aus steuerlichen Gründen durchgeführt werden aber unter den Fallkatalog des $\S 50 \mathrm{c}$ Abs. 10 EStG fallen, steuerlich bestraft. Hierauf soll im einzelnen eingegangen werden.

\subsection{Vor- und Nachteile der Fristenlösung}

Einerseits erhöht die Zehn-Tage-Frist die Rechtssicherheit für Börsenkontrahenten, die keine Steuerumgehungsabsichten verfolgen, andererseits gilt dies auch für die "Stripper". Ein Ver- und Rückkaufgeschäft über elf Tage bleibt folgenlos. Vielfach wird argumentiert, daß die Frist von zehn Tagen ausreiche, das Kursrisiko derartig unkalkulierbar zu machen, daß eine ungefährdete Aufteilung des Körperschaftsteuerguthabens nicht mehr gewährleistet $\operatorname{sei}^{252}$. Zweifellos ist das Kursrisiko beträchtlich erhöht, dennoch ist es fraglich, ob die Zehn-Tage-Frist regelmäßig das gesamte Anrechnungsguthaben (immerhin 3/7 der Bruttodividende) gefährdet. Hierfür spricht auch die Tatsache, daß eine erste Fassung des $\S 50 \mathrm{c}$ Abs. 10 EStG auf Geschäfte mit einer Frist von dreißig Tagen um den Dividendenstichtag abzielte. Diese im Standortsicherungsgesetz vom 13.9.1993 vorgesehene Frist wurde schon wenig später im Steuermißbrauchsbekämpfungsgesetzes (StMBG) vom 21.12.1993 auf zehn Tage verkürzt. Damit trat die Monatsfrist nie in $\mathrm{Kraft}^{253}$. Offiziell begründete der Gesetzgeber diese Fristverkürzung damit, daß der Erwerb von Aktien auch nach Ablauf von zehn Tagen unter Berücksichtigung des Kursrisikos nicht mehr ausschließlich zur Realsisierung des Steuerguthabens

251 Wortlaut des $\S 50 \mathrm{c}$ Abs. $10 \mathrm{EStG}$.

252 Vgl. Frotscher, G. (1994b), a.a.O., S. 43.

253 Vgl. BR-Drs. 788/93 vom 12.11.1993, Art. 1, S 21. 
erfolge $^{254}$. Tatsächlich waren es vor allem die Bankenverbände, die auf eine Fristverkürzung gedrängt hatten, weil sie in der geplanten Regelung eine Beschränkung des Börsenhandels und eine Schwächung des deutschen Finanzstandortes sahen. Insgesamt scheint bei der Suche nach der "richtigen" Frist eine gewisse Willkür im Spiel gewesen zu sein: Nur eine Woche nach Verabschiedung der 30Tage-Frist führte der Staatssekretär des Bundesministeriums der Finanzen (BMF) aus, daß man auch eine Verkürzung der Frist auf zehn oder sogar fünf Tage akzeptieren könne ${ }^{255}$. Auch die Kritik an der bestehenden 10-Tage-Frist ist bis heute nicht verstummt. Problematisch ist vor allem der pauschalierende Charakter dieser Regelung. So ist es für die Fristenlösung völlig unerheblich, ob an einen Nichtanrechnungsberechtigten oder an einen Anrechnungsberechtigten nach der Ausschüttung weiterveräußert wird ${ }^{256}$, und damit folglich auch, ob überhaupt ein Dividendenstripping zwecks Teilung von Körperschaftsteuerguthaben vorliegt.

Kritisch ist auch die potentielle Beeinflußung der Märkte durch die pauschalierende Fristenlösung zu sehen: Ist dem Aktienerwerber der Entlastungsbeweis nicht möglich, so werden Kaufgeschäfte, die innerhalb von zehn Tagen rückgängig gemacht werden, generell steuerlich sanktioniert. Dies gilt bei der 10-Tages-Frist immerhin für Geschäfte, die in einem Zeitraum stattfinden, der 10 Tage vor dem Dividendentermin beginnt und 10 Tage danach endet ${ }^{257}$. Die Ansicht von Dötsch, daß nur in den Tagen vor dem Dividendentermin das Börsengeschehen beeinträchtigt werden könne ${ }^{258}$, ist nicht korrekt, weil durch die Zehn-Tage-Frist ein unbeschränkt steuerpflichtiger Erwerber aus steuerlichen Gründen seine Beteiligungen nach dem Ausschüttungstermin selbst dann nicht verkaufen würde, wenn ein Verkauf für ihn aus wirtschaftlichen Gründen geboten sein könnte. Zwar ist es schwer, die Auswirkung des "Halten-müssens" empirisch zu messen, es kann aber kein Zweifel geben, daß eine Beeinträchtigung des Börsenhandels vorliegt. Dabei ist zu bedenken, daß ein Anteilseigner gerade in den Tagen der Hauptversammlung Informationen über sein Unternehmen erhält, die auch einen Verkaufswunsch auslösen können. Die gesetzliche Regelung läßt aber keine wirtschaftliche Be-

254 Vgl. BT-Drs. 12/6078, S. 125.

255 Vgl. Dötsch, E. (1993a), Standortsicherungsgesetz: Auseinanderfallen von Stammrechten und Dividendenschein - Dividenden-Stripping, in: Der Betrieb (DB), 46. Jg./(1993), Nr. 37, S. 1848.

Vgl. Frotscher, G. (1994b), a.a.O., S. 43.

Vgl. Kindermann, E. (1994), a.a.O., S. 822.

Vgl. Dötsch, E. (1996), a.a.O., S.1132/50. 
gründung $\mathrm{zu}^{259}$. Insoweit sind Anteilseigner, die erst kurz vor einem Ausschüttungstermin Beteiligungen an ihrem Unternehmen erworben haben, denjenigen Anteilseignern gegenüber schlechter gestellt, die ihre Beteiligungen schon länger besitzen und ohne steuerliche Sanktionierung flexibel verkaufen können. Aus Vorsichtsgründen könnte man also Steuerinländern abraten, kurz vor dem Dividendentermin inländische Beteiligungen für ein inländisches Betriebsvermögen zu erwerben.

Als Ergebnis kann festgehalten werden, daß der Gesetzgeber bei Anwendung einer "Fristenlösung" vor einem Zielkonflikt steht: Ist die Frist zu lang, wird auf jeden Fall das Börsengeschehen beeinflußt bzw. verzerrt, ist die Frist zu kurz, wird das Kursrisiko von Stripping-Geschäften nur unzureichend erhöht.

\subsection{Probleme der Regelung für Kurssicherungsgeschäfte}

Die Formulierung des $\S 50$ c Abs. 10 Buchst. b EStG trifft im Prinzip alle Kurssicherungsgeschäfte, soweit sie im Zusammenhang mit einem Rückkaufgeschäft stehen. Damit zielt der Gesetzgeber insbesondere auf die Dividendenstrippingvarianten in Verbindung mit Options- und Hedge-Geschäften. Es ist fraglich, welche Relevanz die Regelung überhaupt in der Praxis erhalten kann. Vieles hängt davon ab, ob "Rückveräußerung" wörtlich zunehmen ist oder nicht. Wenn ja, so kann die Bestimmung allenfalls für Geschäfte gelten, die an der Börse vorbei oder über die Börse aber mit Durchbrechung der Börsenanoymität durch Börseninsider stattfin$\operatorname{den}^{260}$. Ist Rückveräußerung nicht wörtlich zu nehmen ${ }^{261}$, so ist im Prinzip jedes Kurssicherungsgeschäft betroffen, in dessen Verlauf ein Dividendenausschüttungstermin liegt. Dann werden z.B. auch Handelsgeschäfte berührt, die abgeschlossen werden, ohne daß sichere Erwartungen bezüglich der Dividendenhöhe bei den Kontrahenten vorliegen, wie dies mitunter der Fall ist, wenn Ausschüttungen erst einige Monate nach dem Verkaufsgeschäft erfolgen. Bei der Preisfindung solcher langfristiger Kurssicherungsgeschäfte werden allerdings potentielle Markteinflüsse - soweit diese überhaupt bekannt sind - berücksichtigt. Der Optionspreis drückt damit zwangsläufig weit mehr aus als den üblichen ausschüttungsbedingten Kursabschlag. Da sich die Höhe des Sperrbetrags auch nach dem Optionspreis bemißt, kann der Sperrbetrag hier kaum ökonomisch sachgerecht

259 Hierin unterscheidet sich die pauschalierende Regelung des 50c EStG von einer allgemeinen Steuermißbrauchsklausel wie z.B. der $\S 42 \mathrm{AO}$, der wirtschaftlich begrundetes Handeln zulaß $\mathrm{t}$, auch wenn es zu einem für den Fiskus ungunstigeren Steuerergebnis fuhrt.

Vgl. Gondert, H.-G. / Rützel, G. / Dreyer, G. (1995), a.a.O., S. 566.

261 Ansicht von Dötsch; vgl. Dortsch, E. (1996), a.a.O., S 1132/56f. 
sein. Die Regelung ist also einerseits sehr auslegbar, bei weiter Auslegung aber kaum noch sachgerecht. Hätte man die Bestimmung zeitlich abgegrenzt - ähnlich wie beim $\S 50$ c Abs. 10 Buchst. a EStG - so wären die Anteilseigner eher in den Genuß von Rechtssicherheit gekommen. So aber entsteht bei vielen Geschäften die Gefahr einer Einordnung in den § 50c EStG durch die Finanzverwaltung. Derartige Folgen schießen über das Ziel der gesetzlichen Regelung weit hinaus ${ }^{262}$. Wirtschaftsprüfungsgesellschaften befürchteten daher, daß die gesetzliche Neuregelung zu einer Lähmung insbesondere der Deutschen Terminbörse (DTB) führen und starke Einschränkungen von Hedging-Geschäften im OTC-Geschäft hervorrufen würde ${ }^{263}$. Bis heute werden entsprechende Klagen geführt. Allerdings scheinen diese Befürchtungen deswegen unbegründet, weil in der Praxis $\S 50 \mathrm{c}$ Abs. 10 Buchst. $b$ relativ selten relevant wird ${ }^{264}$. Andernfalls müßte es bei allen Kurssicherungsgeschäften inzwischen eine doppelte Preisfindung für Geschäfte mit bzw. ohne $\S-50 c-E S t G-A u f s c h l a g$ geben.

\subsubsection{Einschränkung der Geschäfte "alt gegen jung"}

Auch ein Dividendenstripping mit jungen Aktien zwischen identischen Geschäftspartnern ist tatsächlich nur dann denkbar, wenn keine strikte Börsenanonymität besteht. Insofern wird oft die Ansicht vertreten, daß die Ausklammerung von Stripping-Geschäften mit jungen Aktien wie im Fall der Ausklammerung von kursabgesicherten Rückveräußerungsgeschäften nur für außerbörsliche Geschäfte gelten könne ${ }^{265}$. Dennoch trägt diese Regelung zur Rechtssicherheit bei. Während unter der alten Börsenklausel nachgewiesenermaßen noch zahlreiche Stripper diese Variante des Dividendenstripping gewählt haben, konnte sie - nach herrschender Meinung - mittlerweile erfolgreich unterbunden werden ${ }^{266}$.

Allerdings hätte hierfür wohl auch eine Klarstellung der alten Börsenklausel gereicht, wie sie das Hessische Finanzgericht 1996 getroffen hat. Auf der Grundlage des alten Rechts stellte dieses Finanzgericht in Fällen des Dividendenstripping mit jungen Aktien fest, daß das wirtschaftliche Eigentum der Aktien bei dieser Strip-

262 Kindermann zweifelt an der Verfassungskonformităt solcher auslegbarer Bestimmung wie den § 50c Abs. 10 Buchst. b; vgl. Kindermann, E. (1994), a.a.O., S. 824.

263 Vgl. o. Verf.: DTB-Geschăfte steuerlich gefăhrdet, in: Börsenzeitung vom 26.02.1994.

264 Vgl. Gondert, H.-G. / Rutzel, G. / Dreyer, G. (1995), a.a.O., S. 567.

265 Vgl. Kindermann, E. (1994), a.a.O., S. 824.

266 Vgl. o. Verf.: DTB-Geschäfte steuerlich gefăhrdet, in: Börsenzeitung vom 26.02.1994. 
pingvariante dem Alteigentümer erhalten bleibt. Entsprechend ordnete es den ausländischen Anteilseignern auch die Dividendenansprüche mit den zugehörigen steuerlichen Folgen $\mathrm{zu}^{267}$. Ungeachtet der Bestimmung bleibt es natürlich auch ausländischen Anteilseignern unbenommen, Bezugsrechte und in der Folge junge Aktien zu erwerben und gleichzeitig Altaktien zu veräußern. Ein solches Geschäft erfordert keine außerbörsliche Absprache und kann trotzdem lohnend für den ausländischen Anteilseigner sein, solange der Preis des Bezugsrechts zwischen der Netto- und der Bruttodividende liegt.

\subsection{Probleme der Entlastungsklausel}

Die neue Börsenklausel erscheint allerdings aus einem weiteren Grund sehr angreifbar. Im Gegensatz zur eigentlichen Intention des Gesetzgebers im Jahr 1993 gelten die Beschränkungen der neuen Börsenklausel ausnahmslos für alle aufgezählten Geschäfte. Grundsätzlich werden also auch Börsengeschäfte zwischen Anrechnungsberechtigten erfaßt, soweit sie in den Katalog der neuen Börsenklausel fallen. Erst wenn der Erwerber beweisen kann, daß er von einem Anrechnungsberechtigten erworben hat, bleibt ihm die Teilwertabschreibung nicht verwehrt. Wie aber soll der Erwerber beweisen,

"daß der Veräußerer, bei mittelbaren Erwerb über zwischengeschaltete Veräußerer jeder Veräußerer, anrechnungsberechtigt ist"268 ?

Nach Dötsch soll die Einräumung eines Entlastungsbeweises dem Börsenhandel die Möglichkeit zur Anpassung geben ${ }^{269}$. Man fragt sich, welche Anpassung Dötsch hier meint. Eine tatsächliche Anpassung des Börsenhandels an eine neue Börsenklausel hieße die Aufgabe jeder Börsenanonymität, weil aufgrund der Variantenvielfalt im Prinzip jeder Aktienkauf eines Anrechnungsberechtigten im $\mathrm{Zu}$ sammenhang mit irgendeinem Dividendenstripping stehen kann. Eine Aufdeckung allein der Geschäfte direkt um den Dividendentermin reicht nicht, weil Fälle des §

267 Vgl. Hessisches Finanzgericht (1996), a.a.O., S. 27 bzw. S. 38. Die vermøgensmaßige Zurechnung erfolgte dabei nach $\S 39 \mathrm{AO}$, wonach ein Wirtschaftsgut demjenigen zuzurechnen ist, der die tatsăchliche Herrschaft über das Wirtschaftsgut so ausubt, daß er den Eigentumer im Regelfall für die gewőhnliche Nutzungsdauer von der Einwirkung auf das Wirtschaftsgut wirtschaftlich ausschließen kann.

268 Wortlaut des $\S 50 \mathrm{c}$ Abs. $10 \mathrm{EStG}$.

269 Vgl. Dötsch, E. (1993b): Maßnahmen zur steuerlichen Einschrănkung des DividendenStripping durch das Standortsicherungsgesetz, Institut für Ausländisches und Internationales Finanz- und Steuerwesen (Hrsg.): Hefte zur Internationalen Besteuerung, Nr. 95, Hamburg 1993, S. 24. 
50c Abs. 10 Buchst. b EStG zeitlich unbegrenzt sind. Es ist somit offensichtlich, daß eine Anpassung nur in der Aufhebung des Bankgeheimnisses bezüglich aller kommissionsweise getätigten Aktiengeschäfte bestehen kann $^{270}$.

Solange aber der Börsenhandel und die Kreditinstitute hierzu nicht gezwungen werden, solange kann ein Aktienerwerber kaum erfahren, von wem er seine Anteile gekauft hat $^{271}$. Was aber ist eine unerfüllbare Bestimmung wert? Verfassungsrechtliche Bedenken wurden wegen der Unerfüllbarkeit schon bald nach Verabschiedung des $\S 50 \mathrm{c}$ Abs. $10 \mathrm{EStG}$ geäußert und werden bis heute wiederholt $^{272}$.

\subsubsection{5. Überlappung der Abschreibungsmotive}

Ein weiteres Problem des $\S 50 \mathrm{c}$ EStG besteht im Zusammentreffen mehrerer Ursachen für eine Gewinnminderung. Falls mehrere Ursachen einer Teilwertabschreibung bzw. eines Verlustes aus einer Veräußerung oder einer Entnahme von Anteilen zusammentreffen, wird die steuerliche Wirkung der Teilwertabschreibung bzw. des Verlusts anerkannt ${ }^{273}$. Hieraus folgt ein Abgrenzungsproblem bzw. die Möglichkeit einer Überlagerung der verbotenen ausschüttungsbedingten Teilwertabschreibungen durch anders begründete Abschreibungen ${ }^{274}$. $50 \mathrm{c} \mathrm{EStG} \mathrm{gilt}$ also nur, wenn die Teilwertabschreibung oder der Verlust auf eine Gewinnausschüttung zurückzuführen ist. Dies scheint zwar mit dem Zweck des $\S 50 \mathrm{c} \mathrm{EStG}$ im Einklang zu stehen, könnte ihn aber unterhöhlen, da Streitigkeiten zwischen

270 Vgl. Kindermann, E. (1994), a.a.O., S. 821.

271 Vgl. Sarrazin V. (1994): Bekämpfung unerwünschter Steuergestaltungen, in: Deutsche Steuer-Zeitung (DStZ), 82. Jg. /(1994) Nr. 10, S. 293.

272 Vgl. BDI, DIHT, ZDH, BGA, HDE, BdB, BDA, GDV (1997): Gemeinsame Eingabe vom 17. September 1997 an das BMF, BMJ und BMWi zum Gesetz zur Fortsetzung der Unternehmenssteuerreform, Bonn 1997, zu Artikel 1 - Änderung des Einkommensteuergesetzes, zu Nr. 7 - § 50c Abs. 11 EStG, S. 2; vgl. Eckert, R. (1995), a.a.O., S. 62.; vgl. Kindermann, E. (1994), a.a.O., S. $821 \mathrm{f}$.

273 Vgl. BT-Drs. 8/4157, S. 5.

274 Vgl. Herzig, N. / Hotzel, O. (1988): Ausschüttungsbedingte Teilwertabschreibungen, in: Der Betrieb (DB), 41. Jg/(1988), Nr. 45, S. 2267f.; vgl. Weber-Grellet, H. (1999), a.a.O., S. 296. 
Finanzverwaltung und Anrechnungsberechtigten über die Ursache einer Teilwertabschreibung oder eines Verlustes zu erwarten sind ${ }^{275}$.

Gerade bei börsennotierten Beteiligungen verschärft sich dieses Problem, weil der Wert dieser Beteiligungen täglich neu bestimmt wird und bei der Preisfindung relativ viele Faktoren eine Rolle spielen, z.B. allgemeine Daten zur Branchen- oder Konjunkturlage, Politik- und Trenderwartungen. Abschreibungen können beim Erwerber in vielen Fällen also auch anders begründet werden, da sich die Motive einer Abschreibung überlagern.

\subsection{Unwirksamkeit der Regelung gegen tarifbedingtes Dividenden- stripping}

Wie eingangs erwähnt, ist zwischen Anrechnungsberechtigten tarifbedingtes Dividendenstripping möglich. Das tarifbedingte Dividendenstripping kann aber auch zwischen Steuerinländern und Steuerausländern interessant sein. In diesem Fall greift $§ 50 \mathrm{c} \mathrm{EStG}$ auch in der neuen Fassung nicht. Ist der persönliche Steuersatz des inländischen Erwerbers deutlich niedriger ist als der des Steuerausländers, so wird der Steuerinländer auch bei Verbot einer ausschüttungsbedingten Teilwertabschreibung bereit sein, das Körperschaftsteuerguthaben teilweise weiterzugeben.

\section{Zwischenfazit}

Die neue Börsenklausel nimmt Börsengeschäfte über Kreditinstitute nicht mehr generell von dem Verbot einer steuerlich anerkannten, ausschüttungsbedingten Teilwertabschreibung aus. De facto wird den unter den Buchstaben a, b und c aufgezählten Geschäften die ausschüttungsbedingte Teilwertabschreibung verwehrt, bzw. die inländischen Steuerpflichtigen müssen mit einer entsprechenden Behandlung rechnen, da ihnen ein entlastender Gegenbeweis kaum möglich sein wird. Im einzelnen erscheint die Fristenregelung durchaus umstritten, die zehn Tage sind eher willkürlich gewählt. Schwerer wiegen die aus der generellen Sanktionierung von Kurssicherungsgeschäften resultierenden Unsicherheiten. Hier darf allerdings im erheblichen $\mathrm{Ma} ß$ daran gezweifelt werden, daß die Bestimmungen des $\S 50 \mathrm{c}$ Abs. 10 Buchst. b EStG tatsächlich Bedeutung in der Anwendung erlangen. Fraglich ist zudem, wie bestimmte Mischgeschäfte aus den Fällen $a$ und $b$ geregelt sind. So bleibt z.B. unklar, wie ein vor dem Dividendentermin zwischen einem Steuerausländer und einem Steuerinländer zustande gekommenes Kassa-

275 Vgl. Sorgenfrei (1997a), a.a.O., S. 17, Kindermann, E. (1994), a.a.O., S. 822. Anderer Ansicht: Soffing, G. / Wrede, F. (1980), a.a.O., S. 398. 
verkaufsgeschäft zu beurteilen ist, das von einem erst nach dem Ausschüttungstermin abgeschlossenen Kursabsicherungsgeschäft begleitet wird. Eine derartige Gestaltung führt dazu, daß weder Buchstabe $a$ noch $b$ angewendet werden kann, da die Frist überschritten wird und die vereinbarte Rückveräußerung nicht mehr in einem erkennbaren zeitlichen bzw. inhaltlichen Zusammenhang mit dem Erwerbsgeschäft bzw. der Ausschüttung steht. Solche Geschäfte dürften ohnehin nur schwer als Dividendenstripping erkennbar sein.

Vergleicht man nun die neue mit der alten Börsenklausel, so gelangt man zu mehreren überraschenden Ergebnissen: Einerseits ist die neue Börsenklausel auf den ersten Blick sehr viel strenger als die Vorgängerregelung. Bestimmte Gestaltungen werden ausgeschlossen, die in der Tat relativ viele der bekannt gewordenen Varianten des Dividendenstripping treffen. Andererseits wirkt die Regelung entlastend auf die übrigen Varianten ${ }^{276}$. Die teleologische Reduktion, die im Urteil des Hessischen Finanzgerichts praktiziert wurde, zeigt, daß eine Klarstellung der alten Börsenklausel durchaus die gleiche Rechtssicherheit hinsichtlich des Dividendenstripping mittels Kassageschäften und des Dividendenstripping mit jungen Aktien erzeugt hätte ${ }^{277}$. Die Fragestellung, welche Kurssicherungsgeschäfte als Dividendenstripping gewertet werden können und welche nicht, kann dagegen auch die neue Börsenklausel nicht eindeutig beantworten.

Allerdings trifft die neue Börsenklausel mit ihrer pauschalen Fallklassifizierung mit Sicherheit auch eine Reihe von Geschäften, die nicht oder nicht ausschließlich steuerlich motiviert sind, wie dies gerade bei vielen Kurssicherungsgeschäften der Fall ist. Im übrigen gilt für die neue Börsenklausel natürlich dasselbe wie für die alte. Der Sperrbetrag wirkt meist negativer als eine bloße Verwehrung der Anrechnung. Insofern greift die neue Börsenklausel gleichzeitig zu kurz und zu weit.

Die Analyse der neuen Börsenklausel bliebe unvollständig, wenn man nicht auch das parallel geltende Abschreibungsverbot betrachtete, das der Gesetzgeber zeitgleich mit der neuen Börsenklausel verabschiedet hat. Die Vorstellung der Varianten des Dividendenstripping machte bereits deutlich, daß es zahlreiche Stripping-Geschäfte gibt, bei denen eine ausschüttungsbedingte Teilwertabschreibung überhaupt nicht vorkommt und folglich auch eine Verwehrung der Teilwertabschreibung ins Leere geht.

276 Klein kommt deswegen zu dem Ergebnis, daß die neue Börsenklausel das Dividendenstripping insgesamt weniger wirksam unterbinden kann als die Vorgängerregelung. Vgl. Klein, M. (1997), a.a.O., S. $476 f$.

277 Wobei abgewartet werden muß, ob dieses Urteil vom BFH bestătigt wird. 


\subsubsection{Unterbindung der Weitergabe von Anrechnungsguthaben seit 1994: Das neue Anrechnungsverbot}

Im Rahmen der Bekämpfung des Dividendenstripping kehrte der Gesetzgeber nach vierzehn Jahren Abstinenz zur Methode des Anrechnungsverbots zurück. Das Anrechnungsverbot ist den Einschränkungen einer Teilwertabschreibung durch $\S 50 \mathrm{c} \mathrm{EStG}$ vorrangig, greift das Anrechnungsverbot, so kommt $\S 50 \mathrm{c} \mathrm{EstG}$ nicht zur Wirkung.

Das Anrechnungsverbot ist im Rahmen des Standortsicherungsgesetzes in das Einkommensteuergesetz eingegangen und findet sich im $\S 36$ Abs. 2 Satz 2 Nr. 3 Satz 4 Buchst. g EStG wieder ${ }^{278}$. Anders als $\S 39 \mathrm{KStG}$ wirkt das Anrechnungsverbot direkt beim zwischenzeitlichen, anrechnungsberechtigten Aktienhalter.

Mit dem Verbot hofft der Gesetzgeber, das Dividendenstripping mit Hilfe von Finanzinnovationen, insbesondere das Stripping in Verbindung mit Leihgeschäften, auszutrocknen. Kennzeichnend für diese Geschäfte ist, daß der Steuerinländer keine ausschüttungsbedingte Teilwertabschreibung vornehmen muß bzw. kann, weil sich die Wertpapiere gar nicht in seinem Betriebsvermögen befinden. Diese Varianten des Dividendenstripping kann folglich jeder Steuerinländer privat mit einem Nichtanrechnungsberechtigten eingehen.

Das Körperschaftsteuerguthaben wird über entsprechend höhere Provisionen z.B. für eine Wertpapierleihe oder ein Wertpapierpensionsgeschäft an den Nichtanrechnungsberechtigten weitergegeben. Mit diesen erhöhten Provisionen unterliegen Steuerausländer nicht der deutschen Besteuerung ${ }^{279}$, während Steuerinländer diese Ausgaben als Betriebsausgaben oder Werbungskosten gelten machen können.

Das Anrechnungsverbot greift, wenn es aufgrund der geltend gemachten Werbungskosten oder Betriebsausgaben zu keiner inländischen Einkommensteuererhebung kommt. Unberücksichtigt bleiben allerdings marktübliche Kreditkosten, ihr Abzug löst kein Anrechnungsverbot aus.

278 Die Korperschaftsteuer wird danach nicht anregerechnet, “ $\mathrm{g}$ )... wenn sie auf Einnahmen aus Kapitalvermögen im Sinne des $\S 20$ Abs. 1 Nr. 1 oder 2 entfallt, soweit diese nicht zur Festsetzung einer Einkommensteuer fuhren, weil ihnen damit zusammenhăngende abziehbare Aufwendungen mit Ausnahme marktublicher Kreditkosten gegenuberstehen, die bei dem Empfänger nicht der deutschen Besteuerung unterliegen." § 36 Abs. 2 Satz 2 Nr.3 Satz 4 Buchst. g.

279 Eine Leihprovision könnte höchstens aufgrund einer dinglichen Sicherung unter die beschränkte Steuerpflicht fallen; vgl. § 49 EStG Abs. 1 Nr. 5 EStG. 


\subsection{Rechtsunsicherheiten des Anrechnungsverbots}

Diese Regelung weist diverse Schwächen auf, so daß insgesamt ihre Praxisrelevanz zweifelhaft ist. Zuerst einmal ist umstritten, welche Aufwendungen konkret berücksichtigt werden und das Anrechnungsverbot auslösen: Der Gesetzgeber fordert einen konkreten Zusammenhang zwischen der Dividende und den Aufwendungen. Wie eng dieser Zusammenhang sein muß, ist aber unklar. Nach enger Auslegung muß das Kassageschäft und das Gegengeschäft zwischen denselben Personen stattfinden, nur dann können Aufwendungen für das Gegengeschäft das Anrechnungsverbot auslösen ${ }^{280}$. Anderen Autoren genügt ein offensichtlicher $\mathrm{Zu}$ sammenhang von Kassa- und Gegengeschäft ${ }^{281}$. In diesem Fall wäre auch ein Verlust, den der Steuerinländer aus einem abgeschlossenen Kurssicherungsgeschäft mit irgend einem Dritten erfährt, ein Aufwand, der das Anrechnungsverbot auslöst, weil er im Zusammenhang mit den erzielten Dividenden steht. Derartige Geschäftszusammenhänge können allerdings häufig nur über intensive $\mathrm{Be}$ triebsprüfungen der Steuerbehörden ermittelt werden.

Desweiteren ist unklar, was marktübliche Kreditzinsen $\operatorname{sind}^{282}$. Schwierigkeiten bereitet auch, daß das Anrechnungsverbot nur greift, sofern die vom inländischen Steuerschuldner geleisteten Aufwendungen beim Empfänger nicht der deutschen Besteuerung unterliegen ${ }^{283}$. Im Gegensatz zum $\S 50 \mathrm{c} \mathrm{EStG} \mathrm{legt} \mathrm{der} \mathrm{Gesetzgeber}$ hier die Beweislast der Finanzverwaltung auf. Es ist aber fraglich, wie das Finanzamt den Nachweis erbringen will, daß der Inländer das Stripping-Geschäft mit einem Steuerausländer getätigt hat. Im Bereich der DTB wird dies schon aufgrund des anonymen Computerhandels unmöglich $\operatorname{sein}^{284}$.

Gänzlich ungeklärt ist, ob die Regelung hinfällig ist, sobald der Steuerinländer nur darauf achtet, daß aus dem Stripping-Geschäft für ihn eine Einkommensteuer resultiert und sei es in Höhe von einer DM. Nach dem Gesetzeswortlaut wäre $\S 36$ $\mathrm{KStG}$ nicht einschlägig, solange nur eine verminderte Einkommensteuer beim Steuerinländer anfällt. Zwar wirkt dann wieder $\S 50 \mathrm{c} \mathrm{EStG}$, doch würde das den

280 Vgl. Kindermann, a.a.O., S. 825.

281 Vgl. Dotsch, E. (1996), a.a.O., S. 1038/33.

282 Vgl. Dötsch, E (1996), a.a.O., S.1038f.

283 Vgl. Kindermann, E., a.a.O., S. 824f., 869ff.

284 Vgl. Gondert, H.-G. / Rützel, G. / Dreyer, G. (1995), a.a.O., S. 567; vgl. Kindermann, E. (1994), a.a.O., S. 821. 
Steuerinländer nicht stören, solange keine ausschüttungsbedingten Gewinnminderungen bei ihm anfallen.

Muß der Steuerinländer also nur klug genug sein, die Betriebsausgaben nicht zu hoch anzusetzen? Dann hätte die Regelung aber nicht bewirkt, daß sich der Abschluß eines Stripping-Geschäfts für den Steuerinländer grundsätzlich nicht lohnt.

Eine andere Auslegung ist die, daß alle Aufwendungen ein Anrechnungsverbot in entsprechender Höhe auslösen: In diesem Fall mindert eine Ausgleichszahlung an den Nichtanrechnungsberechtigten, wie sie z.B. im Fall des Dividendenstripping in Verbindung mit Swapgeschäften anfällt, das Volumen der anrechenbaren Körperschaftsteuer. Gleiches gilt für die erhöhte Leihgebühr oder die Optionsprämie, die an den Nichtanrechnungsberechtigten beim Dividendenstripping durch Leihgeschäfte bzw. beim Dividendenstripping mit Optionsgeschäften bezahlt wird. Diese Auslegung erscheint zwar teleologisch korrekt, ist aber nicht zwingend aus dem Wortlaut zu begründen.

\subsection{Steuersystematische Probleme des Anrechnungsverbots}

Wie schon im Falle der verwehrten Teilwertabschreibung ist am Anrechnungsverbot zu kritisieren, daß der Steuerinländer von der gesetzlichen Maßnahme getroffen wird und nicht - mangels Zugriff - direkt der Steuerausländer, auf den die Regelung letztlich zielt.

Grundsätzlich bedenklich ist außerdem das Zusammenwirken von Anrechnungsverbot und Börsenklausel, da die Maßnahmen unterschiedliche steuerliche Folgen auslösen. Die Wirkung des Sperrbetrags des $\S 50 \mathrm{c}$ EStG ist abhängig vom persönlichen Einkommensteuersatz des Anteilseigners und unterscheidet sich damit von Fall zu Fall. Die Aberkennung des Körperschaftsteuerguthabens wirkt dagegen immer gleich: Der Anteilseigner verliert Steuerguthaben in Höhe von 3/7 der Bardividende. Die Auswirkungen einer verwehrten Teilwertabschreibung treffen den Steuerinländer um so härter, je höher sein persönlicher Einkommensteuersatz ist, der im Regelfall über 30\% liegen dürfte. Damit wird aber ein Dividendenstripping über ein Wertpapierleihgeschäft in der Regel weniger stark sanktioniert als ein Dividendenstripping mit einem zwischenzeitlichen Eigentumsübergang der gehandelten Beteiligungen. 


\subsection{Zweifelhafte Anwendbarkeit des Anrechnungsverbots auf DTB- Geschäfte}

Kindermann verweist darauf, daß Verträge im DTB-Handel mit der DTB geschlossen werden ${ }^{285}$. Es ist deshalb fraglich, ob und gegebenenfalls wie eine - salopp gesprochen - Durchgriffsbesteuerung von einem Geschäft zwischen einem Anrechnungsberechtigten und der DTB auf ein Geschäft eines Nichtanrechnungsberechtigten und der DTB erfolgen soll und kann ${ }^{286}$. Die Herstellung des Zusammenhangs zwischen einzelnen Geschäften, die mit der DTB abgeschlossen werden, scheint problematisch.

\subsection{Umgehbarkeit des Anrechnungsverbots}

Neben ungeklärten Fragen zur Auslegung und Anwendung des Anrechnungsverbots dürfte aber ein anderes Problem das entscheidende sein: Die geradezu simple Umgehbarkeit des Anrechnungsverbots. Die im Rahmen der Grundvarianten des Dividendenstripping vorgestellten Kettenleihgeschäfte werden nämlich nicht erfaßt. Es genügt die Zwischenschaltung eines weiteren Anrechnungsberechtigten in das Leihgeschäft: Bei einem solchen Kettenleihgeschäft leistet der Steuerinländer, der die Anrechnung geltend macht, seine Leihgebühr nicht an einen Steuerausländer, sondern an einen Steuerinländer, von dem er die geliehenen Wertpapiere bezogen hat. Der zwischengeschaltete Steuerinländer kassiert die erhöhte Leihgebühr und leitet sie an den Steuerausländer weiter. Die Voraussetzungen des $\S 36$ Abs. 2 Satz 2 Nr. 3 Satz 4 Buchst. g EStG sind so formuliert, daß für keinen der beiden Steuerinländer das Anrechnungsverbot greift. Diese Gestaltung ist auch bei Swap-Geschäften denkbar. Entscheidend ist, daß der Anrechnungsberechtigte die Kompensationszahlung nicht direkt vom Nichtanrechnungsberechtigten bezieht. Zwar könnte an dieser Stelle vermutlich noch ein Gestaltungsmißbrauch nach $\S 42$ $\mathrm{AO}$ vorliegen, dieser wird für die Finanzbehörden aber kaum erkennbar sein.

Das Anrechnungsverbot scheint weiterhin besonders deswegen leicht umgehbar zu sein, weil die erwähnte Nachweispflicht eines Dividendenstripping - anders als im Fall der Börsenklausel - bei der Finanzverwaltung liegt. Das erfordert aber, daß das Finanzamt jede abziehbare Aufwendung mit einer bestimmten Dividendenzahlung in Verbindung bringen muß. Dies wird in der Realität kaum möglich sein.

285 Vgl. Kindermann, E. (1994), a.a.O., S. 821.

286 Gleicher Ansicht ist Unfried; vgl. Unfied, A. (1998): Steuerrecht und Dividendenstripping, Berlin 1998, S. 175. 
Das Anrechnungsverbot kann zwar als notwendige Ergänzung zur Börsenklausel angesehen werden, es ist aber ganz offensichtlich leichter zu umgehen als die Börsenklausel. Andererseits entfaltet es steuerlich die eigentlich korrekte Wirkung in Höhe der Ausschüttungsbelastung, allerdings mangels steuerlichen Zugriffs wieder beim falschen Adressaten, nämlich beim zwischenzeitlichen inländischen Aktieninhaber und nicht beim ausländischen Eigentümer. Dies ist jedoch ökonomisch unbedenklich, weil durch die Nachweispflicht der Finanzverwaltung gewährleistet sein müßte, daß - anders als beim $\S 50 \mathrm{c} \mathrm{EStG} \mathrm{-} \mathrm{tatsächlich} \mathrm{nur} \mathrm{Geschäfte} \mathrm{zwi-}$ schen Anrechnungs- und Nichtanrechnungsberechtigten getroffen werden, die offensichtlich mit Dividendenstrippingabsicht unternommen worden sind.

\subsubsection{Jüngste Gesetzesänderung: Wird die Börsenklausel null und nichtig?}

Seit kurzem stellt sich die Rechtslage völlig neu dar, weil die neue Börsenklausel von 1994 seit 1997 durch eine weitere Ergänzung des § 50c EStG möglicherweise völlig ausgehebelt wird.

Im Rahmen des Gesetzes zur Fortsetzung der Unternehmenssteuerreform vom 29.10.1997 wurde dem $\S 50$ c EStG ein Absatz 11 angefügt, der die Konsequenzen dieser Regelung auch für die Fälle vorschreibt, bei denen ein anrechnungsberechtigter Erwerber von einem anrechnungsberechtigten Veräußerer Anteile erwirbt, sofern bei letzterem keine Besteuerung der Veräußerungsgewinne stattfindet ${ }^{287}$.

Da die Regelung ohne Einschränkung für börsennotierte Wertpapiere gilt, ist auch das Dividendenstripping zwischen Anrechnungsberechtigten betroffen, sofern es sich um Geschäfte mit einem zwischenzeitlichen Eigentumsübergang handelt. Für nicht wesentlich beteiligte Anteilseigner war ein tarifbedingtes Dividendenstripping in der Vergangenheit gerade aufgrund einer fehlenden Veräußerungsgewinnbesteuerung attraktiv. Dies ändert sich natürlich, wenn der Erwerber nun keine ausschüttungsbedingte Teilwertabschreibung mehr vornehmen kann. Insofern kommt die Neuregelung einer indirekten Einführung einer Veräußerungsgewinnbesteuerung gleich ${ }^{288}$.

\section{Vgl. BT-Drs. 13/8325, S. 3.}

288 Die Regelung geht sogar über eine Verăußerungsgewinnbesteuerung hinaus, wenn auch der Erwerb von Beteligungen aus inlandischem Betriebsvermogen betroffen ist, der mit Verlust veräußert wurde. Vgl. Altvater, C. (1997): Zur Anwendung des § 50c EStG auf den Anteilserwerb von Anrechnungsberechtigten, in: Betriebs-Berater (BB), 52. Jg. (1997), Nr. 49, S. 2511. 
Die Neuregelung hat jedoch auch unmittelbare Rückwirkungen auf das hier untersuchte Dividendenstripping mit Steuerausländern. Beim Beteiligungserwerb von anrechnungsberechtigten Veräußerern gelten nach $\S 50 \mathrm{c}$ Abs. $11 \mathrm{EStG}$ nämlich für den erwerbenden Anrechnungsberechtigten weder Bagatellgrenze noch Börsenklausel! Die Neuregelung wird für den anrechnungsberechtigten Erwerber dann nicht wirksam, wenn die Veräußerung nachweislich beim Veräußerer schon steuerpflichtig ist. Nachweispflichtig ist wie bei der neuen Börsenklausel der Erwerber der Anteile ${ }^{289}$, hier entstehen dieselben Probleme. Börsenklausel und der neue $\S 50 \mathrm{c}$ Abs. $11 \mathrm{EStG}$ verhalten sich außerdem konträr nebeneinander ${ }^{290}$ : Börsengeschäfte bleiben nach der neuen Börsenklausel in der Regel immer noch frei von der Sperrbetragsbildung; nach der Gesetzesergänzung von 1997 fallen sie generell unter $\S 50 \mathrm{c} \mathrm{EStG.} \mathrm{Es} \mathrm{ergeben} \mathrm{sich} \mathrm{seltsame} \mathrm{Konsequenzen:}$

Gilt $\S 50 \mathrm{c}$ Abs. 11 EStG vorrangig, so wird der anrechnungsberechtigte Erwerber, z.B. eine inländische Bank, beim Erwerb von Beteiligungen an inländischen Kapitalgesellschaften keine ausschüttungsbedingte Teilwertabschreibungen mehr vornehmen können. Werden die Beteiligungen über die Börse von privaten Veräußerern erworben, wird der Erwerber kaum nachweisen können, daß der Veräußerer der inländischen Besteuerung unterlag ${ }^{291}$.

Gilt dagegen die Börsenklausel vorrangig, könnte sich im Fall der strippingverdächtigen Geschäfte nach $\S 50 \mathrm{c}$ EStG Abs. 10 Buchst. a bis c durch die Neuregelung die Nachweispflicht der neuen Börsenklausel verschärfen: Der erwerbende Steuerinländer muß im Fall der strippingverdächtigen Geschäfte nicht nur nachweisen, daß er von einem Anrechnungsberechtigten erworben hat, sondern auch, daß der Veräußerer einen Veräußerungsgewinn erzielt hat, daß er diesen versteuern muß und daß alle eventuellen Rechtsvorgänger dieses Veräußerers in den neun Jahren vor dem Erwerbsjahr ebenfalls steuerpflichtig waren. Grundsätzlich ist es bei dem Nebeneinander beider Regelungen auch nicht gleichgültig, warum eine ausschüttungsbedingte Teilwertabschreibung verwehrt wird. Komplizierend wirkt nämlich, daß die Bagatellgrenze von $100.000 \mathrm{DM}$ nicht für die Fälle des $\S 50 \mathrm{c}$ Abs. $11 \mathrm{EStG}$ gilt ${ }^{292}$. Diese Konstruktion müßte Steuerinländer in bestimmten

289 Vgl. Prinz, U. (1998a): Aktuelles zu § 50c, in Herrmann, C. /Heuer, G. /Raupach, A. (Hrsg.): Einkommensteuer- und Körperschaftsteuergesetz, Erg.-Lfg. 191, S. 4.

290 Vgl. Prinz, U. (1998a), a.a.O., S. 7.

291 Vgl. Prinz, U. (1998a), a.a.O., S. 6; vgl. Grützner, D. (1997): Verbot der Berücksichtigung ausschuttungsbedingter Gewinnminderungen nach $\S 50 \mathrm{c}$ EStG, in: NWB Nr. 40 vom 29.09.1997, Fach 3, S. 10200.

Vgl. Weber-Grellet, H. (1999), a.a.O., S. 296. 
Fällen zu dem Nachweis motivieren, daß sie, wenn schon nicht von einem im Inland mit seinen Veräußerungsgewinnen Steuerpflichtigen (Beweis nach $\S 50 \mathrm{c}$ Abs. $11 \mathrm{EStG}$ ), so doch wenigstens von einem Nichtanrechnungsberechtigten (also Umkehr des ursprünglichen Beweises nach $\S 50 \mathrm{c} \mathrm{Abs.} 10 \mathrm{EStG}$ ) erworben haben.

Die Finanzverwaltung könnte dann aber im Fall des nachgewiesenen Erwerbs von Nichtanrechnungsberechtigten argumentieren, daß offenbar kein typisches Börsengeschäft vorliege und die Börsenklausel deswegen nicht greifen könne. Wie man es auch dreht und wendet: Es bleiben nur zwei Möglichkeiten. Entweder man akzeptiert einen Vorrang der neuen Börsenklausel ${ }^{293}$ : Dann gilt die geschilderte Rechtslage von 1994; oder man vertritt die Meinung, daß die Neuregelung alle Börsengeschäfte triff ${ }^{294}$ : Dann ist die Börsenklausel de facto ausgehebelt. Es dürfte dann kaum noch Fälle geben, in denen künftig noch Beteiligungen nicht vom $\S 50 \mathrm{c}$ EStG berührt werden. Der Gesetzgeber hätte aber eine indirekte Veräußerungsgewinnbesteuerung auch von Steuerausländern erreicht, die bisher nur mit Gewinnen aus der Veräußerung wesentlicher Beteiligungen im Inland beschränkt steuerpflichtig waren ${ }^{295}$, wobei Deutschland auf dieses Besteuerungsrecht in vielen DBA verzichtet hat ${ }^{296}$.

Sollte dennoch über Nachweiserfolge eine Befreiung von § 50c EStG möglich sein, so müßten konsequenterweise alle Anteilseigner, die Beteiligungen in ihrem

293 Vgl. Altvater, C. (1997), a.a.O., S. 2512, ăhnlich: Graf Kersenbrock, O.-F. / Strunk, G. (1999): Zum Geltungsbereich von 50c Abs. 10 und 11 EstG, in: Betriebsberater (BB), 54. Jg./(1999), Nr. 8, S. 403, die ein BMF-Schreiben vom 13. 798 entsprechend auslegen. Vgl. BStBl I 1998, S. $912 \mathrm{f}$.

294 Vgl. Weber-Grellet, H. (1998), a.a.O., S. 2242, Rz. 71.

295 Hier bestand bis 1998 noch ein weiteres Problem. Die Regelung enthielt eine bedeutende Schlechterstellung der nicht wesentlich beteiligten Veräußerer: Wesentlich Beteiligte unterlagen einer Verăußerungsgewinnbesteuerung nach $\S 34 \mathrm{EStG}$, der eine ermaßßigte Besteuerung vorsah (halber Durchschnittsteuersatz). Nicht wesentlich beteiligte Veräußerer unterlagen zwar formal gar keiner Verăußerungsgewinnbesteuerung, tatsăchlich trugen sie aber die verschlechterte Besteuerung der Erwerber uber den erzielbaren Veraußerungserløs mit. Die steuerlichen Auswirkung des § 50c EStG konnen aber beachtlich nachteiliger sein als die bis 1998 bestehende ermåßigte Verăußerungsgewinnbesteuerung eines wesentlich Beteiligten. Mit der Neuregelung des $§ 34$ EStG dürte sich diese Ungleichbehandlung erheblich verringert haben.

Vgl. $§ 49$ Abs. 1 EStG und Art. 13 Abs. 4 OECD-MA. 
Betriebsvermögen halten, 10 Jahre sauber zwischen "50c-infizierten " und "50cfreien" Anteilen trennen ${ }^{297}$.

Dividendenstrippinggeschäfte, die allein durch eine Teilwertabschreibung des inländischen Geschäftspartners lohnend sind, wären mit einer vollständigen $\mathrm{Ab}$ schaffung der Teilwertabschreibung grundsätzlich unmöglich geworden. Allerdings war eine völlige Streichung der Teilwertabschreibung selbst im ursprünglichen Entwurf des Steuerentlastungsgesetzes 1999/2000/2002 - trotz anders lautenden Pressemeldungen - wohl kaum vorgesehen, andernfalls hätte man $\S 50 \mathrm{c}$ EStG ebenfalls streichen können ${ }^{298}$. Im Visier war offenbar nur die verlustbedingte Teilwertabschreibung ${ }^{299}$, nicht jedoch die ausschüttungsbedingte Teilwertabschreibung $^{300}$.

Fraglich ist allerdings, wie sich das Wertaufholungsgebot auswirken wird. Statt des bisherigen Wahlrechts einer Wertbeibehaltung, sieht die vor kurzem vorgenommene Gesetzesänderung ein strenges Wertaufholungsgebot vor. Gerade bei sehr im Wert schwankenden Beteiligungen wie Aktien besteht für den Inländer so ein erhöhtes Risiko, daß er eine Teilwertabschreibung gar nicht gegenüber der Finanzverwaltung durchsetzen kann $^{301}$.

\section{Zusammenfassung}

Der derzeitige $\S 50 \mathrm{c}$ EStG ist im Bereich der börsennotierten Wertpapiere jenseits jeder Anwendbarkeit und voller Widersprüche. Der Gesetzgeber hat dem anrechnungsberechtigten Steuerinländer die im Börsenbereich unerfüllbare Aufgabe aufgebürdet, nachzuweisen, daß der Veräußerer der inländischen Besteuerung unterliegt. Da der Entlastungsnachweis de facto kaum zu erbringen ist, werden Steuerinländer künftig nur im Ausnahmefall ausschüttungsbedingte Teilwertabschreibungen auf börsengängige Wertpapiere noch vornehmen können. Damit ist die Börsenklausel von der jüngsten Gesetzesreform geradezu ausgehebelt worden. Ei-

297 Vgl. Dötsch, E. (1997), Kommentar zum § 50c EStG in: Dötsch, E. / Eversberg, H. / Jost, W.F. / Witt,G. (Hrsg.): Die Körperschaftsteuer, Loseblattsammlung, Bd. 3, 31. Erg-Lfg. Dez. 1997, S. 1110/5.

298 Vgl. BR-Drs. 14/265, S. 6 bzw. S. 173.

299 Die verlustbedingte Teilwertabschreibung hat insbesondere für den Einzelhandel eine herausragende Bedeutung.

Vgl. Weber-Grellet, H. (1999), a.a.O., S. 290.

301 Die Beweislast liegt hier bei dem Anteilseigner, vgl. § 6 Abs. 2 Satz 2 n.F., vgl. BR-Drs. $129 / 99$. 
ne ausschüttungsbedingte Teilwertabschreibung scheint zudem auch durch die aktuelle Steuerreform zusätzlich erschwert.

Insgesamt erweisen sich die gesetzlichen Maßnahmen zur Unterbindung des Dividendenstripping in Deutschland als lückenhaft und zum Teil nicht praktikabel. Die sogenannte Einmalbesteuerung in Deutschland anfallender Gewinne von Körperschaften ist deswegen keineswegs sichergestellt. Selbst wenn im Bereich des § 50c EStG künftig fast jede ausschüttungsbedingte Teilwertabschreibung gefährdet ist, bleiben Möglichkeiten des Dividendenstripping bestehen, die keine ausschüttungsbedingte Teilwertabschreibung erfordern. Hinsichtlich der immer komplizierter werdenden Stripping-Geschäfte insbesondere im Bereich der Wertpapierleihe - man denke vor allem an die erwähnten Reihengeschäfte - muß man sich einerseits fragen, wie diese überhaupt aufgedeckt werden können, andererseits gilt es zu überlegen, ob immer kompliziertere Spezialgesetze tatsächlich die richtige Antwort auf diese Entwicklung sind.

\subsection{Allokative Folgen des Dividendenstripping und der gesetzlichen Ge- genmaBnahmen}

\subsubsection{Auswirkungen auf die internationale Kapitalallokation}

Dividendenstripping bzw. ein Verzicht auf die Verfolgung dieser Steuergestaltung verringert die steuerliche Benachteiligung der Steuerausländer gegenüber den Steuerinländern. Allerdings wird diese Benachteiligung nicht voll aufgehoben, weil eine komplette Beseitigung der Doppelbelastung durch eine 100\%ige Zuordnung des Körperschaftsteuerguthabens an den ausländischen Anteilseigner unwahrscheinlich ist. In diesem Fall wird zwar der anrechnungsberechtigte Steuerinländer keinen Verlust erleiden, ebensowenig jedoch einen Gewinn erzielen. Somit entfiele für ihn der Anreiz, solche Geschäfte zu tätigen. Bei einer Aufteilung des Anrechnungsguthabens steht der Steuerausländer im Vergleich zum anrechnungsberechtigten Steuerinländer allerdings immer noch schlechter da, weil letzterer ja in den Genuß der uneingeschränkten Anrechnung gelangt.

Sofern ein Anrechnungsland das Dividendenstripping nicht unterbinden kann oder will, kommt es de facto zu einer anteiligen Ausdehnung des Anrechnungsverfahrens auch auf Steuerausländer. Für einen Steuerausländer, der in einem Land mit Körperschaftsteuerintegration ansässig ist, hängt die Anlageentscheidung ceteris paribus vom Anrechnungsumfang ab, der die möglichen Strippingvorteile bestimmt. Besteht im Land der Kapitalgesellschaft, deren Anteile gestrippt werden, ein Teilanrechnungssystem, so werden auch die Körperschaftsteuersätze entscheidungsrelevant. Für Steuerausländer aus Ländern mit klassischen Systemen bedeu- 
tet das Dividendenstripping eine Möglichkeit, der heimischen Doppelbelastung ausgeschütteter Gewinne zu entgehen. Insbesondere aus Staaten mit klassischen Systemen ist deswegen mit Kapitalimporten zu rechnen. Zielgenaue Maßnahmen zur Unterbindung des Dividendenstripping wirken gegenläufig, also kapitalimporthemmend, und stellen somit die isolierende Wirkung des national beschränkten Anrechnungssystems wieder her. Zugleich wird so aus Sicht der Anteilseignern aus Ländern mit klassischem System wieder Kapitalexportneutralität wiederhergestellt.

Es ist sehr umstritten, inwieweit ein national beschränktes Anrechnungssystem wie das deutsche Vollanrechnungssystem gegen die Grundfreiheiten des europäischen Binnenmarkts verstößt ${ }^{302}$. Anrechnungssysteme stehen immer wieder in der Kritik, Ausländer zu benachteiligen ${ }^{303}$. Insofern dürften Maßnahmen, die sich speziell gegen Beteiligungsveräußerungen von Steuerausländern an Steuerinländer richten, erst recht gegen die Kapitalverkehrsfreiheit verstoßen ${ }^{304}$. Interpretiert man den aktuellen $\S 50 \mathrm{c} \mathrm{EStG}$ allerdings so, daß Absatz 11 der Börsenklausel vorgeht, so kann ein spezieller $\S 50 \mathrm{c}$ EStG gegen die Grundfreiheiten des Binnenmarktes nicht (mehr) behauptet werden. Allerdings steht das begleitende Anrechnungsverbot wie das Körperschaftsteuersystem selbst weiterhin in der Diskriminierungskritik der Ökonomen.

Pauschalierende Maßnahmen gegen das Dividendenstripping wie die 10-TageRegelung der Börsenklausel oder ein mögliches generelles Verbot einer ausschüttungsbedingten Gewinnminderung erhöhen allerdings die Kosten der Eigenfinanzierung und zerstören damit die allokativen Eigenschaften des Vollanrechnungssystems, die dieses bei rein inländischer Betrachtungsweise hat. Hiervon ist zumindest der Aktienerwerb für inländisches Betriebsvermögen von Steuerinländern betroffen, weil die klassische Besteuerung auf die Steuerinländer übertragen wird, da der Fiskus die Einmalbesteuerung beim Steuerausländer selbst nicht durchsetzen kann.

302 Offenbar ist auch die EU-Komission der Meinung, daß das deutsche Körperschaftsteuersystem in seiner Beschränkung auf Inländer gegen die Kapitalverkehrsfreiheit verstőßt; vgl. Schreiben der Europäischen Kommission vom 31.10.1995 an die deutsche Bundesregierung, siehe hierzu Hubner, R. (1996): Fehler im System, in: Capital, o.Jg./(1996), Nr. 4 S. $159 \mathrm{f}$.

303 Entsprechende Kritik hat die Kommission auch schon früher an den Teilanrechnungssystemen Belgiens und Frankreichs geäußert; vgl. Mersmann, W. (1971): Diskriminierung ausländischer Beteiligungen bei der Körperschaftsteuerreform?, in Deutsche Steuer-Zeitung [A], 59. Jg./(1971), Nr. 19, S. 311. 
Dies ist allerdings nur eingeschränkt von den deutschen Maßnahmen gegen das Dividendenstripping zu erwarten, da diese - insbesondere durch Ausweichen auf Dividendenstripping ohne Veräußerungsvorgänge - umgehbar erscheinen.

\subsubsection{Steuerliche Beeinflussung der Gewinnverwendung}

Schon 1961 haben Miller und Modigliani gezeigt, daß in einer Welt ohne Steuern eine Dividendenpolitik überflüssig wäre ${ }^{305}$. Dies galt allerdings nur unter der Annahme vollkommener Kapitalmärkte. Steuern und Marktunvollkommenheiten begründen dagegen die Dividendenpolitik von Kapitalgesellschaften. Die Notwendigkeit einer Dividendenpolitik im Fall unterschiedlicher Steuersätze auf einbehaltene und ausgeschüttete Gewinne erkannten 1967 Farrar und Selwyn ${ }^{306}$. Dieser später als Clientele-Effekt bezeichnete Ansatz geht davon aus, daß Unternehmen bei ihrer Ausschüttungspolitik den Steuersatz ihrer Anteilseigner berücksichtigen. Generell gilt dabei, daß Anleger mit einem hohen Grenzsteuersatz niedrige bzw. gar keine, Kleinaktionäre mit niedrigem Grenzsteuersatz dagegen hohe Ausschüttungen bevorzugen. Unterstellt man derartig unterschiedliche Interessengruppen auf der Nachfrageseite des Markts für Dividendenpapiere, so kann es nur Ziel der Dividendenpolitik eines Unternehmens sein, bei der Fixierung der Dividende einen Mittelweg zu finden.

Es wurde bereits erörtert, daß das Vollanrechnungssystem Gewinnverwendungsneutralität herstellt, wenn der Thesaurierungssatz in der Nähe des Spitzensatzes der Einkommensteuer liegt. Damit verliert der Clientele-Ansatz an praktischer Relevanz. Anders verhält es sich im klassischen Körperschaftsteuersystem. Dieses System begünstigt die Gewinnthesaurierung. Das deutsche Körperschaftsteuersystem wirkt nach außen klassisch, da es die internationale Doppelbelastung nicht beseitigt. Damit gilt keine Gewinnverwendungsneutralität für Unternehmen mit ausländischen Anteilseignern. Im klassischen System wird der Clientele-Effekt relativ häufig zur Erklärung der Dividendenpolitik herangezogen ${ }^{307}$. Entsprechend kann man dies auch in Deutschland tun, da immerhin etwa die Hälfte aller Anteilseigner auf dem deutschen Kapitalmarkt zur Gruppe der Nichtanrechnungsberechtigten zählt.

305 Vgl. Miller, M.H. / Modigliani, F. (1961): Dividend Policy, Growth and the Valuation of Shares, in: Journal of Business, Vol. 34/(1961), S. 411-433.

306 Vgl. Farrar, D. / Selwyn, L. (1967): Taxes, Corporate Financial Policy and Return to Investors, in: National Tax Journal, Vol. 11/(1967), S. 444-454.

307 Vgl. z.B. Poterba, J.M. / Summers, L.H. (1984): New Evidence that Taxes Affect the Valuation of Dividends, in: Journal of Finance, Vol. 39/(1984), S. 1397-1415. 
Ist einer Kapitalgesellschaft bekannt, daß eine große Gruppe der Anteilseigner ausländische Anteilseigner sind, die einer Doppelbelastung aus inländischer Körperschaftsteuer und ausländischer Einkommensteuer unterliegen, müßte sie gemäß Clientele-Ansatz Gewinnthesaurierung betreiben. Dies gilt allerdings nicht, wenn Nichtanrechnungsberechtigte frei sind, Veräußerungsgewinne statt Dividenden zu beziehen, also wenn es keine wirksamen Bestimmungen zum Dividendenstripping gibt. Freilich müßte die Dividendenpolitik auch noch Transaktionskosten berücksichtigen, die mit dem Dividendenstripping entstehen. Im Fall fehlender gesetzlicher Beschränkungen liegen diese Transaktionskosten niedrig und umfassen nur Maklerkosten, Courtagen usw. Restriktionen gegen das Dividendenstripping erhöhen die Transaktionskosten und erreichen bei entsprechender Effektivität eine prohibitive Wirkung.

Die beim Dividendenstripping erlangten Veräußerungsgewinne werden in der Regel nur im Wohnsitzland der Besteuerung unterworfen. Freilich hätte der ausländische Anteilseigner auch Anteile eines Unternehmens, das ausschließlich thesauriert, mit einem Veräußerungsgewinn verkaufen können. Allerdings wäre er dann nicht in den (anteiligen) Genuß des Körperschaftsteuerguthabens gekommen. Hinsichtlich der zum Normalsatz versteuerten offenen Reserven wäre er sogar mit einem sehr viel ungünstigeren Körperschaftsteuersatz doppelt belastet. Bei Veräußerung wäre die anteilige Besteuerung der offenen Reserven für ihn definitiv - sofern beim Verkauf keine spätere Ausschüttung in Verbindung mit einer Herabschleusung der Körperschaftsteuer auf den Ausschüttungssatz antizipiert wird.

Ein Verzicht oder eine erfolglose Bekämpfung des Dividendenstripping führt folglich eher zu einer ausschüttungsorientierten Politik. Eine erfolgreiche Unterbindung des Dividendenstripping führt dagegen eher zu Gewinnthesaurierungen in Unternehmen, die ihre Dividendenpolitik zugunsten nichtanrechnungsberechtigter Anteilseigner ausrichten - sofern ein Ausweichen auf Gesellschafterfremdfinanzierung nicht in Frage kommt. Wie gezeigt, ist es mehr als zweifelhaft, daß die Möglichkeiten des Dividendenstripping in Deutschland tatsächlich unterbunden wurden. Insofern ist kaum mit einer Veränderung des Ausschüttungsverhaltens etwa einer verstärkten Thesaurierung - aufgrund der gesetzlichen Maßnahmen der letzten Jahre zu rechnen. Hiervon ist erst recht deswegen auszugehen, weil die Gewinnthesaurierung ein relativ teurer Finanzierungsweg ist. Eine spürbare Auswirkung des Dividendenstripping und seiner Bekämpfung auf die Dividendenpolitik der Kapitalgesellschaften ist daher kaum zu erwarten.

Dies gilt um so mehr deswegen, weil eine börsennotierte Kapitalgesellschaft in der Regel nicht die Struktur ihrer nicht wesentlich beteiligten Anteilseigner kennt. Sie wird davon ausgehen müssen, daß ihre Anteilseigner überwiegend inländische, 
anrechnungsberechtigte Anteilseigner sind. In konkreten Abstimmungssituationen ist letztlich der Steuerstatus des Mediananteilseigners ausschlaggebend.

Neben dem Steuerstatus ist für die Dividendenpolitik der marginale Grenzsteuersatz des Grenzanlegers interessant ${ }^{308}$, der nach einer Studie von Bay in Deutschland ebenfalls eher ein privater Investor ist, bei dem Dividenden voll besteuert werden, Kapitalgewinne dagegen steuerfrei bleiben ${ }^{309}$. Die Ermittlung des marginalen Steuersatzes des Grenzanlegers ist dabei grundsätzlich nicht ganz einfach, sie läßt sich aber abschätzen am Kursabschlag von Aktien in den Tagen nach der Dividendenausschüttung ${ }^{310}$. Aus den Angaben von Bay könnte man folgern, daß auch bei der Betrachtung des Grenzanlegers eher der anrechnungsberechtigte Anteilseigner im Mittelpunkt der Dividendenpolitik der Unternehmen steht. Allerdings muß man sich fragen, ob in der Praxis tatsächlich Unternehmen in ihrer Dividendenpolitik den marginalen Steuersatz des Grenzanlegers berücksichtigen, oder ob sie aus Gründen der Einfachheit den Durchschnittssteuersatz der Anteilseigner vorziehen ${ }^{311}$.

Es wird künftig daher kaum möglich sein zu ermitteln, welche Veränderungen in der Dividendenpolitik deutscher Kapitalgesellschaften auf die Problematik des Dividendenstripping zurückzuführen sind. Reaktionen können höchstens bei Kapitalgesellschaften erwartet werden, denen bekannt ist, daß ein Großteil der Anteilseigner ausländische Nichtanrechnungsberechtigte sind.

\subsubsection{Auswirkungen auf den Börsenhandel}

Grundsätzlich gilt, daß eine höhere Besteuerung von ausgeschütteten Gewinnen (KSt,a und p.ESt) im Vergleich zu thesaurierten Gewinnen (KSt,e und ggf. Veräußerungsgewinnbesteuerung) dazu führen müßte, daß Kapitalanleger eine entsprechend höhere Vor-Steuer-Rendite des Dividendeneinkommens verlangen bzw. motiviert werden, daß Steuergefälle auszunutzen. Denn Kapitaleinkommen läßt 308 Vgl. Sörensen, P.B. (1995): Changing Views of the Corporate Income Tax, in: National Tax
Journal, Vol. 48/(1995), Nr. 2, S. 292.

309 Vgl. Bay, W., a.a.O. S. 147.

310 Vgl. Elton, E, / Gruber, M. (1970): Marginal Stockholder Tax Rates and the ClienteleEffect, in: Review of Economics and Statistics, 52. Jg./(1970), S. 68-74.

311 Vgl. hierzu die Ausfuhrungen von de Bartolome, dessen statistische Studie sich allerdings auf das ökonomische Verhalten von Haushalten bezieht: de Bartolome, C.A.M.(1995): Which tax rate do people use: Average or marginal?, in Journal of Public Economics, Vol. $56 /(1995)$, S. 80ff. 
sich hier immer auf zwei Wegen erzielen: direkt, indem Aktien über den Ausschüttungstag gehalten werden, oder indirekt, indem Aktien vor dem Auschüttungstag verkauft und später zurückgekauft werden. Das Dividendenstripping ist also nichts anderes als ein Marktprozeß, der zu einem Ausgleich einer steuerlichen Differenzierung direkter und indirekter Dividendenvereinnahmung führt.

Je stärker sich Veräußerungsgewinnbesteuerung und Dividendenbesteuerung unterscheiden, desto eher ist damit zu rechnen, daß der Handel mit Dividendenpapieren um den Termin der Dividendenausschüttung angeregt wird. Auf entsprechende Ergebnisse kommen $W u$ und $H s u$ in einer ökonometrischen Studie über die Auswirkung einer Erhöhung der Veräußerungsgewinnbesteuerung im Jahr 1986 in den USA. Dort existierte vor der Steuerreform eine Veräußerungsgewinnbesteuerung, die etwa bei $40 \%$ der für Dividenden üblichen Einkommensteuer lag. Mit der Steuerreform wurde die Besteuerung von Dividenden und Veräußerungsgewinnen aus Wertpapierverkäufen nahezu angeglichen. Seit der Reform war ein signifikanter Rückgang des Börsenhandels um den Dividendenstichtag zu beobachten ${ }^{312}$.

Wie bei jedem Arbitragehandel, so ist es auch im Fall des Dividendenstripping nicht erforderlich, daß sich die unterschiedlichen Preise auf vergleichbare Güter, bzw. in diesem Fall die unterschiedlichen Steuersätze auf vergleichbare Kapitaleinkommen, absolut angleichen. Ausgehend von unvollkommenen Märkten ist entscheidend, welche Transaktionskosten der Arbitragehandel auslöst. Auch jedes Börsengeschäft erzeugt Transaktionskosten. Solange der Gewinn aus dem Arbitragegeschäft diese Transaktionskosten nicht trägt, solange werden StrippingGeschäfte unwirtschaftlich sein und deswegen nicht stattfinden. Zu den Transaktionkosten zählen nicht nur Courtagen und Provisionen, sondern auch Kursrisiken und nicht zuletzt Informationskosten.

Auch auf deutschen Kapitalmärkten wird seit langem eine relativ hohe Umsatztätigkeit bei Aktien um den Dividendenausschüttungstermin beobachtet. Es ist fraglich, inwieweit diese Geschäfte aus Motiven des Dividendenstripping oder aus anderen Gründen erfolgen. Nicht selten wurde eine Beeinträchtigung der Funktionsfähigkeit der Börse aufgrund des Dividendenstripping befürchtet. Insbesondere bei marktengen Wertpapieren können Stripping-Geschäfte zu beträchtlichen Kursschwankungen führen. In der zweiten Hälfte der achtziger und zu Beginn der neunziger Jahre, insbesondere 1991, stiegen die Umsätze einzelner Aktien in den jeweiligen Dividendenmonaten sehr stark an. Mitunter verdoppelten sich die Geschäftsvolumina sogar. Augenfälliger noch in dieser Zeit waren die Umsätze mit

312 Vgl. Wu, C. / Hsu, J: The Impact of the 1986 Tax Reform on Ex-Dividend Day Volume and Price Behaviour, in: National Tax Journal, Vol. 49/(1996), S. $185 f$. 
jungen Aktien. Umsätze von wenigen 100 Stück pro Monat schnellten aufgrund von Leerverkäufen auf Größenordnungen von mehreren Millionen Stück empor $^{313}$.

Neben der Umgehung der steuerbehördlichen Verfolgung mag die Vermeidung von Kursschwankungen ein Hauptmotiv dafür sein, daß viele Stripping-Geschäfte an der Börse vorbei stattfinden. Die Börse dient dabei nur zur Unterlegung des Stripping-Geschäftes mit einem amtlichen Kurs. Aufsehen erregte vor allem ein Fall, in dem ein Geschäft über 35 junge Aktien zwar über den amtlichen Kursmakler abgewickelt wurde, deren festgestellter Kurs jedoch zugleich als Preis für 100.000 Stück aus derselben Transaktion zwischen den Geschäftspartnern dien$\mathrm{te}^{314}$.

1992 ließ sich dagegen ein Rückgang von Umsätzen um den Dividendenterminen feststellen. Die Schlußfolgerung der Landeszentralbank Hessen, daß eine zunehmende Zahl der Börsenteilnehmer nicht mehr bereit gewesen sei, an Wertpapiergeschäften zum Zwecke des Dividendenstripping mitzuwirken ${ }^{315}$, dürfte allerdings zu optimistisch sein. Wahrscheinlicher ist wohl, daß Dividendenstripping - zumindest aber das Gegengeschäft seitdem zunehmend außerhalb der Börse stattfindet - über die DTB abgewickelt wird.

Möglicherweise sind die Auswirkungen der gesetzlichen Gegenmaßnahmen zur Unterbindung des Dividendenstripping weitaus schwerwiegender als die eben diskutierten direkten Auswirkungen dieser Steuergestaltungsform. Die häufigsten Kritikpunkte sollen im folgenden vorgestellt werden.

\subsubsection{Attraktivität des Aktienmarktes}

Auch die gesetzlichen Gegenmaßnahmen entfalten Wirkungen auf den Aktienmarkt. So führt die Zehn-Tages-Frist um den Dividendenstichtag zu einer faktischen Handelssperre. Anrechnungsberechtigte Anteilseigner können Beteiligungen innerhalb von zehn Tage vor dem Dividendenstichtag zwar erwerben, aber aufgrund der gesetzlichen Regelung nur verkaufen, wenn sie bereit sind, eine steuerliche Doppelbelastung zu tragen. Sie sind damit einem erhöhten Kursrisiko ausgesetzt.

313 Vgl. o.Verf. (1994) Strip in der Zockerstube, in: Der Spiegel, Jg./(1994), Nr. 34, S. 65.

314 Vgl. Landeszentralbank Hessen (1992): "Dividendenstripping" im Zwielicht, in: Frankfurter Finanzmarktbericht Nr. 11/92, S. 5 f.

315 Vgl. Landeszentralbank Hessen (1992), a.a.O., S. 6 f. 
Im Fall unvorhergesehener Ereignisse z.B. überraschend negativer Informationen auf der Hauptversammlung, werden resultierende Kursverluste um steuerliche Nachteile erhöht. Entsprechend wird die Nachfrage nach Beteiligungen durch $\S$ 50c Abs. 10 Buchst. a EStG zurückgedrängt.

Gleiches gilt zumindest für den Teil von Kurssicherungsgeschäfte und Wertpapierleihgeschäften, soweit die Marktteilnehmer eine Wirksamkeit des $\S 50 \mathrm{c}$ Abs. 10 Buchst. b EStG bzw. § $36 \mathrm{EStG}$ erwarten bzw. befürchten. Die Zurückdrängung von Kurssicherungsgeschäften dürfte die Attraktivität des deutschen Aktienmarkt generell schwächen, zumal Kurssicherungsgeschäfte weltweit eine wachsenden Bedeutung haben.

Sollte die Gesetzesänderungen des Jahres 1997 tatsächlich die Börsenklausel insgesamt aushebeln, so ist damit zu rechnen, daß inländische Anteilserwerber eine höhere Bruttorendite der Eigenkapitalbeteiligungen einfordern werden oder auf andere Investitions- bzw. Anlagemöglichkeiten ausweichen werden, weil pauschale Verwehrungen von ausschüttungsbedingten Teilwertabschreibungen wie eine Steuererhöhung auf den Dividendenbezug wirken.

\subsubsection{Spaltung des Aktienmarktes}

In der politischen Diskussion des Jahres 1993 über die Reform der alten Börsenklausel wurde der Gedanke an eine völlige Streichung der Börsenklausel schnell wieder verworfen. Man befürchtete unerwünschte Marktwirkungen - z.B. einen gespaltenen Aktienmarkt: der Markt müsse dann differenzieren zwischen zwischen sogenannten 50-c-Aktien mit niedrigeren Kursen und Nicht-50-c-Aktien mit höheren Kursen ${ }^{316}$.

Der $\S 50 \mathrm{c}$ EStG in der aktuellen Fassung hat nicht zu einem gespaltenen Aktienmarkt geführt. Dies überrascht, weil die neue Börsenklausel aufgrund des nicht erfüllbaren Entlastungsbeweises zu einer automatischen Anwendung des $\S 50 \mathrm{c}$ EStG für die in der Börsenklausel genannten Spezialfälle führt.

Der Grund düfte wohl darin liegen, daß alle Aktiengeschäfte von den negativen Wirkungen des $\S 50 \mathrm{c}$ EStG betroffen sind. Ein gespaltener Aktienmarkt wäre nur bei Beweisbarkeit des Erwerbs von Anrechnungsberechtigten möglich und dann sogar zwangsläufig gewesen. Die Tatsache des einheitlichen Aktienkurses seit 1994 ist der beste Beleg für die Unerfüllbarkeit der Entlastungsklausel. Dies gilt natürlich erst recht für die seit 1997 gegebene Situation, nach der für alle Aktien-

316 Vgl. Dötsch, E. (1993b), a.a.O., S. 16. 
geschäfte, bei denen Anrechnungsberechtigte Anteile für ihr Betriebsvermögen erwerben, eine entlastende Nachweispflicht besteht, sofern der Sperrbetrag des $\S$ 50c EStG gemieden werden soll. Daher schließt gerade die neue Rechtslage eine Spaltung des Aktienmarktes nahezu aus.

\subsection{Distributive Folgen des Strippings und der Gegenmaßnahmen}

\subsubsection{Interpersonelle Steuergerechtigkeit}

Eine Beschränkung der Körperschaftsteueranrechnung auf Steuerinländer führt möglicherweise zu einem Verstoß gegen die interpersonelle Steuergerechtigkeit. Dies gilt aber nur, sofern man eine ausländische Einkommensteuer unterstellt, die der deutschen Einkommensteuer entspricht, und dann auch nur, wenn man den inländischen Anteilseigner deutscher Beteiligungen mit dem ausländischen Anteilseigner entsprechender Wertpapiere vergleicht. Fraglich ist, ob dieser Vergleich angemessen ist.

Möglicherweise unterliegt die Bruttodividende eines Steuerausländers auch mit 30\%iger definitiver Körperschaftsteuer einer geringeren Belastung als die Dividende einer Inlandsanlage in seinem Wohnsitzland. Dies ist z.B. der Fall, wenn der Steuerausländer aus einem Land mit klassischem System kommt, in dem der Körperschaftssteuersatz über $30 \%$ liegt und die ausländische Einkommensteuer der deutschen Einkommensteuer entspricht. Eine Betrachtung dieser Besteuerung zwischen Ausländern, die in ihrem Heimatland Beteiligungen halten, und Ausländern, die deutsche Beteiligungen halten, macht deutlich, daß der Anteilseigner mit deutschen Wertpapieren bevorzugt besteuert wird. Schlußfolgerungen zur interpersonellen Gerechtigkeit lassen sich also nur sehr vorsichtig ziehen. Es zeigt sich jedoch, daß die interpersonelle Gerechtigkeit ohne umfassende Steuerharmonisierung bezüglich der Steuersätze und der Bemessungsgrundlage entweder nur im Quellenland oder nur im Wohnsitzland erreicht werden kann.

Nimmt man eine gleiche Gesamtbesteuerung als Maßstab für interpersonelle Steuergerechtigkeit, so müßte ein Anrechnungsland auch ausländische Körperschaftsteuern im Rahmen der Einkommensteuer anrechnen ${ }^{317}$. Dies steht aber im Widerspruch zur finanzwissenschaftlichen Ansicht, daß unterschiedliche Steuersysteme und Besteuerungshöhen Ausdruck unterschiedlicher Politikpräferenzen

317 Eine Anrechnung ausländischer Körperschaftsteuer empfiehlt der Ruding-Report. Eine entsprechende Regelung war auch im Entwurf des Standortsicherungsgesetzes vorgesehen. Sie scheiterte allerdings im Bundesrat und wird seitdem fortwăhrend eingefordert; vgl. Zeitler, F.-C. / Krebs, H.-J. (1993): "Europataugliches" Anrechnungsverfahren im Standortsicherungsgesetz, in: Der Betrieb (DB), 46.Jg./(1993), Nr. 21, 28.05.1993, S. $1051 \mathrm{ff}$. 
verschiedener staatlicher Gemeinschaften sind. Warum aber sollte ein Staat auf Steuern verzichten bzw. Kapitalexporte subventionieren, nur weil beispielsweise hohe Präferenzen für öffentliche Güter im anderen Staat dort für ein hohes Steuerniveau sorgen?

Aus dem eben Gesagten wird deutlich, daß ein Dividendenstripping distributiv unterschiedlich beurteilt werden kann. Die interpersonelle Gerechtigkeit gegenüber anrechnungsberechtigten Steuerinländern wird durch Stripping-Geschäfte erhöht. Dies gilt allerdings nur, wenn das Wohnsitzland des Ausländers eine der deutschen Einkommensteuer entsprechende Steuer auf die Veräußerungsgewinne erhebt. Besteuert das Ausland die Veräußerungsgewinne nicht, wird die interpersonelle Gerechtigkeit gegenüber den anrechnungsberechtigten Steuerinländern verletzt:

Der Steuerausländer unterliegt dann keiner Besteuerung - sieht man einmal von der auch durch Stripping-Geschäfte nicht zu umgehenden restlichen Definitivkörperschaftsteuer $a b$.

Zieht man das ausländische Körperschaftsteuersystem mit in Betracht, so fällt das Ergebnis noch vielschichtiger aus: Dividendenstripping begünstigt nämlich ausländische Anteilseigner aus Staaten mit klassischen Systemen gegenüber ihren Landsleuten, die nur im Wohnsitzland Beteiligungen halten. Es kommt zu einer Quasi-Ausdehnung des Anrechnungssystems auf Anteilseigner in Ländern, die selbst nur klassisch besteuern. Im Ergebnis werden Kapitalimporte aus Ländern mit klassischen Körperschaftsteuersystemen induziert.

\subsubsection{Interstaatliche Steueraufkommensverteilung}

Die Feststellung, daß Deutschland als Quellenland der Dividenden durch das Dividendenstripping Steuerausfälle erleidet, ist trivial. Wie erwähnt, gingen die Steuerausfälle allein der aufgedeckten Stripping-Geschäfte zu Beginn der neunziger Jahre in das Millionenfache. Die Gesamtverluste seit Einführung des Vollanrechnungssystems sind kaum quantifizierbar.

Ebenso trivial ist die Erkenntnis, daß eine gesetzliche Unterbindung des Dividendenstripping Steuerumgehungen reduzieren und Steuereinnahmen erhöhen könnte. Allerdings ist jedes Verbot nur so gut wie seine praktische Durchsetzbarkeit. An letzterer muß - besonders was $\S 50 \mathrm{c}$ Abs. 10 Buchst. b EStG und das neue Anrechnungsverbot für Stripping-Geschäfte ohne Veräußerungen anlangt - gezweifelt werden. Das Dividendenstripping mit jungen Aktien und nachgewiesene außerbörsliche Absprachen werden dagegen grundsätzlich verfolgt. Außerbörsliche Ge- 
schäftsabsprachen aufzudecken ist allerdings ein Problem, das auf freien und anonymen Kapitalmärkten kaum durch Gesetze zu lösen ist.

Die Steuerausfälle durch Dividendenstripping beschränken sich dabei nicht allein auf das Quellenland. Nicht selten verliert auch das Wohnsitzland des ausländischen Anteilseigners Steueraufkommen. Einerseits gelten in vielen Staaten, z.B. in Großbritannien und den Niederlanden, im Vergleich zur Einkommensteuer auf Dividenden ermäßigte Steuersätze für Veräußerungsgewinne. Andererseits besteht für im Ausland erzielte Veräußerungsgewinne wie bei anderen Kapitaleinkommen auch eine erhöhte Hinterziehungsanfälligkeit. Ähnlich wie bei Zinseinkünften gibt es für Veräußerungsgewinne keine grenzüberschreitende Meldepflicht. Somit ist der Wohnsitzstaat bei Kapitalverkehrfreiheit auf die Ehrlichkeit seiner steuerpflichtigen Bürger angewiesen. Diese Ehrlichkeit wird aber weniger angereizt als im Fall des Dividendenbezugs, da es keine im Wohnsitzland anrechenbare Kapitalertragsteuer auf deutsche Veräußerungsgewinne gibt.

Ob und wieviel Steueraufkommen das Wohnsitzland des ausländischen Anteilseigners durch Dividendenstripping verliert, hängt von der Differenz der Steuersätze für Dividenden und Veräußerungsgewinne ab. Sofern das Wohnsitzland eine einheitliche Besteuerung der Kapitaleinkommen kennt, kann es ein Mehraufkommen erzielen, da der Steuerausländer durch Teilung des Anrechnungsguthabens einen höheren Veräußerungsgewinn erzielt als die bei Dividendenbezug erhaltene Nettodividende.

Es zeigt sich, daß jedes Dividendenstripping, das zu einer Weitergabe von Körperschaftsteuerguthaben an Steuerausländer führt, auch die zwischenstaatliche Steuerverteilung in Frage stellt. Während ein Land mit klassischem System das Dividendenstripping zur Erlangung von Körperschaftsteuerguthaben systembedingt nicht zuläßt, laufen Staaten mit Anrechnungssystemen grundsätzlich Gefahr, Körperschaftsteuerverluste hinnehmen zu müssen, da die Einmalbelastung körperschaftsteuerpflichtiger Gewinnen unterlaufen wird. Unterstellt man allerdings, daß Anrechnungsstaaten mit Möglichkeiten zum Dividendenstripping Anleger aus Ländern mit klassischen Körperschaftsteuersystemen anlocken, so verlieren auch diese Länder potentielle Steuereinnahmen. Das Kriterium der zwischenstaatlichen Steuergerechtigkeit wird aber in erster Linie zu Lasten der Anrechnungsländer verletzt.

\subsection{Steuersystematische Aspekte}

Sowohl die Verwehrung der ausschüttungsbedingten Teilwertabschreibung als auch das neue Anrechnungsverbot stellen in gewisser Weise nur Hilfslösungen 
dar. Beide Bestimmungen sind letztlich nicht steuersystematisch. Eine systematische Lösung wäre es, sicherzustellen, daß Nichtanrechnungsberechtigte nicht über einen erhöhten Verkaufspreis in den anteiligen Genuß des Körperschaftsteuerguthabens gelangen. Aufgrund des fehlenden steuerlichen Zugriffs des inländischen Fiskus auf Veräußerungsgewinne ausländischer, beschränkt steuerpflichtiger Anteilseigner, setzen alle Maßnahmen bei der Gruppe der unbeschränkt Steuerpflichtigen $a^{318}$. Die gesetzlichen Regelungen, deren Ziel die Bekämpfung der Steuerhinterziehungstaktik einer einzelnen Gruppe war, wirkt sich damit aber als Last für alle Aktionäre aus. Bedenkt man, daß auch die anrechnungsberechtigten Partner bei Stripping-Geschäften Vorteile aus dem Zustandekommen dieser Geschäfte ziehen konnten, wäre dies hinnehmbar. Da aber davon auszugehen ist, daß die überwiegende Mehrheit aller anrechnungsberechtigten Anleger StrippingGeschäfte - zumindest nicht bewußt - eingeht bzw. eingegangen ist, kann die für sie nachteilige Gesetzesänderung, insbesondere das gestiegene Risiko der Nichtanerkennung einer Teilwertabschreibung, als ein excess burden gewertet werden.

\subsection{Reformvorschläge zur effizienteren Bekämpfung des Dividendenstrip- ping}

\subsubsection{Vorschläge für eine effiziente Durchsetzung der bestehenden Gesetze gegen das Dividendenstripping}

Als radikalster Vorschlag können die Aufgabe der Börsenanonymität und die Beseitigung des Bankgeheimnisses angesehen werden. Ein derartiges Vorgehen hat aber eine abschreckende Wirkung auf in- und ausländische Anleger, weil Börsenanonymität und Bankgeheimnis in den meisten westlichen Volkswirtschaften wenn auch im unterschiedlichen Ausmaß - eine Selbstverständlichkeit sind. Eine Abschaffung des Bankgeheimnisses oder eine entsprechende Ankündigung dürfte eine massive Kapitalflucht auslösen, vergleichbar der Kapitalflucht bei Ankündigung der Zinsabschlagsteuer. Die Kontrollmaßnahmen würden zudem die Marktoffenheit beeinflußen, und die Entwicklung von Finanzinnovationen beeinträchtigen.

Freilich wurde eine Verschärfung der Börsenaufsicht auch im Zusammenhang mit der Bekämpfung des Dividendenstripping eingeführt ${ }^{319}$, indem z.B. DTB-Aufträge nur mit bestimmten Zeitabständen in das Computersystem eingegeben werden

318 Vgl. Dotsch, E. (1993b), a.a.O., S. 28, bzw. ders. (1993a), a.a.O., S. 1848.

319 Vgl. Kindermann, E. (1994), a.a.O., S. 877. 
dürfen oder Kompensationsgeschäfte an der Börse zwischen identischen Käufern und Verkäufern mit einem Zusatzvermerk "C" versehen werden müssen. Derartige Regelungen versagen aber bei gegenseitiger Zeitabstimmung oder bei der Zwischenschaltung von Dritten.

Eine eher marktorientierte Lösung schlägt van Lishaut vor. Danach soll der Handel um sogenannte $50 \mathrm{c}$-Zertifikate erweitert werden. Wenn ein Veräußerer einer Beteiligung § 50c EStG nicht auslöst, so sollte er nach van Lishaut die Möglichkeit haben, beim Aktienverkauf zugleich seine entlastenden Unterlagen an eine Bank oder ein börsennahes Institut veräußern zu können. Würde das Institut nun ein 50c-Zertifikat ausstellen, mit dem der Erwerber beweisen könnte, daß seine Anteile nicht 50c-behaftet sind, könnte ein zeitnaher Erwerb von Beteiligung und 50c-Zertifikat dazu führen, daß der Erwerber keinen Sperrbetrag bilden muß. Das börsennahe Institut müßte die 50c-Zertifikate an den Erwerber von entsprechenden Anteilen veräußern. Damit wäre die systemgerechte steuerliche Behandlung eines bestimmten Aktienpakets nicht gewährleistet. Vielmehr läge es im Ermessen des Erwerbers, eine Behandlung nach $\S 50 \mathrm{c} \mathrm{EStG}$ über sich ergehen zu lassen oder sich davon freizukaufen. Gewonnen wäre so die Sicherheit, daß § 50c EStG insgesamt in Börsengeschäften dem Volumen nach weder zu häufig noch zu selten zur Anwendung käme. Auch das schwierige Nachweisproblem hätte sich erledigt. ${ }^{320}$

Van Lishaut macht seinen Vorschlag zur Durchsetzung des §50c Abs. 11 EStG. Tatsächlich wäre die vorgestellte Lösung auch in der zwischen 1994 und 1997 gültigen Gesetzeslage (neue Börsenklausel ohne $\S 50 \mathrm{c} \mathrm{Abs.} 11 \mathrm{EStG}$ ) denkbar gewesen. Allerdings hätte der Handel mit Zertifikaten ein unvergleichlich höheres Ausmaß angenommen als in der aktuellen Situation.

$\mathrm{Ob}$ es für den Erwerber in der aktuellen Gesetzeslage einen Unterschied bedeutet, 50c-behaftete oder 50c-freie Anteile zusammen mit einem 50c-Zertifikat zu erwerben, hängt von der Preisbildung auf dem Zertifikatemarkt ab. Der Preis der 50c-Zertifikate muß sich nach dem zu bildenden Sperrbetrag, dem erwarteten Ausschüttungsverhalten und dem durchschnittlichen Steuersatz aller potentiellen Erwerber richten. Der Zertifikatehandel führt allerdings zu einer Nivellierung der Steuerlast aller Anteilserwerber. Im Ergebnis bildet sich ein Markt für das tarifbedingte Dividendenstripping.

Allerdings löst ein Zusatzhandel mit sogenannten Steuerzertifikaten beträchtlichen organisatorischen und bürokratischen Aufwand aus. Weitaus einfacher wäre es,

320 Vgl. van Lishaut, I. (1997): Gesetz zur Fortsetzung der Unternehmenssteuerreform: Der neue Absatz 11 des § 50c EStG, in: Der Betrieb (DB), 50. Jg./(1997), Nr. 44, S. 2192. 
eine Kenntlichmachung der 50c-Infizierung direkt auf den Wertpapieren durch einen Zusatzvermerk kenntlich zu machen oder, wie Dötsch vorschlägt, durch Ergänzung der jeweiligen Wertpapierkenn-Nummer ${ }^{321}$. Ein derartiger Zusatzvermerk müßte aber zwangsläufig zu zwei unterschiedlichen Kursen je Aktienart führen, er erfordert zudem eine Verbesserung der Börsenaufsicht und des Computerhandels.

\subsubsection{Alternative Lösungsansätze zur Unterbindung des Dividendenstrip- ping}

Es existiert eine Reihe alternativer Lösungsansätze zur Einschränkung des Dividendenstripping. Im folgenden sollen weniger radikale Ansätze diskutiert werden. Tiefergehende Lösungsansätze, die das Dividendenstripping und die Gesellschafterfremdfinanzierung durch Steuerausländer unterbinden sollen, werden im sechsten Kapitel behandelt.

\subsubsection{Limitierung verdächtiger Aktienbestände}

Während der Beratungen zum Standortsicherunggesetz hat die deutsche Börsenund Kreditwirtschaft eine alternative Börsenklausel zur Unterbindung des Dividendenstripping vorgelegt ${ }^{322}$. Diese Börsenklausel nahm im wesentlichen außerbörsliche Absprachen und das Dividendenstripping mit jungen Aktien aus der 50c-befreienden Wirkung der Börsenklausel aus. Sie enthielt darüber hinaus eine Pauschalgrenze, die eine Sperrbetragsbildung vorsah, wenn:

“der Erwerber am Tage der Hauptversammlung einer inländischen Aktiengesellschaft außerhalb des Anlagevermögens Aktien dieser Gesellschaft in einem Umfang hält, der den handelstäglichen Durchschnittsbestand im letzten Jahr vor der Hauptversammlung um das Fünffache überschreitet und zwar im Maße der Überschreitung"323.

Eine solche Limitierung verdächtiger Aktienbestände würde eine unvergleichlich höhere Praktikabilität gewährleisten als die aktuellen Gesetze. Andererseits verabschiedet sich eine Pauschalbegrenzung von dem Anspruch, das Dividendenstripping generell zu unterbinden. Eine inländische Einmalbesteuerung wäre so nicht

321 Vgl. Dötsch, E. (1997), a.a.O., S. 1110/5.

322 Zum Wortlaut dieses Vorschlags vgl. Kindermann, E. (1994), a.a.O., S. 875.

323 Kindermann, E. (1994) ebd. 
aufrechtzuerhalten. Dividendenstripping wäre sogar bis zum Erreichen einer festgelegten Schmerzgrenze legalisiert. Problematisch an derartigen Pauschalgrenzen ist außerdem, daß sie die Ausnutzung des Freiraums erst anregen und z.B. Umverteilungen überschießender Stripping-Geschäfte auf anrechnungsberechtigte Kontrahenten anreizen, deren Freiräume noch nicht ausgenutzt sind.

\subsubsection{Einführung einer Besteuerung von Veräußerungsgewinnen}

Die Erhebung einer inländischen Veräußerungsgewinnsteuer für Aktienveräußerungen würde dazu führen, daß nicht nur jede Ausschüttung sondern auch jede Realisierung eines Gewinns durch Beteiligungsveräußerung besteuert werden würde, insofern könnte ein geschlossenes Besteuerungssystem erreicht werden. Auf den ersten Blick wäre damit eine inländische Einmalbesteuerung gewährlei$\operatorname{stet}^{324}$. Eine zweifelhafte Regelung wie $\S 50 \mathrm{c} \mathrm{EStG}$ wäre so völlig überflüssig und tarifbedingtes Dividendenstripping verhindert.

Die Veräußerungsgewinnbesteuerung kann technisch recht einfach erweitert werden. Man müßte nur eine Senkung der Beteiligungsgrenze für die steuerliche Erfassung von Veräußerungsgewinnen z.B. auf $5 \%^{325}$ vornehmen. Allerdings würde eine solche Absenkung der Beteiligungsgrenze noch nicht ausreichen, da das Dividendenstripping in der Regel mit noch geringeren Beteiligungen stattfindet. Insofern müßte man wohl alle Kursgewinne aus Aktien besteuern. Denkbar wäre natürlich auch eine generelle Besteuerung von Veräußerungsgewinnen als achte Einkommensart. An dieser Stelle soll aber nicht eine generelle Veräußerungsgewinnbesteuerung diskutiert werden, sondern nur eine Besteuerung realisierter Wertzuwächse, die aus dem Verkauf von Beteiligungen stammen.

Nun ist gerade mit der Absenkung der Beteiligungsgrenze auf 10\% und mit der Verlängerung der Spekulationsfristen von sechs Monaten auf ein Jahr eine verschärfte Veräußerungsgewinnbesteuerung in Kraft getreten ${ }^{326}$. Das Dividendenstripping der Steuerausländer bleibt aber von dieser Maßnahme unberührt, wie

324 Vgl. Dötsch, E. (1996), a.a.O., S. 1119.

325 Siehe hierzu den Änderungsantrag der SPD-Bundestagsfraktion im Rahmen der Gesetzesentwürfe für das StMBG, vgl. BT-Drs. 12/6078, S. 5. Eine Absenkung auf $10 \%$ ist gerade vorgenommen worden, vgl. BR-Drs. 129/99, S. 18.

326 Vgl. Bundesministerium der Finanzen (1997): Reform der Einkommensbesteuerung - Vorschlăge der Steuerreform-Kommission vom 22. Januar 1997, "Petersberger Steuervorschläge", in: Schriftenreihe des Bundesministeriums der Finanzen, Nr. 61, Bonn 1997; vgl. Steuerentlastungsgesetz 1999/2000/2002 BR-Drs. 129/99, S. 19. 
gleich erörtert werden wird. Zuvor noch einige grundsätzliche Überlegungen: Eine strengere Besteuerung von Veräußerungsgewinnen wirft grundsätzlich vielfältige Probleme auf. Private sind verstärkt zu Aufzeichnungen über Erwerbspreis und Erwerbsdatum zu verpflichten. Der Finanzverwaltung wachsen noch umfangreichere Kontrollaufgaben zu, die sie zum Teil der Kreditwirtschaft aufbürden $m u \beta^{327}$. Allokativ steht die Veräußerungsgewinnbesteuerung in der Kritik, weil sie zu einer Doppelbesteuerung thesaurierter Gewinne führt und damit gegen die Investitions- Finanzierungs- und Gewinnverwendungsneutralität verstößt. Erzeugt werden Lock-in-Effekte: Eine ökonomisch rationale Veräußerung wird nicht getätigt, weil sie steuerlich sanktioniert wird. Weiterhin entsteht das Problem der Scheingewinnbesteuerung, wenn keine korrekte Inflationsberücksichtigung erfolgt. Fraglich ist auch, ob sich der Preis dieser Besteuerung lohnt. Die in Deutschland relativ unterentwickelte Bedeutung der Aktie als Vermögensanlage ${ }^{328}$ kann so zementiert werden. Die Eigenkapitalbeschaffung an den deutschen Börsen wird erschwert, weil Aktionäre die Veräußerungsgewinnsteuer in ihre Anlageentscheidungen miteinbeziehen und entsprechend höhere Aktienrenditen verlangen oder auf andere Anlageformen ausweichen werden. Die mögliche Einführung einer speziellen Veräußerungsgewinnsteuer auf Beteiligungsvermögen würde zudem das Einkommensteuersystem verstärkt in Richtung einer Schedulenbesteuerung umgestalten.

Ungeachtet dieser Probleme ist auch mit einer erweiterten Veräußerungsgewinnbesteuerung höchstens das Dividendenstripping zwischen Anrechnungsberechtigten und das Dividendenstripping zwischen Anrechnungsberechtigten und inländischen Nichtanrechnungsberechtigten in den Griff zu bekommen. Das Dividendenstripping mit Steuerausländern bleibt auch weiterhin unerfaßt, da das OECD-MA die Besteuerung von Veräußerungsgewinnen aus Beteiligungspapieren allein dem Wohnsitzland zuordnet. Nur in Nicht-DBA-Fällen könnte eine verschärfte, inländische Veräußerungsgewinnbesteuerung greifen, abhängig ist dies allerdings vom Steuererhebungsverfahren. Das aber könnte Zwischenschaltungen von Dritten in DBA-Ländern anregen. Es entständen umgekehrte, aber ähnliche Probleme, die auch zum Scheitern des $\S 39 \mathrm{KStG}$ geführt haben.

Die Durchsetzung des Quellenlandprinzips bei der Veräußerungsgewinnbesteuerung aus beweglichem Vermögen erfordert also eine radikale Abkehr von der bis-

327 Allerdings bestehen auch hier ökonomische und juristische Grenzen; vgl. Hey, J. (1998): Steuern verwalten durch Banken, in: Finanz-Rundschau (FR), 80. Jg./(1998), Nr. 11, S. $497 \mathrm{ff}$.

328 Vgl. Claussen, C.P. (1995): Die vier aktienrechtlichen Änderungsgesetze des 12. Deutschen Bundestages. Reform oder Aktionismus ?, in: Die Aktiengesellschaft (AG), 40. Jg./(1995), Nr. 4, S. $163 \mathrm{f}$. 
herigen Abkommenspraxis. Fraglich ist, ob das Quellenlandprinzip überhaupt zu verwirklichen ist. Der Fiskus des Quellenlandes wäre auf die Mitarbeit der Kreditinstitute, unter Umständen auch auf die des Steuerausländers oder der Steuerverwaltung des Wohnsitzlandes angewiesen. Zumindest denkbar wäre nämlich auch, daß das Wohnsitzland die Veräußerungsgewinne zugunsten des Quellenlandes besteuerte. Letzteres dürfte aber schon am mangelnden Interesse der ausländischen Steuerbehörden scheitern, die zwar keine Einnahmen, wohl aber Verwaltungsaufwand zu tragen hätten. Die Schwierigkeiten der korrekten Erfassung von Veräußerungsgewinnen und des Zugriffs hierauf dürften Hauptursache dafür sein, daß sich das Wohnsitzlandprinzip bei dieser Steuerart durchgesetzt hat.

Auch aus steuersystematischer Sicht scheint eine Veräußerungsgewinnbesteuerung auf Beteiligungpapiere nicht in das deutsche Körperschaftsteuersystem zu passen. Die Veräußerungsgewinnbesteuerung bewirkt eine doppelte Besteuerung der einbehaltenen Körperschaftsgewinne. Dieser doppelte steuerliche Zugriff paßt nicht zur Einmalbesteuerung ausgeschütteter Gewinne: Eine bestehende partielle Finanzierungsneutralität zwischen Selbst- und Beteiligungsfinanzierung und die Gewinnverwendungsneutralität ${ }^{329}$ werden durch eine zusätzliche Veräußerungsgewinnsteuer verletzt. Gleiches gilt für die Rechtsformneutralität zumindest dann, wenn die Selbstfinanzierung nicht vollständig durch Beteiligungsfinanzierung kompensierbar ist. Steuersystematisch paßt die Veräußerungsgewinnbesteuerung damit eher zu einem klassichen Körperschaftsteuersystem. Dort wird die Doppelbelastung ausgeschütteter Gewinne um eine weitere Doppelbelastung ergänzt, was die Diskriminierung zwischen den Formen der Eigenfinanzierung lindert oder beseitigt $^{330}$.

Man könnte meinen, daß eine Veräußerungsgewinnbesteuerung zu einem Vollanrechnungssystem paßt, wenn Veräußerungsgewinne nur zu einem relativ niedrigen Abgeltungssatz besteuert werden, der in Kombination mit der Körperschaftsteuer auf einbehaltene Gewinne in etwa der durchschnittlichen Einkommensteuerbelastung des durchschnittlichen Anteilseigners entspricht. Freilich bedeutet ein Körperschaftsteuersatz auf einbehaltene Gewinne, der spürbar unter dem Spitzensatz der Einkommensteuer liegt, wiederum ein Versto $ß$ gegen die Gewinnverwendungsneutralität und die Rechtsformneutralität. Eine Veräußerungsgewinnsteuer als Ergänzung zu einer relativ niedrigen Thesaurierungsbelastung ist auch aus Investitionsgesichtspunkten bedenklich, weil sich die Abschreibungsmöglichkeiten eines Unternehmens direkt auf die Körperschaftsteuerbelastung aber nur sehr indirekt auf die Veräußerungsgewinnsteuer auswirken.

329 Unterstellt sei ein Körperschaftsteuersatz in der Năhe des Höchstsatzes der Einkommensteuer. 
Die Überlegung, daß eine Besteuerung von Veräußerungsgewinnen zum vollen Einkommensteuersatz nicht in ein Anrechnungssystem paßt, führt allerdings deswegen noch nicht zur Ablehnung dieser Steuer, weil weder Deutschland noch andere Staaten mit Integrationssystemen die Vollanrechnung allen Steuerpflichtigen gewähren. Da auch Staaten mit Anrechnungssystemen gerade bezüglich ausländischer Anteilseigner in der Regel "klassisch" besteuern, ist eine Veräußerungsgewinnbesteuerung nur für Steuerausländer und alle anderen Nichtanrechnungsberechtigten aus systematischer Sicht sogar zwingend. Im Fall der Steuerausländer muß dabei allerdings gewährleistet werden, daß keine mehrfache Veräußerungsgewinnbesteuerung erfolgt.

Trotz der vielfältigen Probleme der Veräußerungsgewinnbesteuerung und der Tatsache, daß eine solche Steuer in Vollanrechnungsstaaten zur Diskriminierung der Selbstfinanzierung führen kann, sehen - anders als Deutschland - viele Länder mit Vollanrechnungssystemen eine Besteuerung der privaten Veräußerungsgewinne aus Anteilsveräußerungen vor. Dies gilt z.B. für Frankreich, Italien, Finnland und Norwegen. Die Duldung einer damit einhergehende Doppelbelastung der thesaurierten Gewinne in Staaten, die ansonsten die Doppelbelastung ausgeschütteter Gewinne ablehnen, mag überraschen. Sofern in den genannten Staaten Steuerausländer von der Veräußerungsgewinnbesteuerung nicht ausgenommen sind, z.B. aufgrund fehlender DBA, könnte ein Dividendenstripping mit Anrechnungsguthaben durch eine derartige Regelung unterbunden werden. Entscheidend für die Gestaltung des Anrechnungshandels zwischen In- und Ausländern ist also die Frage, inwieweit auch die Steuerausländer einer Veräußerungsgewinnbesteuerung im Quellenland der Dividenden unterliegen und inwieweit diese Veräußerungsgewinnbesteuerung praktisch umgesetzt wird.

\subsubsection{Zurechnung der Dividende nach Haltedauer}

Am Beginn dieses Kapitels wurde schon darauf hingewiesen, daß das Dividendenstripping nur möglich ist, weil die Dividende ausschließlich demjenigen zusteht, der zum Zeitpunkt der Gewinnausschüttung Anteilseigner ist. Alternativ könnte man die Dividende den Anteilseignern auch nach der Haltedauer der Beteiligung zurechnen. Dieser Lösungsvorschlag, der zu einer ähnlichen Behandlung von Dividenden- und Zinspapieren führt, scheint allerdings extrem verwaltungsaufwendig. Die anteilige Zurechnung wiederholt den Besitzer wechselnder Dividendenpapiere ist eines der Probleme, an dem schon die Einführung der Teilhabersteuer scheiterte. Hinzu käme, daß der anteilige Ertrag wohl mit den tatsächlich realisierten Veräußerungsgewinnen und -verlusten verrechnet werden müßte. Andererseits würde jemand, dessen Aktie keine Dividende aber auch keinen Kursverlust erbrachte, besser gestellt sein als jemand, der eine Dividende und einen Kursver- 
lust realisierte. Ein entsprechendes Verfahren würde zudem die deutschen Aktienmärkte von den internationalen Kapitalmärkten mehr oder weniger abschotten und kann schon deswegen kaum ernsthaft in Erwägung gezogen werden.

\section{Zwischenfazit}

Die diskutierten Lösungsansätze im Rahmen des bisherigen Steuersystems vermögen kaum zu überzeugen. Die Kenntlichmachung von 50c-infizierten Aktien scheint, gemessen an den eben diskutierten Vorschlägen, noch der einfachste Lösungsansatz im bestehenden Körperschaftsteuersystem. Fraglich ist, ob in anderen Staaten mit körperschaftsteuerlicher Vollanrechnung eventuell taugliche Maßnahmen gegen das Dividendenstripping gefunden wurden.

\subsection{Dividendenstripping, ein spezifisch deutsches Problem?}

Im folgenden soll aus eben genanntem Grund ein Blick auf andere europäische Staaten geworfen werden, deren Körperschaftsteuersysteme eine Anrechnung in größerem Umfang zulassen.

\subsubsection{Italien}

Wie Deutschland, so wendet auch Italien bezüglich der Körperschaftsteuer ein Vollanrechnungssystem an. Anrechnungsberechtigt sind hier - ebenfalls wie in Deutschland - nur die Anteilseigner, deren Dividende im Inland der Einkommensteuer unterliegen. Folglich bleiben Steuerausländer auch in Italien von der Anrechnung ausgeschlossen. Nur zwei italienische DBA (Frankreich und Großbritannien) sehen unter gewissen Umständen eine Erstattung der Körperschaftsteuer $\operatorname{vor}^{331}$.

Der Anrechnungsausschluß der Steuerausländer wurde in der Vergangenheit nicht selten durch eine Nießbrauchgestaltung (Usufruct of Shares) umgangen. Für eine finanzielle Gegenleistung überläßt der Nichtanrechnungsberechtigte dabei den Nießnutz seiner Beteiligung einem Steuerinländer für eine festgelegte, häufig mehrere Jahre dauernde Periode. Die Höhe der Nießbrauchgebühr erklärt sich dabei aus den erwarteten Dividenden und Körperschaftsteuerguthaben, sowie aus einem Gewinnausfallrisiko. Der anrechnungsberechtigte Geschäftspartner konnte

331 Vgl. Mayr, S. (1998): Neuer Mechanismus bei Ausschüttungen und Anrechnung der Korperschaftsteuer in Italien, in: IWB, Nr. 5 vom 11.03.1998, Fach 5, Gruppe 2, S. 414. 
bis 1992 Abschreibungen der Kosten des Nießbrauchs (Nießbrauchgebühr) geltend machen.

Seit 1992 wird in Italien diese - dem Dividendenstripping ähnelnde - Steuergestaltung mit Spezialvorschriften bekämpft: $\S 7$ II in Artikel 14 des italienischen Körperschaftsteuergesetzes ${ }^{332}$, sieht im Nießbrauchsfall mit Nichtanrechnungsberechtigten einen Anrechnungsausschluß vor (Voraussetzung ist, daß der Steuerausländer über keine feste Einrichtung verfügt, mit der er sonst anrechnungsberechtigt wäre.) $)^{333}$.

Aber auch das "klassische" Dividendenstripping, also der Beteiligungsverkauf durch Nichtanrechnungsberechtigte an Anrechnungsberechtigten vor dem Dividendentermin und anschließendem Rückkauf ist in Italien bekannt. In Italien wurde dieses Verfahren mit dem englischen Ausdruck des "Dividend Washing" be$\operatorname{legt}^{334}$.

Offensichtlich wurde diese Gestaltungstechnik vor allem von inländischen Nichtanrechnungsberechtigten, wie Investmentfonds bzw. bestimmten Kapitalanlagegesellschaften (sog. Investment Companies with Variable Capital "SICAV") genutzt, denn der italienische Gesetzgeber hat gleichzeitig mit der Einschränkung des Aktiennießbrauchs durch Steuerausländer Bestimmungen erlassen, die das Dividendenstripping bzw. das Dividend Washing zwischen inländischen Nichtanrechnungsberechtigten und inländischen Anrechnungsberechtigten treffen: $\S 6$ II des Artikel 14 des italienischen Einkommensteuergesetzes verwehrt dem Käufer von Beteiligungen der betroffenen Gesellschaften die Körperschaftsteueranrechnung. Dieser Paragraph wirkt im Zusammenspiel mit dem schon länger bestehenden $\S 37$ des italienischen Bewertungsgesetzes zur Einkommensteuer (ITAC), der einen Durchgriff auf das Einkommen ermöglicht, wenn dies allein aus steuerlichen Gründen über einen Dritten fließt. Aus dem Zusammenspiel beider Gesetze folgt:

1. Der Anrechnungsberechtigte, der die Anteile zum Zeitpunkt der Ausschüttung innehält, wird nur als zwischengeschaltete Person betrachtet. Das heißt, der

332 Vgl. Gesetzesbeschluß vom 09.09.1992, Nr. 372; in Kraft getreten als Gesetz Nr. 429 am 05.11 .1992 .

333 Vgl. Fantozzi, F. (1994): Dividend Washing and Usufruct of Shares in the Light of the Lack of a General Anti-Abuse Clause, in: European Taxation, Vol. 34/(1994), Nr. 12, S. $454 \mathrm{ff}$.

334 Vgl. Giuliani, F.M. / Uckmar V. (1994): Interposition in Italian Taxation on Income and International Transactions, in: International Tax Review (Intertax), Vol. 22/(1994), Nr. 10, S. 446. 
Veräußerungsgewinn, der an den Nichtanrechnungsberechtigten fließt, wird wie eine Dividende behandelt.

2. Die Kapitalertragsteuer von $10 \%$ ist nicht mehr anrechenbar.

3. Der Anrechnungsberechtigte kann keine ausschüttungsbedingten Abschreibungen vornehmen.

4. Die Körperschaftsteuer der entsprechenden Ausschüttungen ist nicht anrechenbar $^{335}$.

Unverständlich erscheint vor allem die Begrenzung der Regelungen: Eine Nießbrauchgestaltung durch Investmentfonds oder ein Dividend Washing durch Steuerausländer ist bisher noch legal ${ }^{336}$. Ein Dividendenstripping zwischen In- und Ausländern wird daher im italienischen Steuerrecht nicht unterbunden, obwohl diese Lücke im italienischen Steuerrecht seit längerem bekannt ist ${ }^{337}$. Dies verwundert um so mehr, als im italienischen Recht eine allgemeine Gestaltungsmißbrauchsregelung fehlt ${ }^{338}$.

\subsubsection{Großbritannien}

In Großbritannien gab es schon im klassischen Körperschaftsteuersystem von 1965 das Problem des Dividendenstripping. Freilich ging es damals nicht um Erlangung von Anrechnungsguthaben durch Nichtanrechnungsberechtigte. Seinerzeit hatte die Abschaffung der Veräußerungsgewinnbesteuerung zu StrippingGeschäften zwischen steuerpflichtigen und steuerbefreiten Anteilseignern geführt. In der Folge entstanden Spezialgesetze, die diese Gestaltungen verhindern soll$\operatorname{ten}^{339}$. Eine spätere Wiedereinführung der Veräußerungsgewinnbesteuerung entschärfte das Problem. Die aktuelle Veräußerungsgewinnbesteuerung ist allerdings recht kompliziert. Für bewegliche Güter im Privatvermögen - hierzu zählen auch Aktien - gilt heute ein großzügiger Freibetrag von 6.500 Britischen Pfund. Steuerausländer sind von der Veräußerungsgewinnbesteuerung nicht betroffen.

$\mathrm{Da}$ dem Problem des Dividendenstripping zur Aufteilung von Anrechnungsguthaben mit Steuerausländern in Großbritannien bei weitem nicht die gleiche Auf-

335 Vgl. Fantozzi, F. (1994), a.a.O., S. 453.

336 Vgl. Fantozzi, F. (1994), a.a.O., S. 456.

337 Vgl. Giuliani, F.M. / Uckmar V. (1994), a.a.O. S. 447.

338 Vgl. Ward, D.A. (1995), a.a.O., S. 179.

339 Vgl. Gammie, M. (1997a): The End of Imputation: Changes in UK Dividend Taxation, International Tax Review (Intertax), Vol. 25/(1997), Nr. 10, S. 340. 
merksamkeit zukommt wie in Deutschland, liegt auch daran, daß London in zahlreichen DBA mit wichtigen Handelspartnern auch Ausländern eine Anrechnung gewährt. Dennoch enthält das britische Steuerrecht Bestimmungen gegen Steuergestaltungen, bei denen auf Umwegen steuerbefreite Anteilseigner in den Genuß des körperschaftsteuerlichen Anrechnungsguthabens gelangen. Gammie führt aus, daß die Wirksamkeit dieser Regelungen allerdings ziemlich zweifelhaft ist ${ }^{340}$.

In jüngster Zeit ist die britische Abkommenspolitik von der Gewährung einer grenzüberschreitenden Körperschaftsteueranrechnung wieder abgerückt ${ }^{341}$. Nicht zuletzt um die früher gemachten Erfahrungen mit dem Dividendenstripping zu vermeiden, wird in Großbritannien zur Zeit über eine breitere Wiedereinführung der Veräußerungsgewinnbesteuerung nachgedacht ${ }^{342}$.

\subsubsection{Frankreich}

Frankreich gewährt in zahlreichen DBA Portfolioanlegern eine Körperschaftsteuergutschrift, die zu einer umfassenden Anrechnung der französischen Körperschaftsteuer durch Verrechnung mit dem Fiskus des Wohnsitzlandes des ausländischen Anteilseigners führt ${ }^{343}$. Die Möglichkeit der Anrechnung im Wohnsitzland des ausländischen Anteilseigners führt zwar nicht zu einer völligen Gleichstellung von In- und Ausländern, schon weil die Geltendmachung der Anrechnung einen längeren Time-Lag erfordert. Die grenzüberschreitende Anrechnung für Portfolioanleger macht aber das Dividendenstripping, das in Deutschland hauptsächlich von Portfolioanlegern betrieben wird, ganz offensichtlich unnötig. Damit regt Frankreich zwar Kapitalimporte an, verzichtet aber freilich auf Steuereinnahmen. Neben der Existenz allgemeiner Gestaltungsmißbrauchsklauseln wirkt auch in Frankreich eine Veräußerungsgewinnbesteuerung für Wertpapiere hinderlich auf das tarifbedingte Dividendenstripping zwischen Steuerinländern.

340 Vgl. Gammie, M. (1997b), The Future of UK Corporation Tax, in: Head, J.G. / Krever, R. (Hrsg.): Company Tax Systems, Victoria 1997, S. 225.

341 Vgl. Gammie, M. (1997a), a.a.O., S. 337.

342 Vgl. Gammie, M. (1997a), a.a.O., S. 340.

343 Vgl. z.B. DBA Frankreich-Deutschland Art. 20. 


\subsubsection{Finnland und Norwegen}

Finnland und Norwegen praktizieren Vollanrechnungssysteme. In beiden Staaten entspricht der Körperschaftsteuersatz dem proportionalen Steuersatz für Kapitaleinkommen, der in den nordischen Staaten im Rahmen der Einführung eines DualIncome-System etabliert wurde. Dies führt dazu, daß Anteilseigner keine Steuern auf erhaltene Dividenden zahlen, da Anrechnungsanspruch und tarifliche Kapitaleinkommensteuer übereinstimmen. Wirtschaftlich betrachtet ist die Besteuerung der Dividenden abgeschafft worden. Gewinnausschüttungen werden nur noch auf der Unternehmensebene besteuert. Eine Besteuerung der Veräußerungsgewinne aus Anteilsverkäufen unterliegt in beiden Ländern den gleichen Steuersätzen wie die übrigen Kapitaleinkommen. Allerdings bestehen unterschiedliche Freibeträge: In Finnland sind 30\% (bei Erwerb vor 1989 sogar 50\%) des Veräußerungserlöses von der Bemessungsgrundlage abziehbar. In Norwegen erfolgt die Ermittlung des Veräußerungsgewinns durch die sogenannten RISK-Bestimmungen. Danach erhöhen sich die ursprünglichen Anschaffungskosten von Beteiligungen um den anteiligen versteuerten Gewinn, der jährlich seit Anschaffung der Anteile im Unternehmen thesauriert wurde ${ }^{344}$. Die Anreize für ein Dividendenstripping zwischen Inländern sind aufgrund der einheitlichen Flat-Rate-Tax ganz offensichtlich weitgehend beseitigt. Die de facto praktizierte Dividendenfreistellung läßt auch nicht erkennen, warum und wie Steuerinländer ein Dividendenstripping mit Steuerausländern eingehen sollten. Ganz offensichtlich ist das Dividendenstripping in der kurzen Zeit, in der die skandinavischen Vollanrechnungssysteme existieren, noch nicht zu einem Problem geworden, obwohl beide Länder regelmäßig die Anrechnung auf Steuerinländer beschränken.

Spektakulär war bisher in Norwegen ein Fall, bei dem eine norwegische Kapitalgesellschaft alte Aktien von einem Steuerausländer zurückkaufte und gleichzeitig neue Anteile von diesem zeichnen ließ. Diese Gestaltung kommt dem Dividendenstripping mit jungen Aktien sehr nahe. Das norwegische Steuerdirektorium (Skattedirektoratet) stufte den Vorgang als versteckte Dividendenausschüttung $e^{345}$. Die Gestaltung diente allerdings weniger der Vermeidung der Körperschaftsteuer, sondern eher der Umgehung der norwegischen Kapitalertragsteuer (i. H. v. 25\%) auf Dividenden, die nur für Steuerausländer erhoben wird.

344 Vgl. International Bureau of Fiscal Documentation: IBFD (Hrsg.)(1997): European Tax Handbook 1997, S. 338.

345 Vgl. o. Verf. (1997): Norway - Simultaneous decrease and increase in capital a deemed dividend, in: IBFD (Hrsg.): Tax News Services, Vol. 31/(1997), Nr. 35, S. 364. 
Auch wenn das Dividendenstripping kein spezifisch deutsches Problem ist, so spielt es in den anderen Staaten - mit Ausnahme von Italien - doch eher eine unbedeutende Rolle. Die Gründe dafür sind vielfältig. Während in Italien ähnliche Ansätze wie in Deutschland zu beobachten sind, nämlich am national beschränkten Vollanrechnungssystem festzuhalten und das Dividendenstripping durch spezielle Vorschriften zu unterbinden, geht Frankreich mit der Anrechnungseinräumung für ausländische Portfolioanleger den umgekehrten Weg. Großbritannien tat es lange Zeit Frankreich gleich, nimmt allerdings neuerlich Abstand von der früheren Abkommenspolitik. In den skandinavischen Volkswirtschaften, die zur Zeit Vollanrechnungssysteme anwenden, spielt das Dividendenstripping vermutlich deswegen keine Rolle, weil die Vollanrechnungssysteme in Verbindung mit dem Dual-Income-System tatsächlich eine Dividendenfreistellung für Inländer bewirken. Damit entfällt die Möglichkeit, Anrechnungsguthaben aufzuteilen. Auffällig ist, daß mit Ausnahme von Deutschland alle Staaten Veräußerungsgewinne besteuern. Das verhindert zwar nicht völlig das Dividendenstripping zwischen Steuerinländern (und soweit die Veräußerungsgewinnbesteuerung des Quellenlandes auch Steuerausländer trifft, auch das Dividendenstripping der Steuerausländer) schränkt es jedoch erheblich ein.

\section{Fazit zum Problem des Dividendenstripping}

Das Problem des Dividendenstripping bleibt weiterhin ungelöst. Es ist bisher nicht gelungen, das deutsche Steuerrecht so zu gestalten, daß nur Anrechnungsberechtigte tatsächlich anrechnen lassen können. Insbesondere wegen der Anonymität der Börse und der Deutschen Terminbörse ist die Praktikabilität der gesetzlichen Maßnahmen zweifelhaft. Eine Reform der Veräußerungsgewinnbesteuerung zur Unterbindung der Umwandlung von Dividenden in Veräußerungsgewinne scheint zumindest auf internationaler Ebene ein kaum gangbarer Lösungsweg zu sein.

Ein national beschränktes Anrechnungsverfahren ist damit in einer Welt der liberalisierten Kapitalmärkte sehr hinterziehungsanfällig. Am Beispiel Frankreichs wird deutlich, daß man unter Umständen auch eine Beschränkung der nationalen Anrechnung - zumindest für Portfolioanleger - fallen lassen kann, ohne die Integration der Körperschaftsteuer aufzugeben. Allerdings beinhaltet dies einen anteiligen Verzicht auf Körperschaftsteuer.

Eine Lösung des Dividendenstrippingproblems kann offensichtlich nur dann gefunden werden, wenn Anteilsveräußerungen und Dividendenvereinnahmung steuerlich gleich behandelt werden. Die Realisierung (noch) nicht ausgeschütteter 
Gewinne und darf keine anderen Belastungen erzeugen als der Dividendenbezug. Die nachfolgende Behandlung des Problems der Gesellschafterfremdfinanzierung bzw. deren Unterbindung beleuchtet nicht nur eine weitere Benachteiligung ausländischer Anteilseigner im deutschen Körperschaftsteuersystem, es wird auch deutlich werden, daß einige der eben diskutierten Lösungsansätze aufgrund der internationalen Zinsbesteuerung noch zu kurz greifen. 
Hans-Werner Seiler - 978-3-631-75261-6

Downloaded from PubFactory at 01/11/2019 06:36:03AM

via free access 


\section{Die Umgehung der Körperschaftsteuer durch Ausweichen auf Fremd- finanzierung}

Der Steuerausländer kann die grenzüberschreitende Doppelbelastung der Dividenden nicht nur durch Umwandlung dieser Dividenden in Veräußerungsgewinne vermeiden. Es bietet sich auch eine Umwandlung dieser Einkommen in Zinseinkommen an. Auch in Deutschland verdiente Zinsen sind in der Regel nur im Wohnsitzland steuerpflichtig.

Damit eröffnet sich für Steuerausländer ein zweiter Ausweg aus der grenzüberschreitenden Doppelbelastung von Dividenden: statt Eigenkapital Fremdkapital einzubringen. Diese Gestaltung trifft natürlich nicht nur Länder mit Vollanrechnungssystemen ohne grenzüberschreitende Anrechnungsgewährung, sondern auch Länder mit klassischen Körperschaftsteuersystemen. Entsprechend findet seit einiger Zeit unter dem Schlagwort "Thin-Capitalization" auch international eine lebhafte Diskussion über diese Steuergestaltungsform und deren mögliche Einschränkung statt. Freilich sind Länder mit Anrechnungssystemen tendenziell stärker von der Gesellschafterfremdfinanzierung betroffen, weil diese Staaten oft relativ hohe Körperschaftsteuersätze aufweisen. Außerdem zwingt die relative Besserstellung der Steuerinländer in Anrechnungssystemen die Steuerausländer schon aus Wettbewerbsgründen dazu, die üblicherweise höhere Steuerlast zu meiden. Die relative Verschlechterung der steuerlichen Behandlung der Steuerausländer mit Einführung des deutschen Vollanrechnungssystems ging deswegen mit einer sprunghaften Zunahme der sogenannten Gesellschafterfremdfinanzierung einher $^{346}$.

\subsection{Gesellschafterfremdfinanzierung - Begriffsklärung}

Gesellschafterfremdfinanzierung liegt vor, wenn Anteilseigner ihrer Gesellschaft neben Eigenkapital auch Fremdkapital zur Verfügung stellen. Aufgrund des Trennungsprinzips kann die Kapitalgesellschaft als juristische Person mit ihren Anteilseignern Geschäfte machen wie mit fremden Dritten. Für die Gesellschafterfremdfinanzierung gibt es neben den hier interessierenden steuerlichen Gründen auch nichtsteuerliche Gründe, die teilweise schon im Rahmen der Diskussion über die Substituierbarkeit von Eigenfinanzierung und Fremdfinanzierung diskutiert wurden ${ }^{347}$.

Vgl. Baranowski, K.H. (1996), a.a.O., S. 537. 


\subsubsection{Nichtsteuerliche Gründe für Gesellschafterfremdfinanzierungen}

Fremdkapital kann in der Regel flexibler zur Verfügung gestellt bzw. zurückgezahlt werden als Eigenkapital; z.B. kann eine Fremdkapitalfinanzierung für ein Unternehmen günstiger sein, das während einer Gründungs- oder Erweiterungsphase zusätzliche Finanzierungsmittel benötigt, die aber nicht auf Dauer zur Verfügung stehen müssen. Zusätzliches Nennkapital wäre in diesem Fall unzweckmäßig, weil der Kapitalbedarf nur zeitlich befristet ist, Kapitalerhöhungen und herabsetzungen aber umständlich, zeitraubend und teuer sind ${ }^{348}$.

Fremdkapital und Eigenkapital unterscheiden sich auch im Haftungsumfang. Während Eigenkapital Haftungskapital gegenüber den Gläubigern einer Gesellschaft darstellt, gewährt Fremdkapital einen Rückzahlungsanspruch zum Nominalwert. In Deutschland weist Gesellschafterfremdkapital allerdings einige Eigenkapitalcharakteristika auf: So verbietet die Vorschrift des § $32 \mathrm{GmbHG}$ Rückzahlungen von Gesellschafterdarlehen im Fall der Überschuldung oder bei einem Verlust an Stammkapital. Auch Bilanzierungsvorschriften weisen darauf hin, daß Fremdkapital und Gesellschafterfremdkapital nicht völlig gleichgestellt sind. Es bestehen diverse Ausweispflichten für Gesellschafterfremdkapital ${ }^{349}$. Dies ändert aber nichts daran, daß im Liquidationsfall nach Rückzahlung des Fremdkapitals die Rückzahlungsansprüche aus Gesellschafterfremdkapitalfinanzierungen vorrangig sind gegenüber den Rückzahlungsansprüchen der Eigenkapitalgeber. Zeitliche Befristung, höhere Flexibilität und Haftungsaspekte sind die wichtigsten nichtsteuerlichen Gründe für Gesellschafterfremdfinanzierungen, die unbeschränkt und beschränkt Steuerpflichtige, bzw. inländische und ausländische Anteilseigner gleichermaßen betreffen.

\subsubsection{Steuerliche Gründe für Gesellschafterfremdfinanzierungen}

Im weiteren stehen die steuerlichen Beweggründe für Gesellschafterfremdfinanzierungen im Mittelpunkt. Sie lassen sich unterteilen in inländische und internationale Beweggründe.

348 Vgl. Becker, H. (1985): Neuere steuerliche Entwicklungen auf dem Gebiet der internationalen Unternehmensfinanzierung, in: Institut für Ausländisches und Internationales Finanzund Steuerwesen (Hrsg.): Hefte zur Internationalen Besteuerung, Nr. 12, Hamburg 1985, S. 14.

349 So muß Gesellschafterfremdkapital, sofern es aus verbundenen Unternehmen stammt, unter einer gesonderten Ziffer ausgewiesen werden. Für dieses Fremdkapital besteht eine besondere Erläuterungspflicht. Außerdem unterliegt eine Rückzahlung von Darlehen in Konkurssituationen gesetzlichen Einschränkungen; vgl. § 266 Abs. 3 HGB und $\S 32$ GmbHG. 


\subsubsection{Inländische steuerliche Motive}

Ein Anreiz für Gesellschafterfremdfinanzierung besteht in der Bundesrepublik Deutschland aus steuerlichen Gründen hauptsächlich für nichtanrechnungsberechtigte Anteilseigner. Die Besteuerung von Zinsen und Dividenden ist in einem Land mit Vollanrechnungssystem für Anrechnungsberechtigte grundsätzlich identisch und anlageneutral. Für inländische Nichtanrechnungsberechtigte ist die Definitivbelastung der Körperschaftsteuer bei Bereitstellung von Eigenkapital in der Regel ungünstiger als die Bereitstellung von Fremdkapital. Die Fremdfinanzierung ist in diesem Fall vorteilhaft, weil die dafür gezahlten Vergütungen (Zinsen) als Betriebsausgaben den Gewinn und damit die Steuerlast eines Unternehmens mindern. Eigenkapitalvergütungen sind dagegen nicht abzugsfähig. Hinzu kommt, daß gezahlte Zinsen nur zur Hälfte, gezahlte Dividenden aber im vollen Umfang der Gewerbeertragsteuer unterliegen ${ }^{350}$.

\subsubsection{Internationale steuerliche Motive}

Für Steuerausländer ist die Gesellschafterfremdfinanzierung eine besonders reizvolle Finanzierungsform: Die Vergütungen für das eingelegte Fremdkapital bleiben im Inland in der Regel unbesteuert ${ }^{351}$. Grund hierfür ist der oben erörterte weitgehende Verzicht der Bundesrepublik Deutschland auf ihre Quellenlandsteuerbefugnisse auf Zinserträge. Ausländische Anteilseigner können somit der inländischen körperschaftsteuerlichen Definitivbelastung von $30 \%$ und der Quellensteuer auf Dividenden ausweichen. Die erzielten Zinseinkünfte sind nur noch im Wohnsitzstaat steuerpflichtig. Etwas provokativ könnte man auch sagen: Die Steuerausländer genehmigen sich mit der Gesellschafterfremdfinanzierung eine "private Anrechnung"352.

350 Vgl. § 8 Nr. 1 GewStG. Ein inzwischen weggefallener steuerlicher Vorteil der Gesellschafterfremdfinanzierung war die Vermeidung der Vermögensteuer auf Unternehmensebene, die fruher zu einer Doppelbelastung führte, weil die Gesellschaft gem. dem ehem. $\S 1$ Abs. 1 , Nr. 2 VStG neben ihren Gesellschaftern vermögensteuerpflichtig war.

351 Einzige Ausnahme: Das Fremdkapital wird im Inland dinglich gesichert, z.B. mit Grundpfandrechten; vgl. $\S 49$ Abs. 1 Nr. 5c Buchst. aa EStG. Allerdings räumen die deutschen DBA auch dann noch dem Wohnsitzstaat des Glăubigers das Besteuerungsrecht ein.

Vgl. Becker, H. (1985), a.a.O., S. 4. 


\subsubsection{Ist die Gesellschafterfremdfinanzierung tatsächlich ein Problem?}

Ein häufiges Argument gegen die Duldung von Gesellschaferremdfinanzierungen ist die beklagte Unterkapitalisierung von Kapitalgesellschaften. Die Unterkapitalisierungsdiskussion ist in Deutschland nach Ende des Zweiten Weltkriegs fast fortwährend geführt worden. Da keine allgemeingültigen oder empirisch eindeutigen Untersuchungsergebnisse über das "richtige" Verhältnis von Eigen- und Fremdkapital existieren, ist ein Ende der Unterkapitalisierungsdiskussion deutscher Unternehmen nicht in Sicht. Die in dieser Arbeit behandelte Gesellschafterfremdfinanzierung durch Nichtanrechnungsberechtigte hat mit der Unterkapitalisierungsdiskussion allerdings nur teilweise etwas zu tun. Die Unterkapitalisierung erklärt sich natürlich ebenso aus den vorgestellten nichtsteuerlichen Motiven für Fremdkapitaleinbringungen. Tatsächlich geht es bei der Unterbindung übermäßiger Gesellschafterfremdfinanzierungen in Deutschland vor allem um den Verlust von Steueraufkommen. Der deutsche Fiskus sieht in der Gesellschafterfremdfinanzierung vor allem eine Verschiebung der Steuerquellen zu seinen Lasten ${ }^{353}$. Er erkennt in dieser Finanzierungsform eine Gefährdung der Besteuerung im Inland erwirtschafteter Gewinne ${ }^{354}$ und behauptet, daß der Einsatz von Fremdfinanzierung der Nichtanrechnungsberechtigten erhebliche Wettbewerbsvorteile gegenüber Unternehmen mit anrechnungsberechtigten Anteilseignern mit sich bräch$\mathrm{te}^{355}$, die diese Gestaltung nicht anwenden können. Unbestritten ist, daß eine Fremdkapitalfinanzierung grundsätzlich den steuerpflichtigen Gewinn einer Gesellschaft im Gegensatz zur Eigenkapitalfinanzierung mindert. Fraglich ist aber, inwieweit die Gesellschafterfremdfinanzierung ein Wettbewerbsvorteil für Unternehmen sein kann, deren Anteilseigner keine Anrechnungsberechtigung haben. Ließe sich dieses Argument untermauern, so könnte man eine einseitige Beschränkung der Gesellschafterfremdfinanzierung allein der Nichtanrechnungsberechtigten rechtfertigen.

Eine Gesellschafterfremdfinanzierung muß aber nicht grundsätzlich vorteilhaft für ausländische Anteilseigner sein. Sofern es sich um Kapitalgesellschaften in anderen Hochsteuerländern handelt, die ein internationales Schachtelprivileg für Dividenden ausnutzen können, und sofern keine Weiterausschüttung im Land der Muttergesellschaft vorgesehen ist, kommt es auf das Verhältnis des deutschen Ausschüttungssatzes zum ausländischen Körperschaftsteuersatz an. Natürliche

353 Nur so läßt sich erklären, daß die einschränkenden gesetzlichen Maßnahmen zur Gesellschafterfremdfinanzierung ausschließlich Nichtanrechnungsberechtigte betreffen.

354 Vgl. Haase, K.D. / Schneeloch, D. / Siegel T. (1983): Besteuerung der GesellschafterFremdfinanzierung, Stuttgart 1983, S. 47. 
Personen unterliegen aber als ausländische Anteilseigner der Doppelbesteuerung ihrer Dividenden. Für diese Gruppe ist die Gesellschafterfremdfinanzierung fast immer vorteilhaft. Auf jeden Fall können Aussagen zur Vorteilhaftigkeit nur bei Berücksichtigung der ausländischen Besteuerung getroffen werden ${ }^{356}$. Mit Erhöhung des deutschen Ausschüttungssatzes um 21 Prozentpunkte im Jahr 1977 ist die Attraktivität der Gesellschafterfremdfinanzierung jedenfalls erheblich gestiegen. Nichtanrechnungsberechtigte machen seitdem von dieser Finanzierungsalternative erheblichen Gebrauch ${ }^{357}$. Janssen verweist auf Extremfälle von Eigenkapital-Fremdkapital-Quoten Nichtanrechnungsberechtigter in Höhe von $1: 5000^{358}$.

Eine einschränkende Gesetzgebung zur Gesellschafterfremdfinanzierung, die allein auf Nichtanrechnungsberechtigte zielt, richtet sich damit weniger gegen die Unterkapitalisierung als gegen Fiskalverluste, die sich aus den unterschiedlichen internationalen Besteuerungsprinzipien von Dividenden und Zinsen ergeben.

\subsection{Die steuergesetzlichen Maßnahmen zur Einschränkung der Gesell- schafterfremdfinanzierung}

Das Problem der Gesellschafterfremdfinanzierung zwecks Vermeidung der Körperschaftsteuer war seit Einführung des Vollanrechnungssystems bekannt. Überlegungen, wie die Gesellschafterfremdfinanzierung in Griff zu bekommen sei, datieren schon aus der Zeit unmittelbar nach Einfuihrung des Vollanrechnungssystems. Insofern kann man von auffälligen Parallelen zwischen der Bekämpfung des Handels mit Anrechnungsguthaben und der Gesellschafterfremdfinanzierung sprechen. Allerdings erwies sich die Schaffung eines speziellen Gesetzes zur Einschränkung dieses Finanzierungsweges als nicht weniger kompliziert als die Einführung gesetzlicher Maßnahmen gegen das Dividendenstripping. Die Gesellschafterfremdfinanzierung durch Nichtanrechnungsberechtigte wurde allerdings lange Zeit nur über die allgemeine Mißbrauchsvorschrift des $\S 42 \mathrm{AO}$ verfolgt.

356 Hierzu ausführlich: Haase, K.D. / Schneeloch, D. / Siegel T. (1983), a.a.O. S. 50ff.

357 So beobachtete die Bundesregierung schon kurze Zeit nach der Körperschaftsteuerreform nach eigenen Angaben, daß seit 1977 nichtanrechnungsberechtigte Anteilseigner im zunehmenden Ausmaß dazu ubergingen, ihren Gesellschaften Fremdkapital statt Eigenkapital zuzufuhren; vgl. BT-Drs. 8/3648, S. 8f. und S. $26 f$.

358 Vgl. Janssen, B. (1997): § 8a KStG - Zweck der Vorschrift und Kritik ihrer Ausgestaltung, Grttingen 1997, S. 5. 


\subsubsection{Allgemeine Mißbrauchsklausel als Mittel gegen die Gesellschafter- fremdfinanzierung}

Wie im Fall des Dividendenstripping erwies sich der $\S 42 \mathrm{AO}$ auch im Bereich der Gesellschafterfremdfinanzierung als wenig geeignetes Mittel. Die Gründe sind dieselben: $\S 42 \mathrm{AO}$ greift nur, wenn nachgewiesen werden kann, daß eine bestimmte Steuergestaltung ausschließlich gewählt wurde, um ein Steuergesetz zu umgehen. Diese Umgehungsabsicht muß in jedem Einzelfall festgestellt werden. Nur wenn nachgewiesen werden kann, daß eine Gesellschafterfremdfinanzierung ausschließlich in der Absicht vorgenommen wird, die inländische Dividendenbesteuerung zu umgehen, kann $\S 42 \mathrm{AO}$ angewendet werden. Die Beweislast dafür trägt die Finanzverwaltung, die dabei insgesamt wenig erfolgreich war, weil schon die Nennung anderer wirtschaftlicher Gründe - wie die erwähnten nichtsteuerlichen Motive - zur Entlastung der Nichtanrechnungsberechtigten völlig ausreicht.

Im Prozeßfall haben daher die Gerichte häufig zugunsten der Fremdkapitalgeber entschieden. Dem Verhältnis zwischen Fremd- und Eigenkapital wurde keinerlei Bedeutung beigemessen, statt dessen wurde auf die grundsätzliche Finanzierungsfreiheit verwiesen ${ }^{359}$. Es sind fast ausschließlich Verfahren aus weit zurückliegenden Jahren, in denen die Richter zu anderen Urteilen kamen ${ }^{360}$.

Dennoch versuchte die Steuerverwaltung lange Zeit, am Mittel des $\S 42$ AO festzuhalten. In diese Richtung wirkte auch ein Schreiben des Bundesfinanzministeriums von $1987^{361}$, mit dem der $\S 42 \mathrm{AO}$ - sozusagen nachträglich - für die verfolgte Steuergestaltung präzisiert werden sollte. Dieses Schreiben ordnete besonders solche Fälle als mißbräuchliche Steuergestaltung nach $\S 42 \mathrm{AO}$ ein, in denen Nichtanrechnungsberechtigte Fremdfinanzierungen wählen, obwohl das Eigenkapital schon wesentlich unter dem Branchendurchschnitt liegt. Verdächtig galt Eigenkapital, das weniger als $10 \%$ des Rohvermögens entsprach ${ }^{362}$. Kritik entfachte sich daran, daß diese Grenze viel zu restriktiv sei, da sie in vielen Wirtschaftszweigen dem Branchendurchschnitt entspreche ${ }^{363}$.

359 BFH BStBl. II 1976, S. 226f.

360 Z.B. vom RFH; vgl. RStBl. 1940, $35 \mathrm{ff}$.

361 Vgl. BMF-Schreiben vom 16.03.1987, BStBI. I 1987, S. $373 \mathrm{ff}$.

362 Vgl. Kluge, V. (1992): Das deutsche Internationale Steuerrecht, München 1992, S. 197.

363 Vgl. Schneeloch, D. (1987): Verdecktes Nennkapital, in: Deutsches Steuerrecht (DStR), 25. Jg. /(1987), S. 461. 
1992 entschied dann der $\mathrm{BFH}$, daß $\S 42 \mathrm{AO}$ nicht im Einklang gebracht werden könne mit einer als verdächtig angenommenen Relationsgröße des Eigenkapitals. Das Urteil unterstrich die grundsätzliche Finanzierungsfreiheit von Gesellschaften, soweit gesetzliche Vorschriften zum Mindestnennkapital beachtet würden. Damit bestätigte der BFH, daß kapitalersetzende Darlehen als Fremdkapital zu betrachten seien und Zinsen auf solche Darlehen als abzugsfähige Betriebsausgaben zu behandeln seien, sofern Angemessenheit gegeben sei $^{364}$. Mit diesem Urteil wurde die vom BMF in seinem Schreiben vom 1987 empfohlene Vorgehensweise hinfällig. Es markiert das endgültige Scheitern der Einschränkung der Gesellschafterfremdfinanzierungen von Nichtanrechnungsberechtigten ohne eine Spezialvorschrift.

\subsubsection{Spezielle Vorschriften gegen die Gesellschafterfremdfinanzierung}

Ausdrückliche Regelungen gegen Gesellschafterfremdfinanzierungen der Nichtanrechnungsberechtigten wurden seit Ende der siebziger Jahre gefordert und diskutiert. So schlug die Bundesregierung eine Erweiterung des $\S 8 \mathrm{Abs} .3 \mathrm{KStG}$ vor, nach der gewinnabhängige Vergütungen einer Kapitalgesellschaft an Fremdkapital bereitstellende, nichtanrechnungsberechtigte Anteilseigner als verdeckte Gewinnausschüttung einzustufen und folglich auf der Ebene der Kapitalgesellschaft zu besteuern $\operatorname{seien}^{365}$. Diese sogenannte "kleine Lösung" wurde noch erweitert durch einen Vorschlag des Bundesrats, der sich damals dafür aussprach, auch gewinnunabhängige Vergütungen für Gesellschafterfremdfinanzierungen $a b$ einer bestimmten Grenze als verdeckte Gewinnausschüttungen zu behandeln ${ }^{366}$. Dieser Vorschlag wurde im weiteren als "große Lösung" bezeichnet.

Ein Referentenentwurf vom 10.03.1982 sah mit $\S 8 \mathrm{a} \mathrm{KStG}$ eine Spezialregelung vor, die Gesellschafterfremdfinanzierungen durch Nichtanrechnungsberechtigte unterbinden sollte. Dieser Entwurf bestand aus einer "großen Lösung”, ohne einen

364 In dem Fall, über den der BFH zu entscheiden hatte, ging es um die GmbH eines in den Niederlanden ansässigen Ehepaars. Die Eheleute hatten der GmbH einen Kredit uber DM $130.000,--$ gewăhrt; insgesamt erreichte das Eigenkapital der GmbH damit kaum noch $10 \%$ des Gesamtvermogens. Das zuständige deutsche Finanzamt stufte die Kreditzinsen als verdeckte Gewinnausschüttung ein. Die Zinsen wurden entsprechend steuerlich umqualifiziert, d.h. die Abziehbarkeit wurde untersagt und die Zahlungen der Korperschaftsteuer unterworfen. Vgl. BFH vom 05.02.1992, BStBI. II 1992, S. 532.

Vgl. BT-Drs. 8/3648.

Vgl. BT-Drs. 511/79. 
Freiraum von gewinnunabhängigen Vergütungen einzuräumen ${ }^{367}$. De facto stellte er ein Verbot jeglicher Gesellschafterfremdfinanzierungen durch Nichtanrechnungsberechtigte dar. Da jedoch erhebliche Kritik laut wurde, mußte dieser Entwurf mehrfach revidiert.

Die Diskussion um eine Spezialvorschrift riß auch in den folgenden Jahren nicht ab: So folgte 1988 - als sogenannte "Formulierungshilfe" - ein weiterer, der späteren Regelung bereits sehr ähnlicher Entwurf, der aber in einem Hearing vor dem Finanzausschuß des Bundestags verrissen wurde ${ }^{368}$ und - vor allem wegen rechtlicher Bedenken - nicht umgesetzt wurde ${ }^{369}$.

Mit dem endgültigen Scheitern der Anwendung von § 42 AO im Jahr 1992 sah sich der Gesetzgeber offensichtlich schlagartig zum Handeln gezwungen. Alte Entwürfe zum $\S 8 \mathrm{a} \mathrm{KStG}$ wurden aus der Schublade geholt und es wurde eine modifizierte Fassung entwickelt, die im Rahmen des Standortsicherungsgesetzes am 13.9.1993 vom Bundestag verabschiedet wurde. Bereits 1994 trat sie in Kraft. Wie frühere Gesetzesentwürfe, so wurde auch die heute gültige Regelung mit der Unterbindung von Steuerumgehungen bzw. der Sicherstellung der Einmalbesteuerung begründet ${ }^{370}$. Die Argumentation gleicht damit derjenigen zur Gesetzgebung gegen das Dividendenstripping. Die Regelung gilt ausschließlich für nichtanrechnungsberechtigte Anteilseigner einer unbeschränkt steuerpflichtigen Kapitalgesellschaft. Sie enthält Grenzen für gewinnabhängige und gewinnunabhängige Vergütungen.

Mit dem neuen $\S 8 \mathrm{a}$ KStG ist auf den ersten Blick daher die "große Lösung" mit dem Zugeständnis verwirklicht worden, daß bis zu bestimmten Grenzen Fremdkapitaleinlagen noch steuerlich anerkannt werden. Zinsen und Vergütungen werden steuerlich in verdeckte Gewinnausschüttungen umqualifiziert, wenn bestimmte Richtwerte der Fremdkapitalzuführung überschritten werden. Die Umqualifizierung findet nur hinsichtlich der steuerlichen Behandlung der Vergütung statt. Es wird kein Fremdkapital handelsrechtlich in Eigenkapital umgewandelt.

367 Referentenentwurf eines Gesetzes zur Änderung des Körperschaftsteuergesetzes vom 10.03.1982. Zum Wortlaut des damals geplanten § 8a KStG vgl. Haase, K.D. / Schneeloch, D. / Siegel T. (1983), a.a.O., S. 210 f.

368 Vgl. Knobbe-Keuk, B. (1992): Neuer Anlauf zu einem § 8a KStG, in: IWB, Nr. 21 vom 10.11.1992, Fach 2, S. 618.

369 Vgl. Loos, G. (1989): Gesellschafter-Fremdfinanzierung durch nichtanrechnungsberechtigte Anteilseigner, in: Betriebs-Berater (BB), 44. Jg./(1989), Nr. 8, 20.03.1989, a.a.O., S. 536ff. 
Folglich ergeben sich aus $\S 8 \mathrm{a} \mathrm{KStG}$ weder Änderungen in der Bilanzgliederung noch für die Bemessungsgrundlage der Gewerbeertragsteuer. Gesellschafterfremdfinanzierung kann also aus gewerbesteuerlichen Motiven auch bei Anwendung des $\S 8 \mathrm{a} \mathrm{KStG}$ noch vorteilhaft sein.

Die steuerliche Umqualifizierung wirkt sich sowohl bei der Kapitalgesellschaft als auch beim betroffenen Anteilseigner aus. Die Kapitalgesellschaft kann Zinszahlungen, die auf betroffenes Fremdkapital entfallen, nicht als Betriebsausgaben abziehen. Dieses Abzugsverbot führt zu einer Erhöhung des zu versteuernden $\mathrm{Ge}-$ winns der inländischen Kapitalgesellschaft. Die Ausschüttungsbelastung ist für die Fremdkapitalvergütung herzustellen. Von der erhöhten Steuerzahlung der Kapitalgesellschaft sind letztlich alle Gesellschafter betroffen - unabhängig von ihrer Anrechnungsberechtigung. Denn im Ergebnis schüttet die Kapitalgesellschaft durch die Umqualifizierung mehr Gewinn aus, als dies ursprünglich geplant war. Wird z.B. eine Zinszahlung von $100 \mathrm{DM}$ an einen Nichtanrechnungsberechtigten umqualifiziert, so wird der Zinsbetrag als Nettodividende behandelt. Die Gesellschaft zahlt hierauf (30/70 x 100) 42,87 DM Körperschaftsteuer (mit Solidaritätszuschlag 45,22 DM). Insofern ergeben sich wie im Fall des abgeschafften $\S 39 \mathrm{KStG}$ negative Rückwirkungen auch für anrechnungsberechtigte Anteilseigner der betroffenen Gesellschaft. Der Nichtanrechnungsberechtigte erhält statt im Inland steuerfreie Zinseinkünfte nun Vergütungen, die in Höhe von 30\% mit inländischer Körperschaftsteuer belastet sind. Zuzüglich fällt Kapitalertragsteuer auf Dividenden an.

Die steuerliche Umqualifizierung des $\S 8 \mathrm{a} \mathrm{KStG}$ gilt nur für Vergütungen an nichtanrechnungsberechtigte Anteilseigner. Anrechnungsberechtigte Gesellschafter genießen weiterhin volle Finanzierungsfreiheit, sofern sie ihren Einlageverpflichtungen nachkommen. Im Ergebnis müssen sie zwar nicht befürchten, daß angemessene Vergütungen für das von ihnen eingezahlte Fremdkapital als übermässige Gesellschafterfremdfinanzierung in verdeckte Gewinnausschüttung umqualifiziert werden. Gleichwohl sind sie von einer höheren Körperschaftsteuerbelastung ihrer Gesellschaft aufgrund von Umqualifizierungen des Fremdkapitals der nichtanrechnungsberechtigten Gesellschafter mitbetroffen.

Die Einbeziehung von Anrechnungsberechtigten wurde als überflüssig eingeschätzt, weil die Besteuerung der Fremdkapitalvergütungen bei dieser Gruppe von Anteilseignern aufgrund des Anrechnungsverfahren in etwa der Besteuerung von Zinsen entspricht ${ }^{371}$.

371 Vgl. Loos, G. (1989), a.a.O., S. 538. 
Von den Regelungen des $\S 8 \mathrm{a} \mathrm{KStG}$ sind nur Nichtanrechnungsberechtigte mit einer wesentlichen Beteiligung betroffen. Unter einer wesentlichen Beteiligung versteht der Gesetzgeber auch hier eine mittel- oder unmittelbare Beteiligung am Stamm- oder Grundkapital einer Gesellschaft von mehr als $25 \%{ }^{372}$. Die Verteilung der Stimmrechte spielt primär keine Rolle, allerdings kann sie relevant werden, wenn sie einen beherrschenden Einfluß begründe ${ }^{373}$. Der Gesetzgeber wollte damit offenbar sicherstellen, daß nur Anteilseigner berührt werden, die tatsächlich Entscheidungsgewalt über die Finanzierung der Kapitalgesellschaft ausüben.

\subsubsection{Identifikation einer Gesellschafterfremdfinanzierung nach § 8a KStG - Die Quotenlösung}

In der Bundesrepublik Deutschland hat man sich mit der Ausgestaltung des $\S 8 \mathrm{a}$ $\mathrm{KStG}$ im wesentlichen auf eine Quotenregelung festgelegt, bei deren Überschreitung der Gesetzgeber grundsätzlich eine Gesellschafterfremdfinanzierung annimmt.

In Relation gesetzt werden jeweils das von einem Nichtanrechnungsberechtigten eingebrachte Fremdkapital und das auf diesen Nichtanrechnungsberechtigten entfallende Eigenkapital. Für jeden Gesellschafter ist also eine individuelle Fremdkapital-Eigenkapital-Quote (FK-EK-Quote) relevant. Diese fixierte Quote wird als Safe-Haven (Sicherer Hafen) bezeichnet, weil Vergütungen, die aus Kapital, das diese Quote nicht überschreitet, steuerlich keine Gegenmaßnahmen auslösen.

Man betrachtet für die Berechnung des anteiligen Eigenkapitals eines Nichtanrechnungsberechtigten dessen Beteiligungsquote am Ende des vorausgegangenen Wirtschaftsjahres. Dabei wird auf das Eigenkapital der Gesellschaft abgestellt, wie es sich nach handelsrechtlichen Grundsätzen ergibt ${ }^{374}$. Aus dieser Größe wird

372 Vgl. § 8a Abs. $3 \mathrm{KStG}$, dort ist die wesentliche Beteiligung entsprechend definiert. Die Absenkung der wesentlichen Beteiligung nach $\S 17$ EStG durch das Steuerentlastungsgesetz 1999/2000/2002 bewirkt keine Änderung der Reichweite der § 8a KStG.

373 Vgl. Menck, T. (1995): Gesellschafter-Fremdfinanzierung, Kommentar zum § 8a KStG, Erg.-Lfg. Nr. 50, Juni 1995, in: Blümich (Hrsg.): Einkommensteuergesetz, Körperschaftsteuergesetz, Gewerbesteuergesetz Kommentar, Müchen 1997, S. 9f., Rz. 19.

374 Vgl. §§ 266 Abs. 3, 272 HGB. Das Eigenkapital der Gesellschaft wird wie folgt ermittelt: Gezeichnetes Kapital abzügl. ausstehender Einlagen zuzügl. Kapital- und Gewinnrücklagen, zuzügl. Gewinnvortrag (bzw. abzügl. Verlustvortrag), zuzigl. Jahresüberschuß (bzw. abzügl. Jahresfehlbetrag), zuzugl. hälftiger Sonderposten mit Rücklageanteil, zuzulgl. Buchwert von Beteiligungen an anderen Kapitalgesellschaften. 
dann entsprechend der Beteiligung des Anteilseigners das anteilige Eigenkapital ermittelt.

Während der Eigenkapitalbegriff in $\S 8 \mathrm{a} \mathrm{KStG}$ spezifiziert wurde, findet sich für Fremdkapital keine Definition. Das Einführungsschreiben zum § 8a KStG liefert eine beispielhafte Aufzählung von Verbindlichkeiten, die zum Gesellschafterfremdkapital gezählt werden: Hierzu gehören fest und variabel verzinste Darlehen, partiarische Darlehen, stille Beteiligungen, Gewinnschuldverschreibungen und Genußrechtskapital ${ }^{375}$. Kurzfristig überlassene Kredite, z.B. Lieferantenkredite, zählen nicht zum Fremdkapital, dagegen werden Kontokorrentkredite laut Einführungsschreiben dazugezählt ${ }^{376}$, was umstritten ist. Unklar ist auch, ob auf Mindestbestände oder auf höhere schwankende Forderungsbestände abgezielt wird ${ }^{377}$.

Der Fiskus differenziert zwischen Fremdkapitalvergütungen, die zu einem Bruchteil des Kapitals bemessen werden und solchen, die sich in ihrer Höhe nicht nach einem Bruchteil des Kapitals bestimmen. Letztere Vergütungen weisen einen relativ starken Eigenkapitalcharakter auf. Typisch für Eigenkapital ist, daß die Bereitstellung nicht zu einem fixierten Zinsanspruch führt, sondern daß die Entlohnung eher variabel und abhängig vom Erfolg, manchmal auch vom Umsatz der Kapitalgesellschaft ist. Gewinn- oder umsatzabhängige Vergütungen für Fremdkapital entstehen z.B. bei partiarischen Darlehen, bei der Überlassung von Genußscheinkapital und bei stillen Beteiligungen. ${ }^{378}$

Die Entlohnung dieses Kapitals wird wie eine verdeckte Gewinnausschüttung behandelt, sofern das entsprechende Fremdkapital des nichtanrechnungsberechtigten Anteilseigners die Hälfte des rechnerisch auf ihn entfallenden Eigenkapitalanteils übersteigt. Solange diese Quote von 0,5:1 nicht überschritten wird, tritt keine steuerliche Umqualifizierung ein, unabhängig davon, ob das zur Verfügung gestellte Fremdkapital eigenkapitalersetzenden Charakter hat. Erfolgsabhängige Vergütungen, die auf Fremdkapital entfallen, das diesen Safe-Haven überschreitet, werden grundsätzlich steuerlich wie Eigenkapitalvergütungen (Dividenden) behandelt. Der Safe-Haven für erfolgsabhängig vergütetes Fremdkapital ist vergleichsweise klein, da erfolgsabhängige Entlohnungen von Fremdkapital eine gro-

375 BMF-Einfuhrungsschreiben zum § 8a KStG, BStBl. I 1995, S. 25ff., Rz. 44, auch abgedruckt in: Wollert-Elmendorff u.a. (1996) (Hrsg.): Gesellschafter-Fremdfinanzierung, Hamm 1996. Im weiteren zitiert als Einführungsschreiben + Rz.

376 Vgl. Einfuhrungsschreiben, Rz. 47ff.

377 Vgl. Menck (1995), a.a.O., S. 8, Rz. 11.

378 Vgl. Einfuhrungsschreiben, Rz. 53. 
Be Nähe zum Eigenkapital haben und "Gewinnabsaugungsvolumen" erzeugen ${ }^{379}$. Ein entlastender Nachweis, daß das erfolgsabhängig vergütete Fremdkapital eines nichtanrechnungsberechtigten Gesellschafters, das diese Quote übersteigt, keinen eigenkapitalersetzenden Charakter hat, ist vom Gesetzgeber ausgeschlossen.

Typischer für Fremdkapital ist eine erfolgsunabhängige Vergütung. In der Regel besteht eine derartige Vergütung in Form eines festen Zinsanspruchs. Die Entlohnung des Kapitals ist dann nur abhängig von der Höhe der Einlage. Bringt ein nichtanrechnungsberechtigter Anteilseigner Kapital ein, das erfolgsunabhängig entlohnt wird, so gilt ein weiterer Safe-Haven, die FK-EK-Quote darf dann $3: 1$ betragen. Dieser größere Safe-Haven wird damit begründet, daß die Kapitalanlage tatsächlich eher Fremdkapitalcharakter hat. Die FK-EK-Quoten gelten nicht nebeneinander.

Tabelle VI: Unschädliche Kombinationsmöglichkeiten von erfolgsabhängigem und erfolgsunabhängigem Fremdkapital

\begin{tabular}{|c|c|c|}
\hline $\begin{array}{l}\text { Anteiliges Eigenkapital } \\
\text { nichtanrechnungsb. Anteils- } \\
\text { eigner }\end{array}$ & $\begin{array}{l}\text { Erfolgsabhängig entlohntes } \\
\text { Fremdkapital (Safe-Haven: } \\
0,5: 1)\end{array}$ & $\begin{array}{l}\text { Erfolgsunabhängig ent- } \\
\text { lohntes Fremdkapital (Safe- } \\
\text { Haven: 3:1) }\end{array}$ \\
\hline 1000 & 500 & - \\
\hline 1000 & 490 & 60 \\
\hline 1000 & 20 & 2880 \\
\hline 1000 & 10 & 2940 \\
\hline 1000 & 5 & 2970 \\
\hline 1000 & - & 3000 \\
\hline
\end{tabular}

Quelle: Eigenes Beispiel

Gewährt ein nichtanrechnungsberechtigter Anteilseigner erfolgsabhängig und erfolgsunabhängig zu vergütendes Fremdkapital, so ist der Safe-Haven für erfolgsabhängig vergütetetes Fremdkapital vorrangig zu beachten.

Ist dieser Safe-Haven nicht ausgeschöpft, so dient das Sechsfache des noch freien Differenzbetrag als Safe-Haven für das erfolgsunabhängige Fremdkapital. Ein eingezahltes Eigenkapital von 1000 ermöglicht also einem nichtanrechnungsberechtigten Anleger z.B. die in der Tabelle VI aufgeführten Fremdkapitaleinlagen alternativ, ohne daß $\S 8 \mathrm{a} \mathrm{KStG}$ eingreift.

379 Prinz, U. (1995b): Ausgewählte Problemfälle zu § 8a KStG aus der Beratungspraxis, in: Herzig, N. (Hrsg.): Gesellschafterfremdfinanzierung und Beteiligung an ausländischen Gesellschaften im Körperschaftsteuerrecht, Köln 1995, S. 47f.; vgl. Herzig, N. (1994): Standordsicherungsgesetz: Gesetzliche Regelung der Gesellschafter-Fremdfinanzierung in $\S$ 8a KStG (Teil II), in: Der Betrieb (DB), 47. Jg./(1994), Nr. 4, 28.1.1994, S. 170. 


\subsubsection{Identifikation einer übermäßigen Gesellschafterfremdfinanzie- rung: Ausnahmen von der Quotenlösung}

Während ein Überschreiten der FK-EK-Quote für erfolgsabhängig vergütetes Fremdkapital $(0,5: 1)$ generell eine dividendensteuerlichen Behandlung des den Safe-Haven überschreitenden Anteils auslöst, kann erfolgsunabhängiges Fremdkapital unter bestimmten Umständen den Safe-Haven (3:1) ohne steuerliche Folgen überschreiten. Dies ist immer dann der Fall, wenn die Gesellschaft nachweisen kann, daß sie das Darlehen auch von einem fremden Dritten hätte erhalten können. Grundsätzlich unberücksichtigt bleiben auch

- Mittelaufnahmen, die der Finanzierung banküblicher ${ }^{380}$ Geschäfte dienen, und

- Fremdmittel, die nur kurzfristig aufgenommen werden.

Von der ersten Ausnahme sind nach herrschender Meinung allein Unternehmen betroffen, die in Deutschland eine Erlaubnis zum Betrieb von Bankgeschäften nach $\S 32$ Abs. $1 \mathrm{KWG}$ haben ${ }^{381}$. Mit der zweiten Ausnahme sollen kurzfristige Überbrückungskredite folgenlos gehalten werden.

Grundsätzlich anders behandelt werden Holding-Gesellschaften ${ }^{382}$. Ihnen hat der Gesetzgeber einen erweiterten Safe-Haven für erfolgsunabhängig vergütetes $\mathrm{Ka}$ pital in Höhe von 9:1 statt 3:1 eingeräumt. Differenzbeträge, die sich aus ungenutztem Safe-Haven für erfolgsabhängig vergütetes Fremdkapital ergeben, können achtzehnfach statt sechsfach für erfolgsunabhängig vergütetes Fremdkapital genutzt werden. Hinsichtlich des erfolgsabhängigen Fremdkapitals genießen Holdinggesellschaften dagegen keinen erweiterten Safe-Haven.

Der Vorteil für Holdinggesellschaften wird aber zugleich beschränkt durch eine Nichtgewährung von Safe-Haven innerhalb von Beteiligungsketten. Untergeordneten Gesellschaften steht damit direkt kein Gesellschafterfremdkapital zur Verfügung. Mit der Nichtgewährung der Safe-Haven auf untergeordneten Ebenen sollte ein möglicher Kaskadeneffekt unterbunden werden. Für Beteiligungsketten,

380 Bankübliche Geschäfte sind Geschäfte im Sinne des $§ 1$ KWG. Keine banküblichen Geschäfte sind Mittelaufnahmen, die der Finanzierung von Tochtergesellschaften dienen. Vgl. Einfuhrungsschreiben, Rz. 70.

381 Vgl. Hăuselmann, H. / Pachmann T. (1994): Gesellschafterfremdfinanzierung, Bankgeschăft und bankübliches Geschäft, Recht der Internationalen Wirtschaft (RIW), Jg. Nr. 3, S. 234.

382 Als Holdinggesellschaften gelten dabei Kapitalgesellschaften, deren Haupttătigkeit darin besteht, Beteiligungen an Kapitalgesellschaften zu halten und diese zu finanzieren oder deren Vermögen zu mehr als $75 \%$ ihrer Bilanzsumme aus Kapitalgesellschaftsbeteiligungen besteht, vgl. $\S 8$ a Abs. $4 \mathrm{KStG}$. 
die nicht unter das Holding-Privileg fallen, gilt, daß anteiliges Eigenkapital um den anteiligen Buchwert von untergeordneten Gesellschaftsbeteiligungen zu kürzen ist. Dafür stehen jeder Untergesellschaft normale Safe-Haven zur Verfügung.

\subsubsection{Ungereimtheiten der gesetzlichen Regelungen}

Die Formulierung des $\S 8 \mathrm{a} \mathrm{KStG}$ hat im Zeitraum nach seiner Inkraftsetzung zu zahlreichen Unsicherheiten in der praktischen Umsetzung geführt. Zur Beurteilung der einschränkenden Maßnahmen gegen Gesellschafterfremdfinanzierungen ist es unvermeidlich, die wichtigsten Unsicherheiten vorzustellen und zu bewerten. Es ist nicht Ziel dieser Arbeit, alle steuerjuristischen Auslegungsdiskussionen des $\S 8 \mathrm{a} \mathrm{KStG}$ wiederzugeben. Zur Beurteilung dieser Regelung ist jedoch es erforderlich, die problematischen Bereiche der aktuellen Gesetzeslage zu durchleuchten.

\subsection{Unsicherheiten bei der Safe-Haven-Zuordnung}

Die deutschen Regelungen zur Gesellschafterfremdfinanzierung weisen ein besonderes Problem auf, weil der Gesetzgeber - je nach Charakter der Fremdkapitalvergütung - sehr unterschiedliche FK-EK-Quoten einräumt. Wie noch zu zeigen sein wird, ist das deutsche Vorgehen, Fremdkapital graduell nach seinem Eigenkapitalcharakter zu unterscheiden, sehr ungewöhnlich. Dabei kommt der Frage, ob die Fremdkapitalvergütung zu einem Bruchteil des Kapitals erfolgt, eine zentrale Bedeutung zu. Problematisch ist, daß sich eine Entlohnung zu einem Bruchteil eines eingelegten Kapitals keineswegs immer von einer erfolgsabhängigen Entlohnung unterscheiden muß. So existieren nämlich Finanzierungsformen, die in $\mathrm{Ab}$ hängigkeit des erzielten Gewinns einen festen Zinsanspruch gewähren ${ }^{383}$, oder die einen festen Zinsanspruch nur gewähren, sofern ein Unternehmen schwarze Zahlen schreibt. Herzig und auch die Finanzverwaltung sehen diese Finanzierungsformen im Bereich des erfolgsabhängig entlohnten Fremdkapitals ${ }^{384}$. Eine derartige Auslegung läßt erwarten, daß die Mehrheit der sogenannten hybriden Finanzierungsformen, also Mischformen zwischen Eigen- und Fremdfinanzierung, eher dem engeren Safe-Haven zuzuordnen sind. Allerdings ist die Entwicklung im Bereich hybrider Finanzierungen so vielfältig, daß eine eindeutige Einordnung aller Finanzierungsformen weder durch ein Gesetz noch durch ergänzende Durchfüh-

383 Z.B. $6 \%$ Verzinsung bei einem Unternehmensgewinn bis 500.000 DM; $7 \%$ Verzinsung bei einem höheren Unternehmensgewinn.

Vgl. Herzig, N. (1994), a.a.O., S. 170f. 
rungsverordnungen geleistet werden kann. Im Zweifelsfall werden Einzelfallprüfungen den Ausschlag geben.

Dies gilt wohl auch für Fremdkapital mit Stundungsvereinbarungen. Während Fremdkapital mit fester Zinsvereinbarung natürlich zur Gruppe der erfolgsunabhängigen Vergütungen zählt, führt ein Zusatz, der die Aussetzung von Zinszahlungen in Verlustjahren beinhaltet, nach Ansicht der Finanzverwaltung dazu, daß das Fremdkapital - trotz grundsätzlich fixierten Zinssatzes - erfolgsabhängig einzustufen ist. Eine Zusatzbestimmung, die statt der Aussetzung nur eine Stundung der Zinsen vorschreibt, bewirkt ebenfalls eine Einstufung als erfolgsabhängige Vergütung ${ }^{385}$. Dies ist auf starken Widerspruch gestoßen, weil eine Stundung nur einem Zahlungsaufschub entspricht, den Gläubigercharakter aber nicht beeinflußt, da Zinsen bereits angefallen sind ${ }^{386}$. Solche Unsicherheiten beeinflussen aber im beträchtlichen $\mathrm{Ma}$ das Investitionsverhalten der Kapitalanbieter.

Es ist offensichtlich, daß die Intention des Gesetzgebers, gleiches - in diesem Fall Eigenkapital und eigenkapitalähnliches Fremdkapital - gleich zu besteuern, zu beachtlichen Abgrenzungsproblemen führt. Zur Vermeidung des Risikos einer Umqualifizierung werden wesentlich beteiligte Anteilseigner, die ihrer Gesellschaft Fremdkapital zur Verfügung stellen wollen, darauf achten müssen, daß ihre Einlage ausreichenden Fremdkapitalcharakter aufweist.

\subsection{Bedeutung des Drittvergleichs}

Der erfolgreiche Drittvergleich schützt nur im Bereich der erfolgsunabhängigen Vergütung vor den Folgen einer Überschreitung des Safe-Haven von 3:1. Ein Drittvergleich für die Fremdfinanzierung gelingt, wenn die Gesellschaft nachweisen kann, daß sie das Fremdkapital zu gleichen Bedingungen auch von einem fremden Dritten hätte erhalten können. Dies kann z.B. durch Nachweis eines spezifischen ${ }^{387}$ Kreditangebots einer Bank an die Kapitalgesellschaft erfolgen.

Zweifellos ist der Drittvergleich mit zahllosen Problemen behaftet. So ist z.B. ein entsprechendes Angebot der Hausbank des betroffenen Unternehmens wegen des möglichen Gefälligkeitscharakters für die Finanzverwaltung nur von einge-

385 Vgl. Einführungsschreiben, Rz. 55.

386 Vgl. Herzig, N. (1994), a.a.O., S. 171.

387 Unverbindliche Kreditangebote reichen nicht fur einen Drittvergleich aus. Es muß sich um ein rechtlich verbindliches Kreditangebot handeln. 
schränktem Nutzen ${ }^{388}$. Ein nicht ganz ernstzunehmendes Kreditangebot ist schließlich in der Praxis häufig relativ leicht zu beschaffen - z.B. wenn sich der Anbieter entsprechende Gegenleistungen erhoffen kann.

Die Zulassung des Drittvergleichs kann aus systematischer Sicht positiv gesehen werden, da das Kriterium des Dritt- bzw. Fremdvergleichs im § 8a KStG eine Übereinstimmung mit internationalen und nationalen Wertungen aufweist. So findet sich der Drittvergleich in DBA-Regelungen ebenso wie im nationalen Steuerrecht bei der Beurteilung der verdeckten Gewinnausschüttung nach $\S 8 \mathrm{KStG}$. Ebenfalls vorteilhaft ist die Flexibilität des Drittvergleichs: Spezifische Besonderheiten einzelner Wirtschaftssektoren können relativ unproblematisch Berücksichtigung finden. Die Verknüpfung einer Quotenlösung mit dem Drittvergleich hat jedoch bei der Formulierung und bei der Auslegung des $\S 8 \mathrm{a} \mathrm{KStG}$ zu zahlreichen Problemen geführt - was nicht verwundert, denn eine pauschale Begrenzung der Fremdkapitalzuführung und eine gleichzeitige Gewährung eines Drittvergleichs wirken gegensätzlich.

Nach Einführung des $\S 8 \mathrm{a} \mathrm{KStG}$ gab es verschiedene Ansichten darüber, ob der Safe-Haven für alle Gesellschafterkredite oder nur für Fremdkapital gelten sollte, das dem Drittvergleich nicht standhält. Weiterhin herrschte Unklarheit, welche Folgen die Überschreitung eines Safe-Haven auslösen sollte. Fraglich war, ob in einem solchen Fall das gesamte erfolgsunabhängige Fremdkapital, nur die gesamte überschießende Spitze oder die Tranchen, die den Safe-Haven überschreiten, im Drittvergleich zu prüfen wären. Als vorherrschende Meinung und bestätigt durch das Einführungsschreiben der Finanzverwaltung zum $\S 8 \mathrm{a} \mathrm{KStG}$ setzte sich die Ansicht durch, daß auf keinen Fall das gesamte Fremdkapital steuerlich umzuqualifizieren sei. Daraus folgten aber zwangsläufig neue Fragen, z.B. welche Kreditzinsen gegebenenfalls umzuqualifizieren seien. Sollten die Zinszahlungen betroffen sein, die dem Fremdvergleich am wenigsten standgehalten haben, oder die Vergütungen für die zuletzt aufgenommenen Gesellschafterdarlehen, wie es die Finanzververwaltung bekundete? Der Wortlaut des $\S 8 \mathrm{a} \mathrm{KStG}$ bietet hier keinen Anhaltspunkt. Vielfach wird deswegen die Ansicht vertreten, daß die Kapitalgesellschaft hier ein Wahlrecht hätte ${ }^{389}$.

388 Vgl. Hey, F.E.F. (1994), Gesellschafterfremdfinanzierung. Einige Zweifelsfragen zur Anwendung von $\S 8 \mathrm{a} \mathrm{KStG}$, in: Recht der Internationalen Wirtschaft (RIW), 40. Jg./(1994), Nr. 3 S. 226.

389 Meilicke, W. (1994): Erste Probleme mit $\S 8$ a des Körperschaftsteuergesetzes, in: BetriebsBerater (BB), 49. Jg./(1994), Nr. 2, S. 120; Wassermeyer, F. (1994): Stellungsnahme zu ausgewählten Zweifelsfragen bei der Anwendung des § 8a KStG, in Herzig, N. (Hrsg.): Gesellschafterfremdfinanzierung und Beteiligung an ausländischen Gesellschaften im Körperschaftsteuerrecht, Steuerthemen im Brennpunkt, Bd. 9, Köln 1995, S.13. 
Sowohl in der herrschenden Meinung als auch im Einführungsschreiben zum $\S 8 \mathrm{a}$ $\mathrm{KStG}^{390}$ hat sich der Standpunkt durchgesetzt, daß nur die Tranchen, die den SafeHaven überragen, dem Drittvergleich zu unterwerfen sind. Menck kritisiert daran zu Recht die erhebliche Manipulierbarkeit, denn ein auf die Spitze begrenzter Drittvergleich erlaubt innerhalb des Safe-Havens völlig marktfremde Finanzierungsabsprachen, bzw. Vereinbarungen, die den Sinn des Drittvergleichs insgesamt aushöhlen ${ }^{391}$. So ist es z.B. möglich, innerhalb der FK-EK-Quoten eine sicherungslose Gesellschafterfremdfinanzierung einzugehen. Alle Sicherungsmittel des Unternehmens können dann aufgespart werden für die Kredite jenseits des Quotengrenzen. Die hieraus entstehende höhere Bonität erleichtert die Durchführung eines erfolgreichen Drittvergleichs; eine Kreditaufnahme zu marktüblichen Konditionen über die Safe-Haven-Grenze hinaus wird erleichtert.

Diese Manipulierbarkeit ist offenbar auch durch ein Abstellen auf die zeitliche Gewährung des Fremdkapitals nicht zu verhindern. Hat z.B. ein ausländischer Anteilseigner einer Kapitalgesellschaft schon mehrere einzelne Kredite eingeräumt und wird ein weiterer Kredit gewährt, der den Safe-Haven von 3:1 überschreitet und der einem Drittvergleich nicht standhalten würde, so kann es den Anteilseignern nicht verwehrt werden, im Rahmen der erweiterten Fremdkapitalgewährung eine Umstrukturierung der alten Fremdkapitalaufnahmen vorzunehmen. Denkbar ist, daß eine Kapitalgesellschaft die alten Kredite zurückzahlt und etwas später neue Kredittranchen in der steuerlich günstigsten Reihenfolge aufnimmt. Die zeitliche Reihenfolge ist somit durchaus gestaltbar.

Diese Auslegungen lassen insgesamt Zweifel am Sinn eines Drittvergleichs in Verbindung mit einer Quotenregelung aufkommen. Es kann nur eine genauere Gesetzesformulierung zur Beseitigung der entstandenen Unsicherheiten gefordert werden. Daß selbst eine solche Forderung nicht immer ausreicht, zeigt sich z.B. am folgenden Fall, der ebenfalls für Verwirrung sorgt. Nach Ansicht der Finanzverwaltung muß eine inländische Tochtergesellschaft, die einen Kredit bei einer inländischen Bank aufnimmt, für die eine ausländische Muttergesellschaft bürgt, nicht nachweisen, daß sie diesen Kredit auch von einem fremden Dritten ohne die ausländische Bürgschaft erhalten hätte. Dies widerspricht aber dem Sinn des Drittvergleichs, der eine Berücksichtigung sonst gleicher Umstände verlangt. ${ }^{392}$

Zusätzlich verkomplizieren sich die Regelungen zum Drittvergleich aus dem Nebeneinander der Quoten des $\S 8 \mathrm{a} \mathrm{KStG}$ einerseits und der schon früher gültigen

390 Vgl. Einfuhrungsschreiben, Rz. 60.

Vgl. Menck, T. (1995), a.a.O., S. 13, Rz. 35. 
deutschen Gesetzesregelung des $\S 8 \mathrm{Abs} .3 \mathrm{KStG}$ andererseits, der verdeckte Gewinnausschüttungen betrifft. $\S 8 \mathrm{Abs} .3 \mathrm{KStG}$ besteht neben den Regelungen zur Gesellschafterfremdfinanzierung - allerdings vorrangig - fort. Ein grundsätzlicher Unterschied zwischen den beiden Gesetzen besteht darin, daß die Beweislast des Drittvergleichs beim $\S 8$ Abs. $3 \mathrm{KStG}$ bei den Finanzbehörden liegt und nicht, wie im Fall des $\S 8 \mathrm{a} \mathrm{KStG}$, bei der betroffenen Gesellschaft. Da $\S 8 \mathrm{Abs}$. $3 \mathrm{KStG}$ vorrangig gilt, schützt kein Safe-Haven vor einer steuerlichen Umqualifizierung, wenn der Finanzbehörde der Nachweis gelingt, daß eine verdeckte Gewinnausschüttung vorliegt. Die Umqualifizierung nach $\S 8 \mathrm{Abs}$. $3 \mathrm{KStG}$ betrifft damit Fremdkapital, unabhängig davon, ob es innerhalb oder außerhalb eines SafeHavens liegt. Fraglich ist, nach welcher Regelung umqualifiziert wird, wenn der Drittvergleich nicht gelingt, denn eine Umqualifizierung nach $\S 8 \mathrm{Abs} .3 \mathrm{KStG}$ hat im Gegensatz zur Umqualifizierung nach $\S 8 \mathrm{a} \mathrm{KStG}$ zusätzlich noch gewerbeertragsteuerliche Folgen ${ }^{393}$.

Von ganz grundsätzlicher Bedeutung ist die Frage, ob ein Drittvergleich bei einer Regelung wie $\S 8 \mathrm{a} \mathrm{KStG}$ überhaupt zu rechtfertigen ist, weil streng genommen hier Nichtvergleichbares verglichen wird. Vergleichen dürfte man nämlich eigentlich nicht Kapitalgesellschaften mit ähnlichen Geschäftsinhalten und vergleichbarer Größe, sondern Kapitalgesellschaften mit vergleichbaren Anteilseignergruppen.

Ein Drittvergleich zwischen einer auslandsbeherrschten Kapitalgesellschaft mit einer hohen Quote von Gesellschafterfremdfinanzierungen und einer völlig eigenfinanzierten inländischen Kapitalgesellschaft in einem Vollanrechnungsland stellt insofern keinen korrekten Vergleich dar, als die Anteilseigner - synthetische Einkommensbesteuerung und gleiche Steuersätze im In- und Ausland vorausgesetzt der gleichen Steuerlast nur dann unterliegen, wenn die auslandsbeherrschte Kapitalgesellschaft (theoretisch) durch ihre Gesellschafter zu 100\% fremdfinanziert wird. In diesem Fall würde ein Drittvergleich aber immer einen deutlichen Gestaltungsmißbrauch signalisieren. 


\subsection{Behandlung zinslos zur Verfügung gestellter Gesellschafterdarle- hen}

Nach der wohl überwiegenden Meinung im Schriftum erfaßt $\S 8 \mathrm{a}$ KStG Abs. 1 nur Fremdkapital, für das Vergütungen gezahlt werden ${ }^{394}$. Die Finanzverwaltung ist offensichtlich anderer Auffassung. Zwar lassen sich zinslose Darlehen steuerlich nicht in Dividenden umqualifizieren, nach Auffassung der Finanzverwaltung $^{395}$ belasten sie aber den Safe-Haven. Diese Regelung wäre wohl für Fälle vertretbar, wenn ein Darlehen eines Nichtanrechnungsberechtigten in zwei Tranchen geteilt werden könnte, wobei das zuerst aufgenommene Darlehen ein marktunüblich hochverzinstes Darlehen sein könnte, das unter den Safe-Haven fällt, während das überragende Darlehen mangels Zinszahlungen keine Umqualifizierung auslöst. Hiervor schützt aber die Regelung des $\S 8 \mathrm{Abs} .3 \mathrm{KStG}$, der das marktunüblich verzinste Darlehen in eine verdeckte Gewinnausschüttung umqualifiziert. Aufgrund der erwähnten Vorrangigkeit des $\S 8 \mathrm{KStG}$ findet der SafeHaven des $\S 8 \mathrm{a} \mathrm{KStG}$ hier keine Berücksichtigung. Da der Weg der dargestellten Tranchengestaltung versperrt ist, fällt es schwer, nachzuvollziehen, warum die Finanzverwaltung unverzinsliche Darlehen unter den $\S 8 \mathrm{a} \mathrm{KStG}$ fallen läßt. Weder kann ein Zinsabzug bei der inländischen Kapitalgesellschaft geltend gemacht werden, noch fließen Erträge unversteuert ins Ausland. Die Motivation des § 8a KStG trifft den Sachverhalt eines unverzinslichen Darlehens gar nicht ${ }^{396}$. Fraglich ist, ob hier die Finanzierungsfreiheit der Kapitalgesellschaft nicht zu einschneidend verletzt wird.

\subsection{Besondere Probleme im Verlustfall}

Zur Ermittlung des "anteiligen Eigenkapitals" eines Gesellschafters, das als Bezugsgröße für die gewährten Safe-Haven dient, wird auf das Eigenkapital der Gesellschaft abgestellt, wie es sich nach handelsrechtlichen Grundsätzen ergibt. Eine zeitlich befristete Minderung des Eigenkapitals aufgrund von Verlusten soll nicht automatisch zu einer Umqualifizierung führen, da in diesem Fall nicht von einer gezielten Gesellschafterfremdfinanzierung ausgegangen werden kann. Der Gesetzgeber hat die zeitliche Befristung der Gewinnminderung im Einführungsschreiben spezifiziert. Danach kann "das ursprüngliche Eigenkapital durch Einla-

394 Vgl. Ammelung, U. (1995): Das BMF-Einfuhrungsschreiben zu § 8a KStG, in: GmbHRundschau (GmbHR) 1995, 86. Jg./(1995), Nr. 2, S. 96; vgl. Bellstedt, C. (1995), in: Der Betrieb (DB), 48. Jg./(1995), Nr. 1, S. 12 .

Vgl. Einführungsschreiben, Rz. 44.

Vgl. Bellstedt, C. (1995), a.a.O., S. 13. 
gen innerhalb der folgenden drei Wirtschaftsjahre [...] wiederhergestellt werden"397. Das Einführungsschreiben zum $\S 8 \mathrm{a}$ KStG verlangt präzisierend die Herstellung des ursprünglichen Eigenkapitals "in voller Höhe". Ausdrücklich heißt es, daß ein teilweiser Ausgleich nicht ausreiche ${ }^{398}$. Es besteht Uneinigkeit darüber, ob das "ursprüngliche" Eigenkapital tatsächlich wiederhergestellt werden muß, denn es sind viele Fälle denkbar, in denen die Wiederherstellung eines Teils des ursprünglichen Eigenkapitals ausreichen würde, um die gesamte Safe-Haven-Quote einzuhalten $^{399}$. Stellt z.B. ein Nichtanrechnungsberechtigter, der zu $50 \%$ an einer inländischen Gesellschaft beteiligt ist, ein erfolgsunabhängiges Gesellschafterfremdkapital von 2000 zur Verfügung, und beträgt das Eigenkapital der Gesellschaft 2000, das anteilige Eigenkapital des Nichtanrechnungsberechtigten damit 1000 , so dürfte der Nichtanrechnungsberechtigte seine erfolgsunabhängige Fremdkapitaleinlage noch bis 3000 erhöhen, ohne dabei den Safe-Haven (3:1) zu verlassen. Wenn die Gesellschaft nun ihr Eigenkapital von 2000 durch Verluste auf 1200 verringert, wäre der (neue) Safe-Haven $(600$ x 3) um 200 überschritten. Die Safe-Haven-Regelung würde nun eine Eigenkapitalwiederherstellung allein im Umfang von 67 erfordern. Aus der Formulierung des Einführungsschreibens zum $\S 8 \mathrm{a} \mathrm{KStG}$ geht aber hervor, daß sich das "zulässige Fremdkapital" solange nicht wieder erhöht, solange keine vollständige Verrechnung der verlustbedingten Minderung des Eigenkapitals erfolgt ist ${ }^{400}$. Ein ökonomischer Sinn ist in der Wiederherstellung des vollständigen Eigenkapitals kaum zu erkennen.

Problematisch ist auch, daß das Einführungsschreiben im Gegensatz zum § 8a $\mathrm{KStG}$ vorschreibt, wie das verlorene Eigenkapital in den drei Folgejahren wiederhergestellt werden kann. Eine Wiederherstellung des Eigenkapitals ist nämlich nicht möglich durch Verrechnung von Jahresfehlbeträgen mit Gewinnvorträgen und Gewinnrücklagen aus den Wirtschaftsjahren, die dem Verlust vorausgegangen sind. Damit aber unterscheiden sich die Eigenkapitalbegriffe innerhalb der Bestimmungen des $\S 8 \mathrm{a} \mathrm{KStG}$, wofür es kaum eine logische Begründung geben kann. Denn zur ursprünglichen handelsrechtlichen Definition des Eigenkapitalbegriffs - siehe oben - gehört natürlich die Verrechnung mit Gewinnrücklagen und Gewinnvorträgen.

Neben der Detailkritik an den steuerrechtlichen Regelungen zur Verlustberücksichtigung bleibt gerade die steuerliche Umqualifizierung aufgrund überhöhter

397 Einführungsschreiben, Rz. 33.

398 Vgl. Einführungsschreiben, Rz. 35.

399 Vgl. Bellstedt, C. (1995), a.a.O., S. 12; vgl. Hey, F.E.F. (1994), a.a.O., S. $223 f$.

400 Vgl. Einführungsschreiben, Rz. 34. 
Gesellschafterfremdfinanzierung im Verlustfall aus steuersystematischer Sicht sehr problematisch. Eine körperschaftsteuerliche Belastung tritt durch den $\S 8 \mathrm{a}$ KStG unabhängig davon ein, ob die Gesellschaft im Jahr der Zinszahlung mit Verlust abschließt. Der Charakter der Körperschaftsteuer als Steuer auf den Gewinn eines Unternehmens wird damit ins Gegensätzliche verkehrt: Mit der steuerlichen Umqualifizierung findet dann eine Substanzbesteuerung statt ${ }^{401}$. Im Bereich der steuerlichen Verlustfolgen wird damit an dieser Stelle eine Ungleichbehandlung von Personen- und Kapitalgesellschaften deutlich. Die mit dem Anrechnungsverfahren angestrebte Beseitigung der steuerlichen Doppelbelastung tritt ausgerechnet in schwierigen Geschäftsphasen einer Unternehmung wieder ein. In Verlustsituationen verstößt eine steuerliche Umqualifizierung von Zinsen auch gegen die Rechtsform, die Investitions- und die Finanzierungsneutralität. Da von den Auswirkungen alle Anteilseigner betroffen sind - unabhängig von ihrer Anrechnungsberechtigung, werden die allokativen Vorteile des Anrechnungsverfahrens im Ergebnis aufgehoben.

\subsection{Maßgeblichkeit der Vorjahresschlußbilanz}

Entscheidend für die individuell zu bestimmende FK-EK-Quote ist das anteilige Eigenkapital eines Gesellschafters aus dem vorangegangenem Wirtschaftsjahr. Ein zu später Erwerb von Gesellschaftsanteilen kann damit zur Umqualifizierung von Zinsen in körperschaftsteuerpflichtige Gewinne führen, obwohl ein Safe-Haven eigentlich nicht überschritten wurde. Aus der Maßgeblichkeit der Vorjahresbilanz resultieren zweifelhafte Folgen:

Zum einen können nichtanrechnungsberechtigte Gesellschafter nicht im Verlauf eines Geschäftsjahrs mit einer Eigenkapitalzuführung ihren Safe-Haven für Fremdkapitaleinlagen ausbauen. Langfristige Steuerplanung wird nötig. Der nichtanrechnungsberechtigte Anteilseigner muß schon im Vorjahr abschätzen, wieviel Fremdkapital er im nächsten Jahr zur Verfügung stellen will ${ }^{402}$.

401 Knobbe-Keuk sah in der Umqualifizierung von Fremdkapitalerträgen sogar generell eine Substanzbesteuerung, da die Zinszahlungen des Fremdkapitals keinen Gewinn sondern Aufwand ausdrücken. Dieser sehr buchhaltungsorientierte Standpunkt läßt überhaupt keinen Spielraum für steuerliche Umqualifizierungen von Fremd- in Eigenkapitalvergütungen. Vgl. Knobbe-Keuk, B. (1982): Die Fremdfinanzierung inländischer Kapitalgesellschaften durch nichtanrechnungsberechtigte Anteilseigner, in: Steuer und Wirtschaft (StuW), 59. Jg./(1982), Nr. 3, S. 210.

402 Dies führt neuerdings zu hektischen Kapitalerhöhungen von ausländischen Anteilseignern jeweils kurz vor Ende des Geschăftsjahres; vgl. Hoffmann, W.D. (1995): Das (einstweilige) Nichtstun als Gestaltungsmittel gegen den § 8a KStG, in: Internationales Steuerrecht (IStR), 4. Jg./(1995), Nr. 4, S. 176. 
Kurzfristig auftretender Kapitalbedarf läßßt sich aber nicht prognostizieren. Infolgedessen verfügen Kapitalgesellschaften, die sich aus Nichtanrechnungsberechtigten zusammensetzen, über eine geringere Finanzierungsfreiheit und Finanzierungsflexibilität als Kapitalgesellschaften mit anrechnungsberechtigten Anteilseignern.

Zum anderen haben neu hinzukommende, nichtanrechnungsberechtigte Gesellschafter im Verlauf des ersten Jahres gar keinen Safe-Haven. Dies stellt eine schwerwiegende Einschränkung der Finanzierungsfreiheit dar. In Finanznot geratene Gesellschaften können durch Aufnahme weiterer nichtanrechnungsberechtigter Gesellschafter trotz eines sich vergrößernden Eigenkapitalvolumens im Jahr der Aufnahme keine zusätzliche Fremdfinanzierung durch die neuen Gesellschafter erlangen, ohne daß deren Vergütung steuerlich in Eigenkapitalvergütungen umqualifiziert werden würde ${ }^{403}$. Unter diesem Aspekt müssen inländische Kapitalgesellschaften eher daran interessiert sein, anrechnungsberechtigte Neugesellschafter aufzunehmen.

\subsection{Darlehensgewährung durch Dritte}

Im Einführungsschreiben zum $\S 8 \mathrm{a} \mathrm{KStG}$ betont das $\mathrm{BMF}$, daß auch Zwischenschaltungen von Anrechnungsberechtigten bzw. nahestehenden Dritten nicht vor der steuerlichen Umqualifizierung schützen. Insbesondere sogenannte Back-toback-Finanzierungen - eine Bank gibt das Darlehen an die Kapitalgesellschaft und der nichtanrechnungsberechtigte Anteilseigner unterhält bei der Bank eine Einlage in gleicher Höhe - werden nach Ansicht der Finanzverwaltung erfaßt. Umstritten ist auch, ob eine Bürgschaft bzw. eine Patronatserklärung des Nichtanrechnungsberechtigten schon ausreicht, um $\S 8 \mathrm{a} \mathrm{KStG}$ auszulösen ${ }^{404}$. Gleiche Probleme bestehen auch für Konzernfinanzierungen, wodurch fast unlösbare Nachweis- und Kontrollaufgaben entstehen ${ }^{405}$.

403 Wollert-Elmendorff u.a. weisen darauf hin, daß unter Umständen die Bildung eines Rumpfwirtschaftsjahres helfen könne, vgl. Wollert-Elmendorff u.a. (1996), a.a.O., S.101.

404 Vgl. Einführungsschreiben, Rz. 21; anderer Ansicht ist Hey, F.E.F. (1993): Gesellschafterfremdfinanzierung. Einige Gedanken zum neuen $\S 8 \mathrm{a} \mathrm{KStG}$, in: Recht der Internationalen Wirtschaft (RIW), 39. Jg./(1993), Nr. 10, S. 836.

405 Vgl. Borggräfe, K. (1995): Darlehensgewăhrung durch Dritte i. S. d. § 8 a Abs. 1 Satz 2 KStG, in Finanz-Rundschau (FR), 77. Jg./(1995), Nr. 10, S. 359. 
Ebenso unklar ist, ob nahestehende Dritte $\S 8 \mathrm{a} \mathrm{KStG}$ auslösen können, wenn sie anrechnungsberechtigt $\operatorname{sind}^{406}$. Wäre dies der Fall, so wäre die Integrationswirkung des Anrechnungssystems auch an dieser Stelle durchbrochen: Durch das Zinsabzugsverbot und die Besteuerung beim anrechnungsberechtigten Dritten würde eine Doppelbesteuerung von Kapitalerträgen erfolgen. Wegen der erheblichen Rechtsunsicherheiten in diesem Bereich dürfte in den nächsten Jahren mit gerichtlichen Auseinandersetzungen zu rechnen sein.

\section{Zwischenfazit}

Die Ungereimtheiten der deutschen Unterkapitalisierungsbeschränkungen, die durch das nachfolgende Einführungsschreiben eher noch verstärkt wurden, führen zu zahlreiche Unsicherheiten: Unterschiedliche FK-EK-Quoten verursachen $\mathrm{Zu}$ ordnungsprobleme bei hybriden Finanzierungsformen und Stundungsvereinbarungen. Aus dem Zusammenspiel zwischen Drittvergleich und Quotenlösung resultieren Rechtsunsicherheiten bezüglich der Frage, auf welche Kredite der Drittvergleich angewendet werden kann. Neben der Manipulierbarkeit von Drittvergleichen bleiben Fragen offen, die z.B. die Beweislast betreffen. Die Behandlung zinsloser Darlehen schränkt die Finanzierungsflexibilität von Kapitalgesellschaften mit nichtanrechnungsberechtigten Anteilseignern gegenüber Kapitalgesellschaften mit anrechnungsberechtigten Gesellschaftern zusätzlich ein. Aufgrund der Regelungen im Verlustfall wird der Gewinnsteuercharakter der Körperschaftsteuer verändert, allokative Vorteile des Anrechnungssystems werden für die betroffene Kapitalgesellschaft teilweise aufgehoben, außerdem wird die Finanzierungsfreiheit für Unternehmen gerade in schwierigen Wirtschaftslagen weiter eingeschränkt. Die Maßgeblichkeit der Vorjahresschlußbilanz verstößt gegen die Finanzierungsfreiheit und diskriminiert potentielle nichtanrechnungsberechtigte $\mathrm{Ge}-$ sellschafter. Rechtsunsicherheit entsteht auch in der Frage, welche weiteren indirekten Finanzierungen über nahestehende Dritte noch betroffen werden und welche nicht. Ohnehin erwachsen den Finanzverwaltungen noch schwer lösbare Ermittlungsprobleme. Die bestehenden Rechtsunsicherheiten lassen künftige Gerichtsentscheidungen zu diesen und weiteren Fragen erwarten. Möglicherweise wird der Gesetzgeber einige Unklarheiten früher oder später ausräumen. Die Kompliziertheit der Anwendung des $\S 8 \mathrm{a} \mathrm{KStG}$, die durch das 15seitige Einführungsschreiben eher zugenommen hat, steht im Widerspruch zu Grundanforderungen an eine effziente Besteuerung, nämlich: Klarheit, Einfachheit und Anwendbarkeit der Steuergesetze. Die unterschiedliche Ermittlung des steuerpflichtigen

406 Bejahend: Finanzverwaltung, vgl. Einführungsschreiben, Rz. 16. Verneinend Janssen; vgl. Janssen, B. (1998): Die Anwendung von $\S 8 \mathrm{a} \mathrm{KStG}$ auf nahestehende Personen und Dritte gem. § 8a Abs. 1 Satz 2 KStG, in IWB, Nr. 7 vom 08.04.1998, Fach 3, Gruppe 4, S. $375 f f$. 
Gewinns aufgrund des Steuersteuerstatus der Gesellschafter ist zudem unter Gerechtigkeitsaspekten fraglich. Es ist zu befürchten, daß allein die Rechtsunsicherheiten, die sich zur Zeit aus der gesetzlichen Regelung ergeben, die Finanzierungsfreiheiten ausländisch beherrschter Kapitalgesellschaften stark einschränken. $\mathrm{Ob}$ dieser Eindruck zutreffend ist, hängt freilich auch von der Vermeidbarkeit bzw. der Umgehbarkeit des Gesetzes ab.

\subsubsection{Lücken der gesetzlichen Regelungen}

Welche Bedeutung man den eben gestellten Fragen der Auslegung tatsächlich zumißt, hängt davon ab, wie "wasserdicht" die Bestimmungen gegen Umgehungsversuche sind. Ist es den Nichtanrechnungsberechtigten grundsätzlich möglich, den bestehenden Regelungen auszuweichen, so verlieren die eben aufgeworfenen Fragen an Gewicht. Die aktuelle gesetzliche Regelung eröffnet überraschend vielfältige Vermeidungsmöglichkeiten, die zum Teil auch schon kurz nach der Einführung des $\S 8 \mathrm{a} \mathrm{KStG}$ offensichtlich und auch genutzt wurden:

\subsection{Negative Anreizwirkung der Beteiligungsgrenze}

Ziel der deutschen Maßnahmen zur Einschränkungen der Gesellschafterfremdfinanzierung ist, daß insbesondere ausländische Anteilseigner mehr Eigen- als Fremdkapital im Vergleich zur Situation vor Einführung des § 8a KStG einbringen sollen. Um so pikanter ist es daher, wenn man feststellen muß, daß die Regelung teilweise kontraproduktiv wirkt: Nicht wesentlich beteiligte Nichtanrechnungsberechtigte werden nämlich jetzt aufpassen müssen, daß sie nicht durch erhöhte Einlagen eine wesentliche Beteiligung begründen. Nicht wesentlich beteiligte Steuerausländer werden auf diese Weise angeregt, erst recht möglichst Fremdkapital zur Verfügung stellen. Wesentlich beteiligte Anteilseigner werden unter Umständen motiviert, einen Teil ihre Beteiligungen zu verkaufen, sich aber auf Umwegen, z.B. durch vertragliche Vereinbarungen, Einfluß zu sichern ${ }^{407}$.

\subsection{Umgehungsmöglichkeit durch Sachdarlehen}

Ein Weg, seinen Kapitalbedarf zu decken, führt über "versteckte" Finanzierungen. Nichtanrechnungsberechtigte Anteilseigner können statt Kapital- einfach

407 Ist jedoch ein beherrschender Einfluß nachweisbar, was bei indirekten Beteiligungen nicht immer leicht ist, greift allerdings doch § 8a KStG wegen § 8a Abs. $3 \mathrm{KStG}$. 
Sacheinlagen in die Gesellschaft einbringen ${ }^{408}$. Indem der Nichtanrechnungsberechtigte und nicht die Gesellschaft die geplante Anschaffung vornimmt, wird § 8a KStG erfolgreich umgangen. Eine Entlohnung der Sacheinlage (Leasingrate, Miete, Pacht) fällt nicht unter die Einschränkung der Gesellschafterfremdfinanzierung, so daß die inländische Kapitalgesellschaft die Kosten als Betriebsausgaben steuermindernd geltend machen kann, während ausländische Gesellschafter ihre Einnahmen nur noch im Wohnsitzland versteuern.

Dieser Umweg bietet sich vor allem dann an, wenn mit dem Fremdkapital des Gesellschafters Anlagevermögen angeschafft werden soll. Freilich ist dies keine notwendige Vorbedingung. Gesellschafterkapital kann auch durch das Sale-LeaseBack-Verfahren zugeführt werden. Indem der Nichtanrechnungsberechtigte schon vorhandene Wirtschaftsgüter kauft und vermietet, wird bereits vorhandenes Vermögen für eine Kapitalzuführung nutzbar gemacht, ohne daß Safe-Haven verbraucht werden.

\subsection{Umgehungsmöglichkeit durch Personengesellschaften}

Der Gesetzgeber wollte mit der Regelung zur Gesellschafterfremdfinanzierung nicht die Finanzierungsfreiheit der Personengesellschaften begrenzen ${ }^{409}$. Diese eröffnet allerdings ein großes Gestaltungspotential, da es nur der Zwischenschaltung deutscher Personengesellschaften zur Ausschaltung des § 8a KStG bedarf. Gründet z.B. eine ausländische Muttergesellschaft als Anteilseigner einer inländischen Kapitalgesellschaft zusätzlich in Deutschland eine Personengesellschaft und überträgt die Muttergesellschaft die Anteile an der inländischen Tochtergesellschaft dieser Personengesellschaft, dann ist folgende Situation denkbar: Die ausländische Muttergesellschaft nimmt ein Darlehen bei einer ausländischen Bank auf und stattet so die inländische Personengesellschaft mit Kapital aus. Diese wiederum stattet die inländische Kapitalgesellschaft mit Eigenkapital aus ${ }^{410}$.

408 Vgl. Ammelung, U. (1995), a.a.O., S. 99; vgl. Wollert-Elmendorff (1996), a.a.O., S. 87; zweifelnd Mattausch, H. (1994): Die internationale Konzernfinanzierung unter dem Einfluß des $\S 8 \mathrm{a} \mathrm{KStG}$, in: Wirtschaftstandort Deutschland im Internationalen Steuerrecht, Forum der Internationalen Besteuerung, Bd. 5, Köln 1994, S. 108.

Vgl. Hey, F.E.F. (1994), a.a.O., S. 229.

410 Wichtig ist, daß eine Beteiligungsfinanzierung und nicht etwa eine (weitergeleitete) Fremdfinanzierung zwischen der inländischen Personen- und der Kapitalgesellschaft besteht. Die Fremdfinanzierung ist aufgrund von $\S 8 \mathrm{a}$ Abs. 5 Satz $2 \mathrm{KStG}$ ausgeschlossen. Da die inländische Personengesellschaft anrechnungsberechtigt ist und zugleich der Zinsabzug im Inland geltend gemacht werden kann, wird die Intention des § 8a KStG tatsăchlich umgangen; vgl. Mattausch, H. (1994), a.a.O., S. 106f. 
Da Personengesellschaften nicht dem $\S 8 \mathrm{a} \mathrm{KStG}$ unterliegen, besteht für sie also keine Beschränkung des Zinsabzugs. Die indirekte Refinanzierung bei der ausländischen Bank führt dazu, daß die Zinsaufwendungen im Inland als Sonderbetriebsausgaben abzugsfähig sind ${ }^{411}$. Unter Umständen gelingt es der Muttergesellschaft sogar, die Zinszahlungen im Ausland nochmals geltend zu machen ${ }^{412}$. Unverfolgt bleiben auch Gestaltungen, bei denen Steuerausländer Finanzierungen über eine Enkelgesellschaft (Personengesellschaft) an eine Tochtergesellschaft (Kapitalgesellschaft) leiten. Die Enkelgesellschaft ist zwar eine der Muttergesellschaft nahestehende Person, aber da sie anrechnungsberechtigt ist, greift $\S 8 \mathrm{a}$ $\mathrm{KStG}$ nicht ${ }^{413}$.

\subsection{Gründung von Holding-Gesellschaften}

Der erweiterte Safe-Haven für Holdinggesellschaften erzeugt Anreize zur Reorganisation von Unternehmen ${ }^{414}$. Der springende Punkt ist, daß nach dem Gesetzeswortlaut die Beschränkung nur im Verhältnis zu Tochtergesellschaften gelten kann, an denen die Muttergesellschaft wesentlich beteiligt ist. Enkelgesellschaften werden davon nicht betroffen, sofern sie nicht aufgrund einer wesentlichen Beteiligung der nichtanrechnungsberechtigten Muttergesellschaft unter den $\S 8 \mathrm{a} \mathrm{KStG}$ fallen. Daher lohnt sich die Gründung einer mehrstufigen Holding, da dem erweiteren Safe-Haven keine Nachteile gegenüberstehen.

\subsection{Ausnahme banküblicher Geschäfte}

Durch die Ausnahme banküblicher Geschäfte sind nach überwiegender Meinung Banken von den Beschränkungen des $\S 8 \mathrm{a} \mathrm{KStG}$ praktisch nicht betroffen. Damit sollte der Finanzierungssituation von Kreditinstituten Rechnung getragen wer$\operatorname{den}^{415}$.

411 Vgl. Wollert-Elmendorff u.a. (1996), a.a.O., S. $108 f$.

412 Vgl. Altheim, M. (1995): Gestaltungsspielräume nach Einführung des § 8a KStG (Teil 1) in: Internationales Steuerrecht (IStR), 4. Jg./(1995), S. 375.

413 Vgl. Janssen, B. (1997), a.a.O., S. 195.

414 Vgl. Schauhoff, S. (1993): Tax Planning under Germany's new 'Thin Capitalization' Rules, in: International Tax Review (Intertax), Vol. 21/(1993), Nr. 10, S. 470f.

415 Vgl. Köster, K. (1993): Implications of the New Thin Capitalization Legislation for NonResident Shareholders of a German Subsidiary, in: European Taxation, Vol. 33/(1993), Nr. 12, S. 402; Prinz, U. (1995a): Kommentar zu § 8a KStG, in: Herrmann, C. / Heuer, G. I 
Üblicherweise haben Kreditinstitute einen sehr hohen Anteil an Fremdkapitaleinlagen von Gesellschaftern. Theoretisch hätte hier die Einräumung des Drittvergleichs zwar ausreichen müssen. Vermutlich war es jedoch die Lobby der Auslandsbanken in Deutschland, die die Sonderregelung durchgesetzt hat. Argumentiert wurde offenbar mit dem Hinweis, daß die Auslandsbanken auf die Finanzierung durch ihre ausländischen Muttergesellschaften existenziell angewiesen seien. Die Möglichkeit des Drittvergleichs geht nach Ansicht der Bankenverbände deswegen ins Leere, weil erst die günstigen Kredite der Muttergesellschaften die Bankgeschäfte in Deutschland überhaupt ermöglichten ${ }^{416}$. Da dies für inländische Banken kaum gelten kann, überrascht es, daß diese ebenfalls nicht unter den $\S 8 \mathrm{a}$ $\mathrm{KStG}$ fallen ${ }^{417}$. Aus allokativer Sicht liegt hier eine Verletzung der intersektoralen Neutralität vor. Für Nichtanrechnungsberechtigte erscheint es daher sinnvoll, als Kreditinstitut aufzutreten und "bankübliche Geschäfte" mit der inländischen Kapitalgesellschaft zu betreiben, was allerdings eine Genehmigung zum Betrieb von Bankgeschäften nach $\S 32$ Abs. $1 \mathrm{KWG}$ erfordert.

\subsection{Kurzfristige Kredite}

Kurzfristige Darlehen zählen nicht zum Fremdkapital, das den Safe-Haven des § 8a KStG belastet. Die Abgrenzung der folgenlosen, kurzfristigen Kredite ist mit Rechtsunsicherheit behaftet, klar ist aber schon jetzt, daß sich auch hier nutzbare Wege der Steuervermeidung eröffnen. In diese Richtung weist auch ein Urteil des Finanzgerichts München, das der herrschenden Literaturmeinung zu folgen scheint, nach der unter kurzfristigen Darlehen Kredite mit einer Laufzeit von unter fünf Jahren zu verstehen sind ${ }^{418}$. Sollte sich diese Ansicht durchsetzen, so fallen viele Gesellschafterdarlehen gar nicht unter die Beschränkungen des Gesetzge-

Raupach, A. (Hrsg.): Einkommensteuer- und Körperschaftsteuergesetz, Erg.-Lfg. 178, S. 76ff, Rz. 106ff.

416 Vgl. Janssen, B. (1997): § 8a KStG: Zweck der Vorschrift und Kritik ihrer Ausgestaltung, Göttingen 1996, S. 172.

417 Theoretisch fallen auch Kreditinstitute mit ihren Geschäften, die nicht "bankublich" sind, unter den $\S 8 \mathrm{a} \mathrm{KStG}$, dabei steht ihnen dann aber der übliche Safe-Haven zu. Dies fuhrt unter Berücksichtigung der Bedeutung dieser Geschăfte am Gesamtgeschăft regelmäßig zur Irrelevanz des $\S 8 \mathrm{a} \mathrm{KStG}$.

418 Vgl. Prinz, U. (1998b): “Fremdkapital” im Sinne des § 8a KStG, in: Finanz-Rundschau, 80. Jg./(1998), Nr. 2, S. 73f. Darin Verweise auf weitere Autoren, die unter kurzfristigen Krediten in diesem Zusammenhang Darlehen von bis zu unter funf Jahren Laufzeit verstehen. Eine andere Ansicht vertritt die Finanzverwaltung. Sie will Darlehen nur als kurzfristig ansehen, wenn Laufzeiten von unter sechs Monaten vereinbart sind; vgl. Einfuhrungsschreiben, Rz. $47 \mathrm{ff}$. Ein BFH-Urteil hierzu steht noch aus. 
bers. Für die Steuerbehörden können sich hier außerdem Probleme mit revolvierenden Darlehen ergeben.

\section{Zwischenfazit}

Die möglichen Umgehungstaktiken zur Vermeidung der deutschen Unterkapitalisierungsbeschränkungen können in ihrer Gesamtheit wenige Jahre nach Einführung dieser Regelung noch kaum abgeschätzt werden. Wie deutlich wurde, existieren zahlreiche Möglichkeiten zur Schonung der FK-EK-Quoten. Bedenkt man weiterhin, daß die Safe-Haven-Regelungen selbst zusätzlichen Raum für Fremdfinanzierungen lassen, so relativiert sich der auf den ersten Blick sehr restriktiv wirkende $\S 8 \mathrm{a} \mathrm{KStG}$. Dieser Eindruck wird bestärkt durch die Möglichkeit der SafeHaven-Erweiterung, die eine Holding-Gründung erlaubt. Die zusätzliche Möglichkeit, gewinnunabhängig vergütetes, überschreitendes Fremdkapital mit einem Drittvergleich vor der steuerlichen Umqualifizierung zu schützen, läßt Zweifel an der Daseinsberechtigung des $\S 8 \mathrm{a} \mathrm{KStG}$ entstehen. Oder sollte es sich hier etwa nur um eine Steuer für die Nichtinspruchnahme eines Steuerberaters - also um eine sogenannte Dummensteuer - handeln? Wegen der Umgehungsmöglichkeiten wird $\S 8 \mathrm{a} \mathrm{KStG}$ jedenfalls kaum nennenswerte Steueraufkommenserhöhung bewirken. Die in der Gesetzesbegründung eingeforderte Einmalbesteuerung kann so nicht sichergestellt werden. Damit ist der Anrechnungsausschluß der ausländischen Anteilseigner nicht gewährleistet. Die Gesellschafterfremdfinanzierung bleibt als Schlupfloch ausländischer Anteilseigner ebenso erhalten wie verfeinerte Versionen des Dividendenstripping.

\subsection{Allokative Beurteilung der Gesellschafterfremdfinanzierung und der gesetzlichen Gegenmaßnahmen}

Folgt man dem umstrittenen Argument von Sinn, daß es für eine allokationsneutrale Besteuerung reiche, allein einen Finanzierungsweg nicht steuerlich zu diskriminieren, so müßte man die Gesellschafterfremdfinanzierung durch Nichtanrechnungsberechtigte begrüßen. Die Vermeidung der internationalen Doppelbelastung - bzw. die Umgehung der deutschen Körperschaftsteuer - kann dazu führen, daß ein Steuerausländer Kapitalexportneutralität genießt, da die Bereitstellung von Fremdkapital im In- und Ausland für ihn eine identische Besteuerung auslöst. Stammt der Steuerausländer selbst aus einem Vollanrechnungsland, so ist seine Fremdkapitaleinlage in Deutschland steuerlich genauso belastet wie eine Eigenkapitalbeteiligung in seinem Wohnsitzland. Es besteht grenzüberschreitende partielle Finanzierungsneutralität. Stammt er aus einem Land mit klassischem System, so wird er angereizt, auf eine heimische Beteiligungsinvestition zugunsten einer 
fremdfinanzierten Investition in Deutschland oder in seinem Wohnsitzland zu verzichten. An dieser Situation ändert offensichtlich auch die Beschränkung der Gesellschafterfremdfinanzierung durch $\S 8 \mathrm{a} \mathrm{KStG}$ nicht viel, vorausgesetzt der Steuerausländer läßt sich nicht vom ersten Eindruck des Gesetzes abschrecken. Diese Gefahr sollte allerdings nicht unterschätzt werden; erfordert ein Durchblick durch die Gesetzeslage doch einen hohen Informationsaufwand gerade für fremdsprachige Investoren. Deswegen dürfte auch von noch so unwirksamen Beschränkungen der Gesellschafterfremdfinanzierung eine negative Signalwirkung auf ausländische Kapitalgeber ausgehen.

Soweit die Anwendung der Unterkapitalisierungsregeln trotz aller Ausweichmöglichkeiten unvermeidlich ist, sind bereits im vorangegangenem Abschnitt Verstöße gegen die Rechtsform-, die Finanzierungs und die Investitionsneutralität festgestellt worden. Festzuhalten ist weiterhin die Verletzung der intersektoralen Neutralität durch die Ausnahme banküblicher Geschäfte. Eine Verletzung dieser Neutralität stellen auch die besonderen FK-EK-Quoten für Holdinggesellschaften dar, sofern der zur Gründung von Finanzholdings erforderliche Aufwand mittlere und kleinere Kapitalgesellschaften stärker abschreckt als große Unternehmen. Inwieweit sich insgesamt aus Sicht des ausländischen Anteilseigners Besteuerungsveränderungen ergeben, hängt auch davon ab, ob sein Wohnsitzland die steuerliche Umqualifizierung in Deutschland berücksichtigt.

Die Durchsetzung von wirksamen Thin-Capitalization-Rules kann man als eine Abkehr vom Wohnsitzlandprinzip und damit auch als Abkehr von einer kapitalexportneutralen Besteuerung von Zinsen bewerten ${ }^{419}$. Stattdessen erfolgt eine Hinwendung zur Quellenbesteuerung bzw. zur Quellenlandbesteuerung. Handelt es sich bei dem ausländischen Anteilseigner um eine Kapitalgesellschaft und vollzieht der ausländische Fiskus die Maßnahmen des Quellenlandes nach, indem er die Zinseinkünfte nicht mehr besteuert (sondern freistellt), wäre Kapitalimportneutralität (wieder-)hergestellt. In Deutschland investierende ausländische Anteilseigner werden sich aber im Regelfall auf ein solches Verhalten ihres Wohnsitzlandes nicht verlassen können, so daß eine internationale Doppelbelastung auch bei Zinseinkommen entsteht.

Die Umgehbarkeit des $\S 8 \mathrm{a} \mathrm{KStG}$ führt dagegen dazu, daß die internationale Doppelbelastung ausländischer Anteilseigner nicht gesichert wird. Der Fremdfinanzierungsweg bleibt offen. Sind die Steuerausländer und ihre deutschen Kapitalgesellschaften über die Feinheiten der Rechtslage informiert, so dürften sich durch die deutschen Thin-Capitalization-Rules keine schwerwiegenden Verhaltensänderungen ergeben. 
Man könnte sich fragen, ob eine so durchlässige Spezialvorschrift gegen die Gesellschafterfremdfinanzierung möglicherweise sogar beabsichtigt war. Der Gesetzgeber befand sich nämlich offenbar in einem Zielkonflikt: Einerseits bestand 1993 ein akuter Handlungsdruck. Das erwähnte BFH-Urteil, das die Finanzierungsfreiheit auch den Nichtanrechnungsberechtigten zubilligte, schaffte plötzlich eine derartige Rechtsklarheit, daß sich Nichtanrechnungsberechtigte oder deren Gesellschaften kaum noch von der allgemeinen Gestaltungsmißbrauchsklausel des $\S 42 \mathrm{AO}$ tangiert fühlen mußten ${ }^{420}$. Folglich mußte der Fiskus mit einer weiteren Zunahme der Fremdfinanzierung nichtanrechnungsberechtigter Gesellschafter rechnen und entsprechend reagieren. Andererseits lag es auch nicht im Interesse der Entscheidungsträger, ausländische Investoren aus Deutschland zu verdrängen.

\subsection{Distributive Beurteilung der Gesellschafterfremdfinanzierung und der gesetzlichen Gegenmaßnahmen}

\subsubsection{Interessenskonflikte zwischen Steuerinländern und Steuerausländern (Interpersonelle Verteilung)}

Eine verstärkte Einbringung von Fremdkapital durch Nichtanrechnungsberechtigte führt zu einem Interessenskonflikt der Anteilseigner einer Kapitalgesellschaft. Gesellschafter, die den erwirtschafteten Ertrag des Unternehmens in Form von Fremdkapitalvergütungen erhalten, haben ein geringeres Interesse an hohen Gewinnen als Anteilseigner, die ausschließlich Eigenkapital bereitstellen. Allerdings kann davon ausgegangen werden, daß eine Gewinnerzielungsabsicht bei wesentlich beteiligten Anteilseignern im gewissen Umfang immer vorhanden ist. Eine mögliche Verschärfung des $\S 8 \mathrm{a} \mathrm{KStG}$ würde diesen Interessenkonflikt vergröBern. Der aktuelle $\S 8 \mathrm{a} \mathrm{KStG}$ ändert aber aufgrund seiner Vermeidbarkeit die Interessen der Anteilseigner nicht grundsätzlich.

Sollten Unternehmen aber trotz aller Umgehungsmöglichkeiten steuerliche Umqualifizierungen aufgrund des $\S 8 \mathrm{a} \mathrm{KStG}$ hinnehmen müssen, wirkt die Erhöhung der Ertragsteuern negativ für alle Anteilseigner und zwar unabhängig davon, ob sie anrechnungs- oder nichtanrechnungsberechtigt sind. Insofern kann es zu Spannungen zwischen anrechnungs- und nichtanrechnungsberechtigten Gesellschaftern kommen. Dieser Konstruktionsfehler des $\S 8 \mathrm{a} \mathrm{KStG}$ ist - wie gezeigt - schon im Zusammenhang mit der Bekämpfung der Weitergabe von Anrechnungsguthaben durch den früheren $\S 39 \mathrm{KStG}$ gemacht worden. Es ist kaum nachvollziehbar,

420 Vgl. Rath, W.-D. (1994): Gesellschafter-Fremdfinanzierung nach § 8a KStG - Konsequenzen für die Unternehmensfinanzierung, in: Herzig, N. (Hrsg.): Die Unternehmensbesteuerung im Standortsicherungsgesetz, Köln 1994, S. 68. 
warum der Gesetzgeber nicht den Versuch unternommen hat, die Wirkungen des deutschen Unterkapitalisierungsregelung auf die Nichtanrechnungsberechtigten zu beschränken - zumal die Erfassung der Anrechnungsberechtigten ja, wie bereits erwähnt, aus steuersystemmatischer Sicht bei Gesetzeseinführung nicht für erforderlich gehalten wurde.

In der Literatur werden mögliche Ersatzansprüche anrechnungsberechtigter Anteilseigner bei erfolgter Umqualifizierung von Zinsen in Dividenden als nur schwer begründbar und kaum durchsetzbar eingeschätzt ${ }^{421}$. Mögliche Ausnahmen werden nur dann gesehen, wenn es aufgrund des Verhaltens des Nichtanrechnungsberechtigten zu einer Umqualifizierung kommt. Dies könnte z.B. der Fall sein, wenn ein ausländischer Anteilseigner die Geschäftsleitung seiner Kapitalgesellschaft nicht über nahestehende Dritte informiert, deren Existenz die Finanzverwaltung dazu veranlaßt, eine Umqualifizierung vorzunehmen. Zur Vermeidung solcher Situationen sind im voraus zu treffende Gewinnverteilungsabreden aufgrund potentieller Zinsabzugsverbote denkbar ${ }^{422}$. Mit diesen Vereinbarungen können Umverteilungswirkungen zwischen den Anteilseignergruppen korrigiert werden. Allerdings können auch Konflikte zwischen Nichtanrechnungsberechtigten aufgrund der Unterkapitalisierungsregelungen auftreten. Denkbar ist z.B. der Fall, daß verschiedene nichtanrechnungsberechtigte Gesellschafter in einem Konsortialvertrag eine Finanzierung nach ihren jeweiligen Beteiligungsquoten vereinbaren, jedoch nur ein Teil der Gesellschafter die Voraussetzung zu einer Qualifizierung als Holdinggesellschaft erfüllt ${ }^{423}$.

Generell bedenklich am $\S 8 \mathrm{a} \mathrm{KStG}$ ist jedenfalls, daß ausländisch beherrschte Gesellschaften ihre Strukturen an steuerlichen Gegebenheiten ausrichten müssen ${ }^{424}$, und dies um so mehr, je größer die Dominanz ausländischer Anteilseigner ist.

\subsubsection{Interstaatliche Steueraufkommensverteilung}

Qualifiziert ein Land ins Ausland fließende Zinsen in Dividenden um, so gewinnt es Steueraufkommen. Umgekehrt verliert das Ausland - also das Wohnsitzland des ausländischen, fremdfinanzierenden Gesellschafters - Steuereinnahmen. $\mathrm{Ob}$

421 Vgl. Herzig, N. (1994), a.a.O., S. 176.

422 Vgl. Rath, W.-D. (1994), a.a.O., S. 71 f.

423 Vgl. Rath, W.-D. (1994), a.a.O., S. 74. Vgl. auch Abschnitt 5.2.2.2.

424 Vgl. Mattausch, H.(1995): Einführungsschreiben zu § 8a KStG, in: Fischer, L. (Hrsg.): Besteuerung wirtschaftlicher Aktivitäten von Ausländern in Deutschland, Koln 1995, S.59. 
nun der ausländische Fiskus oder ob gar beide im Vergleich zur Situation ohne Umqualifizierung einen Einnahmeverlust erleiden, hängt davon ab, wer die Last der Umqualifizierung trägt.

Wie im weiteren noch gezeigt werden wird, ist seit längerem eine weltweite $\mathrm{Zu}$ nahme nationaler Gesetzesregelungen gegen Gesellschafterfremdfinanzierungen zu beobachten. Damit bedurfte es auch besserer internationaler Verständigungsverfahren zur Regelung der Konflikte zwischen Quellen- und Wohnsitzländern, die wegen ihrer Besteuerungsansprüche auftreten. Die OECD hat deswegen 1992 Empfehlungen zur steuerlichen Behandlung der grenzüberschreitenden Gesellschafterfremdfinanzierung formuliert.

Zwar wurde das Problem der Gesellschafterfremdfinanzierung in der Neufassung des OECD-MA nicht direkt geregelt. Im begleitenden Kommentar zur Abkommensrevision findet sich jedoch soetwas wie ein Konsens zum Thema "Unterkapitalisierung". Er enthält die Empfehlung, daß

1. Berichtigungen im Quellenstaat nur in einem Rahmen erfolgen, der durch den Grundsatz des Fremdverhaltens (Drittvergleichs) umschrieben ist ${ }^{425}$;

2. der Staat des Zinsempfängers (Wohnsitzstaat) die Maßnahmen des Quellenlandes, "wenn möglich" nachvollziehen und den betroffenen Zinsen die Schachtelentlastung seines Rechts gewähren soll ${ }^{426}$;

3. Zweifelsfragen im DBA-Verständigungsverfahren zu bereinigen sind.

Es ist umstritten, inwieweit das aktuelle deutsche Vorgehen gegen bestehende DBA verstößt. Die Meinungen hierzu sind geteilt ${ }^{427}$. Die Herzig-Arbeitsgruppe -

425 Vgl. Vogel (1996), a.a.O., S. 959, Rz. 63d. Es ist offensichtlich, daß der deutsche Ausschluß eines Drittvergleichs bezüglich erfolgsabhängiger Vergütungen bei Überschreitung des Safe-Haven von 0,5:1 in einem krassen Widerspruch zu den Empfehlungen des OECDKonsens steht.

426 Vgl. Michielse, G.M.M. (1997) Treaty Aspects of Thin Capitalization, in: Bulletin for International Fiscal Documentation, Vol. 51./(1997), Nr. 12, S. 567.

427 Bejaht wurden Verstöße gegen DBA-Recht vor allem von Knobbe-Keuk, die Art. 9, 10, 11 und 24 OECD-MA verletzt sah; vgl. Knobbe-Keuk, B. (1993): Wieder ein Entwurf zu § 8a KStG - Wiederauflage einer Regelung zur Gesellschafterfremdfinanzierung im Standortsicherungsgesetz, in: Der Betrieb (DB), 46. Jg./(1993), Nr. 2, S. 63ff. Bejahend aus anderen Gründen Baranowski, der argumentiert, daß eine Ausnahmeregelung des $\S 8 \mathrm{a} \mathrm{KStG}$ zur Ausländerdiskriminierung führen könne: $\S 8 \mathrm{a} \mathrm{KStG}$ gilt nämlich nicht für Fremdfinanzierungen, die mit Wohnungsbauförderungsmitteln aus öffentlichen Haushalten gefordert werden. Insofern werden einige inländische Nichtanrechnungsberechtigte besser gestellt sein als ausländische Nichtanrechnungsberechtigte; vgl. Einführungsschreiben Rz. 99f.; vgl. Baranowski, K.-H. (1996), a.a.O., S. 237ff. Ob dies allerdings einer Ausländerdiskriminierung gleichkommt, hängt letztlich davon $\mathrm{ab}$, wieviele inländische Nichtanrechnungsberechtigte von dieser Ausnahme profitieren können. 
immerhin Mitschöpferin der aktuellen Regelungen - hat sich aufgrund der "beträchtlichen Vielfalt der verschiedenen DBA" hierzu nicht eindeutig geäußert. Allerdings wurde festgestellt, daß gerade neuere DBA derartig auslegbare Formulierungen enthalten, daß $\S 8 \mathrm{a} \mathrm{KStG}$ nicht gegen diese verstoße $\mathrm{e}^{428}$. Die Arbeitsgruppe räumt aber ein, daß in anderen Fällen die abgeschlossenen DBA Vorrang hätten. Entsprechend wird häufig auf die Gefahren eines einseitigen DBAVerstoßes durch $\S 8 \mathrm{a} \mathrm{KStG}$ hingewiesen. Einerseits ist zu befürchten, daß das Ausland mit ähnlichen Maßnahmen des "Treaty-Overriding" reagiert ${ }^{429}$, andererseits wird die internationale Doppelbelastung ausländischer Anteilseigner zementiert und teilweise zu einer Doppelbesteuerung ausländischer Darlehensgeber erweitert. Tatsache ist, daß die deutschen Doppelbesteuerungsabkommen zunehmend Regelungen enthalten, die dem Quellenland ein unbeschränktes Besteuerungsrecht auf Zinsen einräumen, soweit diese aus gewinnabhängig entlohnten Darlehen stammen ${ }^{430}$. Bespielhaft hierfür ist das DBA USA-Deutschland ${ }^{431}$.

Interessant ist dabei der Aspekt, daß sich der einzelne Steuerpflichtige kaum gegen eine deutsche Vertragsverletzung wehren kann. Eine DBA-Verletzung kann nämlich nur von dem jeweiligen Vertragsstaat gerügt werden. Bedenkt man, daß viele Vertragsstaaten vor kurzem Thin-Capitalization-Rules eingeführt haben oder deren Einführung diskutieren, so ist eine Rüge an die Adresse der Bundesrepublik Deutschland kaum zu erwarten ${ }^{432}$.

\subsection{Fiskalische Aspekte}

Möglicherweise stand die damalige Bundesregierung im Vorwahljahr 1993 und mit Blick auf den Maastricht-Vertrag auch unter dem politischen Druck, eine erkennbare Gegenfinanzierung zu den Maßnahmen des Standortsicherungsgesetzes vorzulegen. Zumindest kurzfristig mußten die steuersenkenden Maßnahmen des Standortsicherungsgesetzes eine negative Einnahmenentwicklung bewirken. Dies galt insbesondere für die Senkung der Körperschaftsteuersätze und der Einkommensteuer auf gewerbliche Einkünfte sowie für die Beseitigung von steuerlichen

428 Verwiesen wurde in diesem Zusammenhang auf das deutsche DBA mit den USA, vgl. Herzig, N. (1993): Gesellschafter-Fremdfinanzierung von Kapitalgesellschaften, a.a.O., S. 240.

429 Vgl. Frotscher, G. (1994a), a.a.O., S. 210.

430 Vgl. Vogel (1996), a.a.O., S. 950, Rz. 49.

431 Vgl. DBA Deutschland USA, Art. 10 Abs. 5.

432 Vgl. Frotscher, G. (1994a), a.a.O., S 210. 
Hemmnissen für Holding-Gesellschaften. Entsprechend wurden die Maßnahmen gegen die Gesellschafterfremdfinanzierung ausdrücklich auch als Gegenfinanzierungselement zu den "Steuergeschenken" des Standortsicherungsgesetzes begrün$\operatorname{det}^{433}$.

Analysiert man die Umgehbarkeit der deutschen Thin-Capitalization-Rules, so sind tatsächlich kaum Einnahmewirkungen zu erwarten. Selbst die HerzigArbeitsgruppe, die die Vorgabe für den letzten Gesetzesentwurf lieferte, verneinte einen Einnahmenzuwachs, den die Bundesregierung aufgrund eines früheren strengeren - Entwurfs - noch auf 700. Mill. DM bezifferte ${ }^{434}$. So dürften die anderen Finanzierungsmaßnahmen des Standortsicherungsgesetzes - wie die Verschlechterung der Abschreibungsbedingungen für Betriebsgebäude, betrieblich genutzte PKW und pauschale Wertberichtungen einnahmewirksamer gewesen sein.

Im Rahmen der aktuellen Steuerreform stand auch eine Verschärfung der deutschen Thin-Capitalization-Rules zur Diskussion ${ }^{435}$. Zwar fand eine solche Verschärfung keinen Eingang in das Steuerentlastungsgesetzes 1999/2000/2002 $2^{436}$, es kann aber kaum ausgeschlossen werden, daß bei weiterem Finanzierungsbedarf der öffentlichen Haushalte diese Vorschläge erneut auf den Tisch gelegt werden.

\subsection{Mögliche Alternativ-Lösungen zur Unterbindung der Gesellschafter- fremdfinanzierung}

\subsubsection{Verschärfung des $§ 8 \mathrm{a}$ KStG}

Im Vorfeld der Einführung des $\S 8 \mathrm{a} \mathrm{KStG}$ sind zum Teil sehr viel restriktivere Gesetzesentwürfe diskutiert worden. So schlug der Bundesrat noch $1993 \mathrm{im} \mathrm{Zu-}$ sammenhang mit der Ablehung des Standortsicherungsgesetzes vor, gewinnabhängigen Vergütungen überhaupt keinen Safe-Haven und gewinnunabhängigen Vergüten nur einen Safe-Haven von 1:1 einzuräumen ${ }^{437}$.

433 Vgl. Mattausch, H. (1994), a.a.O., S. 89.

434 Vgl. Herzig, N. (1993): Gesellschafter-Fremdfinanzierung von Kapitalgesellschaften - Bericht aus einer Arbeitsgruppe - , in: Steuern und Wirtschaft (StuW), 70. Jg./(1993), Nr. 3, S. 239.

435 Vgl. o. Verf. (1999): Lafontaine auf Sparkurs, in: Handelsblatt, 18.01.1999, S. 1.

436 Vgl. BR-Drs. 129/99.

437 Vgl. Herzig. N. (1993), a.a.O., S. 248. 
Abgesehen von rechtlichen Problemen, die aus einer sehr strengen Einschränkung der Gesellschafterfremdfinanzierung resultieren, würden restriktivere Regelungen nichtanrechnungsberechtigte Anteilseigner eher davon abhalten, ihren Kapitalgesellschaften Fremdkapital anzubieten. Der volkswirtschaftlichen Nutzen solcher Maßnahmen ist aber mehr als fraglich. Wie noch deutlich werden wird, wäre eine solche Klausel, wie sie der Bundesrat seinerzeit vorschlug, sehr streng im internationalen Vergleich gewesen. In diesem Fall würden Steuerausländer ceteris paribus Eigen- und Fremdkapital eher in ihrem Wohnsitzland oder in Drittländern mit schwächeren Thin-Capitalization-Rules anlegen. Es käme folglich bei Einführung eines strengeren $\S 8 \mathrm{a} \mathrm{KStG} \mathrm{zu}$ einem Kapitalabfluß, bis die im Inland erzielbare Fremdkapitalrendite nach Steuern der Rendite von Fremdkapital in Drittstaaten nach Steuern bzw. der Rendite vor Steuern im Wohnsitzland ausländischer Anteilseigners entspräche.

\subsubsection{Durchsetzung der Quellenlandbesteuerung von Zinsen}

Die Einbeziehung von Zinsen in die Bemessungsgrundlage der Körperschaftsteuer wäre ein möglicher Ausweg aus dem Dilemma der Körperschaftsteuerumgehung durch Gesellschafterfremdfinanzierung. Die prinzipielle Einführung einer Quellenbesteuerung von Zinsen wäre ein ebenso radikale Änderungen der Gepflogenheiten der internationalen Besteuerung wie eine Quellenlandbesteuerung für Veräußerungsgewinne eine radikale Änderung der Gepflogenheiten der internationalen Besteuerung darstellen. Allerdings ist eine Quellenbesteuerung von Zinsen, auf die im Zusammenhang mit Überlegungen zur Dividendenfreistellung noch tiefer eingegangen wird, vermutlich leichter zu praktizieren als eine Besteuerung von Veräußerungsgewinnen am Entstehungsort. Auch aus der aktuellen Diskussion zur Zinsbesteuerung in der EU wird deutlich, daß eine sichere Erfassung von Zinsen nur per Besteuerung an der Quelle gewährleistet werden kann - wenn nicht auf ein administrativ aufwendiges Meldeverfahren zurückgegriffen werden soll. Das heißt nicht, daß die Steuereinnahmen aus Zinseinkünften zwangsläufig dem Quellenland verbleiben müssen. Das bisherige reine Wohnsitzlandprinzip wird allerdings kaum haltbar sein, denn die Besteuerung an der Quelle wird der betroffene Staat kaum ohne Ansprüche an das Steueraufkommen vornehmen.

\subsection{Maßnahmen zur Einschränkung der Gesellschafterfremdfinanzierung im internationalen Bereich}

Es stellt sich auch hier die Frage, ob andere Staaten überzeugendere Lösungen zur Unterbindung der Gesellschafterfremdfinanzierung durch Steuerausländer gefunden haben. 
Nicht nur in der Bundesrepublik Deutschland ist das Problem der Gesellschafterfremdfinanzierung mit gesetzlichen Maßnahmen angegangen worden. Auch im Ausland kann insbesondere seit Beginn der neunziger Jahre eine Zunahme sogenannter Thin-Capitalization-Rules beobachtet werden. Gemeinsam ist diesen Regelungen zum einen eine Festlegung bestimmter Werte, die eine zulässige von einer nicht zulässigen Gesellschafterfremdfinanzierung abgrenzen (Identifikation). Zum anderen wird festgelegt, welche steuerlichen Konsequenzen einer nicht mehr zulässigen Gesellschafterfremdfinanzierung drohen.

Das folgende Kapitel soll einen beispielhaften Überblick über die verschiedenen Vorgehensweisen ausländischer Fisci zur Unterbindung der Gesellschafterfremdfinanzierung geben.

Die Bekämpfung der Gesellschafterfremdfinanzierung unterscheidet sich international in verschiedenen Bereichen. Zum einen wird das Problem der Identifikation einer Gesellschafterfremdfinanzierung unterschiedlich angegangen. Zum anderen ergreifen die Staaten auch unterschiedlich Maßnahmen, wenn eine Gesellschafterfremdfinanzierung geduldete Grenzen überschreitet.

\subsubsection{Das Identifikationsproblem}

Auch im Ausland wird oftmals eine bestimmte Eigenkapital-FremdkapitalRelation (FK-EK-Relation) vom Gesetzgeber fixiert, bei deren Überschreitung eine übermäßige Gesellschafterfremdfinanzierung angenommen wird. Dabei lassen andere Länder ebenfalls häufig eine Hintertür offen und erlauben der betroffenen Kapitalgesellschaft eine Nachweismöglichkeit, daß keine übermäßige Fremdfinanzierung der Anteilseigner vorliegt.

In manchen Ländern ist ganz bewußt auf eine Fixierung bestimmter FK-EKRelation verzichtet worden. Statt dessen bestehen Regelungen, die es den Steueradministrationen ermöglichen, Einzelfallprüfungen der Unternehmensfinanzierung vorzunehmen. Der Sinn solcher Ansätze liegt in der Berücksichtigung branchentypischer Besonderheiten. Dies geschieht oft auf dem Wege des Drittvergleichs, ähnlich wie bei der steuerlichen Behandlung von Verrechnungspreisen.

Darüber hinaus versuchen Staaten, das Problem der Gesellschafterfremdfinanzierung allein mit allgemeinen Antimißbrauchsregeln oder mit Bestimmungen zur Aufdeckung verdeckter Gewinnausschüttungen zu erfassen. In einigen Staaten werden - ähnlich dem deutschen Vorgehen - mehrere Methoden gleichberechtigt oder nachrangig angewendet. 


\subsubsection{Länder mit FK-EK-Relationen}

Bei einem Vergleich der Quotenregelungen ist zu beachten, daß die Begriffe Eigenkapital und Fremdkapital von Land zu Land variieren. Aufgrund unterschiedlicher Ermittlungsweisen des Eigen- und des Fremdkapitals eröffnet z.B. ein gleicher Safe-Haven in zwei Ländern für einen Gesellschafter keineswegs den gleichen steuerunschädlichen Fremdfinanzierungsspielraum für einen Gesellschafter. So zählen z.B. in Spanien zum Fremdkapital alle hybriden Finanzierungsformen, während in der Schweiz nur Kapital gemeint ist, das zu verzinsen ist. Folglich ist eine identische FK-EK-Quote nicht gleichbedeutend mit einem gleichwertigen Safe-Haven.

Eine Quotenlösung besteht in den meisten Ländern nur für Anteilseigner mit tatsächlichen Einfluß auf die Kapitalgesellschaft. Als Kriterium gilt häufig die Verfügungsmöglichkeit über eine wesentliche direkte oder indirekte Beteiligung bzw. über entsprechende Stimmrechte.

Die Anwendung der FK-EK-Quoten unterscheidet sich zum Teil beträchtlich:

Tabelle VII: Ausländische Safe-Haven Regelungen

\begin{tabular}{|c|c|c|c|c|c|}
\hline & $\begin{array}{l}\text { Zulässige, } \\
\text { anteilige } \\
\text { FK-EK- } \\
\text { Quote eines } \\
\text { Anteilseig- } \\
\text { ners }\end{array}$ & $\begin{array}{l}\text { Spezielle } \\
\text { FK-EK- } \\
\text { Quote für } \\
\text { ertragsab- } \\
\text { hängi-ge } \\
\text { Entlohnun- } \\
\text { gen }\end{array}$ & $\begin{array}{l}\text { Besondere } \\
\text { Quote für } \\
\text { Holding- } \\
\text { gesell- } \\
\text { schaften }\end{array}$ & $\begin{array}{l}\text { Overall-FK- } \\
\text { EK-Quote }\end{array}$ & $\begin{array}{l}\text { Mindestbe- } \\
\text { teiligung } \\
\text { der betrof- } \\
\text { fenen An- } \\
\text { teilseigner }\end{array}$ \\
\hline Belgien & $1: 1$ & & & & \\
\hline $\begin{array}{l}\text { Deutschland } \\
\text { (zum Vgl.) }\end{array}$ & $3: 1$ & $0,5: 1$ & $9: 1$ & & $>25 \% \quad 5)$ \\
\hline Frankreich & $1,5: 1$ & & & & $\begin{array}{|ll|}>50 \% & 1) \\
\end{array}$ \\
\hline Japan & $3: 1$ & & & $3: 1$ & \\
\hline Kanada & $3: 1$ & & & & $>25 \%$ \\
\hline Luxemburg & $3: 1$ & & $13: 1$ & & \\
\hline Portugal & $2: 1$ & & & & $>25 \%$ \\
\hline Schweiz & $3: 1$ & & & & 7) \\
\hline Slowakei & $4: 1$ & & & & \\
\hline Spanien & $3: 1$ & & & & $>25 \% \quad 5)$ \\
\hline Tschechien & & & & $\begin{array}{|ll|}4: 1 & 3) \\
\end{array}$ & $>25 \%$ \\
\hline Ungarn & & & & $4: 1$ & \\
\hline
\end{tabular}

1. Mehr als $50 \%$ des Nennkapitals oder der Stimmrechte. 
2. Es gilt weiterhin eine 6:1 Quote für Banken und Versicherungen.

3. Es gilt weiterhin eine 6:1 Quote für Banken und Versicherungen und eine 20:1 Quote für nicht wesentlich beteiligte Anteilseigner.

4. Ausgenommen sind Finanzinstitute.

5. Direkter oder indirekter Beteiligungsbesitz.

6. In Luxemburg gilt eine spezielle 10: 1 Quote für festverzinsliches Fremdkapital, das in Wertpapieren verbrieft ist.

7. Entscheidung uber wesentlichen Einfluß wird fallweise getroffen von der Finanzverwaltung

8. Quote gilt für Gesellschafterfremdkapital aller Nichtanrechnungsberechtigter zum anteiligen Eigenkapital..

9. Quote bezieht sich auf das gesamte Eigenkapital der Gesellschaft.

Quelle: Eigene Zusammenstellung

\subsection{Kanada, Spanien, Portugal: Quotenregelung für Nichtanrech- nungsberechtigte}

Im Vollanrechnungsland Kanada wird der Jahreshöchststand der Verbindlichkeiten gegenüber allen wesentlich beteiligten, ausländischen Gesellschaftern ins Verhältnis zum Eigenkapital der Gesellschaft gesetzt. Letzteres wird zu Jahresendwerten berechnet, was Gestaltungsspielräume eröffnet. Dagegen kann das Abstellen auf Höchstbeträge im Fall von Überlappungen von Finanzierungen zu einer Falle für die Gesellschaft werden. Überschreitet dieses Fremdkapital eine FK-EKQuote von 3:1, greifen steuerliche Gegenmaßnahmen für das überragende Fremdkapital. Die kanadischen Thin-Capitalization-Rules zielen damit nur auf die Fremdkapitaleinbringung der Nichtanrechnungsberechtigten ${ }^{438}$.

In Spanien besteht ein körperschaftsteuerliches Teilanrechnungssystem mit nur sehr geringem Anrechnungsumfang in Höhe von 10\% der Bardividende (Bruttodividende abzüglich Körperschaftsteuer [35\%], d.h. die Anrechnung beträgt $18,57 \%$ der erhobenen Körperschaftsteuer). Für Ausländer gilt ein Anrechnungsausschluß. Spanien wendet wie Deutschland eine 3:1 FK-EK-Quote an, die, ebenfalls wie in Deutschland, nur für Anteilseigner mit wesentlichen Beteiligungen (über 25\%) gilt. Zur Ermittlung der FK-EK-Quote wird dabei nur auf das durchschnittlich vorhandene Eigen- und Fremdkapital während des Bemessungszeitraums abgestellt. Diese Regel scheint nicht nur administrativ einfacher als die deutsche Methode, nach der zu keinem Zeitpunkt die Quote überschritten werden darf. Das spanische Körperschaftsteuerrecht läßt den Anteilseignern auch noch die Chance, mit einer Anpassung ihrer Kapitaleinlagen in Form einer Erhöhung der

438 Vgl. Blumenberg, J. (1997): Die Besteuerung der Gesellschafter-Fremdfinanzierung, Baden-Baden 1997, S. 386f; vgl. Sec. 18 kanadische EStG. 
Eigen- und/oder einer Absenkung der Fremdkapitaleinlage zu reagieren ${ }^{439}$. Eine spezielle Quote für gewinn- oder umsatzabhängiges Kapital ist - wie in allen anderen betrachteten Ländern - unbekannt. Beschränkungen der Gesellschafterfremdfinanzierungen sind in Spanien auf ausländische juristische und natürliche Personen begrenzt. Inländische Steuerpflichtige werden anders als im deutschen Recht von den Gesellschafterfremdfinanzierungsregelungen nicht direkt betroffen. Deshalb werden z.B. von seiten der Bundesrepublik Zweifel an der Gültigkeit der Bestimmungen für deutsche Anteilseigner geäußert, da im DBA Spanien-Deutschland ein Diskriminierungsverbot enthalten ist ${ }^{440}$.

Auch das Nachbarland Portugal hat 1996 eine FK-EK-Quote eingeführt. Die Quote von 2:1 gilt nur für ausländische Anteilseigner mit mindestens 25\%iger Beteiligung. Es genügt allerdings auch ein bedeutender Stimmrechtsanteil. Hier reicht bereits ein kurzfristiges, einmaliges Überschreiten der Quote für die Feststellung einer übermäßigen Gesellschafterfremdfinanzierung. Wie im deutschen Fall der 3:1 Quote für erfolgsunabhängiges Kapital, besteht für die Gesellschaft die Möglichkeit, im Fall einer Überschreitung mit einem erfolgreichen Drittvergleich die gesetzlichen Folgen der Gegenmaßnahmen zu vermeiden ${ }^{441}$.

Die vorgestellten Beschränkungen der Unterkapitalisierung dienen ganz offensichtlich der Aufrechterhaltung national beschränkter Anrechnungssysteme. Hierfür spricht die Beschränkung auf Nichtanrechnungsberechtigte.

439 Interessant ist im Fall Spaniens die Tatsache, daß eine Umqualifizierung von Zinsvergütungen in Dividenden wegen der Freistellung der Schachteldividenden von der deutschen Korperschaftsteuer und Gewerbesteuer gunstiger ist als die deutsche Zinsbesteuerung. Dies gilt für spanische Tochtergesellschaften, die an deutsche Muttergesellschaften ausschutten, nicht aber fur einen mehrstufigen Gesellschaftsaufbau mit spanischen Enkel- und Tochtergesellschaften; vgl. DBA Deutschland - Spanien; vgl. Courage, C. (1996): Änderungen des spanischen Körperschaftsteuergesetzes für ausländische Investoren, in: IWB, Nr. 22 vom 27.11.1996, Fach 5, Gruppe 2, S. 217.

440 Vgl. Selling, H.-J. (1994): Unternehmensbesteuerung in Spanien, in: Lang, J. (Hrsg.): Unternehmensbesteuerung in EU-Staaten, Veroffentlichungen der Deutschen Steuerjuristischen Gesellschaft (DStJG), Bd. 16, Køln 1994, S. 232.

441 Vgl. de Sousa da Camara, F. / Leitao, Morais / Teles, J. Galvao (1996): Portugal enacts Safe Haven Exeption to Thin Capitalization Rules, in: Tax Notes International, Vol. 13/(1996), Nr. 8, S. 585. 


\subsection{Belgien und Frankreich: FK-EK-Quoten für In- und Ausländer}

Relativ strenge Unterkapitalisierungsregelungen traten 1997 in Belgien mit einer 1:1 FK-EK-Quote in Kraft. Diese Quote gilt für alle Anteilseigner, also für inländische wie für ausländische Gesellschafter. Die Gültigkeit der belgischen ThinCapitalization-Rules für alle Anteilseigner erklärt sich offensichtlich aus dem belgischen Körperschaftsteuersystem, das einem klassischen System mit ermäßigtem, abgeltendem Einkommensteuersatz entspricht. Gesellschafterfremdfinanzierung ist daher in Belgien auch für inländische Steuerpflichtige eine steuerlich lohnende Gestaltungsform. Bei Überschreitung der 1:1 Quote erfolgt eine steuerliche Umqualifizierung der Zinsen in Dividenden.

Nicht betroffen von der 1:1 Quote sind allerdings Zinszahlungen zwischen belgischen Gesellschaften, jedoch unterliegen belgische Gesellschaften ebenfalls seit 1997 einer besonderen FK-EK-Quote von 7:1, sofern die Gesellschaft Fremdkapitalvergütungen für Darlehen an Gesellschaften leisten, die keiner oder einer geringen Körperschaftsteuer unterliegen. Wird diese Quote überschritten, so gilt ein Abzugsverbot dieser Zinsen. Der Gesetzgeber wollte mit dieser Regelung Strukturen einschränken, bei denen eine inländische Gesellschaft eine ausländische Tochtergesellschaft in einem Niedrigsteuerland mit hohem Eigenkapital ausstattet, das diese Tochtergesellschaft (z.B. als irische IFSC) dem Konzern als Fremdkapital zur Verfügung stellt ${ }^{442}$.

Im Gegensatz zu den deutschen Regelungen zielt die 1:1 Quote nicht auf das anteilige, sondern auf das gesamte Eigenkapital der Gesellschaft. Berücksichtigt man die Gültigkeit der Quote auch für inländische natürliche Personen, kommen die belgischen Regelungen einer tatsächlichen Bekämpfung einer Unterkapitalisierung eindeutig näher. Im belgischen Fall erklärt sich die generelle Gültigkeit insofern, als das belgische Körperschaftsteuersystem im Prinzip einem klassisches System entspricht.

Da die Gesellschafterfremdfinanzierung im klassischen System der Vermeidung der Doppelbelastung sowohl der Steuerinländer wie der Steuerausländer dient, ist die allgemeine Gültigkeit systemkonform .

Frankreich läßt eine FK-EK-Quote von 1,5:1 $\mathrm{zu}^{443}$. Obwohl ein Vollanrechnungssystem praktiziert wird, ist die französische Quotenregelung nicht auf Steuerausländer beschränkt. Von den französischen Thin-Capitalization-Rules sind nur

442 Vgl. Froesch, T. / Goyvaerts, G. (1997): Belgien: Wichtige Änderungen im Steuerrecht, in: Internationales Steuerrecht (IStR), 6. Jg./(1997), Nr. 18, S. 553. 
Mehrheitsgesellschafter betroffen. Dies mag insofern überraschen, als Frankreich zwar ausländischen Portfolioanlegern in vielen Fällen eine grenzüberschreitende Anrechnung der Körperschaftsteuer gewährt. Da sich diese Anrechnung aber sehr häufig auf Beteiligungen von bis zu 10\% beschränkt, erscheint die Gesellschafterfremdfinanzierung für Steuerausländer mit Beteiligungen zwischen 10\% und 50\% unter Umständen recht attraktiv.

Die Begrenzung des französischen Safe-Haven gilt nicht, wenn das ausleihende Unternehmen als "Französische Muttergesellschaft" nach dem französischen Steuerrecht einzustufen ist. Diese Einstufung ist sehr weitgehend, sie schließt auch nichtansässige Unternehmen ein. Es liegt der Verdacht nahe, daß diese Ausnahme gegen Art. $52 \mathrm{EGV}$ verstößt ${ }^{444}$.

\subsection{Japan: Die Overall-Quote}

Auch Japan, ein Land mit - national beschränkter - körperschaftsteuerlicher Teilanrechnung, kennt eine 3:1 FK-EK-Quote, die allerdings doppelt angewendet wird. Grundsätzlich gilt eine anteilige FK-EK-Quote nur für nichtansässige natürliche Personen und Kapitalgesellschaften. Ein nicht ausgenutzter Safe-Haven eines Gesellschafters kann von anderen Gesellschaftern übernommen werden. Kurzfristige Überschreitungen eines Safe-Haven eines einzelnen Gesellschafters bleiben folgenlos, solange das jahresdurchschnittliche Fremdkapital des Anteilseigners sein anteiliges Eigenkapital (Nettovermögen) nicht um das Dreifache übersteigt ${ }^{445}$. Folgenlos bleibt die Überschreitung auch dann noch, wenn das Verhältnis von Fremd- zu Eigenkapital der Gesellschaft insgesamt die Relation von 3:1 nicht übertrifft. Diese Overall-Quote gilt für das gesamte Fremdkapital der Gesellschaft, das ins Verhältnis zum gesamten Nettovermögen der Gesellschaft gesetzt wird. Selbst wenn die Overall-Quote überschritten wird, läßt das japanische Steuerrecht noch einen entlastenden Drittvergleich mit einem vergleichbaren, inländisch beherrschten Unternehmen $\mathrm{zu}^{446}$. Die Anwendung einer Overall-Quote in einem Anrechnungsland, das eine Anrechnung für Steuerausländer ausschließt, läßt die Schlußfolgerung zu, daß der japanische Gesetzgeber tatsächlich zumindest auch auf die Unterkapitalisierung zielt.

444 Vgl. Cussons, P. (1996): Discrimination in Europe, in: EU Tax Notes, No. 12, July 95 / March 96, a.a.O., S. 4.

445 Vgl. Bati, A. (1993): Japan: Taxation of Dividends and Interest, in: Bulletin for International Fiscal Documentation, Vol. 47/(1993), Nr. 4, S.208ff.

Vgl. Blumenberg, J. (1997), a.a.O., S. 385. 


\subsection{Andere Pauschalbegrenzungen}

Bulgarien erlaubt seit dem 1.7.1996 nur den Abzug von Zinszahlungen an Muttergesellschaften oder Anteilseigner, solange die Zinsaufwendungen unter $10 \%$ der Gesamtaufwendungen der Kapitalgesellschaft liegen ${ }^{447}$. Eine derartige Regelung schränkt die Finanzierungsfreiheit generell ein.

Österreich berücksichtigt - ähnlich wie Japan - sowohl das Verhältnis der Bilanzsumme zum Eigenkapital, als auch das Gesellschafterfremdkapital im Verhältnis zum Eigenkapital, und wendet unterschiedliche Quoten je nach der Gesamtkapitalisierung $\mathrm{an}^{448}$. Auch in Luxemburg arbeitet die Steuerverwaltung mit verschiedenen Quoten ${ }^{449}$. In beiden Ländern gilt - bedingt durch das klassische Körperschaftsteuersystem - keine Beschränkung dieser Quoten auf Steuerausländer.

\subsubsection{Länder mit Einzelfallprüfungen}

Einzelfallbezogene Prüfungen ähneln dem deutschen Vorgehen vor 1994, das Problem über allgemeine Mißbrauchbekämpfungsregeln zu lösen. Einzelfallprüfungen (Case to Case Law) können auf verschiedenste Weise geregelt sein. Viele Länder erlassen spezielle Vorschriften zur Gesellschafterfremdfinanzierung, die einen Drittvergleich vorsehen. Andere Staaten verwenden nur bereits vorhandene Vorschriften zur Unterbindung der verdeckten Gewinnausschüttung, ähnlich dem deutschen $\S 8$ Abs. $3 \mathrm{KStG}$. Außerdem greifen einige Staaten ausschließlich auf allgemeine Gestaltungsmißbrauchsvorschriften zurück, die dem deutschen $\S 42$ AO ähneln.

\subsection{Niederlande}

Ausdrückliche Thin-Capitalization-Rules sind in den Niederlanden nicht bekannt ${ }^{450}$. Allerdings werden konzerninterne Darlehen unter bestimmten Umständen mit einem Zinsabzugsverbot belegt. Entschieden wird dabei, ob überzeugende wirtschaftliche Gründe für die Darlehensaufnahme bestehen.

447 Vgl. International Bureau of Fiscal Documentation (IBFD) (1997), a.a.O., S. 77.

448 Vgl. Strukturanpassungsgesetz 1996, in: Österreichische Steuer-Zeitung (ÖStZ), 49. Jg./(1996), Nr. 6, S. $149 f$.

449 Vgl. International Bureau of Fiscal Documentation (IBFD) (1998), a.a.O, S. 310.

450 Vgl. International Bureau of Fiscal Documentation (IBFD) (1998), a.a.O., S. 342. 
Interessanterweise gelten die Beschränkungen von konzerninternen Darlehen nicht, wenn sie über dritte Personen fremdfinanziert werden. Offensichtlich wird dann u. U. noch ein Fremdvergleich vorgenommen. Weitere Ausnahmen bestehen in Fällen bestimmter Betriebsübernahmen ${ }^{451}$. Grundsätzlich irrelevant ist dabei der Steuerstatus des Darlehensgebers, was sich aus dem klassisches Körperschaftsteuersystem erklärt, das Gesellschafterfremdfinanzierungen für In- und Ausländer interessant macht.

\subsection{Großbritannien}

Großbritannien beschränkt die gesetzlichen Bestimmungen zur Aufdeckung einer Gesellschafterfremdfinanzierung auf ausländische Anteilseigner ${ }^{452}$, was typisch für Länder mit Anrechnungssystemen ist. Man nimmt dort eine Gesellschafterfremdfinanzierung generell an, wenn Zinsen innerhalb eines Konzerns gezahlt werden, in dem $75 \%$ ige-Mutter-Tochter Beziehungen ${ }^{453}$ bestehen, und wenn diese Zinsen nicht für Kapitalbereitstellungen ohne "special relationship" gezahlt worden wären. Ein Drittvergleich wird bezüglich der Fremdkapitalsumme und der Ausleihbedingungen angestellt. Was genau unter dem Begriff "special relationship" - außer der erwähnten 75\%-Beteiligung - zu verstehen ist, bleibt unklar. Auch wenn nicht kodifiziert, so bleiben Gesellschafterfremdfinanzierungen bis zu einer 1:1-Quote überlicherweise unberührt.

\subsection{Italien}

Auch das Vollanrechnungsland Italien kennt keine feste FK-EK-Quote zur Beschränkung der Gesellschafterfremdfinanzierung ${ }^{454}$. Gesetzliche Maßnahmen zur Unterbindung der Gesellschafterfremdfinanzierung sind allerdings in der Diskussion, mit ihrer baldigen Einführung muß gerechnet werden ${ }^{455}$. Zur Zeit gelten allgemeine und spezielle Regelungen, die restriktiv auf die Gesellschafterfremdfinanzierung wirken. Allgemein gilt, daß die Abziehbarbarkeit von Zinsen abhängig

451 Vgl. Geurts, O.B.C.J. (1997): Wichtige Neuerungen 1996/97 im niederlăndischen Steuerrecht, in: IWB, Nr. 13 vom 09.07.1997, Fach 5, Gruppe 2, S. 266.

452 Vgl. International Bureau of Fiscal Documentation (IBFD) (1998), a.a.O., S. 542.

453 Darunter werden direkte und indirekte Mutter-Tochter Beziehungen verstanden.

454 Vgl. International Bureau of Fiscal Documentation (IBFD)(1998), a.a.O., S. 290.

455 Vgl. International Bureau of Fiscal Documentation (IBFD) (1997), a.a.O., S. 271. 
ist vom Verhältnis zwischen steuerpflichtigem Einkommen und Gesamteinkommen ( $\mathrm{x}$ ist der Prozentsatz der abziehbaren $\operatorname{Zinsen}^{456}$.:

(Steuerpfl. Einkommen/Gesamteinkommen) x $100=\mathrm{X}$

Mit einer Vielzahl von Einzelregelungen versucht Italien die Gesellschafterfremdfinanzierungen zu beschränken. Hierzu gehören Anpassungsvorschriften des zulässigen Gesellschafterfremdkapitals bei dauerhaften (mehr als einjährigen Verlusten) sowie ein sehr umstrittener steuerlicher Zugriff auf Beteiligte im Fall von Back-to-back-Finanzierungen. Auf letzteres soll kurz genauer eingegangen werden, weil das italienische Vorgehen im Prinzip gegen internationale Besteuerungsgrundsätze der $O E C D$ verstößt.

Betroffen von dieser Regelung sind auch nicht in Italien Ortsansässige, die Gelder oder gewinnunabhängige Wertpapiere (also keine Aktien, Genußscheine oder ähnliche Wertpapiere) z.B. bei deutschen Banken als Sicherheit hinterlegen für Finanzierungen von Gesellschaften mit Sitz in Italien durch italienische Ban$\operatorname{ken}^{457}$. Unabhängig vom Sitz der Bank verlangt der italienische Fiskus die Meldung und Abführung eines Betrages von $20 \%$ der bezogenen Zinseinkünfte. Der italienische Gesetzgeber unternimmt mit dieser Regelung einen Zugriff auf Zinszahlungen, die nur im Ausland stattfinden. Zum einen überschreitet er die maximal mögliche Zinsbesteuerung von 10\%, die das OECD-MA dem Quellenland einräumt. Dies muß kein Verstoß gegen die Grundsätze des OECD-MA sein, wenn man argumentiert, daß die Zinszahlung ja gar nicht aus dem Quellenland (Italien), sondern z.B. zwischen einer deutschen Bank und einem deutschen, in Italien nichtanrechnungsberechtigten Gesellschafter erfolgt ist. Allerdings findet hier (zumindest theoretisch) ein Zugriff auf fremde Steuersubjekte statt. Fraglich ist, inwieweit ein solches Steuergesetz überhaupt anwendbar ist. Zweifel müssen auch dem italienischen Finanzministerium gekommen sein. In einem Erlaß vom 6.11.1996 schränkt es die Abführungspflicht ein. Danach muß die im Ausland an den ausländischen Nichtanrechnungsberechtigten zinszahlende Bank dann keine $20 \%$ ige Abzugssteuer für Italien einbehalten, wenn ihr eine beglaubigte Erklärung darüber vorliegt, daß die vom ausländischen Unternehmen gewährte Geldeinlage nicht mit der Finanzierung der italienischen Gesellschaft durch die italienische Bank in Zusammenhang steht. Handelt es sich bei dem im Ausland ansässigen Kreditinstitut nicht um eine ausländische Bank, sondern um eine Auslandsniederlassung einer italienischen Bank, dann ist bei gleichem Sachverhalt die Abzugs-

456 Valente, P. (1997): Dynamics of Cross Border Flows of Multinationals: The Italian Tax Implications, in: Bulletin for International Fiscal Documentation, Vol. 51/(1997), Nr. 11, S. 512; vgl. § 63 italienisches EStG.

457 Diese indirekte Gesellschafterfremdfinanzierung wird in Italien günstiger behandelt, als eine direkte Fremdfinanzierung; vgl. Mayr, S. (1996): Neuerungen im italienischen Steuerrecht, in: NWB, Nr. 14 vom 24.07.1996, Fach 5 Gruppe 2, S. 396. 
steuer einzubehalten, da der italienische Fiskus die Geldanlage als in Italien bewirkt ansieht. Erfolgen die Zinszahlungen an den Nichtanrechnungsberechtigten durch ein ausländisches Nichtfinanzinstitut (z.B. eine nichtitalienische Holding) so hat der Nichtanrechnungsberechtigte die die $20 \%$ ige Steuer zu deklarieren. ${ }^{458}$

Die Regelungen erscheinen - salopp gesprochen - "mit heißer Nadel gestrickt". Es ist sehr fraglich, ob ein Zugriff auf Steuersubjekte möglich ist, die weder im Sinne einer beschränkten noch im Sinne einer unbeschränkten Steuerpflicht von Italien aus erfaßbar sind. Auch ein Vergleich mit der an die Staatsangehörigkeit knüpfenden Steuerpflicht amerikanischer Staatsbürger kann kaum angestellt werden. Im Fall der Nichtdeklarierung fehlt den italienischen Steuerbehörden nämlich jede Möglichkeit der Sanktionierung der ausländischen Bank bzw. des Gesellschafters. Mangelnde Durchsetzbarkeit macht den Wert solcher Regelungen mehr als fraglich.

\subsubsection{Bewertung der ausländischen Thin-Capitalization-Rules}

Feste FK-EK-Quoten haben den Vorteil, daß sie Rechtsicherheit gewähren, bis zu welcher Höhe eine Gesellschafterfremdfinanzierung steuerlich geduldet wird. Freilich gewähren die Quoten auch keine hundertprozentige Sicherheit vor Umqualifizierungen, da - wie in Deutschland - so auch in anderen Ländern häufig unabhängig von Safe-Haven-Regelungen noch gesetzliche Bestimmungen existieren, die übermäßige Zinszahlungen als verdeckte Gewinnausschüttungen behandeln. Allerdings gewähren die FK-EK-Quoten in der Tat mehr Rechtsicherheit für Zinszahlungen, die dem Marktzinsniveau entsprechen. Halten diese aber auch einem Drittvergleich stand, wie er nach Art. 9 OECD-MA und nach dem OECDKonsens verlangt wird, so dürfte zumindest nach OECD-Empfehlung sowieso keine steuerliche Umqualifizierung in Dividenden erfolgen. Einzelfallprüfungen haben - positiv ausgedrückt - den Vorteil höherer Flexibilität und erzeugen deswegen - negativ ausgedrückt - zugleich höhere Rechtsunsicherheit. Der Stein des Weisen scheint hinsichtlich der Identifikation einer Gesellschafterfremdfinanzierung auch im Ausland noch nicht gefunden worden zu sein. Die Unterschiedlichkeit der Identifikationsregeln bestätigt, daß es sich mehr oder weniger um willkürlich festgelegte Grenzen handelt, die weniger mit Unterkapitalisierungsbefürchtungen als vielmehr mit Angst vor zuviel Steuergestaltung zu tun haben. Dies gilt insbesondere für Anrechnungsstaaten, in denen - abgesehen von Frankreich - die Gültigkeit der Thin-Capitalization-Rules für Steuerausländer beschränkt ist.

458 Vgl. Napolitano, E. / Höckenreiner, R. (1997): Die neuen italienischen Steuermißbrauchsbekämpfungsregeln und internationale Besteuerungsgrundsătze, in: Internationales Steuerrecht (IStR), 1997, 6. Jg./(1997), Nr. 2, S. 45. 


\subsubsection{Konsequenzen einer aufgedeckten Gesellschafterfremdfinan- zierung}

Die Maßnahmen bei Feststellung einer Gesellschafterfremdfinanzierung lassen sich wie folgt unterteilen:

1. Die Zinsen des betroffenen Fremdkapitals werden steuerlich wie Eigenkapital behandelt (steuerliche Umqualifikation).

2. Die von ihren Gesellschaftern fremdfinanzierte Kapitalgesellschaft darf die Zinsen des betroffenen Fremdkapitals nicht mehr als Betriebsausgabe abziehen (Abzugsverbot).

Diese Maßnahmen werden international einzeln oder kumulativ eingesetzt. Üblich ist, daß nur das übersteigende Fremdkapital betroffen ist, nicht jedoch die gesamte Fremdkapitaleinlage von Anteilseignern.

Während sich die steuerliche Umqualifizierung direkt beim betroffenen Gesellschafter auswirkt, ist das Abzugsverbot für Zinsen eine gewinnmindernde Maßnahme, die alle Anteilseigner gleichmäßig trifft. Dies schließt natürlich nicht aus, daß gesellschaftsinterne Vereinbarungen getroffen werden, die Ausgleichsansprüche zwischen Anteilseignern regeln. Wer letztlich die Steuerlast trägt, hängt von der Existenz und der Gestaltung dieser zusätzlichen Regelungen ab. Wie gezeigt, werden in Deutschland das Abzugsverbot und die steuerliche Umqualifizierung kumulativ angewendet.

\subsubsection{Zinsabzugsverbot}

Den Weg eines ausschließlichen Abzugsverbots gehen Dänemark, Frankreich, Kanada, Portugal ${ }^{459}$ und Japan. Dagegen gilt das Zinsabzugsverbot in Verbindung mit weiteren Maßnahmen bei allen hier untersuchten Staaten mit ThinCapitalization-Rules mit Ausnahme von Luxemburg. Holdings in Luxemburg sind von allen Steuern - auch von der Körperschaftsteuer - befreit. Sie unterliegen nur einer Steuer für Aktienemissionen (Eigenkapitalaufnahme) ${ }^{460}$. Das Zinsabzugsverbot wirkt allein auf der Gesellschaftsebene und gilt üblicherweise nur für Zinsen, die einen vorhandenen Safe-Haven überschreiten. Mit dem Zinsabzugsverbot erhöht sich der steuerpflichtige Gewinn der Körperschaft und folglich die zu zahlende Körperschaftsteuer.

459 Vgl. Cussons, P. (1996), a.a.O, S.4ff.

460 Vgl. International Bureau of Fiscal Documentation (IBFD) (1997), a.a.O., S. 294. 
Von den Folgen des Zinsabzugsverbots sind regelmäßig auch Gesellschafter betroffen, die keine oder eine steuerlich akzeptierte Fremdkapitaleinlage gewähren. Gesellschafter, die kein Zinsabzugsverbot verursachen, können sich natürlich durch Gewinnverteilungsverträge gegen die negativen Folgen des Zinsabzugsverbots wehren. Problematisch ist das Zinsabzugsverbot, wenn es aus ThinCapitalization-Rules resultiert, die allein auf Steuerausländer zielen. In diesem Fall entstehen - wie bei der deutschen Regelung - Interessenkonflikte zwischen Steuerinländern und Steuerausländern.

Hingegen rufen Einschränkungen der Gesellschafterfremdfinanzierung, die sowohl für Steuerinländer als auch für Steuerausländer gelten, keine Konflikte zwischen diesen beiden Gesellschaftergruppen (Frankreich, Belgien) hervor. Auch das japanische Abzugsverbot dämpft den möglichen Konflikt zwischen den Gesellschaftergruppen, weil die Quote der Steuerausländer nur dann wirksam wird, wenn auch die "Overall-Quote" verletzt ist, für die letztlich alle Gesellschafter verantwortlich sind.

\subsubsection{Umqualifizierung}

Die Umqualifizierung von Zinseinkünften in Dividendeneinkünfte führt dazu, daß andere Kapitalertragsteuersätze im Quellenland der Kapitalerträge zur Anwendung gelangen. In den meisten Fällen ist der Kapitalertragsteuersatz auf Dividenden höher als derjenige auf Zinsen. Die Beschränkungen der Gesellschafterfremdfinanzierung enthalten die Umqualifizierung in der Regel als zusätzliche Maßnahme zum Zinsabzugsverbot. Dies ist z.B. in Spanien und Deutschland der Fall.

\section{Fazit zum Problem der Gesellschafterfremdfinanzierung}

Die Gesellschafterfremdfinanzierung ist eine Methode, mit der ausländische Anteilseigner in Deutschland den Ausschluß von der Körperschaftsteueranrechnung umgehen können. Freilich ist diese Umgehung nur möglich, wenn die Fremdfinanzierung überhaupt als gleichwertige Alternative zur Eigenfinanzierung in Frage kommt. Die deutschen Maßnahmen zur Einschränkung der Gesellschafterfremdfinanzierung sind voller Widersprüche und können leicht unterlaufen werden. Auch die ausländischen Thin-Capitalization-Rules erscheinen eher willkürlich gezogene Pauschalbegrenzungen zu sein, die ähnliche Probleme aufwerfen. International kann aufgrund zunehmender Verbreitung von Thin-CapitalizationRules eine verstärkte Hinwendung zur Quellenlandbesteuerung bei Kapitaleinkommen festgestellt werden. Eine Verschärfung der deutschen Regelungen - bei unveränderter Besteuerung von Gesellschafterfremdkapital in anderen Ländern - 
führt mit hoher Wahrscheinlichkeit zu einer Abwanderung ausländischer Investoren und ist insofern kaum erstrebenswert. Aus heutiger Sicht scheint allein eine Senkung des Ausschüttungssatzes der Körperschaftsteuer eine mögliche Lösung, mit der Deutschland für ausländische Investoren auch aus steuerlicher Sicht ein attraktiver Anlageort bleiben - bzw. wieder werden - kann. Auf der Suche nach Lösungsansätzen für das Problem des Dividendenstripping sollten diese Erkenntnisse berücksichtigt werden. 


\section{Alternative Lösungsansätze zur Besteuerung körperschaftsteuerpflich- tiger Gewinne ausländischer Anteilseigner}

Zur Unterbindung des Dividendenstrippings erscheint eine alleinige Verschärfung der Veräußerungsgewinnbesteuerung keine Lösung. Gründe hierfür sind weniger die erörterte grundsätzliche Kritik an der Veräußerunggewinnbesteuerung oder ihre mangelnde Systemkonformität zum Anrechnungssystem als vielmehr die Tatsache, daß Veräußerungsgewinne aus beweglichem Vermögen im wesentlichen der Besteuerung des Wohnsitzlandes unterliegen. Schärfere Kapitalmarktkontrollen sind ebenfalls nur bedingt eine Lösung, da sie die Kapitalmärkte in ihren Grundfunktionen behindern. Auch dem Problem der Gesellschafterfremdfinanzierung, ist wegen der vorrangigen Wohnsitzlandbesteuerung von Zinsen nur schwer mit Spezialgesetzen beizukommen. Zwar ist es richtig, daß Gesellschafterfremdfinanzierung auch ohne Anrechnungssystem ein Problem ist, da dann das Ausweichen auf Fremdkapitaleinbringung auch für Inländer interessant ist. Umgekehrt profitieren Ausländer in Ländern ohne Anrechnungssystem genauso von der Gesellschafterfremdfinanzierung. Dennoch stellt die Gesellschafterfremdfinanzierung ein spezielles Problem des Anrechnungssystems dar, weil im Anrechnungssystem häufig eine Arbeitsteilung erfolgt: Inländer geben Eigenkapital, Ausländer liefern Fremdkapital. Fraglich ist hier vor allem, inwieweit die grundsätzliche Finanzierungsfreiheit von Kapitalgesellschaften unzumutbar eingeschränkt wird.

Eine Gemeinsamkeit der Spezialgesetze zum Dividendenstripping und zur Gesellschafterfremdfinanzierung liegt darin, daß sie in ihren Auswirkungen vor allem inländische Steuerpflichtige treffen, entweder durch die Auferlegung unerfüllbarer Nachweispflichten oder durch Verwehrung der Körperschaftsteueranrechnung bzw. der Geltendmachung von Gewinnminderungen. Problematisch ist auch die aufgezeigte Vermeidbarkeit der Spezialgesetze: In beiden Bereichen ist es dem Gesetzgeber nicht gelungen, "wasserdichte" Regelungen zu finden. Angesichts der zunehmenden Globalisierung der Kapitalmärkte ist es aber fraglich, wie lange sich eine Volkswirtschaft - die einen relativ hohen Offenheitsgrad aufgrund ihrer starken Außenhandelsabhängigkeit aufweist - ein auf nationale Sachverhalte beschränktes körperschaftsteuerliches Vollanrechnungssystem leisten kann, das zu Steuerumgehungen geradezu einlädt.

Es erscheint daher zwingend, Überlegungen anzustellen, welche generellen Auswege sich aus der dargestellten Lage eröffnen. Hier bietet sich einerseits die Ausdehnung der Körperschaftsteueranrechnung an, andererseits kann auch die Abkehr vom Anrechnungssystem in Betracht gezogen werden. Bevor diese Maßnahmen diskutiert werden, ist zu klären, ob nicht die Zulassung bestimmter Finanzinnovationen dazu führen könnte, sozusagen über Marktprozesse die Steuerbarrieren zu durchbrechen, ohne daß gegen die grundsätzliche Ziele der Kapitalbesteuerung 
verstoßen wird. Ist dies nicht der Fall, so verbleiben als Lösungsweg verschiedene Steuersystemreformen, die in der Reihe ihres zunehmenden Reformaufwandes diskutiert werden sollen.

\section{1. Die Verbundaktie (Stapled Stock) - eine Marktlösung gegen die Dis- kriminierung ausländischer Anteilseigner}

Die Finanzinnovation Verbundaktie wird mitunter als Marktlösung oder als weitere Gestaltungsmöglichkeit zur Überwindung national beschränkter Anrechnungssysteme gepriesen ${ }^{461}$. Inwieweit diese Aktienart diesem Ziel tatsächlich gerecht werden kann, soll im folgenden Abschnitt untersucht werden.

\subsubsection{Die Verbundaktie - ein internationales Wertpapier für national be- schränkte Anrechnungssysteme}

Verbundaktien sind verknüpfte Wertpapiere mit Eigenkapitalcharakter, die in der Regel aus einem inländischen und einem ausländischen Wertpapier kooperierender Unternehmen bestehen. In Deutschland hat die Verbundaktie bisher nur geringe Bedeutung erlangt. Dagegen spielt sie im angelsächsischen Raum schon eine größere Rolle, weshalb sich auch der Begriff der "Stapled Stocks" (zusammengeheftete Aktien) für diese Wertpapierbündelung durchgesetzt hat.

In erster Linie zielen Verbundaktien darauf, die körperschaftsteuerliche Doppelbesteuerung ausländischer Anteilseigner zu mindern bzw. aufzuheben. Üblich ist, daß zumindest einer der betroffenen Staaten, in denen die Verbundaktie plaziert wird, ein körperschaftsteuerliches Anrechnungssystem anwendet, das keine Anrechnung auf ausländische unmittelbare oder mittelbare Dividendenausschüttungen an inländische Anteilseigner gewährt.

Die Verbundaktie gewährleistet, daß ausländische Anteilseigner, deren Wohnsitzstaaten eine körperschaftsteuerliche Anrechnung praktizieren, in den Genuß dieser (ausländischen) Anrechnung gelangen, zugleich aber Anteilseigner am inländischen Unternehmen bleiben. Erreicht wird dies, indem ausländische Anteilseigner ihre Dividenden direkt aus einer Kapitalgesellschaft beziehen, die in ihrem Wohnsitzland (Ausland) unbeschränkt steuerpflichtig ist, und nicht aus der Kapitalgesellschaft im Inland. Das Anrechnungsguthaben, das dem Ausländer in seinem Wohnsitzland bei einer inländischen Beteiligung zustünde, ist damit gerettet. Die

461 Vgl. Herzig, N. (1996): Anrechnungsverluste als steuerliches Hemmnis grenzuberschreitender Kooperationen, in: Internationales Steuerrecht (IStR), 5. Jg./(1996), Nr. 4, S. 200. 
Anteilseigner haben innerhalb ihres Wohnsitzlandes unmittelbaren Zugriff auf die Gewinne der Kapitalgesellschaft, obwohl ihre Stimmrechte jenseits der Landesgrenze nicht verloren gehen. Die Verbundaktie kann somit die Mehrfachbelastung körperschaftsteuerpflichtiger Gewinne, die in dem Land des ausländischen Anteilseigners anfallen, vermeiden oder mindern. Die Mehrfachbelastung von Gewinnen, die nicht im Wohnsitzland des Anteilseigners erzielt wurden, bleibt allerdings bestehen. Auch an der Mehrfachbelastung von ausländischen Anteilseignern, die ihren Wohnsitz in einem Land ohne Anrechnungssystem haben, ändert die Verbundaktie nichts. Sie trägt damit quasi zur Durchsetzung des Wohnsitzlandprinzips bei der Dividendenbesteuerung bei.

Allerdings sind der Verbundaktie schon bei der Einführung ökonomische Grenzen gesetzt: Jedes Unternehmen, das im Ausland Verbundaktien anbieten will, hat Kosten für deren Unterbringung aufzubringen. Diese rentieren sich nur dann, wenn eine größere Gruppe von Anteilseignern in den Genuß der Vorteile der Verbundaktien gelangt. Die Ausgabe von Verbundaktien kann folglich nur für Unternehmen interessant sein, die ein größeres Engagement in einem ausländischen Anrechnungsstaat eingehen wollen oder schon eingegangen sind, indem sie beispielsweise eine Tochtergesellschaft im Ausland etabliert haben, die dort körperschaftsteuerpflichtige Gewinne erzielt. Geprüft werden muß ferner, inwieweit der ausländische Kapitalmarkt zur Plazierung von Stapled Stocks geeignet ist. Ein gewisser Bekanntheitsgrad der Tochtergesellschaft im betroffenem Ausland, jedoch zumindest der heimischen Muttergesellschaft, ist dabei von Nutzen.

$\mathrm{Zu}$ den Unterbringungskosten zählen Informationskosten, Vorbereitungskosten und Kosten der Plazierung. Die Informationskosten zur Einführung von Stapled Stocks dürften eine beachtliche Abschreckung ausüben; z. B. sind im Gegensatz zur Plazierung einer deutschen Aktie an einer ausländischen Börse die Probleme zu beachten, die sich aus der Verknüpfung von in- und ausländischen Wertpapieren ergeben. Jedes Unternehmen, das eine Ausgabe von Stapled Stocks erwägt, muß sich mit dem Handels-, Börsen-, und Körperschaftsteuerrecht von mindestens zwei Staaten und dessen Zusammenspiel auseinandersetzen. Mitunter erweisen sich auch Zusammenschlüsse in drei Staaten als vorteilhaft ${ }^{462}$, womit sich allerdings der Informationsaufwand entsprechend erhöht.

462 Siehe z.B. den Zusammenschluß der Unternehmen The Reed Stenhouse Companies Ltd./Alexander and Alexander Services Inc. (USA, Kanada, Großbritannien) oder Rothmans International PLC, Dunhill Holdings PLC (Großbritannien, Luxemburg, Niederlande), vgl. Smith, D.W., The Canadian Perspective, in: IFA (Hrsg.): Dividend Access Shares (Stapled Stocks), Den Haag u.a., 1996, S.122. 


\subsubsection{Gestaltungsformen von Verbundaktien}

Verbundaktien bestehen typischerweise aus einer Stammaktie einer Muttergesellschaft und einem Wertpapier, das zu einer Dividende berechtigt, die von einer Tochtergesellschaft oder einem kooperierenden Unternehmen ausgeschüttet wird. Dieses Wertpapier wird im allgemeinen als Income Access Share oder als Dividend Access Share bezeichnet. Sehr oft wird nur ein Teil der Aktien der Muttergesellschaft mit einem Income Access Share verknüpft. Der englische Name drückt ziemlich treffend den Zweck dieses Wertpapiers aus: Es eröffnet dem ausländischen Anteilseigner einer inländischen Kapitalgesellschaft den Zugriff auf Gewinnausschüttungen einer Tochtergesellschaft in seinem Wohnsitzland. Die übliche internationale Doppelbelastung ausgeschütteter Gewinne wird vermieden. Beispiel: Eine inländische Kapitalgesellschaft im Land I hat eine Tochtergesellschaft im Ausland A, das ein körperschaftsteuerliches Anrechnungssystem anwendet. An der inländischen Kapitalgesellschaft sind zugleich ausländische Anteilseigner aus A beteiligt. Schüttet die Tochtergesellschaft an die inländische Muttergesellschaft aus, so geht bei der Weiterausschüttung den ausländischen Aktionären aus $\mathrm{A}$ in der Regel das Recht auf Anrechnung verloren. Income Access Shares verkürzen nun den Weg der Ausschüttungen. Statt über die Muttergesellschaft im Land I, fließen die Ausschüttungen dem ausländischen Aktionär direkt zu. Die Dividenden bleiben im Land A.

Die Ausgabe von Income Access Shares an ausländische Aktionäre kann sowohl nachträglich als auch gleichzeitig mit der Emission der Aktie der Muttergesellschaft erfolgen. Die Ausgabe der Income Access Shares kann entweder direkt von der Tochtergesellschaft vorgenommen werden ${ }^{463}$, sie kann aber auch von einer zwischengeschalteten Gesellschaft durchgeführt werden, die ebenfalls im Land der Tochtergesellschaft eingerichtet wird ${ }^{464}$. Üblicherweise erfolgt mit der Ausgabe der Income Access Shares eine Einschränkung der Dividendenbezugsrechte, die in der gekoppelten Aktie der Muttergesellschaft verbrieft sind. Diese Aktie verbrieft jedoch weiterhin das Stimmrecht an der Muttergesellschaft. Die Einschränkung des Dividendenbezugsrechts erfolgt in dem Umfang, in dem das Income Access Share einen Dividendenanspruch gewährt. Ergebnis dieser Konstruktion: Ein ausländischer Anteilseigner verfügt mit seiner Verbundaktie über die gleichen Stimm- und Dividendenbezugsrechte wie ein inländischer Anteilseigner, der allein eine Aktie an der inländischen Kapitalgesellschaft besitzt.

463 So z.B. im Fall der deutschen Genußscheinausgabe als Bestandteil der Verbundaktie der Firma Redland. 
Kennzeichnend für Income Access Shares ist, daß ihr Einsatz immer im Rahmen einer hierarchischen Unternehmensanordnung erfolgt. Income Access Shares ermöglichen stets Ausschüttungen vom hierarchisch untergeordneten Unternehmensteil an den Anteilseigner.

Eine anteilige Verknüpfung der Stammaktie mit Income Access Shares muß dabei nicht für einen konstant bleibenden Aktienanteil bestehen. Wie am Beispiel der einzigen Verbundaktie mit deutscher Beteiligung noch deutlich werden wird, kann sich der Umfang der Verknüpfung auch flexibel nach der Nachfrage von anrechnungsberechtigten Anteilseignern aus dem Land der Tochtergesellschaft bzw. nach der Nachfrage der Anteilseigner aus dem Land der Muttergesellschaft richten. Es werden dann jeweils soviele Wertpapierverknüpfungen hergestellt, wie nötig sind, damit alle anrechnungsberechtigten Anteilseigner im Land der Tochtergesellschaft in den Genuß der Anrechnung gelangen.

Darüber hinaus existieren auch vollständig verknüpfte Stapled Stocks ohne spezielle Income Access Shares. Sogenannte Zwillingsfirmen, die einen Unternehmenssitz in einem Anrechnungsland und einen zweiten Unternehmenssitz in einem weiteren Land haben, dem alle weiteren Tochtergesellschaften auf der übrigen Welt unterstehen, treten mitunter mit einer gemeinsamen Verbundaktie auf, die untrennbar ist und ein gleiches Dividendenrecht verbrieft. Bezüglich der Dividende haben die Anteilseigner dann ein interessantes Wahlrecht. Sie können entscheiden, von welcher der beiden verknüpften Aktien sie die fällige Ausschüttung beziehen ${ }^{465}$. Sofern die Anteilseigner in dem Anrechnungsstaat ansässig sind, in dem eine der Zwillingsfirmen liegt, werden sie die Ausschüttung der ansässigen Gesellschaft wählen, da dann das Anrechnungsguthaben nicht verloren geht.

Selbst wenn das Wohnsitzland des Anteilseigners keine Anrechnung gewährt, kann das Wahlrecht noch interessant sein, z.B., weil die Sätze der Körperschaftsteuer oder der Kapitalertragsteuer differieren.

Solche vollständig verknüpften Verbundaktien kommen bisher nur im Ausland vor. Beispielhaft sei hier das Unternehmen Rothmans genannt, das Aktien der britischen Muttergesellschaft mit Aktien einer niederländischen Finanzholding verknüpfte. Auch Vendome Plc in Großbritannien und Vendome $S A$ in Luxemburg haben diese Struktur gewählt. Mit einer Umstrukturierung der übergeordneten $R i$ -

465 Vgl. Derouin, P. (1996): Introduction, in: IFA (Hrsg.): Dividend Access Shares (Stapled Stocks), Den Haag u.a., S. 9. 
chemont-Gruppe wurden diese Konstruktionen aus dem Jahr 1993 zwei Jahre später wieder aufgelöst. In der Regel sind Verbundaktien allerdings langlebiger ${ }^{466}$. Wegen der Unterschiedlichkeit der Rechtssysteme sind die Ausgestaltungen der Verbundaktien extrem variantenreich. Im Gegensatz zu einigen europäischen Staaten verlangt z.B. das Steuerrecht der USA zwingend, daß Income Access Shares Liquidationsrechte enthalten müssen ${ }^{467}$. Die Niederlande akzeptieren keine minimalen Nennwerte der Income Access Shares, da nach holländischer Auffassung der sehr geringe Nennwert dieser Wertpapiere Hinweis furr verdeckte Gewinnausschüttungen ist ${ }^{468}$. Der Nennwert muß aber in der Praxis prinzipiell möglichst gering sein, weil sonst das Aktienpaket aus Aktie der Muttergesellschaft und Income Access Share immer mehr wert wäre, als eine einzelne Aktie der Muttergesellschaft. In Deutschland wird ein geringer Nennwert der Income Access Shares und eine daraus folgende Unproportionalität zwischen Gewinnverteilung und Nennwert als unproblematisch eingeschätzt ${ }^{469}$.

Die Ausgestaltung von Verbundaktien kann sich auch durch die Art der Verknüpfung unterscheiden. Generell muß verhindert werden, daß der Anteilseigner die Verbundaktie in ihre Bestandteile auflösen $\mathrm{kann}^{470}$. Eine Trennung beider Papiere könnte dem Anteilseigner unter Umständen Gewinnansprüche aus beiden Wertpapieren einräumen. Es bestünde die Gefahr, daß die Verbundaktie zu einem anderen Kurs gehandelt wird als die Stammaktie, weil sich die Rechte und möglicher-

466 So wird z.B. die älteste Verbundaktie mit europäischer Beteiligung, die britisch-kanadische Verbundaktie der Thomson Corporation, die 1978 emittiert wurde, bis heute gehandelt; vgl. Aidin, M.R. (1996): The British Perspective, in IFA(Hrsg.): Dividend Access Shares (Stapled Stocks), Den Haag u.a., S. 56f.

467 Vgl. Canellos, P. (1996) in: The Discussion of the Tax Challanges, in: Transcript Tax of the Seminar Proceedings, in IFA (Hrsg.): Dividend Access Shares (Stapled Stocks), Den Haag u.a. 1996, S. 35.

468 Vgl. Marseille, H. (1996) in: The Discussion of the Tax Challanges, in: Transcript of the Seminar Proceedings, in: IFA (Hrsg.): Dividend Access Shares (Stapled Stocks), Den Haag u.a. 1996, S. 31 .

469 Vgl. Haarmann, W. (1996): Verknüpfung von Beteiligungen zur Sicherung des Anrechnungsguthabens (Stapled Stocks), in: Herzig, N. (Hrsg.): Körperschaftsteuerguthaben bei grenzüberschreitenden Kooperationen, Köln 1996, S. 52ff.; ebenso Smith, C. / Thalhammer, B. (1997): Die Verbundaktie. Ein Praxisbeispiel von Stapled Stock, Institut für Ausländisches und Internationales Finanz- und Steuerwesen (Hrsg.): Hefte zur Internationalen Besteuerung Nr. 113, Hamburg 1997, S. 37f.

470 Dies schließt nicht aus, daß der nichtanrechnungsberechtigte Anteilseigner seine Verbundaktie jederzeit gegen eine "normale" Stammaktie der Muttergesellschaft eintauschen kann. 
weise auch die Fungibilität der Wertpapiere voneinander unterscheiden. Das vorrangige Ziel von Stapled Stocks, die Aufhebung der steuerlichen Benachteiligung ausländischer Anteilseigner, wäre durch eine Bevorzugung der Verbundaktieninhaber verfehlt.

Die Verknüpfung der beiden Wertpapiere kann grundsätzlich auf unterschiedliche Weise erfolgen. Denkbar ist z.B. eine dingliche Verknüpfung, d.h. die Aktien werden tatsächlich miteinander verbunden oder es wird nur ein Wertpapier ausgegeben, das Eigentum an beiden Unternehmen verbrieft.

Eine weitere Möglichkeit sind depotrechtliche Verknüpfungen. Diese können erreicht werden, indem ein Treuhänder die Wertpapiere beider Gesellschaften in ein Depot nimmt und dem Anteilseigner Miteigentum an den verbundenen Wertpapieren gewährt. In deutschen Börsen werden ausländische Aktien generell nur in Form von Miteigentumsanteilen an einem Sammelzertifikat beim Deutschen Auslandskassenverein gehandelt. Insofern bietet sich für ein ausländisches Unternehmen mit deutscher Partnergesellschaft eine depotrechtliche Verknüpfung an, die über die Kassenvereine herstellbar ist.

Theoretisch möglich wäre auch eine Vinkulierung beider Wertpapiere. Eine gleichzeitige Vinkulierung eines inländischen- und eines ausländischen Wertpapiers erscheint in der Praxis jedoch sehr aufwendig. Die Muttergesellschaft müßte zudem ihre Aktienstruktur ändern, z.B. eine Vinkulierung der Altaktien vornehmen.

Ein weiterer Weg zur Herstellung der Untrennbarkeit ist die gesellschaftsrechtliche Verknüpfung. Gründet man in jedem Land eine Beteiligungsgesellschaft, die nur die Beteiligungen der inländischen und der ausländischen Gesellschaft hält, und läßt nur Anteile an den Beteiligungsgesellschaften im Handel zu, so kann ebenfalls über die verbundenen Unternehmen nur noch zusammen verfügt werden. Dem Anteilseigner wird so jedoch das direkte Stimmrecht an seiner Gesellschaft entzogen.

Wichtig ist die rechtliche Einordnung der Income Access Shares in das jeweilige Steuersystem. In Großbritannien gelten Income Access Shares börsenrechtlich als ausländisches Wertpapier, auch wenn sie Gewinnbezugsrechte aus britischen Unternehmen verbriefen. Daraus folgen Einschränkungen für britische Pensionsfonds und Versicherungsgesellschaften, die in diese Wertpapiere nur sehr begrenzt investieren dürfen. Umgekehrt dürfen kanadische Pensionsfonds in Kanada Income Access Shares erwerben, die in Kanada vor allem von US-Unternehmen herausgegeben werden. Die kanadischen Pensionsfonds machen hiervon Gebrauch, obwohl sie im kanadischen Körperschaftsteuersystem keine Anrechnung geltend 
machen dürfen ${ }^{471}$. Wären die kanadischen Pensionsfonds nicht berechtigt, ausländische Stapled Stocks zu erwerben, so wäre es vermutlich kaum zu StapledStocks-Strukturen zwischen den USA und Kanada gekommen, von denen die übrigen anrechnungsberechtigten kanadischen Anteilseigner profitieren können, da der kanadische Kapitalmarkt von den heimischen Pensionsfonds dominiert wird.

\subsubsection{Abgrenzung von Verbundaktien zu verwandten Kooperations- formen}

$\mathrm{Zu}$ unterscheiden sind Verbundaktien von verknüpften Unternehmen, zwischen denen Ausgleichsverträge bestehen, wie z.B. bei der britischen Unilever Plc und der holländischen Unilever $N V$. Mit Ausgleichsverträgen können Unternehmen wie Unilever beispielsweise festlegen, daß jede Gesellschaft im Bedarfsfall die andere Gesellschaft in die Lage versetzt, eine Gewinnausschüttung in Höhe der eigenen Ausschüttung zu leisten ${ }^{472}$. Kennzeichnend für die Ausgleichsverträge ist, daß hier keine ausländischen Anteilseigner in den Genuß der Anrechnung ihres Wohnsitzlandes gelangen. So erhalten die britischen Anteilseigner von Unilever nur die britische Anrechnung, wenn sie britische Unilever-Aktien halten. Dividendenpapiere werden hierbei nicht miteinander verknüpft. Bei Shell bestehen solche Ausgleichsverträge bezüglich des Firmenvermögens zwischen dem holländischen und dem britischen Zweig des Konzerns. Eine andere Kooperationsform ist die Zwillingsgesellschaft. Die Gesellschaften aus zwei Staaten geben in diesem Fall nur eine einheitliche Aktie aus, die nur ein Dividendenbezugsrecht verbrieft. Zwar wird diese Aktie noch als Stapled Stock bezeichnet, das steuerliche Ziel von Stapled Stocks wird aber verfehlt. Eine Verbundaktie ohne Dividendenbezugswahlrecht ist beispielsweise die gemeinsame Aktie von Eurotunnel SA und Eurotunnel Plc. Bei potentiellen Ausschüttungen dieser Aktie ist noch unklar, in welchem Umfang britische und französische Aktionäre eine Anrechnung erhalten sollen $^{473}$.

Umgekehrt ist auch die Existenz von Income Access Shares keine hinreichende Voraussetzung für eine Stapled-Stocks-Konstruktion. Möglich ist z.B., daß die Income Access Shares innerhalb einer Unternehmensgruppe bleiben und damit nicht im Aktienhandel erscheinen. Dies ist der Fall beim Zusammenschluß der ArjoWiggins-Appleton-Gruppe. Innerhalb dieser Unternehmensgruppe hält eine fran-

471 Vgl. Smith, D. W. (1996): The Canadian Perspective, in: IFA (Hrsg.): Dividend Access Shares (Stapled Stocks), a.a.O., S. 124f. bzw. ebd., S. 17.

472 Vgl. Smith, C.M.A. / Thalhammer, B. (1997), a.a.O., S. 15.

Vgl. Derouin, P. (1996), a.a.O., S. 5. 
zösische Holding alle Income Access Shares einer britischen Tochtergesellschaft in Frankreich und zugleich $39 \%$ an der britischen Muttergesellschaft ${ }^{474}$. Die Aktionäre der französischen Holding kommen also in den Genuß der Income Access Shares, obwohl sie diese nicht selbst halten. Die britischen Aktien des verbundenen Unternehmens sind aber nicht mit den französischen Holdingaktien geheftet. Unternehmensgruppen mit Ausgleichsverträgen oder Income Access Shares innerhalb der Unternehmensgruppen fallen in der englischen Literatur unter den Sammelbegriffe "Linked Shares", den man im deutschen theoretisch auch mit "Verbundaktie" übersetzen könnte, was jedoch eher Verwirrung stiften dürfte. Man sollte also besser differenzieren zwischen Unternehmen mit Ausgleichsverträgen, Zwillingsgesellschaften ohne Income Access Shares und Unternehmensgruppen mit internen Income Access Shares.

\subsubsection{Verbundaktien in Deutschland}

\subsubsection{Verbundaktien mit ausländischer Muttergesellschaft}

Der bisher einzige Fall einer Verbundaktie am deutschen Aktienmarkt ist die Verbundaktie der Firma Redland, ein britisches Unternehmen, dessen Konzerngewinn in manchen Jahren bis zur Hälfte in Deutschland erzielt wurde. Das Unternehmen ist eine Aktiengesellschaft, deren Anteile an der Londoner Wertpapierbörse notiert werden. Die Aktionäre waren bis 1994 überwiegend in Großbritannien ansässig. Die Ausschüttung von in Deutschland entstandenen Konzerngewinnen auf dem "natürlichen Weg" an die Anteilseigner der Muttergesellschaft führte vor 1994 zwangsläufig zur Mehrfachbesteuerung. Ein in Großbritannien ansässiger Anteilseigner trug im Fall einer Ausschüttung der deutschen Tochtergesellschaft eine Mehrfachbelastung: Neben der definitiven deutschen Ausschüttungskörperschaftsteuer unterlag er der britischen Advanced Corporation Tax, die für die britische Muttergesellschaft nicht auf die Körperschaftsteuer anrechenbar war, sowie der persönlichen Einkommensteuer. Auch deutsche Anteilseigner unterlagen einer internationalen Mehrfachbelastung, da die deutsche Körperschaftsteuer durch den Umweg über das Ausland Definitivchrakter erhielt.

Am 7. Dezember 1994 wurde die Redland-Verbundaktie an der Frankfurter Wertpapierbörse plaziert. Ein Teil der Aktien der britischen Muttergesellschaft Redland Plc ist seit 1994 verbunden mit Gewinnbeteiligungspapieren der deutschen Tochtergesellschaft, einer GmbH. Bisher wurde das deutsche Aktienrecht so ausgelegt, daß eine Verknüpfung deutscher mit ausländischen Aktien als unzulässig 
galt, was aber nicht unumstritten ist ${ }^{475}$. Im Fall der Firma Redland hätte außerdem - bei Zulässigkeit - die deutsche Tochtergesellschaft erst in eine Aktiengesellschaft umgewandelt werden müssen. Dies erwies sich zur Schaffung von Stapled Stocks jedoch als unnötig, da die vergleichsweise weniger strengen Ausgabevorschriften für Genußscheine zur Schöpfung der ersten deutsch-ausländischen Verbundaktie genügten. Mit der Verknüpfung von Genußschein und Aktie gelangen deutsche Anteilseigner in den Genuß des deutschen Körperschaftsanrechnungsguthabens, das ihnen bei alleinigen Besitz britischer Aktien der britischen Muttergesellschaft nicht zugestanden hätte. Die Aktie der Muttergesellschaft gewährt als Verbundaktie dem deutschen Aktionär außerdem die gleichen Stimmrechte wie die weiterhin im Umlauf befindlichen "unverbundenen" Aktien der Redland Plc. Für die außerdem bestehende Gleichstellung deutscher Verbundaktionäre und britischer Aktionäre war einzig eine Satzungsänderung der britischen Aktie nötig: Der Dividendenanspruch wurde für Verbundaktionäre um den Betrag gemindert, der durch den (deutschen) Genußschein ausgeschüttet wird ${ }^{476}$.

Mit dieser Satzungsänderung wurde gewährleistet:

1. Verbundaktie und Mutteraktie sind in ihren Dividendenrechten gleichgestellt, d.h. die Bruttodividenden einer Verbundaktie und einer Aktie sind identisch.

2. Es entstehen keine unterschiedlichen Aktienarten einer Gesellschaft; die Fungibilität bleibt erhalten.

3. Deutsche und britische Anteilseigner genießen jeweils die Anrechnung, die ihnen ihr Wohnsitzland einräumt, somit wird aus deutscher Sicht Kapitalexportneutralität erreicht.

Der Anteil der verknüpften Aktie muß dabei nicht konstant sein, sondern richtet sich nach der Nachfrage nach der Aktie bzw. der Verbundaktie. Redland wählte eine depotrechtliche Verknüpfung, was sich schon deswegen anbot, weil ausländische Aktien in Deutschland, wie erwähnt, als Sammelzertifikat gehandelt werden. Die britische Muttergesellschaft hinterlegte die Genußrechte der Tochtergesellschaft als Inhaber-Sammelzertifikat bei der Deutschen Kassenverein $A G$ zugunsten der Auslandskassenverein AG. Letztere stellte Sammelzertifikate über Verbundaktien und Genußscheine in gleicher Anzahl aus. Erwirbt oder veräußert ein in Deutschland ansässiger Aktionär eine Redland-Aktie an der Wertpapierbörse Frankfurt, so erfolgt das Aktiengeschäft, je nach Angebot und Nachfrage, in Frankfurt oder über einen britischen Treuhänder in London. Dabei findet eine Verbuchung über die Kassenvereine statt, sofern der Aktionär nicht ausdrücklich eine Redland-Aktie ohne Genußschein ordert. Kaufen nun deutsche Kapitalanle-

475 Vgl. Haarmann, W., (1996), a.a.O., S. $47 \mathrm{ff}$.

Ausfuhrlich zur Redland-Verbundaktie vgl. Smith, C.M.A. / Thalhammer, B. (1997), a.a.O., S. $20 \mathrm{ff}$. 
ger vermehrt die Redland-Verbundaktie, so erhöht sich die Zahl der Verbundaktien. Erwerben hingegen überwiegend britische oder internationale Anleger von deutschen Veräußerern, so verringert sich die Zahl der verknüpften RedlandAktien. Die Gesamtzahl der emittierten Redland-Aktien bleibt davon natürlich unberührt.

Die Redland-Verbundaktie ist bisher die einzige Stapled-Stocks-Konstruktion, die das deutsche Anrechnungssystem tangiert. Da die Redland-Emission bisher aber als Erfolg gesehen werden kann, könnte das Beispiel Schule machen. Mit Nachahmern muß über kurz oder lang gerechnet werden, zumal die deutsche Finanzverwaltung bisher - soweit ersichtlich - keine Zweifel an der Rechtskonformität der Verbundaktie geäußert hat. Allerdings lohnt sich die Einrichtung einer Verbundaktie, in der Regel nur dann, wenn die ausländische Muttergesellschaft daran interessiert ist, Eigenkapitalgeber im Land der Tochtergesellschaft zu gewinnen.

\subsubsection{Verbundaktien mit deutscher Muttergesellschaft}

Eine spiegelverkehrte Konstruktion, also eine deutsche Muttergesellschaft mit ausländischer Tochtergesellschaft und ausländischen Aktionären aus dem Land der Tochtergesellschaft, die von einer Verbundaktie in ihrem Land profitieren, ist bisher nicht verwirklicht worden. $\mathrm{Zu}$ untersuchen wären die Gründe, warum deutsche Unternehmen trotz ihrer zunehmenden Auslandsorientierung bisher nicht zu diesem Finanzierungsmittel gegriffen haben: Es mag daran liegen, daß es zur Zeit noch umstritten ist, ob deutsche Aktien so ausgestattet werden dürfen, daß sie als Bestandteil einer Verbundaktie gehandelt werden können. Problematisch ist, daß möglicherweise eine Regelung eingeführt werden müßte, nach der eine Aktie nur mit einem verbundenen Wertpapier zusammen übertragen werden darf. Definiert man diese Einschränkung als Nebenleistungspflicht, die das deutsche Aktienrecht für Namensaktien grundsätzlich zuläßt ${ }^{477}$, dann schließt das deutsche Recht Verbundaktien möglicherweise grundsätzlich aus ${ }^{478}$. Die aufgezeigte Vielfalt der Verknüpfungsformen nimmt allerdings einer solchen Schlußfolgerung den Wind aus

477 Vgl. 68 II AktG.

478 Als Nebenleistungspflichten läßt das Gesetz nämlich nur wiederkehrende, nicht in Geld bestehende Leistungen zu; vgl. Nirk, R. (1997), in: Nirk, R. u.a. (Hrsg.): Handbuch der Aktiengesellschaft, 3. Aufl. 1994, Losebl.-Ausg. Stand: 5/97, Teil I, Rz. 587f., S.368f. Da ein Verăußerungsvorgang keine wiederkehrende Leistung des Anteilseigners ist, kann die gemeinsame Verăußerung beider Wertpapiere - noch dazu an einen einzigen Erwerber nicht über die sogenannten Nebenpflichten eines Aktionärs rechtlich abgesichert werden. Im Ergebnis könnte eine Verknüpfung deutscher Aktien mit ausländischen Wertpapieren nach aktuellem Recht noch auf Schwierigkeiten stoßen; vgl. Haarmann, W. (1996), a.a.O., S. 48. 
den Segeln. Keineswegs muß eine dingliche Verknüpfung in Deutschland vorgenommen werden. Denkbar erscheint auch der umgekehrte Redland-Fall, also eine depotrechtliche Verknüpfung im Ausland. Andere mögliche Ausprägungsformen, z.B. die Beschränkung des Gewinnanspruchs aus der Aktie der Muttergesellschaft für den Verbundaktionär, werden vom aktuellen deutschen Aktienrecht nicht erkennbar blockiert.

Spezielle deutsche Gesetze, die in präventiver Form die Verbundaktie unterbinden, existieren nicht. Sieht die Finanzverwaltung die Verbundaktie als ein Mittel des Steuermißbrauchs an, so könnte sie allerdings eine Umqualifizierung der Ausschüttung der ausländischen Tochtergesellschaft an die ausländischen Aktionäre vornehmen, indem sie die ausgeschütteten Gewinne der inländischen Kapitalgesellschaft zurechnet und anschließend eine verdeckte Gewinnausschüttung an ausländische Aktionäre unterstellt. In jedem Fall käme es zu einer Steuererhebung bei der unterstellten verdeckten Gewinnausschüttung ${ }^{479}$. Stützen könnte sich die Finanzverwaltung allerdings nur auf den $\S 42 \mathrm{AO}$. Ökonomisch ließe sich ein solches Vorgehen aber kaum rechtfertigen: Das deutsche Körperschaftsteuerrecht beschränkt ja gerade mit dem Argument der inländischen Einmalbesteuerung die Anrechnung auf inländische Anteilseigner. Erwirtschaftet eine ausländische Gesellschaft nun im Ausland Gewinne und schüttet diese Gewinne an die dortigen Gesellschafter aus, so entspricht es dem Sinn des Anrechnungsverfahrens, daß diesen Anteilseignern die Anrechnung ihres Wohnsitzlandes erhalten bleibt. Trotzdem ist die Befürchtung nicht unberechtigt, daß der Gesetzgeber im Fall weiterer Verbundaktienemissionen mit deutscher Beteiligung mit restriktiven Gegenmaßnahmen in Form neuer Gesetz reagieren könnte. Ein entsprechendes Verhalten wird schon seit Mitte der achtziger Jahre im Ausland beobachtet ${ }^{480}$.

Ein weiterer Grund, warum Deutschland keine Vorreiterrolle bei der Entwicklung von Stapled Stocks einnimmt, liegt vermutlich in der steuerlichen Behandlung

479 Eine Besteuerung ließe sich dann nur vermeiden, wenn das deutsche Unternehmen aus dem EK 04 oder dem EK 01 ausschütten kann, wovon nicht ausgegangen werden kann, vgl. Haarmann, W. (1997): Internationale Kooperationen und Sicherung von Anrechnungsguthaben (Stapled Stock), in: Herzig, N. (Hrsg.): Steuerorientierte Umstrukturierung von Unternehmen, Schriftenreihe: Der Betrieb, Stuttgart 1997, S. 268.

480 Ausgerechnet die USA als Land mit klassischem System haben bereits 1984 Regeln gegen den Einsatz von Stapled Stocks erlassen. Allerdings aus anderen als den hier diskutierten Motiven fur den Einsatz von Verbundaktien. Die USA qualifizieren Stapled Stocks unter bestimmten Voraussetzungen als inländische Wertpapiere, um Vorteile zu verringern, die sich aufgrund unterschiedlich hoher Kapitalertragsteuersätze für inländische (30\%) und ausländische (15\%) Wertpapiere in DBA-Fällen ergeben; vgl. IRC, Sec. 269B; vgl. Canellos, P.C. (1996): The US Perspective, in: IFA (Hrsg.): Dividend Access Shares (Stapled Stocks), Den Haag u.a. 1996, S.135. 
ausländischer Gewinne, die an inländische Körperschaften fließen. Deutsche Unternehmen erfahren bei Ausschüttungen von Tochtergesellschaften eine Freistellung. Nicht alle Staaten gewähren eine Freistellung auf der Unternehmensebene. Bis Anfang 1995 begünstigte z.B. gerade das britische Körperschaftsteuerrecht die Einrichtung von Verbundaktien: Die britische Ausschüttungskörperschaftsteuer ACT (Advanced Corporation Tax) mußte bei Ausschüttung einer ausländischen Tochtergesellschaft an eine britische Muttergesellschaft sofort gezahlt werden, und zwar unabhängig vom Zeitpunkt einer Weiterausschüttung an die Anteilseigner. Während bei inländischen Ausschüttungen die ACT als eine Vorauszahlung der britischen Körperschaftsteuer fungierte - und nur im Ausschüttungsfall anfiel galt dies nicht für Gewinne, die von ausländischen Tochtergesellschaften an inländische Unternehmen ausgeschüttet wurden. Sofern in einem Veranlagungszeitraum ein Unternehmen nicht über einen ausreichenden verrechenbaren Betrag an Körperschaftsteuer verfügte, blieben diesem Unternehmen nur noch Vortragsmöglichkeiten (zeitlich unbegrenzt) und Rücktragsmöglichkeiten (sechs Jahre). Im Ergebnis schoben Unternehmen, deren körperschaftsteuerpflichtige Gewinne überwiegend aus dem Ausland stammten, beachtliche ACT-Vorträge vor sich her. Auf diese Weise erlangten die Steuervorauszahlungen Definitivcharakter. Die nichtanrechenbare ACT machte Gewinnausschüttungen von ausländischen Tochtergesellschaften unwirtschaftlich. Diese sogenannte ACT-Trap (ACT-Falle) bewirkte, daß Großbritannien ein äußerst ungünstiger Holdingstandort für internationale Gesellschaften war. Eine Steuerreform im Jahr 1995 entschärfte diese ACT-Falle ${ }^{481}$.

\subsection{3. Ökonomische Beurteilung von Verbundaktien}

Die Verbundaktie erleichtert inländischen Unternehmen mit ausländischen Tochtergesellschaften die Eigenkapitalaufnahme im Ausland. Ausländische Anteilseigner könnten bei Einsatz deutscher Verbundaktien mit ausländischen Income Access Shares in ihrem Anlageverhalten aus steuerlichen Gründen indifferent sein zwischen diesen Verbundaktien und Beteiligungen an einer im Wohnsitzland heimischen Kapitalgesellschaft. Dieses Ergebnis wäre zwar auch mit einem Börsengang der ausländischen Tochtergesellschaft erreichbar, allerdings nur auf Kosten einer größeren Unabhängigkeit der Tochtergesellschaft gegenüber der Muttergesellschaft. Über die Verbundaktie kann der ausländische Anteilseigner dagegen direkt am unternehmerischen Entscheidungsproze $\beta$ in der Muttergesellschaft beteiligt werden.

481 Vgl. Wenz, M. (1995): Advance Corporation Tax in Großbritannien, in: IWB, Nr. 8 vom 26.4.1995, Fach 5, Gruppe 2, S. 347-364. 
Der Idee des Anrechnungssystems kann mit der Verbundaktie auch in einer Welt zunehmender multinationaler Unternehmen Geltung verschafft werden. Verbundaktien gewährleisten allerdings nur, daß inländische Gewinne von Kapitalgesellschaften an inländische Anteilseigner fließen können, ohne daß dies - wie es beim Umweg über ausländische Muttergesellschaften der Fall wäre - die Körperschaftsteueranrechnung ausschließt. Aus Sicht der Befürworter der Integrationstheorie mag dies positiv bewertet werden. Die Grenzen der Stapled Stocks macht es dennoch deutlich: Diese Finanzinnovation beseitigt nicht den Anrechnungsausschluß ausländischer Anteilseigner. Würde sie in Deutschland zugelassen, käme dies nicht einer Öffnung des körperschaftsteuerlichen Anrechnungssystems gleich. Somit ändern Verbundaktien auch nichts am generellen Anreiz für Steuerausländer aus Nicht-Vollanrechnungsländern, der deutschen Körperschaftsteuer durch Dividendenstripping und Gesellschafterfremdfinanzierung auszuweichen.

\subsection{Vorschläge zur Reform des Körperschaftsteuersystems}

Im Rahmen der Diskussion über eine veränderte Besteuerung der Steuerausländer und Überlegungen einer möglichen Reform des Körperschaftsteuersystems ist eine europäische juristische Besonderheit zu beachten: Für das Ende 1993 bestehende Recht gilt, daß eine Differenzierung von steuerlichen Vorschriften nach dem Wohnort auch künftig erlaubt ist. Ein neu eingeführtes Recht, das auf diese Differenzierung verzichtet, ist aber offenbar nicht rückgängig zu machen! Dies kann man aus Art. $73 \mathrm{~d}$ EGV und der Erklärung aus dem Schlußprotokoll zum Unionsvertrag schließen ${ }^{482}$. Einige Autoren bezeichnen diese Bestimmung daher auch als "Stillhalteklausel",483. Diese Besonderheit setzt möglicherweise dem Reformeifer gewisse Grenzen, bzw. erklärt das lange Festhalten am derzeitigen Körperschaftsteuersystem.

\subsubsection{Ausweitung des Anrechnungssystems}

Eine grenzüberschreitende Anrechnung wäre ein möglicher Weg aus der Diskriminierung von Steuerausländern gegenüber Steuerinländern in Anrechnungssystemen. Eine Ausdehnung der Anrechnungsberechtigung über die Grenze bedeutet die Abkehr vom vielbeschworenen Grundsatz der inländischen Einmalbesteuerung und die Zuwendung zum Grundsatz einer generellen Einmalbesteuerung.

482 Vgl. Geiger, R. (1995): EG-Vertrag, 2. Aufl., München 1995, S. 222, Rz. 2

483 Vgl. Dautzenberg, N. (1993): Zur notwendigen Reform der beschränkten Steuerpflicht aufgrund des Maastrichter Vertrages, IWB Fach 2, Nr. 11, 11.06.1993, S. 649. 
Die isolierende Wirkung von körperschaftsteuerlichen Anrechnungssystemen könnte so aufgebrochen werden. Die inländischen, allokativen Vorteile des Anrechnungsverfahrens blieben erhalten und könnten, je nach Ausprägung der grenzüberschreitenden Anrechnung, internationalisiert werden.

Es überrascht daher wenig, daß sich bei einer Unternehmensbefragung der Ruding-Kommission Anfang der neunziger Jahre über achtzig Prozent der befragten Unternehmen für ein europaeinheitliches körperschaftsteuerliches Anrechnungsverfahren aussprachen, das inländischen wie ausländischen Anteilseignern aus anderen EU-Staaten Steuergutschriften gewährt, die auf die nationale Einkommensteuer anrechenbar sind ${ }^{484}$.

\subsubsection{Einseitige Körperschaftsteueranrechnung}

Die Einführung einer einseitigen grenzüberschreitenden Anrechnung durch ein Land mit Anrechnungssystem wird von vielen Ökonomen für politisch undurchführbar gehalten, weil sie den fiskalischen Interessen der Staaten zuwiderlaufen ${ }^{485}$. Trägt nämlich das Wohnsitzland die Kosten der Steueranrechnung, dann müßte dieser Staat Entlastungen für eine Steuer gewähren, die er nicht selbst eingenommen hat. Das Wohnsitzland würde mit seinen eigenen Finanzmitteln Kapitalexporte subventionieren, was politisch schwer durchsetzbar sein dürfte.

Dennoch spricht einiges für eine Berücksichtigung ausländischer Körperschaftsteuern bei der inländischen Einkommensbesteuerung natürlicher Anteilseigner: Die internationale Doppelbelastung könnte wie die nationale Doppelbelastung beseitigt werden, Kapitalexportneutralität aus Sicht des inländischen Anteilseigners wäre - Anrechnungsüberhänge einmal vernachlässigt - erreicht, außerdem bestände nicht länger eine Begünstigung inländischer Muttergesellschaften, die in Deutschland und vielen anderen Ländern Gewinne ausländischer Tochtergesellschaften ohne zusätzliche inländische Körperschaftsteuer thesaurieren kann.

484 Vgl. Commission of the European Communities (1992)(Europarische Kommission): Report of the Committee of independent Experts on Company Taxation, Brüssel, Luxemburg 1992, S.119.

485 Vgl. Catalaens, H. (1993): Standortsicherung durch Anrechnung ausländischer Korperschaftsteuer?, in Steuer und Wirtschaft (StuW), 70. Jg./(1993), Nr. 3, S. 258; vgl. Saß, G. (1993): Steuerharmonisierung in der EG - Perspektiven fur eine Harmonisierung der Korrperschaftsteuer und der Gewinnermittlung, in: Der Betrieb (DB), 46. Jg. /(1993), Nr. 3, S. 117; vgl. Sato, M. /Bird R.M. (1975), a.a.O., S. 426ff. 
Auch der Finanzierungsneutralität käme man näher. Dividenden wären - wie im Ausland verdiente Zinsen - nicht länger doppelt steuerlich belastet ${ }^{486}$.

Neben den fiskalischen Problemen eines einseitigen Vorgehens ist aber zu bedenken, daß eine einseitige Anrechnung auch bei Ländern auf wenig Gegenliebe stoßen, die selbst ihren Anteilseignern keine Entlastung gewähren. In Ländern mit klassischem System wären ausländische Anteilseigner aus Ländern mit Anrechnungssystemen gegenüber Inländern steuerlich bessergestellt, da nur noch letztere der vollen Doppelbelastung unterliegen würden. Die bestehende Kapitalimportneutralität des klassischen Systems wäre im Zusammenspiel mit dem anrechnenden Land aufgehoben.

Trägt dagegen das Quellenland der Dividenden die einseitige Anrechnung, indem es auf Körperschaftsteuer verzichtet bzw. diese erstattet, so lockt es Kapitalimporte ins Land. Ein solches Verhalten löst in Extremfällen - z.B. wenn es nicht in DBA-Vereinbarungen abgesichert ist - steuerliche Retorsionsmaßnahmen im Ausland aus. Das Ausland könnte nämlich versucht sein, ein Land, das auf eine international übliche Körperschaftsteuer verzichtet, als Oasenland einzustufen und mit Maßnahmen zu bekämpfen, wie sie aus dem deutschen Außensteuerrecht bekannt sind.

Diese Überlegungen zeigen, daß einer Kapitalattrahierung selbst im Fall einseitiger Maßnahmen im Quellenland der Dividenden gewisse Grenzen gesetzt sind. Andererseits ist deutlich geworden, daß eine grenzüberschreitende Anrechnung ausländischer Körperschaftsteuer im Wohnsitzland letztlich nur auf Gegenseitigkeit zwischen Anrechnungsländern in Betracht kommt ${ }^{487}$. Hierfür sprechen ebenso fiskalische Gründe.

Folgerichtig weichen auch die Empfehlungen des Ruding-Reports von einer einseitigen Ausweitung der Körperschaftsteueranrechnung ab, wie sie einige Staaten als Quellenland der Dividenden zur Zeit praktizieren. Die Expertengruppe empfahl statt dessen für den Fall, daß sich die EU-Mitgliedsländer für ein gemeinsames Anrechnungssystem entscheiden, als ersten Schritt eine Ausweitung der Anrechnung auf Gegenseitigkeit also eine gegenseitige Anrechnung ${ }^{488}$.

486 Vgl hierzu ausführlich Krause-Junk, G. / Müller, R. (1997): Zur steuerlichen Behandlung von Ausschüttungen im Ausland verdienter Gewinne, in: Burmester, G. / Endres, D.(Hrsg): Aussensteuerrecht, Doppelbesteuerungsabkommen und EU-Recht im Spannungsverhältnis, Festschrift für H. Debatin zum 70. Geburtstag, München 1997, S. $255 \mathrm{ff}$.

Vgl. Saß, G. (1993), a.a.O., S. 117.

Vgl. Commission of the European Communities (1992), a.a.O., S. $443 \mathrm{f}$. 


\subsubsection{Gegenseitige Körperschaftsteueranrechnung}

Staaten mit Anrechnungssystemen können bilateral eine grenzüberschreitende Anrechnung der Körperschaftsteuer auf die Einkommensteuer im Wohnsitzland vereinbaren oder sich Erstattungen der Körperschaftsteuer auf Gegenseitigkeit einräumen. Im ersten Fall trägt wieder das Wohnsitzland, im zweiten Fall das Quellenland der Dividenden die Steuerausfälle. Unabhängig davon, welches Vorgehen gewählt wird, tritt das Problem ungleicher Fiskalkosten bei der bilateralen Körperschaftsteueranrechnung auf, wenn die Kapital- und Dividendenströme zwischen den betroffenen Volkswirtschaften nicht ausgeglichen $\operatorname{sind}^{489}$ oder wenn die beteiligten Länder die Körperschaftsteuer nur im unterschiedlichen Ausmaß anrechnen. Derartige Fiskalausfälle können möglicherweise durch Verhandlungen geteilt werden ${ }^{490}$. Im Fall unterschiedlicher Anrechnungsumfänge ist es allerdings dem Staat mit geringerem Anrechnungsumfang kaum zumutbar, daß er ausländische Körperschaftsteuern im höheren Ausmaß anrechnet als inländische Körperschaftsteuer, da andernfalls Investitionen im eigenen Land diskriminiert werden. Der Ruding-Ausschuß empfahl daher eine bilaterale Anrechnung des Wohnsitzlandes zu begrenzen auf den Anrechnungsumfang des Landes, das eine geringere Anrechnung gewährt ${ }^{491}$.

\subsubsection{Grenzüberschreitende Anrechnung von Körperschaftsteuern in anderen Ländern}

In der Praxis ist kein Fall einer Anrechnung ausländischer Körperschaftsteuer auf inländische Einkommensteuer durch das Wohnsitzland bekannt ${ }^{492}$. Allerdings ist ein solches (sogar einseitiges) Vorgehen vom Finanzausschuß des Deutschen Bundestages im Vorfeld des Standortsicherungsgesetzes vorgeschlagen worden ${ }^{493}$.

489 Vgl. van Raad, K. (1995): In a World where Classical and Integration Systems co-exist, Article 10 OECD Model should not disregard the Underlying Corporation Income Tax, in: IFA (Hrsg.): International Taxation of Dividends reconsidered in Light of Corporate Tax Integration, London u.a. 1995, S. 56.

490 Diese Möglichkeit besteht grundsătzlich auch bei unilateraler Körperschaftsteueranrechnung, vgl. Schuler, R.U. (1991): Korperschaftsteuerliche Aspekte der geplanten Unternehmenssteuerreform, Köln 1991, S. 171.

491 Vgl. Commission of the European Communities (Europarische Kommission) (1992), a.a.O., S. 444 .

Vgl. van Raad, K. (1995), a.a.O., S. 52. 
Der entsprechende Regierungsentwurf ${ }^{494}$, der eine begrenzte Körperschaftsteueranrechnung vorsah, fand jedoch im Bundesrat keine Mehrheit. Im nachfolgenden Kompromiß des Vermittlungsausschusses wurde die Anrechnung ausländischer Körperschaftsteuern auf die Einkommensteuer natürlicher Personen fallengelas$\operatorname{sen}^{495}$. Deutschland wäre bei Durchsetzung des Regierungsvorschlags somit das erste Land gewesen, das als Wohnsitzland sein Anrechnungssystem auf ausländische Körperschaftsteuern erweitert hätte.

Entgegen der deutschen Sichtweise, daß eine Entlastung durch Anrechnung ausschließlich Sache des Wohnsitzstaates sei, lassen sich in den OECD-Staaten nur Fälle finden, in denen Quellenländer durch (teilweisen) Verzicht auf die Besteuerung der Unternehmensgewinne eine grenzüberschreitende Anrechnung per Erstattung bzw. per Verrechnung mit anderen Steuern ermöglichen. Allerdings ist die Gewährung des Anrechnungsguthabens für ausländische Anteilseigner auch im Vorfeld zur Körperschaftsteuerreform von 1977 in Deutschland gefordert wor$\operatorname{den}^{496}$.

$\mathrm{Zu}$ diesen Staaten zählen Frankreich, Großbritannien, Finnland, Irland, Italien und Neuseeland. Die Anrechnungsgewährung erfolgt auf sehr unterschiedliche Weise. Dabei kann es sich natürlich nicht um eine tatsächliche Anrechnung durch das Quellenland handeln, weil das Quellenland den persönlichen Einkommensteuersatz des Anteilseigners in dessen Wohnsitzland nicht kennt. In der Praxis kommt das französische Vorgehen einer echten Anrechnung am nächsten. Die französische Körperschaftsteueranrechnung wird über das Wohnsitzland des Anteilseigners abgewickelt, sofern dieses Land in einem DBA mit Frankreich eine entsprechende Vereinbarung getroffen hat ${ }^{497}$.

494 Vgl. BR-Drs. 368/93, S. 11.

495 Bis heute wird allerdings noch mit der Vorlage eines modifizierten Vorschlags zur Anrechnung ausländischer Körperschaftsteuern bei natürlichen Anteilseignern gerechnet, vgl. Dötsch, E. / Cattelaens, H. / Gottstein, S. / Stegmüller, H. / Zenthöfer, W. (1995), a.a.O., S. 314.

496 Vgl. z.B. Rath, W.-D. (1976): Die Besteuerung ausländischer Muttergesellschaften und ihrer deutschen Tochtergesellschaften in Deutschland nach der Körperschaftsteuerreform, in: Betriebs-Berater (BB), 31. Jg. /(1976), Nr. 23, S. $1070 \mathrm{ff.}$

497 Vgl. z.B. das französische DBA mit Belgien (Art.15, Abs 2), Deutschland (Art. 20 Abs. 1b), Griechenland (Art. 21B), Großbritannien (Art. 9), Italien (Art.10 Abs.3b), den Niederlanden (Art. 10 Abs. 3a), Luxemburg (Art. 8 Abs. 3a), Portugal (Art. 24), Schweden (Art 10, Abs. 4) und Spanien (Art. 10 Abs. 4). 
Zur Zeit gewährt Frankreich Anteilseignern aus über dreißig Staaten eine Anrechnung durch Einräumung des "Avoir Fiscal" "498. Diese Anrechnung erhalten allerdings regelmäßig nur natürliche Personen mit Beteiligungen von unter $10 \%$, die im Vertragsstaat einkommensteuerpflichtig sind. Allein im DBA mit Italien wird die Körperschaftsteuergutschrift auch Kapitalgesellschaften per Erstattung gewährt. Eine Zwischenschaltungen weiterer nicht in Italien ansässiger Kapitalgesellschaften wurde ausgeschlossen, andernfalls wäre ein Export französischer Körperschaftsteuererstattungen über italienische Kapitalgesellschaften in Drittländer ermöglicht worden. Die französische Körperschaftsteueranrechnung erfolgt über den Fiskus im Wohnsitzland des Anteilseigners. Eine direkte Erstattung der Körperschaftsteuer durch die französische Steuerverwaltung ist nicht vorgesehen.

Die französische Anrechnung wurde schon unmittelbar nach Einführung des Anrechnungssystems, das zwischen 1966 und 1992 als Teilanrechnungssystem konzipiert war, auf ausländische Anteilseigner aus den wichtigsten Handelspartnerländern Frankreichs ausgedehnt. Entsprechend schnell begannen nach Einführung der damaligen Teilanrechnung auch die Neuverhandlung des DBA zwischen Frankreich und Deutschland. Dieses DBA räumt in einem Zusatzprotokoll seit 1970 für deutsche Dividendenempfänger rückwirkend zum 01.01.1968 die französische Anrechnung ein ${ }^{499}$. Deutschland ist das erste Land gewesen, dem Frankreich den "Avoir-Fiscal" eingeräumt hat. Ursache hierfür ist möglichweise die damals relativ niedrige deutsche Körperschaftsteuer auf ausgeschüttete Gewinne. Frankreich lief Gefahr, deutsche Anteilseigner im gegenseitigen Vergleich zu stark zu besteuern ${ }^{500}$. Die spätere Gewährung des Avoir-Fiscal in anderen DBA auch in DBA mit Nicht-EU-Ländern - läßt allerdings vermuten, daß Frankreich vor allem einen Abzug ausländischer Investoren verhindern wollte. Das französische Vorgehen entspricht einem echten Anrechnungsverfahren ${ }^{501}$. Es ermöglicht seit dem Übergang zum Vollanrechnungssystem im Jahr 1992 im erhöhten Aus$\mathrm{ma}$ eine Besteuerung der Dividende nach dem Leistungsfähigkeitsprinzip, ist aber aufgrund der Verrechnung mit der Steueradministration des Wohnsitzlandes mit einem relativ hohen Verwaltungsaufwand verbunden.

498 Vgl. de Fréminent, P. (1994): Perspective of France, in: IFA(Hrsg.): Corporate Tax on Distributions, Deventer 1994, S. 69ff.

499 Vgl. Bellier, L. (1970): Die Ausdehnung des französischen "avoir fiscal" auf die im Ausland ansässigen Aktionäre französischer Gesellschaften, in: Europäische Steuer-Zeitung, 0. Jg./(1970), Nr. 43, S. 129.

Vgl. Sato, M. / Bird, R.M. (1975), a.a.O., S. 437.

501 Zur technischen Abwicklung siehe Bellier, L. (1970), a.a.O., S. $132 f$. 
Einfacher erscheint im Vergleich das britische Verfahren. Das Teilanrechnungsland Großbritannien gewährt ausländischen Anteilseignern eine Steuergutschrift in Form einer Erstattung, sofern sie aufgrund fehlender britischer Steuerpflicht nicht in Großbritannien angerechnet werden kann. Voraussetzung für das Erstattungsverfahren ist ein entsprechender Antrag des Anteilseigners bei der zentralen Behörde für Erstattungen. Die um die Steuererstattung erhöhte Dividende unterliegt der Einkommensteuer im Wohnsitzland, insofern kann auch hier eine Besteuerung nach Leistungsfähigkeit durch das Wohnsitzland erfolgen.

Das Vereinigte Königreich hat diese Regelungen wie Frankreich nur in DBAVereinbarungen eingeräumt. So gewähren die DBA mit den USA und Kanada sowie mit fast allen EU-Staaten eine grenzüberschreitende Körperschaftsteuergutschrift $^{502}$. Deutsche Anteilseigner erhalten allerdings keine Erstattungen. Die britischen Vereinbarungen zur Erstattung bzw. Anrechnung der britischen Körperschaftsteuer gehen weiter als die französischen Abkommen, weil auch ausländische Kapitalgesellschaften in den Genuß der Regelungen kommen. Großbritannien gewährt Anteilseignern mit weniger als 10\%igen Beteiligungen die volle Steuergutschrift. bzw. Erstattung ${ }^{503}$. Eine hälftige Anrechnung bzw. Erstattung erhalten Anteilseigner mit höherer Beteiligungsquote. Kapitalgesellschaften, die zu mehr als 50\% von nichtansässigen Anteilseignern beherrscht werden, stehen allerdings keine Gutschriften zu. Auch aus Irland sind einseitige grenzüberschreitende Körperschaftsteuererstattungen bekannt ${ }^{504}$.

Andere Staaten räumen Teilanrechnungen nur auf Gegenseitigkeit ein. Italien gewährt ausländischen Anteilseignern nur dann eine Teilanrechnung, wenn deren Wohnsitzland ebenfalls eine Teilanrechnung den italienischen Anteilseignern einräumt. Daher hat Italien nur mit Frankreich und Großbritannien entsprechende Abkommen geschlossen ${ }^{505}$.

Auch Neuseeland - seit 1988 ein Land mit Vollanrechnungssystem - gewährt seit 1993 ausländischen Portfolioanlegern, seit 1996 allen ausländischen Anteilseignern eine spezielle Teilanrechnung. Der Inselstaat ist bestrebt, die Kapitalertrag-

502 Vgl. Thömmes, O. (1996): Grenzuberschreitende Anrechnung von Körperschaftsteuern, in: Herzig, N. (Hrsg.): Körperschaftsteuerguthaben bei grenzüberschreitenden Kooperationen, Köln 1996, S. 32.

$503 \mathrm{Ob}$ angerechnet oder erstattet wird, hängt davon $\mathrm{ab}$, ob ein Steuerausländer noch andere in Großbritannien steuerpflichtige Einkunfte erzielt oder nicht.

Vgl. z.B. Art. 10 DBA Irland-USA vom 28.07.1997.

Vgl. Cusson P (1996), a.a.O., S. 4. 
steuer so hoch wie möglich zu belassen, da diese im Wohnsitzland des ausländischen Anteilseigners angerechnet wird. Dagegen ermäßigt Neuseeland die inländische Körperschaftsteuer, die auf Gewinne an Ausländer entfällt durch einen sogenannten "Foreign Investor Tax Credit". Seit 1993 bzw. 1996 wird damit statt einer Körperschaftsteuer von $33 \%$ wird nur eine Steuer von $21,18 \%$ für den ausländischen Anteilseigner definitiv ${ }^{506}$. Die auf die verbleibende Ausschüttung fallende Kapitalertragsteuer von in der Regel 15\% kann sich der ausländische Anteilseigner üblicherweise im Wohnsitzland anrechnen lassen. Neuseeland hat damit die Besteuerung der ausländischen Anteilseigner ungefähr um die Kapitalertragsteuer verringert ${ }^{507}$. Hätte es nur auf die Kapitalertragsteuer verzichtet, wie dies z.B. in Australien geschieht, so wäre die Steuerersparnis nicht dem ausländischen Anteilseigner sondern dem Fiskus des Wohnsitzlandes zugute gekommen ${ }^{508}$. Allerdings ergeben sich auch im neuseeländischen Fall Mehreinnahmen für den ausländischen Fiskus, weil sich im Wohnsitzland die einkommensteuersteuerpflichtigen Dividenden erhöht haben.

\section{Zwischenfazit}

Die praktizierten Methoden grenzüberschreitender Körperschaftsteueranrechnungen entsprechen alle einem Besteuerungsverzicht des Quellenlandes der Dividenden. Abgesehen von Finnland und Italien gewähren die vorgestellten Staaten eine grenzüberschreitende Anrechnung ohne Reziprozität.

Eine Integration ausländischer Körperschaftsteuern durch das Wohnsitzland des Anteilseigners ist bisher in der Realtität nicht anzufinden, was vor allem am politischen Widerstand gegen solche Regelungen liegen dürfte, die in der Öffentlichkeit eher als Subventionierung der Kapitalflucht aufgefaßt werden.

506 Im Prinzip wird so ein ăhnlicher Effekt erreicht, wie er auch in einem Korperschaftsteuersystem mit gespaltenen Satz erreicht wird. Allerdings gilt hier die Ermaßigung nur fur Steuerauslănder, nicht aber für inländische Nichtanrechnungsberechtigte.

507 Vgl. Wilkinson, B. (1997): Dividend Imputation in the Context of Globalization - Extension of the New Zealand Foreign Investor Tax Credit Regime to Non-Resident Direct Investors, in: Bulletin for International Fiscal Documentation, Vol. 51/(1997), Nr. 8/9, S. 368.

508 Vgl. Smith, A. MC (1994): Dividend Imputation and International Equity Investment: Unilateral Extension of Imputation to Non-resident Investors, in: Australian Tax Forum, Vol. 11./(1994), S. 262. 


\subsubsection{Finanzwissenschaftliche Bewertung der grenzüberschreitenden Anrechung}

Auffällig ist, daß die französischen Regelungen die Portfolioanleger besser stellen als die ausländischen Direktinvestoren. Der Grund liegt offensichtlich darin, daß die internationalen DBA-Regelungen für Kapitalgesellschaften Maßnahmen zur Beseitigung der Doppelbesteuerung in Form der Freistellung und Anrechnung vorsehen. Geht man davon aus, daß vor allem Kapitalgesellschaften als Direktinvestoren auftreten, ist in der Tat eine grenzüberschreitende Anrechnung für ausländische Kapitalgesellschaften gar nicht nötig, sofern DBA-Regelungen bzw. unilaterale Maßnahmen des Sitzlandes der Muttergesellschaft zur Anrechnung der ausländischen Körperschaftsteuer bzw. zur Freistellung von einer inländischen Körperschaftsteuer führen. Dies gilt allerdings nur insoweit, wie man den Fall der Weiterausschüttung vernachlässigt. Trotzdem sehen das DBA Frankreich-Italien und britische Abkommen die Körperschaftsteuergutschrift auch für Kapitalgesellschaften vor, obwohl deren Beteiligungserträge aufgrund der DBA nicht doppelt besteuert werden. Hinter der in der Regel hälftigen Körperschaftsteuergutschrift für Kapitalgesellschaften steht die pauschale Annahme, daß die begünstigte ausländische Muttergesellschaft die Hälfte ihrer Beteiligungserträge an ihre Anteilseigner weiterauschüttet ${ }^{509}$. Ganz offensichtlich wollte man damit mittelbar und unmittelbar beteiligte ausländische Anteilseigner möglichst ähnlich behandeln.

Ein Grund für die einseitige grenzüberschreitende Körperschaftsteueranrechnung bzw. -erstattung dürfte die Attrahierung ausländischer Investitionen sein bzw. die Befürchtung, daß ausländisches Kapital bei einem Übergang vom klassischen System zum Anrechnungssystem abwandert ${ }^{510}$. Beleg hierfür ist der Zeitpunkt der britischen und französischen Anrechnungsausweitungen: Die meisten Vereinbarungen wurden sehr bald nach dem jeweiligen Wechsel des Körperschaftsteuersystems getroffen.

Ein interessanter Aspekt ist zudem die Gleichbehandlung der Besteuerung ausgeschütteter Gewinne zumindest auf der Ebene der Körperschaftsteuer, die unabhängig von der Struktur der Anteilseigner erfolgt ${ }^{511}$. Diese Gleichbehandlung besteht aber nur beim Streubesitz, weil in Frankreich und Großbritannien inländische und ausländische Anteilseigner mit Beteiligungen von über $10 \%$ nach wie vor ungleich behandelt werden. Dieses Vorgehen erzeugt damit bei weitem keine Kapitalim-

509 Vgl. Kessler, W. (1996): Die Euroholding, München 1996, S. 270.

510 Vgl. Krause-Junk, G. (1988): Überlegungen zu einem künftigen europäischen Körperschaftsteuersystem, in: Konjunkturpolitik, 34. Jg./(1988), Nr. 5/6, S. 275.

511 Vgl Krause-Junk, G. (1988), ebd., S. 275. 
portneutralität. Es entstehen im Vergleich zur Situation eines "Staying-Local" bei vielen grenzüberschreitenden Kooperationen von Kapitalgesellschaften Anrechnungsverluste für Anteilseigner ${ }^{512}$.

Allokativ vorteilhaft an einer bilateralen Anrechnung ohne Beschränkungen ist, daß der Kapitalfluß zwischen zwei Ländern mit Anrechnungssystemen nicht mehr automatisch diskriminiert wird. Sollte allerdings für ausländische Direktinvestitionen von Kapitalgesellschaften die Freistellung gelten, dann werden in Hochsteuerländern ausländische Portfolioanleger bzw. natürliche Personen gegenüber diesen Direktinvestoren steuerlich benachteiligt sein: Während für Direktinvestoren die niedrigere ausländische Körperschaftsteuer als Definitivbelastung wirkt, werden Portfolioanleger bei Anrechnung im Wohnsitzland auf das höhere inländische Besteuerungsnivau hochgeschleust. Die Anwendung unterschiedlicher Besteuerungsprinzipien - Wohnsitzlandprinzip für Portfolioinvestoren und Quellenlandprinzip für Direktinvestoren - kann man zwar vertreten, indem man einen höheren Wettbewerbsdruck der Direktinvestoren im Investitionsland unterstellt, aber die unterschiedlichen Besteuerungsprinzipien fordern steuerbedingte Gegenmaßnahmen heraus: In der oben genannten Situation werden Zusammenlegungen von Portfoliobeteiligungen in zwischengeschalteten Kapitalgesellschaften im Wohnsitzland der Anteilseigner angeregt.

Unabhängig von diesen Überlegungen gilt, daß eine grenzüberscheitende Körperschaftsteueranrechnung dem Dividendenstripping und der Gesellschafterfremdfinanzierung durch Steuerausländer den Boden entzieht. Zur Aufhebung des Dividendenstripping durch Portfolioanleger könnte bereits eine gegenseitige Teilanrechnung ausreichen, weil schon geringere Steuerguthaben die Risiken einiger Varianten des Dividendenstripping erhöhen. Sicherheit vor Dividendenstripping zur Weitergabe von Anrechnungsguthaben an Ausländer stellt sich allerdings erst bei gegenseitiger Vollanrechnung ein. Dies gilt noch mehr für die Gesellschafterfremdfinanzierung. Erst bei Vollanrechnung der Körperschaftsteuer im Wohnsitzland des Anteilseigners werden Zinsen und Dividenden - identische Steuersätze für Kapitaleinkommen vorausgesetzt - gleich besteuert.

Die gegenseitige (Voll-)Anrechnung bereitet aber Probleme im Verhältnis zu Drittstaaten. Gegenüber diesen Ländern verkompliziert sich unter Umständen die Durchsetzbarkeit des Anrechnungsausschlusses. Kessler verweist darauf, daß

512 Vgl. hierzu Modellrechnungen von Herzig, N., der am Beispiel einer Betriebseinbringung und eines Anteilstausches zwischen deutschen und französischen Unternehmen nachweist, daß den Anteilseignem beider Staaten regelmaßig steuerliche Nachteile durch Anrechnungsverluste entstehen. Vgl. Herzig, N. (1996): Anrechnungsverluste als steuerliches Hemnis grenzuberschreitender Kooperationen, in: Internationales Steuerrecht (IStR), 5. Jg./(1996), Nr. 4, S.196-200. 
grenzüberschreitende Körperschaftsteuergutschriften gerade auch Ausländern aus Drittstaaten neue Möglichkeiten der Erlangung von Körperschaftsteuererstattungen eröffnet ${ }^{513}$. Beispielsweise können auch deutsche Anteilseigner von der britischen Anrechnungsgewährung für Steuerausländer profitieren, obwohl die britische Anrechnung nicht im DBA Großbritannien-Deutschland vereinbart ist. Da das DBA Großbritannien-Dänemark diesen Vorteil gewährt, aber keine einschlägige Anti-Mißbrauchklausel enthält, können Anrechnungsguthaben unter Umständen über Dänemark an Anteilseigner in Drittstaaten weitergeleitet wer$\operatorname{den}^{514}$. Hier bietet sich die Zwischenschaltung einer Holdinggesellschaft in Dänemark an. Die Möglichkeit eines sogenannten Imputation-Credit-Shopping spricht also eindeutig gegen bilaterale Anrechnungsausdehnungen.

Deutlich wird dabei auch, daß eine gegenseitige Körperschaftsteueranrechnung nur eine Lösung sein kann, wenn möglichst viele - bestenfalls alle - Länder entsprechend verfahren. Existieren viele Länder mit klassischen System, so werden deren Einwohner immer motiviert sein, in Anrechnungsländern via Dividendenstripping oder Gesellschafterfremdfinanzierung eine Einmalbesteuerung ihrer Kapitalerträge zu erlangen. So vorteilhaft die gegenseitige, grenzüberschreitende (Voll)-Anrechnung sein mag - letztlich werden die positiven Eigenschaften des Anrechnungssystems internationalisiert, so wenig werden die aufgezeigten Steuervermeidungsstrategien im Verhältnis zu Drittstaaten verhindert.

Hinzu kommen fiskalische und administrative Probleme: Konflikte um die Steueraufkommensverteilung sind insbesondere bei unausgeglichenen Dividendenströmen und gegenseitiger Anrechnung vorprogrammiert. Man denke nur an die Diskussion um die Steueraufkommensverteilung im Zusammenhang mit der Einführung eines europäischen Mehrwertsteuersystems nach dem Ursprungslandprinzip. Bei unausgeglichenenen Kapitalströmen ist wahrscheinlich ein vereinbarter Höchststeuersatz für die Körperschaftsteuer notwendig, andernfalls könnten Kapitalimportländer mit hohen Steuersätzen vollanrechnende Kapitalexportländer um jedes Steueraufkommen aus ausländischen Dividenden bringen. Ein Minimalkompromi $\beta$ a la Ruding-Report, die Anrechnung nur jeweils im niedrigeren Umfang auf Gegenseitigkeit zu gewähren, könnte diese Problem entschärfen. Freilich werden dann aber die allokativen und distributiven Ziele der Integration verfehlt. Außerdem scheint diese Lösung aus administrativer Sicht wenig attraktiv, weil die Steuerbehörden gezwungen wären, auf jede ausländische Dividende andere Anrechnungssätze anzuwenden.

513 Vgl. Kessler, W.: Grenzüberschreitende Körperschaftsteuer-Gutschriften - Gestaltungsmöglichkeiten nach geltendem Recht, in: Internationales Steuerrecht (IStR), 4.Jg./(1995), Nr. 8, S. 405-408; ders. (1996), a.a.O., S. $291 \mathrm{f}$.

514 Vgl. Kessler, W. (1995), a.a.O., S. 408 


\subsubsection{Alternative Körperschaftsteuersysteme}

Das Problem der unterschiedlichen Behandlung inländischer und ausländischer Anteilseigner läßt sich auch mit einer Abkehr vom Anrechnungssystem lösen. Es bieten sich alternative Körperschaftsteuersysteme an, z.B. die Rückkehr zum klassischen System, sofern eine generelle volle Doppelbelastung in Kauf genommen werden soll. Weiter kann eine Minderung oder Beseitigung der Doppelbelastung auf die Ebene der Gesellschaft verlagert werden. Denkbar ist ebenfalls eine Freistellung der Dividenden bei den Empfängern.

\subsubsection{Rückkehr zum klassischen System?}

Vor allem aufgrund der internationalen Eigenschaften des klassischen Systems ist dieses Körperschaftsteuersystem in jüngerer Zeit öfter vorgeschlagen worden, wobei häufig eine Milderung der Doppelbelastung im begrenzten Umfang wurde empfohlen wurde ${ }^{515}$.

Steuerinländer und Steuerausländer werden gleichbehandelt. Beide Gruppen unterliegen der Doppelbelastung. Vernachlässigt man Steuersatzdifferenzen, so ist Kapitalexportneutralität und Kapitalimportneutralität für unmittelbaren Beteiligungsbesitz erreicht. Für mittelbare Beteiligungen gilt entsprechendes, sofern es aufgrund von unilateralen Maßnahmen oder eines DBA nicht zu einer Doppelbesteuerung von Gewinnen mit inländischer und ausländischer Körperschaftsteuer kommt. Anteilseigner können der Doppelbelastung des klassischen Systems allerdings durch "ewige" Thesaurierung und via Fremdfinanzierung zumindest teilweise entgehen. Dies gilt auch für Auslandsinvestitionen.

Das klassische System beseitigt zwar naturgemäß das Dividendenstripping um Anrechnungsguthaben. Die Tatsache, daß das Problem der Gesellschafterfremdfinanzierung im klassischen System ungelöst bleibt, nimmt dieser Systemalternative aber viel Reiz. Berücksichtigt man die zusätzlichen Aspekte, die aus allokativer und distributiver Sicht gegen dieses Körperschaftsteuersystem sprechen, so kann eine solche Lösung kaum attraktiv erscheinen. Der Preis für die Beseitigung des Dividendenstripping um Körperschaftsteuerguthaben erscheint letztlich zu hoch.

515 In diese Richtung geht der Shareholder-Relief-Vorschlag im Anhang zum Ruding-Report; vgl. Commission of the European Communities (Europäische Kommission)(1992), a.a.O. S. 446ff. Ähnlich auch der Reformvorschlag von Betten, der einen ermäßigten Einkommensteuersatz enthalt; vgl. Betten, R. (1992): A Proposed EC System for the Taxation of Corporate Income and Dividends, in: European Taxation, Vol. 32/(1992), Nr. 1, S. $8 \mathrm{ff}$. 


\subsubsection{Körperschaftsteuersysteme mit Entlastungen auf Gesellschafts- ebene}

Auf der Gesellschaftsebene kann die Doppelbelastung durch eine Ermäßigung der Körperschaftsteuer erreicht werden. Dafür stehen zwei Wege offen, die bei genauerem Hinsehen identisch sind:

1. Das System mit ermäßigten Ausschüttungssteuersatz

2. Das Dividendenabzugssystem

Im Ergebnis entsprechen sich ein System mit gespaltenem Körperschaftssteuersatz und das Dividendenabzugssystem ${ }^{516}$. Beide Systeme beseitigen naturgemäß das Dividendenstripping. Besonders interessant ist, daß beide Systeme - allerdings nur bei voller Beseitigung der Doppelbelastung - Eigenkapitaleinbringungen und Fremdkapitaleinbringungen von Steuerinländern und Steuerausländern gleichbehandeln. Es entsteht also auch kein steuerlicher Anreiz für Gesellschafterfremdfinanzierungen. Zwar mildern beide Systeme - je nach ihrer Ausgestaltung - die Doppelbelastung ausgeschütteter Gewinne. Dennoch weisen sie beachtliche allokative und distributive Unterschiede im Vergleich zum Vollanrechnungssystem auf, da durch einen pauschalen (ermäßigten) Körperschaftsteuersatz alle im zweiten Kapitel vorgestellten Neutralitätspostulate verletzt werden. Auch eine Berücksichtigung der Leistungsfähigkeit des Anteilseigners bei der Besteuerung der Bruttodividende wird nicht erreicht. Nur ein Ausschüttungssatz von $0 \% \mathrm{bzw}$. die volle Abziehbarkeit der Dividenden könnte diese Nachteile verhindern.

Systeme, die auf der Gesellschaftsebene die Doppelbelastung mildern, weisen weiterhin einen Nachteil auf: Sie leiden an einer starken Anfälligkeit für Steuerhinterziehungen. Je stärker die Doppelbelastung auf Gesellschaftsebene beseitigt wird, desto mehr verlagert sich die Besteuerung der Bruttodividenden auf den Dividendenbezieher. Der Dividendenbezieher erhält keinen Anreiz, den Dividendenbezug steuerlich zu deklarieren. Daher erfordern diese Systeme relativ hohe Kapitalertragsteuern, die von der ausschüttenden Kapitalgesellschaft abzuführen sind. Das aber mindert die administrative Einfachheit, die man diesen Systemen auf den ersten Blick vielleicht zuschreiben mag, bedeutend.

Im internationalen Steuerrecht setzen sich aber - wie früher festgestellt - seit Jahren niedrigere Kapitalertragsteuersätze durch. So erzwang die EU mit dem Wegfall der Kapitalertragsteuer auf Dividenden aus wesentlichen Beteiligungen letztlich in Griechenland die Abschaffung eines Dividendenabzugssystems mit voller Abziehbarkeit. Wegen der Hinterziehungsanfälligkeit dieses Systems erhob Grie-

516 So entsprechen sich z.B. ein System mit einem Ausschüttungssatz von $0 \%$ und ein Dividendenabzugssystem mit vollständiger Abziehbarkeit der ausgeschütteten Gewinne. 
chenland damals (bis 1992) Kapitalertragsteuern in Höhe von $42 \%$ bis $50 \%$, die die griechische Körperschaftsteuer sogar noch überstiegen. Alternativ hätte man natürlich mit Pflichtmeldungen an das Finanzamt das Hinterziehungsproblem angehen können, damit wären aber ausländische Dividendenbezieher kaum ohne internationale Zusammenarbeit zu disziplinieren gewesen. Da Staaten mit Dividendenabzugssystemen heute in der Regel große Schwierigkeiten haben, hohe Kapitalertragsteuersätze für Steuerausländer durchzusetzen ${ }^{517}$, läge die fiskalische Last der Beseitigung der internationalen Doppelbelastung immer bei diesen Ländern. Körperschaftsteuersysteme mit Entlastung auf der Gesellschaftsebene können damit kaum eine Alternative zum Anrechnungssystem sein.

\subsubsection{Dividendenfreistellung}

Die Dividendenfreistellung stellt das Gegenstück des Dividendenabzugssystems dar: Die Kapitalgesellschaft zahlt Körperschaftsteuer auf ihren Gewinn unabhängig von der Gewinnverwendung; im Ausschüttungsfall bleiben die Dividenden beim Empfänger außerhalb der einkommensteuerlichen Bemessungsgrundlage. Für die Kapitalgesellschaft besteht Gewinnverwendungsneutralität und partielle Finanzierungsneutralität bezüglich der Eigenfinanzierungsformen ${ }^{518}$. Umfassende Finanzierungsneutralität kann dagegen nur zufällig bestehen, wenn ein Anteilseigner mit Zinseinkünften einer Einkommensteuer unterliegt, die der Körperschaftsteuer zufällig entspricht.

Im Fall einer grenzüberschreitenden, generellen Dividendenfreistellung wäre die steuerliche Belastung der Ausschüttung im Quellenland definitiv, während Dividenden im Wohnsitzland ohne weitere Besteuerung an die Anteilseigner durchgeleitet werden ${ }^{519}$. Die Freistellung kann dabei unabhängig davon sein, ob der Anteilseigner eine natürliche oder eine juristische Person ist und ob er eine wesentliche oder eine geringere Beteiligung hält. Eine Einführung der Dividendenfreistellung bedeutet also einerseits eine Erweiterung des DBA-Schachtelprivilegs auf Minderbeteiligungen $^{520}$. Andererseits scheint die Dividendenfreistellung eine verlockend einfache Lösung für die Steuerhinterziehungsprobleme der internationalen Kapitaleinkommensteuer zu sein. Das System erlaubt sogar die Abschaffung

517 Vgl. Vogel, K. (1996), a.a.O., S. 782.

518 Wertzuwachssteuern oder Veräußerungsgewinnsteuern seien an dieser vernachlässigt.

519 Vgl. Pumbo, M. (1995), a.a.O., S. 134.

520 Vgl. Wisser, L. (1992), a.a.O., S. 188. 
jeglicher Kapitalertragsteuer auf Dividenden in nationaler wie internationaler Hinsicht.

Eine einmalige Besteuerung im Quellenland beseitigt mit der Anrechnung auch den Handel mit Anrechnungsguthaben. Die Ansicht, daß zugleich die Gesellschafterfremdfinanzierung an Attraktivität verliert ${ }^{521}$, ist dagegen fraglich. Entscheidend ist, ob die Besteuerung der Zinsen im Wohnsitzland des Investors höher oder niedriger ist als die Ausschüttungsbesteuerung im Quellenland ${ }^{522}$. Ist diese Besteuerung höher, so wird die Gesellschafterfremdfinanzierung lohnend sein. Die Gesellschafterfremdfinanzierung ist in einem Regime der multilateralen Dividendenfreistellung nur dann mit letzter Sicherheit nicht mehr attraktiv, wenn die Besteuerung aller Kapitalerträge im Quellenland zum gleichen Steuersatz erfolgt und das Wohnsitzland neben Dividenden auch Zinsen von der Besteuerung freistellt. Grubert und Mutti weisen nach, daß eine Abschaffung des Zinsabzugs in Verbindung mit einer Zins- und Dividendenfreistellung im Investitionsland zu einem kräftigen $A b f l u ß$ fremdfinanzierter ausländischer Investitionen führen muß, wenn Steuerausländer in ihrem Wohnsitzland keine entsprechende Zins- und Dividendenfreistellung erhalten ${ }^{523}$. Ein solches System der "rückwärtigen Integration" Grubert und Mutti sprechen von "backward integration" - wäre ein radikaler Bruch mit der bisherigen nationalen und internationalen Besteuerung von Kapitalerträgen. Könnte man sich international auf dieses Vorgehen einigen, so wäre die Durchsetzung des Quellenprinzips bei der Kapitaleinkomensbesteuerung erreicht. Das Quellenlandprinzip wäre damit allerdings nicht zwingend, denn die Steuereinnahmen könnten natürlich auch zwischen den Ländern geteilt werden. Auf diese Weise wäre Kapitalimportneutralität in allen Ländern erfüllt. Bei einem internationalem Vorgehen wäre auch Kapitalexportneutralität erreichbar. Steuerbedingte Anreize zur Gesellschafterfremdfinanzierung bzw. Wege zur Erlangung von Anrechnungsguthaben wären beseitigt. Angesichts der $\mathrm{zu}$ beobachtenden Hinterziehbarkeit der Kapitaleinkommen im Wohnsitzländer - man denke insbesondere an Zinsbesteuerung - scheint dieses Vorgehen am meisten zu überzeugen. Vorausetzung ist aber eine Einigung möglichst vieler Länder auf eine Mindestbesteuerung.

Vor allem aus distributiver Sicht steht dieser Ansatz allerdings in der Kritik. Die interstaatliche Steuergerechtigkeit wäre verletzt, sofern es keine ausgeglichenen

521 Diese Ansicht vertritt u.a. Wisser, vgl. Wisser, L (1992), a.a.O., S.188.

522 Auch die Möglichkeiten der Hinterziehbarkeit der Zinseinkünfte dürfte eine Rolle spielen.

523 Vgl. Grubert, H. / Mutti, J. (1994): International Aspects of Corporate Tax Integration: The contrasting Role of Debt and Equity Flows, in: National Tax Journal, Vol. 47/(1994), S. $125 \mathrm{ff}$. 
Investitionsströme zwischen den Ländern gäbe. In diesem Fall könnte zwar eine Korrekturverrechnung, z.B. in Form eines Clearingsystems, die Wohnsitzländer an den Fiskaleinnahmen beteiligen. Dabei entsteht jedoch automatisch ein relativ hoher Verwaltungsaufwand. Die grenzüberschreitende Dividendenfreistellung, bzw. noch mehr die rückwärtige Integration, dürfte aber noch mehr Kritik hinsichtlich der Verletzung der interpersonnellen Gerechtigkeit hervorrufen: Bei ausschließlicher Quellenlandbesteuerung muß eine Pauschalbesteuerung erfolgen. Folglich könnte auch nicht mehr nach Aspekten des Leistungsfähigkeitsprinzips besteuert werden; horizontale und vertikale Steuergerechtigkeit wäre nicht mehr. Die Kapitaleinkommensbesteuerung wäre aus der synthetischen Einkommensbesteuerung herausgelöst, bzw. letztere würde nicht mehr existieren. Genau in diese Richtung weisen einige nationale Steuerreformen in Skandinavien.

Trotz dieser Einwände erscheint eine einheitliche Flat-Rate-Besteuerung aller Kapitaleinkommensarten an der Quelle überzeugender (letztlich sogar aus distributiver Sicht) als die Alternative: der ungewollte Verzicht auf eine Besteuerung aufgrund von Hinterziehungen.

\section{Zusammenfassung und Fazit}

Im Ergebnis kann man festhalten, daß eine bilaterale Ausweitung der Anrechnung die Hinterziehungsanfälligkeit des körperschaftsteuerlichen Anrechnungssystems nicht beseitigt, solange es noch viele Länder mit klassischem Körperschaftsteuersystem gibt. Die Abkehr vom Anrechnungssystem ist eine relativ radikale Lösung für die behandelten Probleme. Allerdings fuihren alternative Körperschaftsteuersysteme zu anderen Schwierigkeiten. Soweit es sich um klassische Systeme handelt, wird gegen zahlreiche Neutralitätspostulate verstoßen, distributive Anforderungen bleiben ebenfalls unerfüllt. Steuersysteme, die Wettbewerbsnachteile für junge und wachsende Unternehmen beinhalten, lassen sich im übrigen auch stabilitätspolitisch - man denke nur an die brennenenden Beschäftigungsfragen - kaum rechtfertigen.

Die gleiche Kritik trifft Körperschaftsteuersysteme, die auf der Unternehmensebene die Doppelbelastung nicht völlig beseitigen. Darum stellen auch diese Systeme keine Alternative zum Anrechnungssystem dar. Die Dividendenfreistellung wirkt dagegen aus allokativer Sicht attraktiver. Zwar wird hier das Prinzip der Leistungsfähigkeit hinsichtlich der Kapitaleinkommensbesteuerung verletzt. Dies kann aber deswegen eher akzeptiert werden, weil auch im derzeitigen Steuersystem an der Verwirklichung dieses Prinzips inzwischen gezweifelt werden muß. Gerade hinsichtlich der internationalen Kapitaleinkommensbesteuerung - und hier insbesondere der Besteuerung von Zinsen - ist offenkundig, daß nach Leistungsfä- 
higkeit höchstens noch Steuerehrliche und Unwissende besteuert werden. Insofern erscheint eine Quellenbesteuerung aller Kapitaleinkommen, international gesehen also eine Quellenlandbesteuerung, als das kleinere Übel.

Die Besteuerung grenzüberschreitender Kapitalerträge wird künftig eher im Quellenland gewährleistet werden können und das auch nur, wenn substitierbare Kapitaleinkommensarten gleich besteuert werden. So gesehen befindet sich das nordische Steuermodell auf dem richtigen Weg, es müßte "nur" international angewendet werden und zwar auch auf grenzüberschreitende Kapitaleinkommen. Wie am Beispiel Finnlands und Norwegens schon deutlich gemacht wurde, könnte dieses Steuermodell durchaus mit einem Anrechnungssystem verbunden werden, allerdings entspräche das System de facto einer Dividendenfreistellung ${ }^{524}$. Dividendenstripping um Anrechnungsguthaben stellt hier kein praktisches Problem mehr dar - selbst das tarifbedingte Dividendenstripping hätte sich erledigt. Um internationales Kapitaleinkommen tatsächlich gleich zu besteuern, müßte die Abziehbarkeit von Zinsen beseitigt werden und eine Besteuerung beim Schuldner erfolgen. Thin-Capitalization-Rules bewirken genau dies, allerdings nicht konsequent genug; konsequenter wäre hier die erörterte Abkehr vom Wohnsitzlandprinzip.

Bei aller Kritik an der mangelnden Berücksichtigung distributiver Ziele darf man nicht übersehen, daß eine kapitalattrahierende Steuerpolitik Wachstums- und Beschäftigungsergebnisse erzielen kann, die über ein erhöhtes Steueraufkommen auch dem Staat die Möglichkeit geben, distributive und stabilitätspolitische Ziele zu verwirklichen.

524 In Norwegen wird Körperschaftsteuer von $28 \%$ erhoben, der Anteilseigner erhält die Nettodividende (Dividende abzgl. Körperschaftsteuer) und hat hierauf eine Flat-Rate-Tax von 28\% (Kapitaleinkommen) zu entrichten, die genau der Körperschaftsteueranrechnung entspricht, insofern ist die Nettodividende von ihm nicht weiter zu versteuern. Vgl. International Bureau of Fiscal Documentation (Hrsg.)(1998), a.a.O., S. 355, S. 363. 


\section{Schlußfolgerungen und ein Lösungsvorschlag}

Die weltweite Liberalisierung der Kapitalmärkte, sowie insbesondere die Schaffung des Gemeinsamen Marktes in Europa, haben zu einer zunehmenden Globalisierung der Unternehmenstätigkeit geführt. Bezogen auf Europa ist auch weiterhin mit einer wachsenden Verflechtung der nationalen Märkte zu rechnen, dafür spricht sowohl die Währungsunion zwischen elf EU-Staaten als auch die mittelfristig zu erwartende Osterweiterung der Europäischen Union.

Die national konzipierten Steuersysteme, die Grundsätze wie eine inländische Einmalbesteuerung stur verfolgen - sogar da, wo dies aussichtlos erscheint - lassen den Spruch "business go global, taxes stay local" als treffende Zustandsbeschreibung erscheinen. Die nationale Beschränkung des deutschen Vollanrechnungssystems steht im Widerspruch zur weltwirtschaftlichen Entwicklung. Schlimmer noch: Chancen, die sich aus Marktöffnungen ergeben, werden aus steuerlichen Gründen nicht genutzt: Das Anrechnungssystem in seiner aktuellen Form versucht Märkte zu segmentieren, die sich kaum noch segmentieren lassen.

Wie in dieser Arbeit deutlich wurde, läßt sich der Anrechnungsausschluß von Steuerausländern offenkundig nicht gewährleisten. Sowohl die früheren Maßnahmen gegen die Weitergabe von Anrechnungsguthaben, als auch die aktuellen Gesetze zur Unterbindung des Dividendenstripping zeichnen sich durch Umgehbarkeit, mangelnde Praktikabilität und negative Auswirkung in allokativer und distributiver Hinsicht aus. Finanzmarktkontrollen und / oder eine Veräußerungsgewinnbesteuerung allein auf ausländische Anteilseigner können hier keine passende Antworten zu sein.

Hinsichtlich der Unterkapitalisierungsvorschriften fällt vor allem die Umgehbarkeit der gesetzlichen Gegenmaßnahmen auf. Die Regelungen zur Gesellschafterfremdfinanzierung durch Steuerausländern scheinen überhaupt nur den Zweck zu erfüllen, daß wirtschaftspolitische Eingeständnis zu vermeiden, daß grenzüberschreitende Kapitalströme nur schwer zu besteuern sind, solange unterschiedliche Besteuerungsprinzipen auf austauschbare Kapitaleinkomensarten angewendet werden. Für die "Alibi-Funktion" des Gesetzes und seine geringe Wirksamkeit spricht auch, daß entgegen anderen Erwartungen bis heute noch niemand vor das Bundesverfassunggericht gezogen ist, um seine Abschaffung zu erstreiten.

Die Benachteiligung ausländischer Anteilseigner in Anrechnungssystemen kann auch nicht durch den Einsatz von Verbundaktien aufgehoben werden. Nur in Einzelfällen kann diese relativ komplizierte Finanzinnovation die internationale Doppelbelastung von Steuerausländern bilateral aufheben, nämlich zwischen Vollanrechnungsländern. Um die Schlußlichtstellung des deutschen Standortes hinsicht- 
lich ausländischer Investitionen und Kapitalanlagen zu verbessern, scheint es aber sinnvoll, nicht auf die Verbundaktie zu hoffen, sondern das Körperschaftsteuersystem investitionsfreundlicher zu gestalten. Kurzfristig gesehen, - sozusagen als Second-best-Lösung - bietet sich die Ausdehnung des Anrechnungssystems auf Gegenseitigkeit an, grundsätzlich könnten die allokativen und distributiven Vorteile des Anrechnungssystems so bewahrt werden. Allerdings werden die behandelten Hinterziehungsmodelle nicht vollständig beseitigt, solange nur bilateral zwischen Anrechnungsländern eine Anrechnung gewährt wird, ansonsten aber viele Länder mit klassischen Systemen existieren. Außerdem schlägt der administrative Aufwand einer solchen Regelung negativ zu Buche.

Zur kompletten Beseitigung der Hinterziehungsmodelle scheint dagegen eher ein Dividendenfreistellungssystem eingebettet in ein Dual-Income-System mit niedriger aber konsequenter Besteuerung der Kapitaleinkommen an der Quelle sinnvoll. Freilich leidet das Dual-Income-System wiederum an der Umdeklarierung von Arbeitseinkommen in Kapitaleinkommen, so daß andere Steuerumgehungswege zu kontrollieren wären. Aus internationaler Sicht sollte eine konsequente Besteuerung von Kapitaleinkommen an der Quelle auch eine Zinsbesteuerung im Quellenland beinhalten. Eine solche Regelung, die die Voraussetzungen für Kapitalimportneutralität schafft, schließt auch Kapitalexportneutralität nicht aus, sofern man sich international auf eine Mindestbesteuerung einigen könnte, um auf diese Weise einen potentiellen ruinösen Steuerwettbewerb zu verhindern. Es ist nur eines zu befürchten: soviel internationale Kooperation in der Steuerpolitik ist kurzfristig kaum zu erwarten. 


\section{Abkürzungsverzeichnis}

a.a.O.

Abs.

ACT

a.F.

AO

Art.

Aufl.

BB

Bd.

BDA

BdB

BDI

BFH

BGA

BGBl

BMF

BMJ

BR-Drs.

BStBl.

BT-Drs.

Buchst.

bzw.

DB

DBA

ders.

d.h.

DIHT

DStJG

DStR

DStZ

ebd.

EC

EG

EGV

EK

Erg-Lfg.

EstG

EU

EuGH

EWG
Am angegebenen Ort

Absatz

Advanced Corporation Tax

Alte Fassung

Abgabenordnung

Artikel

Auflage

Betriebs-Berater (Zeitschrift)

Band

Bundesvereinigung der deutschen Arbeitgeberverbände

Bundesverband deutscher Banken

Bundesverband der Deutschen Industrie

Bundesfinanzhof

Bundesverband des Deutschen Groß- und Außenhandels

Bundesgesetzblatt

Bundesministerium der Finanzen

Bundesministerium der Justiz

Bundesratsdrucksache

Bundesteuerblatt

Bundestagsdrucksache

Buchstabe

Beziehungsweise

Der Betrieb (Zeitschrift)

Doppelbesteuerungsabkommen

Derselbe

das heißt

Deutscher Industrie- und Handelstag

Jahrbuch der Deutschen Steuerjuristischen Gesellschaft

Deutsches Steuerrecht

Deutsche Steuerzeitung

Ebenda

European Community

Europäische Gemeinschaft

EG-Vertrag

Eigenkapital

Ergänzungslieferung

Einkommensteuergesetz

Europäische Union

Europäischer Gerichtshof

Eurpäische Wirtschaftsgemeinschaft 
f.

FA

ff.

FK

FR

GDV

$\mathrm{GmbH}$

GmbHG

HDE

HGB

Hrsg.

IBFD

IFA

IMF

IstR

Intertax

IWB

Jg.

$\mathrm{KStG}$

Lfg.

MA

n.F.

NF.

$\mathrm{Nr}$.

NWB

OECD

o.J.

o.V.

ÖStZ

Plc

RFH

RIW

Rz.

SA

s.

S.

$\mathrm{Sec}$

SICAV

sog.

StandOG

StbJB

StMBG folgende

Finanzarchiv (Zeitschrift)

fortfolgende

Fremdkapital

Finanz-Rundschau (Zeitschrift)

Gesamtverband der Deutschen Versicherungswirtschaft

Gesellschaft mit beschränkter Haftung

GmbH-Gesetz

Hauptverband des Deutschen Einzelhandels

Handelsgesetzbuch

Herausgeber

International Bureau of Fiscal Documentation

International Fiscal Association

International Monetary Fund

Internationales Steuerrecht (Zeitschrift)

International Taxation Review

Internationale Wirtschafts-Briefe

Jahrgang

Körperschaftsteuergesetz

Lieferung

Musterabkommen

neue Fassung

Neue Folge

Nummer

Neue Wirtschafts-Briefe

Organisation for Economic Cooperation and Development

ohne Jahr

ohne Verfasser

Östereichische Steuer-Zeitung (Zeitschrift)

Public limited company

Reichsfinanzhof

Recht der Internationalen Wirtschaft

Randziffer

Societe Anonyme

Siehe

Seite

Section

Investment Companies with Variable Capital

Sogenannt(e)

Standortsicherungsgesetz

Steuerberater-Jahrbuch

Gesetz zur Bekämpfung des Mißbrauchs und zur Bereinigung des 
Steuerrechts

StuW

SVR

u.a.

u.a. (+ Ortsname)

u.a. (+ Personennamen)

vgl.

Vol.

Vorl.

WPg

z.B.

$\mathrm{ZDH}$

z.Z.
Steuer und Wirtschaft (Zeitschrift)

Sachverständigenrat

Unter anderem

und andernorts

und andere

Vergleiche

Volume

Vorläufig

Die Wirtschaftsprüfung (Zeitschrift)

zum Beispiel

Zentralverband des Deutschen Handwerks

zur Zeit 
Hans-Werner Seiler - 978-3-631-75261-6

Downloaded from PubFactory at 01/11/2019 06:36:03AM

via free access 


\section{Literaturverzeichnis}

Aidin, M. R. (1996): The British Perspective, in IFA (Hrsg.): Dividend Access Shares (Stapled Stocks), Den Haag u.a. 1996, S. 49-61.

Altheim, M. (1995): Gestaltungsspielräume nach Einführung des $\S 8 \mathrm{a} \mathrm{KStG}$ (Teil

I), in: Internationales Steuerrecht (IStR), 4. Jg./(1995), Nr. 8, S. 373-377.

Altvater, C. (1997): Zur Anwendung des $\S 50 \mathrm{c} \mathrm{EStG}$ auf den Anteilserwerb von Anrechnungsberechtigten, in: Betriebs-Berater (BB), 52. Jg./(1997), Nr. 49, S. 2510-2513.

Alworth, $J$. (1988): The finance, taxation and investment decision of mulitnationals, Oxford 1988.

Ammelung, $U$. (1995): Das BMF-Einführungschreiben zu $\S 8 \mathrm{a} \mathrm{KStG}$, in: GmbHRundschau, 86. Jg./(1995), Nr. 2, S. 93-99.

Baranowski, K.-H. (1996): Besteuerung von Auslandsbeziehungen, 2. Aufl., Herne u.a. 1996.

Bati, A. (1993): Japan: Taxation of Dividends and Interest, in: Bulletin for International Fiscal Documentation, Vol. 47/(1993), Nr. 4, S. 202-210

Bay, W. (1990): Dividenden, Steuern und Steuerreformen. Ein internationaler Vergleich, Wiesbaden 1990

$B D I, D I H T, Z D H, B G A, H D E, B d B, B D A, G D V$ (1997): Gemeinsame Eingabe vom 17. September 1997 an das BMF, BMJ und BMWi zum Gesetz zur Fortsetzung der Unternehmenssteuerreform, Bonn 1997.

Becker, H. (1985): Neuere steuerliche Entwicklungen auf dem Gebiet der internationalen Unternehmensfinanzierung, in: Institut für Ausländisches und Internationales Finanz- und Steuerwesen (Hrsg.): Hefte zur Internationalen Besteuerung, Nr. 12, Hamburg 1985.

Bellier, L. (1970): Die Ausdehnung des französischen "avoir fiscal" auf die im Ausland ansässigen Aktionäre französischer Gesellschaften, in: Europäische Steuer-Zeitung, o. Jg./(1970)., Nr. 43, S. 127- 138.

Bellstedt, C. (1995): Das Einführungsschreiben zu $§ 8 \mathrm{a} \mathrm{KStG,} \mathrm{in:} \mathrm{Der} \mathrm{Betrieb}$ (DB), 48. Jg./(1995), Nr. 1, S. 8-14.

Betten, R. (1992): A Proposed EC System for the Taxation of Corporate Income and Dividends, in: European Taxation, Vol. 32/(1992), Nr. 1, S. 7-12.

Bippus, B. E. (1994); Dividenden-Stripping - Strategien zur Vermeidung der Besteuerung inländischer Dividendenerträge ausländischer Anteilseigner, in: Recht der Internationalen Wirtschaft (RIW), 40. Jg./(1994), Nr. 11, S. 945960.

Blokland, T. / Burgers, I.J.J. (1997): New Dutch Rules on the Taxation of Gains derived from "Sbstancial Participations", in: Bulletin for International Fiscal Documentation, Vol. 51/(1997), Nr. 7, S. 321-324. 
Blumenberg, J. (1997): Die Besteuerung der Gesellschafter-Fremdfinanzierung, Schriften des Instituts für Auländisches und Internationales Finanz- und Steuerwesen der Universität Hamburg, Bd. 31, Baden-Baden 1997.

Boadway, R. / Bruce N. (1992): Problems with integrating Corporate Income Taxes in an open Economy, in: Journal of Public Economics, Vol. 48/(1992), o. Nr., S. 39-66.

Boadway, R. / Wildasin D. (1984): Public Sector Economics, 2. Aufl., Toronto 1984

Böckli, P. (1979): Die Verweigerung der Steuergutschrift gegenüber Steuerausländern nach der deutschen Körperschaftsteuerreform 1977 aus Sicht eines Vertragsstaates, in: Steuer und Wirtschaft (StuW), 56. Jg./(1979), Nr. 1, S. 115.

Borggräfe, J. (1979): Steuerrecht zwischen verfassungswidriger Konzeption und gesetzeswidriger Anwendung, in: Der Betrieb (DB), 32. Jg./(1979), Nr. 19, S. 907-915.

Borggräfe, K. / Jakobs, N. (1995): Darlehensgewährung durch Dritte i.S. d. § 8 a Abs. 1 Satz 2, in: Finanz-Rundschau (FR), 77 Jg./(1995), Nr. 10, S. 358-363.

Brown, C.V. / Jackson, P.M. (1990): Public Sector Economics, 4. Aufl., Oxford u.a. 1990.

Brümmerhoff, D. (1990): Finanzwissenschaft, 5. Aufl., München 1990.

Bundesministerium der Finanzen (1971): Gutachten der Steuerreformkommission, in: Schriftenreihe des Bundesministeriums der Finanzen, Nr. 17, Bonn 1971.

Bundesministerium der Finanzen (1997): Reform der Einkommensbesteuerung Vorschläge der Steuerreform-Kommission vom 22. Januar 1997, "Petersberger Steuervorschläge", in: Schriftenreihe des Bundesministeriums der Finanzen, Nr. 61, Bonn 1997.

Canellos, P.C. (1996): The US Perspective, in: IFA (Hrsg.): Dividend Access Shares (Stapled Stocks), Den Haag u.a., S.127-143.

Canellos, P.C. (1996) in: The Discussion of the Challanges, in: Transcript Tax of the Seminar Proceedings, in IFA (Hrsg.): Dividend Access Shares (Stapled Stocks), Den Haag u.a., a.a.O., S. 24-41.

Catalaens, H. (1993): Standortsicherung durch Anrechnung ausländischer Körperschaftsteuer?, in Steuer und Wirtschaft (StuW), 70. Jg./(1993), Nr. 3, S. 249259.

Claussen, C.P. (1995): Die vier aktienrechtlichen Änderungsgesetze des 12. Bundestages. Reform oder Aktionismus ?, in: Die Aktiengesellschaft (AG), 40. Jg./(1995), Nr. 4, S. 163-172.

Cnossen, S. (1993): What Kind of Corporation Tax?, in: Bulletin for International Fiscal Documentation, Vol. 47/(1993), Nr. 1, S. 3-16. 
Commission of the European Communities (Europäische Kommission) (1992): Report of the Committee of independent Experts on Company Taxation, Brüssel, Luxemburg 1992.

Courage, C. (1996): Änderungen im spanischen Körperschaftsteuergesetz für ausländische Investoren, IWB, Nr. 22 vom 27.11.1996, Fach 5, Gruppe 2, S. 213-220

Croneberg, M. (1973): Die Teilhabersteuer. Ein Beitrag zur Körperschaftsteuerreform unter besonderer Berücksichtigung der Unternehmensfinanzierung, Braunschweig 1973.

Cussons, P. (1996): Discrimination in Europe, in: EU Tax Notes, Nr. 12, July 1995 / March 1996, S 1-10.

Dautzenberg, N. (1993): Zur notwendigen Reform der beschränkten Steuerpflicht aufgrund des Maastrichter Vertrages, IWB, Nr. 11 vom 11.06.1993, Fach 2, S. 645-652.

de Bartholome, C.A.M. (1995): Which tax rate do people use: Average or marginal?, in Journal of Public Economics, Vol. 56/(1995), S. 79-96.

Debatin, H. (1983): Probleme der internationalen Doppelbesteuerung, in: Handbuch der Finanzwissenschaft, 3. Aufl., Tübingen 1983, S. 269-309.

de Fréminent, P. (1994): Perspective of France, in: IFA (Hrsg.): Corporate Tax on Distributions, Deventer 1994, S. 55-81.

Derouin, P. (1996): Introduction, in: IFA (Hrsg.): Dividend Access Shares (Stapled Stocks), Den Haag u.a., S. 1-12.

de Sousa da Camara, F. / Leitao, M. / Teles, J.G. (1996): Portugal enacts Safe Haven Exeption to Thin Capitalization Rules, in: Tax Notes International, Vol. 13/(1996), Nr. 8, S. 585

Deutsche Bundesbank (1997): Entwicklung und Bestimmungsgründe grenzüberschreitender Direktinvestitionen, in: Deutsche Bundesbank (Hrsg.), Monatsbericht August, 49. Jg./(1997), Nr. 8, S. 63-82.

Dötsch, E. (1980): Das Gesetz zur Änderung des Einkommensteuergesetzes, des Körperschaftsteuergesetzes und anderer Gesetze, in: Der Betrieb (DB), 33. Jg./(1980), Nr. 33, S. 1563-1567.

Dötsch, E. (1993a): Standortsicherungsgesetz: Auseinanderfallen von Stammrecht und Dividendenschein - Dividenden-Stripping, in: Der Betrieb (DB), 46. $\mathrm{Jg} /(1993)$, Nr. 37, S. 1842-1848.

Dötsch, E. (1993b): Maßnahmen zur steuerlichen Einschränkung des DividendenStripping durch das Standortsicherungsgesetz, Institut für Ausländisches und Internationales Finanz- und Steuerwesen (Hrsg.): Hefte zur Internationalen Besteuerung, Nr. 95, Hamburg 1993.

Dötsch, E. / Cattelaens, H. / Gottstein, S. / Stegmüller H. / Zenthöfer, W. (1995): Körperschaftsteuer, 11. Aufl., Stuttgart 1995. 
Dötsch, E. (1996): Kommentar zu § 50c EStG, in: Dötsch, E. / Eversberg, H. / Jost, W.F. / Witt, G.(Hrsg.): Die Körperschaftsteuer, Loseblattsammlung, Bd. 3, 27. Erg.Lfg., S. 1111/3-1133, bzw. ebd. Kommentar zu 36 EStG, S. 1019-1040/1.

Dötsch, E. (1997): ebd., 31. Erg.Lfg., S. 1110/3-1110/7.

Dötsch. E. (1998): s. Herzig, N.

Eckert, $R$. (1995): $\S 50$ c Abs. 10 EStG zur Vermeidung des Dividendenstripping verfassungsgemäß?, in: Der Betrieb (DB), 48. Jg./(1995), Nr. 2, S. 62-66.

$E G$ (1977): Europäische Wohlverhaltensregeln für Wertpapiertransaktionen vom 25.07.1977, Amtsblatt der EG Nr. 212/37 vom 20.08.1977

Elton, E. / Gruber, M. (1970): Marginal Stockholder Tax Rates and the ClienteleEffect, in Review of Economics and Statistics, Vol. 52/(1970), S. 68-74.

Engels, W./ Stützel, W. (1968): Teilhabersteuer, 2. Aufl., Frankfurt am Main 1968. Evers, R. (1923): Kommentar zum Körperschaftsteuergesetz 1920/22, Berlin 1923.

Fantozzi, F. (1994): Dividend Washing and Usufruct of Shares in the Light of the Lack of a General Anti-Abuse Clause, in: European Taxation, Vol. 34/(1994), Nr. 12, S. 452-456.

Farrar, D.E. / Selwyn, L.L. (1967): Taxes, Corporate Financial Policy and Return to Investors, in: National Tax Journal, Vol. 11/(1967), Nr. 4, S. 444-454.

Fecht, $R$. (1977): Einkommensbesteuerung, II: Körperschaftsteuer, in: Handwörtbuch der Wirtschaftswissenschaften, Bd. 2, Stuttgart u.a. 1980, S. 218-240.

Finanzministerium Nordrhein-Westfalen (1978): Erlaß vom 28.08.1978, abgedruckt in: Die Wirtschaftsprüfung (Wpg), 31 Jg./(1978), Nr. 21, S. 609.

Frenkel, J.A. / Razin, A. / Sadka, E. (1991): International Taxation in an Integrated World, Massachusetts 1991

Froesch, T. / Goyvaerts, G. (1997): Belgien: Wichtige Änderungen im Steuerrecht, in: Internationales Steuerrecht (IStR), 6. Jg./(1997), Nr. 18, S. 553554.

Frotscher, G. (1994a): Gesellschafter-Fremdfinanzierung durch nicht anrechnungsberechtigte Anteilseigner, in: Internationales Steuerrecht (IStR), 3 Jg./(1994), Nr. 5, S. 201-211.

Frotscher G. (1994b): Wertminderungen von Anteilen, Kommentar zu § 50c EStG, in: Frotscher, G. (Hrsg.): EStG Praxis Kommentar, Freiburg, 65. Erg.Lfg. 11/93 bzw. 69. Erg-Lfg. 08/94, S. 1-46.

Fullerton, D. (1983): s. King, M.A.

Gammie, M. (1997a): The End of Imputation; Changes in UK Dividend Taxation, in: International Tax Review (Intertax), Vol. 25/(1997), Nr. 10, S. 333-341. 
Gammie, M. (1997b): The Future of UK Corporation Tax, in: Head, J.G. / Krever, R. (Hrsg.): Company Tax Systems, Victoria 1997, S. 207-269.

Geiger, R. (1995): EG-Vertrag, 2. Aufl., München 1995.

Gelin, S. (1996): French Tax Update in: Tax Notes International, Nr.: 4, S. 248249.

Geurts, O.B.C.J. (1997): Wichtige Neuerungen 1996/97 im niederländischen Steuerrecht, in: IWB, Nr. 13 vom 09.07.1997, Fach 5 Gruppe 2, S. 261-268.

Giuliani, F.M. / Uckmar, V. (1994): Interposition in Italian Taxation on Income and International Transactions, in: International Tax Review (Intertax), Vol. 22/(1994), Nr. 10, S. 440-447.

Gondert, H.-G. / Rützel, G. / Dreyer, G. (1995): Arbitragegeschäfte an der DTB, in: Die Bank, o. Jg./(1995), S. 562-568.

Graf Kerrsenbrock, O.-F. / Strunk, G. (1999): Zum Geltungsbereich von § 50c Abs. 10 und 11 EstG bei Börsengeschäften, in: Betriebs-Berater, 54. Jg./(1999), Nr. 8, S. 398-405.

Grubert, H. / Mutti, J. (1994): International Aspects Of Corporate Tax Integration:

The Contrasting Role Of Debt And Equity Flows, in: National Tax Journal, Vol. 47/(1994), Nr. 1, S. 111-133.

Grützner, D. (1997): Verbot der Berücksichtigung ausschüttungsbedingter Gewinnminderungen nach $\S 50 \mathrm{c}$ EStG, in NWB Nr. 40 vom 29.09.1997, Fach 3, S. 10189-10200.

Haarmann, W. (1996): Verknüpfung von Beteiligungen zur Sicherung des Anrechnungsguthabens (Stapled Stocks), in: Herzig, N. (1996): Körperschaftsteuerguthaben bei grenzüberschreitenden Kooperationen, Steuerthemen im Brennpunkt, Bd. 10, Köln 1996, S. 41-57.

Haarmann, W. (1997): Internationale Kooperationen und Sicherung von Anrechnungsguthaben (Stapled Stocks), in: Herzig, N. (Hrsg.): Steuerorientierte Umstrukturierungen von Unternehmen, Schriftenreihe: Der Betrieb, Stuttgart 1997

Haase, D. / Schneeloch, D. / Siegel, T. (1983): Besteuerung der GesellschafterFremdfinanzierung, Stuttgart 1983

Häuselmann, H. / Pachmann, T. (1994): Gesellschafterfremdfinanzierung, Bankgeschäft und bankübliches Geschäft, in: Recht der Internationalen Wirtschaft (RIW), 40. Jg./(1994), Nr. 3, S. 230-234.

Haller, H. (1971): Die Steuern. Grundlinien eines rationalen Systems öffentlicher Abgaben, 2. Aufl., Tübingen 1971

Head, J.G. (1997): Company Tax Systems - From Theory to Policy, in: Head, J.G. / Krever, R. (Hrsg.): Company Tax Systems, Victoria 1997, S. 1-47.

Herber, B. P. (1983): Modern Public Finance, 5. Aufl., Illinois 1983.

Herzig, $N$. (1981): Anteilsrotation bei laufender Geschäftstätigkeit, in: BetriebsBerater (BB), 36. Jg./(1981), Nr. 2, S. 109-113. 
Herzig, N. / Hötzel, O. (1988): Ausschüttungsbedingte Teilwertabschreibungen, in: Der Betrieb (DB), 41. Jg./(1988), Nr. 45, S. 2265-2272.

Herzig, N. (1993): Gesellschafter-Fremdfinanzierung von Kapitalgesellschaften Bericht aus einer Arbeitsgruppe - , in: Steuern und Wirtschaft (StuW), 70. Jg./(1993), Nr. 3, S. 237-248.

Herzig, N. (1994): Standortsicherungsgesetz: Gesetzliche Regelung der Gesellschafter-Fremdfinanzierung in $\S 8 \mathrm{a} \mathrm{KStG}$ (Teil II), in: Der Betrieb (DB), 47. Jg./(1994), Nr. 4, S. 168-177

Herzig, N. (1996): Anrechnungsverluste als steuerliches Hemmnis grenzüberschreitender Kooperationen, in: Internationales Steuerrecht (IStR), 5. Jg./(1996), Nr. 4, S. 196-200.

Herzig, N. / Dötsch, E. (1998): Körperschaftsteuer 2000, in: Der Betrieb (DB) 51 . Jg./(1998), Nr. 1/2, S. 15-20.

Hessisches Finanzgericht (1996): Urteil vom 02.12.1996, Geschäftsnummer $4 \mathrm{~K}$ 3180/94, Kassel 1996.

Hey, F.E.F. (1993): Gesellschafterfremdfinanzierung. Einige Gedanken zum neuen $\S 8 \mathrm{a} \mathrm{KStG}$, in: Recht der Internationalen Wirtschaft (RIW), 39. Jg./(1993), Nr. 10, S. 833-838.

Hey, F.E.F. (1994): Gesellschafterfremdfinanzierung. Einige Zweifelsfragen zur Anwendung von $\S 8 \mathrm{a} \mathrm{KStG}$, in: Recht der Internationalen Wirtschaft (RIW), 40. Jg./(1994), Nr. 3, S. 221-230.

Hey, J. (1998): Steuern verwalten durch Banken, in: Finanz-Rundschau (FR), 80. Jg./(1998), Nr. 11, 497-509.

Höckenreiner, R. (1997): s. Napolitano, E.

Hoffmann, W.-D. (1995): Das (einstweilige) Nichtstun als Gestaltungsmittel gegen den $\S 8 \mathrm{a} \mathrm{KStG}$, in: Internationales Steuerrecht (IStR), 4. Jg./(1995), Nr. 4, S. 176-178.

Horst, T. (1980): A Note on the optimal Taxation of international Invest-ment Income, in: Quarterly Journal of Economics, Vol. 94/(1980), Nr. 4, 793-798.

Hübner, R. (1996): Fehler im System, in: Capital, o. Jg./(1996), Nr. 4, S. 159-165.

International Bureau of Fiscal Documentation (Hrsg.)(1997): European Tax Handbook, Amsterdam 1997.

International Bureau of Fiscal Documentation (Hrsg.)(1998): European Tax Handbook, Amsterdam 1998.

International Bureau of Fiscal Documentation (Hrsg.)(1999): European Tax Handbook, Amsterdam 1999.

Janssen, B. (1997): § 8a KStG - Zweck der Vorschrift und Kritik ihrer Ausgestaltung, Göttingen 1997. 
Janssen, B. (1998): Die Anwendung von $\S 8 \mathrm{a} \mathrm{KStG}$ auf nahestehende Personen und Dritte gem. $\S 8 \mathrm{a}$ Abs. 1 Satz $2 \mathrm{KStG}$, in: IWB, Nr. 7 vom 08.04.1998, Fach 3, Gruppe 4, S. 375-390.

Jebens, (o.Vorn.) (1980): Kommentar zum § 50c EStG, Nachtrag Nr. 50, November 1980, in Lademann, Söffing, Brockhoff (Hrsg.): Kommentar zum Einkommensteuergesetz, Stuttgart 1980.

Kaiser, H. (1980): Körperschaftsteuerliches Anrechnungsverfahren und Ausländerproblematik, in: Steuerberater-Kongreß 1980, o.Jg./(1980), S. 191-211.

Kaiser, M. (1992): Konsumorientierte Reform der Unternehmensbesteuerung, Heidelberg 1992.

Kampmann, $R$. (1983): Theoretische und ökonometrische Untersuchungen zur Körperschaftsteuerüberwälzung, Frankfurt am Main u.a. 1983.

Keidel, S. (1996): Finanzbehörden wollen Banken zur Kasse bitten, in: Handelsblatt, 26.09.1996.

Keidel, S. (1997): Dividendenstripping und kein Ende - Hessischer Sumpf, in Handelsblatt, 10/11.01.1997.

Kessler, W. (1995): Grenzüberschreitende Körperschaftsteuer-Gutschriften - Gestaltungsmöglichkeiten nach geltendem Recht, in: Internationales Steuerrecht (IStR), 4. Jg./(1995), Nr. 8, S. 405-408.

Kessler, W. (1996): Die Euro-Holding, München 1996.

Kindermann, E. (1994): Börsengeschäfte in zeitlichem Zusammenhang mit Dividendenterminen = "Dividenden-Stripping?" Eine Bewertung nach neuem und altem Recht -Teil 1 -, in: Wertpapier Mitteilungen (WM), 48. Jg./(1994), Nr. 19, S. 817-826; - Teil 2 - in: Wertpapier Mitteilungen (WM), 48. Jg./(1994), Nr. 20, S. 869-879.

King, M.A. / Fullerton, D. (1983): The Taxation of Income from Capital: A Comparative Study of the U.S., U.K., Sweden and West Germany - The Theoretical Framework - , NBER Working Paper 1058, Cambridge 1983.

Klein, M. (1997): §50c Abs. $10 \mathrm{EStG}$ und der "Anteilserwerb über die Börse" als Mittel des Dividenden-Strippings, in: Finanz-Rundschau (FR), 79. Jg./(1997), Nr. 13, S. 473-477.

Kluge, V. (1992): Das deutsche Internationale Steuerrecht, 3. Aufl., München 1992.

Knobbe-Keuk, B. (1982): Die Fremdfinanzierung inländischer Kapitalgesellschaften durch nichtanrechnungsberechtigte Anteilseigner, in: Steuer und Wirtschaft (StuW), 59. Jg./(1982), Nr. 3, 201-222.

Knobbe-Keuk, B. (1992): Neuer Anlauf zu einem § 8a KStG, in: IWB, Nr. 21 vom 10.11.1992, Fach 2, S. 615-618.

Knobbe-Keuk, B. (1993): Wieder einmal ein Entwurf zu § 8a KStG - Wiederauflage einer Regelung zur Gesellschafterfremdfinanzierung im Standortsicherungsgesetz, in: Der Betrieb (DB), 46. Jg./(1993), Nr. 2, S. 60-66. 
Koblenzer, T. (1997): Die Besteuerung Nichtansässiger - ein historischer Rückblick, Internationales Steuerrecht (IStR), 6. Jg./(1997), Nr. 4, S. 97-101.

Koch, K. (1980): Verbot ausschüttungsbedingter Teilwertabschreibungen und ausschüttungsbedingter Veräußerungsverluste - § 50c EStG -, in: Deutsche Steuer-Zeitung (DStZ), 68. Jg./(1980), Nr. 18, S. 339-341.

Köster, K. (1993): Implications of the New Thin Capitalization Legislation for Non-Resident Shareholders of a German Subsidiary, in: European Taxation, Vol. 33/(1993), Nr. 12, S. 398-407.

Krawitz, N. (1994): Aktuelle Änderungen der einkommensteuerlichen Behandlung des sog. Dividendenstripping, in: Deutsches Steuerrecht (DStR), 32. Jg./(1994), Nr. 25, S. 881-889.

Krause-Junk, G. (1988): Überlegungen zu einem künftigen europäischen Körperschaftsteuersystem, in: Konjunkturpolitik, 34. Jg./(1988), Nr. 5/6, S. 268289.

Krause-Junk, G. / Müller, R. (1997): Zur steuerlichen Behandlung von Ausschüttungen im Ausland verdienter Gewinne, in: Burmester, G. / Endres, D. (Hrsg.): Aussensteuerrecht, Doppelbesteuerungsabkommen und EU-Recht im Spannungsverhältnis, Festschrift für Helmut Debatin zum 70. Geburtstag, München 1997, S. 255-266.

Krebs, H.-J. (1980): Änderungen des Körperschaftsteuerrechts-Neuregelung der Übertragung von Gesellschaftsanteilen durch nichtanrechnungsberechtigte Anteilseigner auf anrechnungsberechtigte Erwerber, in: Betriebs-Berater (BB), 35. Jg./(1980), Nr. 24, S. 1257-1265.

Krebs, H.-J. / Zeitler, F.-C. (1993): "Europataugliches" Anrechnungsverfahren im Standortsicherungsgesetz, in: Der Betrieb (DB), 46. Jg. /(1993), Nr. 21, S. 1051-1054.

Landeszentralbank Hessen (1992): "Dividenden-Stripping" im Zwielicht, Frankfurter Finanzmarkt-Bericht, September 1992, Nr. 11/92.

Landeszentralbank Hessen (1998): Dem Dividendenstripping auf der Spur, Frankfurter Finanzmarkt-Bericht, Februar 1998, Nr. 29.

Lang, $J$. (1994): Besteuerung der Unternehmen in Staaten der Europäischen Union

- Resümee, in: Deutsche Steuerjuristische Gesellschaft (DStJG) Bd. 16, Lang, J.(Hrsg.): Unternehmensbesteuerung in EU Staaten, Köln 1994, S. 295-317.

Lang, J. (1996): s. Tipke, K.

Littmann, E. (1981): Besteuerung von Gewinnausschüttungen an Anteilseigner nach Erwerb von einem nicht anrechnungsberechtigten Anteilseigner - § 50c EStG, in: Deutsche Steuer-Zeitung (DStZ), 69. Jg./(1981), Nr. 17, S. 355362. 
Loos, G. (1989): Gesellschafter-Fremdfinanzierung durch nichtanrechnungsberechtigte Anteilseigner, in: Betriebs-Berater (BB), 44.Jg./(1989), Nr. 8, S. $532-540$.

Manke, K. (1977): Auswirkungen der Körperschaftsteuerreform auf das Außensteuerrecht, in: Steuerberater-Jahrbuch (StbJb) 1977/78, Bd. 29, S. 269-294.

Marseille, H. (1996) in: The Discussion of the Tax Challanges, in: Transcript of the Seminar Proceedings, in: IFA (Hrsg.): Dividend Access Shares (Stapled Stocks), Den Haag u.a. 1996, S. 24-41.

Mattausch, $H$. (1994): Die internationale Konzernfinanzierung unter dem Einfluß des $\S 8 \mathrm{a} \mathrm{KStG}$, in: Fischer, L. (Hrsg.): Wirtschaftstandort Deutschland im Internationalen Steuerrecht, Forum der Internationalen Besteuerung, Bd. 5, Köln 1994, S. 88-112.

Mattausch, H. (1995): Einführungsschreiben zu § 8a KStG, in: Fischer, L. (Hrsg.): Besteuerung wirtschaftlicher Aktivitäten von Ausländern in Deutschland, Forum der Internationalen Besteuerung, Bd. 8, Köln 1995, S. 58-84.

Mayr, S. (1996): Neuerungen im italienischen Steuerrecht, in: NWB, Nr. 14 vom 24.07.1996, Fach 5, Gruppe 2, S. 395f.

Mayr, S. (1998): Neuer Mechanismus bei Ausschüttungen und Anrechnung der Körperschaftsteuer in Italien, in IWB, Nr. 5 vom 11.03.1998, Fach 5, Gruppe 2, S. 413-426.

Meillicke, W. (1994): Erste Probleme mit $\S 8$ a des Körperschaftsteuergesetzes, in: Betriebs-Berater (BB), 49. Jg./(1994), Nr. 2, S. 117-121.

Menck, T. (1985): Welteinkommen und Territorialität der Besteuerung nach deutschem Recht und in deutscher Sicht, in: Engelschalk, M. u.a. (Hrsg.): Steuern auf ausländische Einkünfte, München 1985, S. 28-41.

Menck, T. (1995): Gesellschafter-Fremdfinanzierung, Kommentar zum $\S 8 \mathrm{a} \mathrm{KStG,}$ Erg-Lfg. Nr. 50, Juni 1995, in: Blümich (Hrsg.): Einkommensteuergesetz, Körperschaftsteuergesetz, Gewerbesteuergesetz Kommentar, München 1997, S. 1-26.

Mersmann, W. (1971): Diskriminierung ausländischer Beteiligungen bei der Körperschaftsteuerreform?, in: Deutsche Steuer-Zeitung (DStZ) [A], 59. Jg./(1971), S. 310-313.

Michielse, G.M.M. (1997): Treaty Aspects of Thin Capitalization, in: Bulletin for International Fiscal Documentation, Vol. 51./(1997), Nr. 12, S. 565-573.

Miller, M.H. / Modigliani, F. (1961): Dividend Policy, Growth and the Valuation of Shares, in: Journal of Business, Vol. 34/(1961), S. 411-433.

Monti, M. (1997): The Single Market and beyond: Challenges for Tax Policy in the European Union, in: EC-Tax Review, Vol. 6/(1997), Nr. 1, S. 2-3.

Musgrave, P.B. (o.J.): Interjurisdictional Ccordination of Taxes on Capital Income, in: Cnossen, S. (Hrsg.): Tax Coordination in the European Community, Series on International Taxation, Nr. 7, o.O., o.J. 
Musgrave, R.A. / Musgrave, P.B. / Kullmer, L. (1993): Die öffentlichen Finanzen in Theorie und Praxis, 5. Aufl., Tübingen 1993.

Napolitano, E. / Höckenreiner, R. (1997): Die neuen italienischen Steuermißbrauchsbekämpfungsregeln und internationale Besteuerungsgrundsätze, in: Internationales Steuerrecht (IStR), 1997, 6. Jg./(1997), Nr. 2., S. 44-45.

Nirk, R. (1994): Handbuch der Aktiengesellschaft, 3. Aufl. 1994.

OECD (1991): Taxing Profits in a Global Economy - Domestic and International Issues, Paris 1991.

o. Verf. (1993): Enormes Ausmaß, in WirtschaftsWoche 1993, Nr. 41. S. 131-132

o. Verf. (1993): Das Dividenden-Stripping wird künftig erleichtert, in: Handelsblatt vom 31.05.1993.

o. Verf. (1994): DTB-Geschäfte steuerlich gefährdet, in: Börsenzeitung, 26.02.1994.

o. Verf. (1994): Strip in der Zockerstube, in: Der Spiegel 1994, Nr. 34, S. 64-66.

o. Verf. (1997): Dividendenstripping früh bekannt, in: Handelsblatt vom 11 / 12.01.1997.

o. Verf. (1997): Norway - Simultaneous decrease and increase in capital a deemed dividend, in: IBFD (Hrsg.): Tax News Services, Vol. 31/(1997), Nr. 35, S. 364.

o. Verf. (1998): Kapitalmarkt / Grundsatzentscheidung des Bundesfinanzhofs "Dividendenstripping kein Rechtsmißbrauch, in: Handelsblatt vom 23.11.1998.

o. Verf. (1999): Lafontaine auf Sparkurs, in Handelsblatt vom 18.01.1999

Peffekoven, $R$. (1983): Probleme der internationalen Finanzordnung, in: Handbuch der Finanzwissenschaft, 3. Aufl., Tübingen 1983, Bd. 4, S. 219-268.

Perridon, L. / Steiner, M. (1995): Finanzwirtschaft der Unternehmung, 8. Aufl., München 1995

Poterba, J.M. / Summers L. H. (1984) New Evidence that Taxes Affect the Valuation of Dividends, in: Journal of Finance, Vol. 39/(1984), S. 1397-1415.

Prinz, U. (1995): Kommentar zu § 8a KStG, in: Hermann, C. / Heuer, G. / Raupach, A. (Hrsg.): Einkommensteuer und Körperschaftsteuergesetz, Erg.-Lfg. 178, S. 1-138.

Prinz, U. (1995): Ausgewählte Problemfälle zu § 8a KStG aus der Beratungspraxis, in: Herzig, N. (Hrsg).: Gesellschafterfremdfinanzierung und Beteiligung an ausländischen Gesellschaften im Körperschaftsteuerrecht, Steuerthemen im Brennpunkt, Band 9, Köln 1995, S. 41-106.

Prinz, U. (1998): Aktuelles zu § 50c, in: Hermann, C./ Heuer, G./ Raupach, A.: Einkommensteuer- und Körperschaftsteuergesetz, Kommentar, Erg.Lfg. 191, Januar 1998, S. 1-14. 
Prinz, U. (1998): "Fremdkapital" im Sinne des § 8a KStG, in: Finanz-Rundschau, 80. Jg./(1998), Nr. 2, S. 72-74.

Pumbo, M. (1995): Ausländische Einkünfte im körperschaftsteuerlichen Anrechnungsverfahren, Hamburg 1995.

Rabald, B. (1986): Zur Berücksichtigung von Steuerguthaben beim Erwerb nichtnotierter Anteile, in: Die Wirtschaftsprüfung (Wpg), 39. Jg./(1986), Nr. 1, S. 7-16.

Rädler, A. (1994): Vorstellungen des EG-Sachverständigenausschusses zur Unternehmensbesteuerung (Ruding-Ausschuß), in: Herzig, N. (Hrsg.): Harmonisierung der Körperschaftsteuersysteme in den EU-Staaten, Steuerthemen im Brennpunkt, Bd. 6, Köln 1994.

Rath, W.-D. (1976): Die Besteuerung ausländischer Muttergesellschaften und ihrer deutschen Tochtergesellschaften in Deutschland nach der Körperschaftsteuerreform, in: Betriebs-Berater (BB), 31. Jg./(1976), Nr. 23, S. 1066-1072.

Rath, W.-D. (1994): Gesellschafter-Fremdfinanzierung nach $\S 8 \mathrm{a} \mathrm{KStG}$ - Konsequenzen für die Unternehmensfinanzierung, in: Herzig, N. (Hrsg.): Die Unternehmensbesteuerung im Standortsicherungsgesetz, Steuerthemen im Brennpunkt, Bd. 8, Köln 1994, S. 67-74.

Raupach, A. (1997): Das körperschaftsteuerliche Anrechnungsverfahren - Bestandsaufnahme und Kritik, in: Widmann, S. (Hrsg.): Besteuerung der GmbH und ihrer Gesellschafter, Deutsche Steuerjuristische Gesellschaft, Bd. 20, Köln 1997, S. 21-56.

Riedel, W. (1982): Die steuerpolitische Willensbildung bei der Körperschaftsteuerreform 1977, Frankfurt am Main u.a. 1982.

Sarrazin, V. (1994) Bekämpfung unerwünschter Steuergestaltungen, in: Deutsche Steuer-Zeitung, 82. Jg./(1994), Nr. 10, S. 289-295.

Saß, G. (1993): Steuerharmonisierung in der EG - Perspektiven für eine Harmonisierung der Körperschaftsteuer und der Gewinnermittlung, in: Der Betrieb (DB), 46. Jg./(1993), Nr. 3, S. 113-124.

Sato, M. / Bird, R.M. (1975): International Aspects of the Taxation of Corporations and Shareholders, in: IMF-Staff Papers, Vol. 22/(1975), S. 384-455.

Schad, H. J. / Thiel, R. (1972): Die Veräußerung von Anteilen an einer Kapitalgesellschaft, Der Betrieb (DB), Nr. 11, S. 497-502.

Schanz, G. (1896) Der Einkommensbegriff und die Einkommensteuergesetze, in: Finanzarchiv, 13.Jg./(1896), S. 1-87.

Schauhoff, S. (1993): Tax Planning under Germany's 'Thin Capitalization Rules', in: International Tax Review (Intertax), Vol. 21/(1993), Nr. 10, S. 466-473.

Schaumburg, H. (1993): Internationales Steuerrecht, Köln 1993. 
Scheffler, $W$. (1996): Steuerfreistellung für Auslandsinvestitionen, in: Jacobs, Otto H. / Spengel, C. (Hrsg.): Aspekte der Unternehmensbesteuerung, BadenBaden 1996, S. 155-183.

Schneeloch, D. (1987): Verdecktes Nennkapital, in: Deutsches Steuerrecht (DStR), 25. Jg./(1987), S. 458-462.

Schuler, R. U. (1991): Körperschaftsteuerliche Aspekte der geplanten Unternehmenssteuerreform, Köln 1991.

Schwarzkopf, O. (1993): Die Problematik unterschiedlicher Körperschaftsteuersysteme innerhalb der EG, Finanzwissenschaftliche Schriften, Bd. 53, Frankfurt am Main u.a. 1993.

Selling, H.-J. (1994): Unternehmensbesteuerung in Spanien, in: Lang, J. (Hrsg.): Unternehmensbesteuerung in EU-Staaten, Veröffentlichungen der Deutschen Steuerjuristische Gesellschaft (DStJG), Bd. 16, Köln 1994, S. 195-242.

Sinn, H.-W. (1984): Systeme der Kapitaleinkommensbesteuerung. Ein allokationstheoretischer Vergleich, Sonderdruck aus: Bös, D. / Rosen, M. / Seidl, C. (Hrsg.): Beiträge zur neuen Steuertheorie, Berlin 1984.

Sinn, H.-W. (1985): Kapitaleinkommensbesteuerung, Tübingen 1985.

Sinn, H.-W. (1991): Taxation and the Cost of Capital: The "old" View, the "new" View, and another View, in: Bradford, D.(Hrsg.): Tax Policy and the Economy 5, Cambridge (Massachusetts).

Smith. A.MC (1994): Dividend Imputation and International Equity Investment: Unilateral Extension of Imputation to Non-resident Investors, in: Australian Tax Forum, Vol. 11/(1994), S. 247-269.

Smith, C.M.A. / Thalhammer, B. (1997): Die Verbundaktie. Ein Praxisbeispiel von Stapled Stock, in: Institut für Ausländisches und Internationales Finanz- und Steuerwesen (Hrsg.): Hefte zur Internationalen Besteuerung Nr. 113, Hamburg 1997

Smith, D.W. (1996): The Canadian Perspective, in IFA (Hrsg.): Dividend Access Shares (Stapled Stocks), Den Haag u.a. , S. 93-125.

Söffing, G. / Wrede, F. (1980): Das Gesetz zur Änderung des EStG, des KStG und anderer Gesetze (Teil II), in: Finanz-Rundschau, 35.(62.)Jg./(1980), Nr. 17, S. 397-404.

Sörensen P.B. (1995): Changing Views of the Corporate Income Tax, in: National Tax Journal, Vol. 48/(1995), Nr. 2, S. 279-294.

Sorgenfrei, U. (1997a): Dividendenstripping, in: Steuerpraxis der Kreditinstitute, 42. Lieferung, April 1997, Nr. 4413, S. 1-20.

Sorgenfrei, U. (1997b): "Bilaterales Dividenden-Stripping" und Kapitalverkehrsfreiheit (Teil I), in: Internationales Steuerrecht (IStR), 6. Jg./(1997), Nr. 23, S. 705-711; (Teil II), in: Internationales Steuerrecht (IStR), 6. Jg./(1997), Nr. 24, S. 737-741.

Streck, M. (1991): Körperschaftsteuergesetz, 3. Aufl. München 1991.

Streck, M. (1997): Körperschaftsteuergesetz, 5. Aufl. München 1997. 
Thiel, R. (1972): s. Schad, H.J.

Thiel, J. (1997): Die Besteuerung der Gesellschafter - eine Crux des Körperschaftssteuer-Anrechnungsverfahrens, in: Steuerberater Jahrbuch (StbJb) 1996/97, S.79-97.

Thömmes, O. (1996): Grenzüberschreitende Anrechnung von Körperschaftsteuern, in: Herzig, N. (Hrsg.): Körperschaftsteuerguthaben bei grenzüberschreitenden Kooperationen, Köln 1996, S. 13-40.

Thümler, A. (1994): Körperschaftsteuerliches Anrechnungsverfahren und internationales Steuerrecht, Frankfurt am Main u.a. 1994.

Tipke, K. / Lang, J. (1996): Steuerrecht, 15. Aufl., Köln 1996.

Ülner, A. (1994): Wertminderung von Anteilen durch Gewinnausschüttung, Kommentar zum § 50c EStG, Erg.-Lief. Nr. 48, Oktober 1994, in: Blümich (Hrsg.): Einkommensteuergesetz, Körperschaftsteuergesetz, Gewerbesteuergesetz Kommentar, München 1997.

Unfried, A. (1998): Steuerrecht und Dividendenstripping, Berlin 1998.

Valente, $P$. (1997): Dynamics of Cross-Border Flows of Multinationals: The Italian Tax Implications, in: Bulletin for International Fiscal Documentation, Vol. 51/(1997), Nr. 11, S. 510-515

van den Tempel, A. J. (1970): Corporation Tax and Individual Income Tax in the European Communities, Brüssel 1970

van Lishaut, I. (1997): Gesetz zur Fortsetzung der Unternehmenssteuerreform: Der neue Absatz 11 des $\S 50$ c EStG, in: Der Betrieb (DB), 50. Jg./(1997), Nr. 44, S. 2190-2196.

van Raad, K. (1995): In a World where Classical and Integration Systems co-exist, Article 10 OECD Model should not disregard the Underlying Corporation Income Tax, in: IFA (Hrsg.): International Taxation of Dividends reconsidererd in Light of Corporate Tax Integration, London u.a. 1995, S. 45-58.

Vogel, K. (1973): Der ausländische Aktionär, München 1973.

Vogel, K. (1995): Introductory Notes, in: IFA (Hrsg.): International Taxation of Dividends Reconsidered in Light of Corporate Tax Integration, London u.a. 1995.

Vogel, K. (1996): Doppelbesteuerungsabkommen der Bundesrepublik Deutschland auf dem Gebiet der Steuern vom Einkommen und Vermögen, Kommentar, 3. Aufl., München 1996.

Ward, D.A. (1995): Abuse of Tax Treaties, in: International Tax Review (Intertax), Vol. 23/(1995), Nr. 4, S. 176-186

Wassermeyer, F. (1994): Stellungnahme zu ausgewählten Zweifelsfragen bei der Anwendung des $\S 8 \mathrm{a} \mathrm{KStG}$, in: Herzig, N. (Hrsg):: Gesellschafterfremdfi- 
nanzierung und Beteiligung an ausländischen Gesellschaften im Körperschaftsteuerrecht, Steuerthemen im Brennpunkt, Bd. 9, Köln 1995, S. 1-15.

Weber-Grellet, H. (1998): Wertminderungen von Anteilen durch Gewinnausschüttungen, in: Schmidt, L.(Hrsg.): Einkommensteuergesetz Kommentar, 17. Aufl., zu 50c EStG, S. 2225-2243.

Weber-Grellet, H. (1999): § 50c Abs. 11 EStG - Zur Belastbarkeit des Einkommensteuerrechts, in: Betriebs-Berater (BB), 54. Jg./(1999), Nr. 6, S. 289-297. Weindl, J. (1992): Die Kombination von Veräußerungs- und Ausschüttungsvorgängen als Gestaltungsmißbrauch?, in: Betriebs-Berater (BB), 47. Jg./(1992), Nr. 21, S. 1467-1471.

Wenger, E. (1989): Wirtschaftswachstum, Unternehmensfinanzierung und internationaler Kapitalverkehr unter dem Einfluß der Besteuerung von Vermögenseinkünften, in: Finanzarchiv, Neue Folge, Bd. 47, o.Jg./(1989), S. 181249.

Wenz, M. (1995): Advance Corporation Tax in Großbritannien, in: IWB, Nr. 8 vom 26.04.1995, Fach 5, Gruppe 2, S. 347-364.

Wied, E. (1997): Dividendenstripping, in Kommentierte Finanzrechtsprechung (KFR), Oktober 1997, Fach 4, S. 305-310.

Wilkinson, B. (1997): Dividend Imputation in the Context of Globalization - Extension of the New Zealend Foreign Investor Tax Credit Regime to NonResident Direct Investors, in: Bulletin for International Fiscal Documentation, Vol. 51/(1997), Nr. 8/9, S. 363-371.

Willemsen, A. (1986): Hat sich das Körperschaftsteuergesetz 1977 bewährt?, in: Institut für Ausländisches und Internationales Finanz- und Steuerwesen (Hrsg.): Hefte zur Internationalen Besteuerung, Nr. 20, Hamburg 1986.

Willens, $R$. (1993): Dividend-Stripping Proposed Regulations Broaden the Scope of Risk Diminution, in: The Journal of Taxation, Vol. 79/(1993), S. 138-142.

Wilson, P.A. (1990): Australian dividend access plans, in: International Tax Review (Intertax), [Vol. 18]/(1990), Nr. 1, S. 42-44.

Wisser, L. (1992): Überlegungen zu einem gemeinsamen Körperschaftsteuersystem für die Mitgliedstaaten der Europäischen Gemeinschaft, Europäische Hochschulschriften, Reihe 5, Bd. 1295, Frankfurt am Main 1992.

Wollert-Elmendorff, Deutsche Industrie-Treuhand GmbH, Deloitte \& Touche $\mathrm{GmbH} \mathrm{/} \mathrm{Deutsche} \mathrm{Baurevision} \mathrm{(1996)} \mathrm{(Hrsg.):} \mathrm{Gesellschafter-}$ Fremdfinanzierung, Hamm 1996.

$W u, C . / H s u, J$. (1996): The Impact of the 1986 Tax Reform on Ex-Dividend Day Volume and Price Behaviour, in National Tax Journal, Vol. 49/(1996), S. 177-192.

Zeitler, F.-C. (1993): s. Krebs, H.-J. 


\section{FINANZWISSENSCHAFTLICHE SCHRIFTEN}

Band 1 Werner Steden: Finanzpolitik und Einkommensverteilung. Ein Wachstums- und Konjunkturmodell der Bundesrepublik Deutschland. 1979.

Band 2 Rainer Hagemann: Kommunale Finanzplanung im föderativen Staat. 1976.

Band 3 Klaus Scherer: Maßstäbe zur Beurteilung von konjunkturellen Wirkungen des öffentlichen Haushalts. 1977.

Band 4 Brita Steinbach: "Formula Flexibility" - Kritische Analyse und Vergleich mit diskretionärer Konjunkturpolitik. 1977.

Band 5 Hans-Georg Petersen: Personelle Einkommensbesteuerung und Inflation. Eine theoretisch-empirische Analyse der Lohn- und veranlagten Einkommensteuer in der Bundesrepublik Deutschland. 1977.

Band 6 Friedemann Tetsch: Raumwirkungen des Finanzsystems der Bundesrepublik Deutschland. Eine Untersuchung der Auswirkungen der Finanzreform von 1969 auf die Einnahmenposition der untergeordneten Gebietskörperschaften und ihrer regionalpolitischen Zieladäquanz. 1978.

Band 7 Wilhelm Pfähler: Normative Theorie der fiskalischen Besteuerung. Ein methodologischer und theoretischer Beitrag zur Integration der normativen Besteuerungstheorie in der Wohlfahrtstheorie. 1978.

Band 8 Wolfgang Wiegard: Optimale Schattenpreise und Produktionsprogramme für öffentliche Unternehmen. Second-Best Modelle im finanzwirtschaftlichen Staatsbereich. 1978.

Band 9 Hans P. Fischer: Die Finanzierung des Umweltschutzes im Rahmen einer rationalen Umweltpolitik. 1978.

Band 10 Rainer Paulenz: Der Einsatz finanzpolitischer Instrumente in der Forschungs- und Entwicklungspolitik. 1978.

Band 11 Hans-Joachim Hauser: Verteilungswirkungen der Staatsverschuldung. Eine kreislauftheoretische Inzidenzbetrachtung. 1979.

Band 12 Gunnar Schwarting: Kommunale Investitionen. Theoretische und empirische Untersuchungen der Bestimmungsgründe kommunaler Investitionstätigkeit in NordrheinWestialen 1965-1972. 1979.

Band 13 Hans-Joachim Conrad: Stadt-Umland-Wanderung und Finanzwirtschaft der Kernstädte. Amerikanische Erfahrungen, grundsätzliche Zusammenhänge und eine Fallstudie für das Ballungsgebiet Frankfurt am Main. 1980.

Band 14 Cay Folkers: Vermögensverteilung und staatliche Aktivität. Zur Theorie distributiver Prozesse im Interventionsstaat. 1981.

Band 15 Helmut Fischer: US-amerikanische Exportförderung durch die DISC-Gesetzgebung. 1981.

Band 16 Günter Ott: Einkommensumverteilungen in der gesetzlichen Krankenversicherung. Eine quantitative Analyse. 1981.

Band 17 Johann Hermann von Oehsen: Optimale Besteuenung. (Optimal Taxation). 1982.

Band 18 Richard Kössler: Sozialversicherungsprinzip und Staatszuschüsse in der gesetzlichen Rentenversicherung. 1982.

Band 19 Hinrich Steffen: Zum Handlungs- und Entscheidungsspielraum der kommunalen Investitionspolitik in der Bundesrepublik Deutschland. 1983.

Band 20 Manfred Scheuer: Wirkungen einer Auslandsverschuldung des Staates bei flexiblen Wechselkursen. 1983. 
Band 21 Christian Schiller: Staatsausgaben und crowding-out-Effekte. Zur Effizienz einer Finanzpolitik keynesianischer Provenienz. 1983.

Band 22 Hannelore Weck: Schattenwirtschaft: Eine Möglichkeit zur Einschränkung der öffentlichen Verwaltung? Eine ökonomische Analyse. 1983.

Band 23 Wolfgang Schmitt: Steuern als Mittel der Einkommenspolitik. Eine Ergänzung der Stabilitätspolitik? 1984.

Band 24 Wolfgang Laux: Erhöhung staatswirtschaftlicher Effizienz durch budgetäre Selbstbeschränkung? Zur Idee einer verfassungsmäßig verankerten Ausgabengrenze. 1984.

Band 25 Brita Steinbach-van der Veen: Steuerinzidenz. Methodologische Grundlagen und empirisch-statistische Probleme von Länderstudien. 1985.

Band 26 Albert Peters: Ökonomische Kriterien für eine Aufgabenverteilung in der Marktwirtschaft. Eine deskriptive und normative Betrachtung für den Allokationsbereich. 1985.

Band 27 Achim Zeidler: Möglichkeiten zur Fortsetzung der Gemeindefinanzreform. Eine theoretische und empirische Analyse. 1985.

Band 28 Peter Bartsch: Zur Theorie der längerfristigen Wirkungen 'expansiver' Fiskalpolitik. Eine dynamische Analyse unter besonderer Berücksichtigung der staatlichen Budgetbeschränkung und ausgewählter Möglichkeiten der öffentlichen Defizitfinanzierung. 1986.

Band 29 Konrad Beiwinkel: Wehrgerechtigkeit als finanzpolitisches Verteilungsproblem. Möglichkeiten einer Kompensation von Wehrungerechtigkeit durch monetäre Transfers. 1986.

Band 30 Wolfgang Kitterer: Effizienz- und Verteilungswirkungen des Steuersystems. 1986.

Band 31 Heinz Dieter Hessler: Theorie und Politik der Personalsteuern. Eine Kritik ihrer Einkommens- und Vermögensbegriffe mit Blick auf die Leistungsfähigkeitstheorie. 1994.

Band 32 Wolfgang Scherf: Die beschäftigungspolitische und fiskalische Problematik der Arbeitgeberbeiträge zur Rentenversicherung. Eine Auseinandersetzung mit der Kritik an der lohnbezogenen Beitragsbemessung. 1987.

Band 33 Andreas Mästle: Die Steuerunion. Probleme der Harmonisierung spezifischer Gütersteuern. 1987.

Band 34 Günter Ott: Internationale Verteilungswirkungen im Finanzausgleich der Europäischen Gemeinschaften. 1987.

Band 35 Heinz Haller: Zur Frage der zweckmäßigen Gestalt gemeindlicher Steuern. Ein Diskussionsbeitrag zur Gemeindesteuerreform. 1987.

Band 36 Thomas Kuhn: Schlüsselzuweisungen und fiskalische Ungleichheit. Eine theoretische Analyse der Verteilung von Schlüsselzuweisungen an Kommunen. 1988.

Band 37 Walter Hahn: Steuerpolitische Willensbildungsprozesse in der Europäischen Gemeinschaft. Das Beispiel der Umsatzssteuer-Harmonisierung. 1988.

Band 38 Ulrike Hardt: Kommunale Finanzkraft. Die Problematik einer objektiven Bestimmung kommunaler Einnahmemöglichkeiten in der gemeindlichen Haushaltsplanung und im kommunalen Finanzausgleich. 1988.

Band 39 Jochen Michaelis: Optimale Finanzpolitik im Modell überlappender Generationen. 1989.

Band 40 Bernd Raffelhüschen: Anreizwirkungen der sozialen Alterssicherung. Eine dynamische Simulationsanalyse. 1989.

Band 41 Berend Diekmann: Die Anleihe- und Darlehenstransaktionen der Europäischen Gemeinschaften. 1990.

Band 42 Helmut Kaiser: Konsumnachfrage, Arbeitsangebot und optimale Haushaltsbesteuerung. Theoretische Ergebnisse und mikroökonometrische Simulation für die Bundesrepublik Deutschland. 1990. 
Band 43 Rüdiger von Kleist: Das Gramm-Rudman-Hollings-Gesetz. Ein gescheiterter Versuch der Haushaltskonsolidierung. 1991.

Band 44 Rolf Hagedorn: Steuerhinterziehung und Finanzpolitik. Ein theoretischer Beitrag unter besonderer Berücksichtigung der Hinterziehung von Zinserträgen. 1991.

Band 45 Cornelia S. Behrens: Intertemporale Verteilungswirkungen in der gesetzlichen Krankenversicherung der Bundesrepublik Deutschland. 1991.

Band 46 Peter Saile: Ein ökonomischer Ansatz der Theorie der intermediären Finanzgewalten Die Kirchen als Parafisci. 1992.

Band 47 Peter Gottfried: Die verdeckten Effizienzwirkungen der Umsatzsteuer. Eine empirische allgemeine Gleichgewichtsanalyse. 1992.

Band 48 Andreas Burger: Umweltorientierte Beschäftigungsprogramme. Eine Effizienzanalyse am Beispiel des "Sondervermögens Arbeit und Umwelt". 1992.

Band 49 Jeanette Malchow: Die Zuordnung verteilungspolitischer Kompetenzen in der Europäischen Gemeinschaft. Eine Untersuchung aufgrund einer Fortentwicklung der ökonomischen Theorie des Föderalismus. 1992.

Band 50 Barbara Seidel: Die Einbindung der Bundesrepublik Deutschland in die Europäischen Gemeinschaften als Problem des Finanzausgleichs. 1992.

Band 51 Ralph Wiechers: Markt und Macht im Rundfunk. Zur Stellung der öffentlich-rechtlichen Rundfunkanstalten im dualen Rundfunksystem der Bundesrepublik Deutschland. 1992.

Band 52 Klaus Eckhardt: Probleme einer Umweltpolitik mit Abgaben. 1993.

Band 53 Oliver Schwarzkopf: Die Problematik unterschiedlicher Körperschaftsteuersysteme innerhalb der EG. 1993.

Band 54 Thorsten Giersch: Bergson-Wohlfahrtsfunktion und normative Ökonomie. 1993.

Band 55 Li-Fang Chou: Selbstbeteiligung bei Arzneimitteln aus ordnungspolitischer Sicht. Das Beispiel der Bundesrepublik Deutschland. 1993.

Band 56 Harald Schlee: Einkommensteuerliche Behandlung von Transferzahlungen. Zur Neuordnung der Familienbesteuerung sowie der Besteuerung von Versicherungsleistungen und Sozialtransfers. 1994.

Band 57 Alexander Spermann: Kommunales Krisenmanagement. Reaktionen baden-württembergischer Stadtkreise auf steigende Sozialhilfekosten und Einnahmenausfälle (198092). 1993.

Band 58 Otto Roloff / Sibylle Brander / Ingo Barens / Claudia Wesselbaum: Direktinvestitionen und internationale Steuerkonkurrenz. 1994.

Band 59 Claudia Wesselbaum-Neugebauer: Internationale Steuerbelastungsvergleiche. 1994.

Band 60 Stephanie Miera: Kommunales Finanzsystem und Bevölkerungsentwicklung. Eine Analyse des kommunalen Finanzsystems vor dem Hintergrund der sich abzeichnenden Bevölkerungsentwicklung am Beispiel Niedersachsens unter besonderer Berücksichtigung des Landkreises Wolfenbüttel und seiner Gemeinden. 1994.

Band 61 Wolfgang Schert: Die Bedeutung des kaldorianischen Verteilungsmechanismus für die gesamtwirtschaftlichen Wirkungen der staatlichen Neuverschuldung. 1994.

Band 62 Rainer Volk: Vergleich der Vergünstigungseffekte der verschiedenen investitionsfördernden Maßnahmen. 1994.

Band 63 Hans-Georg Napp: Kommunale Finanzautonomie und ihre Bedeutung für eine effiziente lokale Finanzwirtschaft. 1994. 2., unveränderte Auflage 1994.

Band 64 Bernd Rahmann / Uwe Steinborn / Günter Vornholz: Empirische Analyse der Autonomie lokaler Finanzwirtschaften in der Europäischen Gemeinschaft. 1994. 
Band 65 Carsten Kühl: Strategien zur Finanzierung der Altlastensanierung. 1994.

Band 66 Stephan Boll: Intergenerationale Umverteilungswirkungen der Fiskalpolitik in der Bundesrepublik Deutschland. Ein Ansatz mit Hilfe des Generational Accounting. 1994.

Band 67 Karl Justus Bernhard Neumärker: Finanzverfassung und Staatsgewalt in der Demokratie. Ein Beitrag zur konstitutionellen Finanztheorie. 1995.

Band 68 Christian Haslbeck: Zentrale versus dezentrale Internalisierung externer Effekte bei unvollständiger Information. 1995.

Band 69 Regina Müller: Horizontale oder vertikale Transfers zur Durchsetzung eines horizontalen Finanzausgleichs. 1995.

Band 70 Christian Hockenjos: Öffentliche Sportförderung in der Bundesrepublik Deutschland. Darstellung und finanztheoretische Analyse. 1995.

Band 71 Manfred Rosenstock: Die Kontrolle und Harmonisierung nationaler Beihilfen durch die Kommission der Europäischen Gemeinschaften. 1995.

Band 72 Christian Rüsch: Wohnungsbau- und Wohneigentumspolitik im Rahmen der Einkommensteuer. Eine Analyse unter steuersystematischen, verteilungspolitischen und fiskalischen Aspekten. 1996.

Band 73 Stephan Winters: Die kollektive Vorsorge für den Pflegefall im Alter. Eine Untersuchung am Beispiel der gesetzlichen Pflegeversicherung in den Niederlanden. 1996.

Band 74 Knut Blind: Allokationsineffizienzen auf Sicherheitsmärkten: Ursachen und Lösungsmöglichkeiten. Fallstudie: Informationssicherheit in Kommunikationssystemen. 1996.

Band 75 Barbara Petrick-Rump: Ökonomische Wirkungen von Steueramnestien. Untersuchung konkreter Erfahrungen ausgewählter Länder mit dem Einsatz von Steueramnestien anhand eines effizienten Steueramnestieprogramms. 1996.

Band 76 Georg Hirte: Effizienzwirkungen von Finanzausgleichsregelungen. Eine Empirische Allgemeine Gleichgewichtsanalyse für die Bundesrepublik Deutschland. 1996.

Band 77 Ulrike Kirchhoff: Die rheinland-pfälzischen Gemeinden im System des Finanzausgleichs. 1996.

Band 78 Kerstin Keil: Der soziale Mietwohnungsbau: Mängel und Alternativen. 1996.

Band 79 Bernhard Manzke: Kinderlastenausgleich versus verstärkte Einwanderung. Alternative Ansätze zur langfristigen Sicherung der Gesetzlichen Rentenversicherung. 1997.

Band 80 Hariolf M. Wenzler: Institutionenökonomik und öffentliche Finanzkontrolle. Eine Analyse am Beispiel der Europäischen Union. 1997.

Band 81 Joachim Nagel: Supply-Side Policy in den USA. Eine theoretische und empirische Analyse der angebotsorientierten Wirtschaftspolitik Reagans unter besonderer Berücksichtigung steuerlicher Aspekte. 1997.

Band 82 Heinz Lampert: Krise und Reform des Sozialstaates. 1997.

Band 83 Monika Hanswillemenke / Bernd Rahmann: Zwischen Reformen und Verantwortung für Vollbeschäftigung. Die Finanz- und Haushaltspolitik der sozial-liberalen Koalition von 1969 bis 1982.1997.

Band 84 Berthold Fürst: Die Maastrichter Budgetkriterien im Konflikt mit der Verschuldungsautonomie der deutschen Gebietskörperschaften. 1997.

Band 85 Burkhard Pahnke: Einkommensorientierte Förderung des sozialen Mietwohnungsbaues. Bestandsaufnahme und Kritik. 1998.

Band 86 Judith Safford: Staatsverschuldung im Vereinigten Königreich. Die öffentliche Verschuldung unter der Konservativen Regierung von 1979-1994. Ursachen und Auswirkungen. 1998. 
Band 87 Ralf Oberheide: Die Bekämpfung der Steuerumgehung. 1998.

Band 88 Achim Truger: Die neue Finanzwissenschaft zwischen Realitätsferne und Irrelevanz der Annahmen. Eine methodologische Analyse potentieller Verteidigungsstrategien der neuen Finanzwissenschaft gegen den Vorwurf der Realitätsfeme ihres entscheidungstheoretischen Fundamentes. 1998.

Band 89 Karin Bickel: Familienbezogene Elemente im System der gesetzlichen Rentenversicherung. Unter besonderer Berücksichtigung von Ein-Eltern-Familien. 1999.

Band 90 Wolfgang Schert: Schlüsselzuweisungen und Kreisumlage. Die Problematik der Finanzierung der Landkreise am Beispiel des kommunalen Finanzausgleichs von RheinlandPfalz. 1998.

Band 91 Sandra Ehmann: Familienpolitik in Frankreich und Deutschland - ein Vergleich. 1999.

Band 92 Hendrik Suermann: Einkommensteuerliche Behandlung von Währungsgewinnen und -verlusten. Eine finanzwissenschaftliche Analyse des Steuerrechts in den USA und in Deutschland. 1999.

Band 93 Rolf Bösinger: Die Neuordnung des bundesstaatlichen Finanzausgleichs 1995. Eine theoretische und empirische Analyse unter Berücksichtigung von allokationstheoretischen und polit-ökonomischen Gesichtspunkten. 1999.

Band 94 Ulrich Ermschel: Finanzwirtschaftliche Konsequenzen beim Übergang auf das Ursprungslandprinzip im Europäischen Binnenmarkt. Eine Untersuchung am Beispiel des unvollkommenen oligopolistischen Neufahrzeugmarktes. 1999.

Band 95 Ute Hansen: Überwälzte Leistungen der Administration. Eine empirische und theoretische Analyse. 1999.

Band 96 Hans-Werner Seiler: Zur Durchsetzung der Einmalbesteuerung deutscher Körperschaftsgewinne. Strategien zur Vermeidung der im deutschen Körperschaftsteuersystem angelegten Benachteiligung ausländischer Anteilseigner. Eine finanzwissenschaftliche Analyse. 2000. 
Hans-Werner Seiler - 978-3-631-75261-6

Downloaded from PubFactory at 01/11/2019 06:36:03AM

via free access 